\title{
Software intellectual property rights : economics and policy analysis
}

Citation for published version (APA):

Harison, E. (2005). Software intellectual property rights : economics and policy analysis. [Doctoral Thesis, Maastricht University]. Datawyse / Universitaire Pers Maastricht. https://doi.org/10.26481/dis.20051109eh

Document status and date:

Published: 01/01/2005

DOI:

10.26481/dis.20051109eh

Document Version:

Publisher's PDF, also known as Version of record

\section{Please check the document version of this publication:}

- A submitted manuscript is the version of the article upon submission and before peer-review. There can be important differences between the submitted version and the official published version of record.

People interested in the research are advised to contact the author for the final version of the publication, or visit the DOI to the publisher's website.

- The final author version and the galley proof are versions of the publication after peer review.

- The final published version features the final layout of the paper including the volume, issue and page numbers.

Link to publication

\footnotetext{
General rights rights.

- You may freely distribute the URL identifying the publication in the public portal. please follow below link for the End User Agreement:

www.umlib.nl/taverne-license

Take down policy

If you believe that this document breaches copyright please contact us at:

repository@maastrichtuniversity.nl

providing details and we will investigate your claim.
}

Copyright and moral rights for the publications made accessible in the public portal are retained by the authors and/or other copyright owners and it is a condition of accessing publications that users recognise and abide by the legal requirements associated with these

- Users may download and print one copy of any publication from the public portal for the purpose of private study or research.

- You may not further distribute the material or use it for any profit-making activity or commercial gain

If the publication is distributed under the terms of Article $25 \mathrm{fa}$ of the Dutch Copyright Act, indicated by the "Taverne" license above, 
(C) 2005 Elad Harison

All rights reserved.

Cover design by Efrat Fridenzon-Harison

Typeset in Computer Modern

Prepared with ATEX, using the memoir class

Published by Universitaire Pers Maastricht ISBN 9052784949

Printed in the Netherlands by Datawyse Maastricht 


\title{
Software Intellectual Property Rights \\ Economics and Policy Analysis
}

\author{
PROEFSCHRIFT
}

ter verkrijging van de graad van doctor aan cle Universiteit Maastricht, op gezag van de Rector Magnificus, Prof. Mr. G.P.M.F. Mols, volgens het besluit van het College van Decanen,

in het openbarr te verdedigen op

woensdag 9 novernber 2005 om 14.00 uur

door

Elad Harison

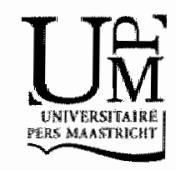


Promotor:

Prot. Dr. R. Cowan

\section{Beoordelingscommissie:}

Prof. Dr. P. Mohnen, voorzitter

Prof. Dr. D. Foray

Prof. Dr. C. de Neubourg

This resegrch was funded by the Netherlands Organisation for Scientific Research (NWO), grant $490-24-232$. 


\section{Acknowledgements}

Completing a PhD was an old dream of mine. It was probably conceived in my teenage when I aspired to become a lawyer, rather than an engineer or an economist. This thesis seems to have fulfilled (at least in part) this early wish by addressing three fields of personal interest, Law, Techmology and Economics, and the rich and complex links between them.

First and foremost I would like to thank my supervisor Robin Cowan who helped me to fulfill this long awaited dream. Robin guided my way in the wenues of academic research. He was a source of inspiration and generously shared his knowledge and experience with me throughout the research period. From the very beginning, Robin also helped me in resolving some of the practical aspects of scientific research: funding, organization and participation in research networks and conferences in my field. It was a great pleasure and a honour to be his student.

I am greatly indebted to Paul David, Dominique Foray, Pierre Mohnen and lid Steinmueller who shared with me their knowledge and views on the economics of IPRs on numerous occassions and to Chris de Neubourg for reading and approving of my thesis.

I would like to thank Luc Soete, MERIT/UNU-Intech's director, and to my colleagues at MERIT and at Intech, Anthony Arundel, Catalina Biondoy, Oxana Chervonnaya, Rishab Aiyer Ghosh, Hugo Hollanders, Paola Criscuolo, Geoffrey Gachino, Pedro Martinez-Lara, Nicola Matteucci, Lymn Mytelka, Herman Pijpers, Andreas Reinstaller, Bulat. Sanditow and Bart Verspagen, for their support and fresh insights throughout my studies. I enjoyed the company of Müge Orman and Gottried Leibbrandt with whom I shared long office hours and cliscussed now ideas and research methods. Wilma Coenegrachts, Silvana de Sanctis and Corien Gijsbers provided pleasant and efficient work environment and helped the to sort out my way within the labyrinth of miversity administration.

A Marie Curie scholarship enabled me to stay six months at the Copenliagen Business School and to complete large parts of the empirical study. I am grateful to Patrick Llerena, Peter Lotz and Peter Maskell for their help in organizing my stay. I would like to thank Lee Davis and Markus Reitzig who provided many useful suggestions on different parts of the thesis. A special thanks goes to Maria Theresa Larsen for her friendship and hospitality.

I also thank Egon Berghout and my colleagues at the Department of Economics, University of Groningen, for their support during the final stages of the thesis.

Parts of this work were presented at the DRUID Winter and Stmmer Conferences (Copenhagen, Helsingor and Aalborg), the International Telecommunications Saciety Biennial and Regional Conferences (Buenos Aires, 2000; Hong Kong; 2001; Helsinki, 2003), the EUNIP Conferece (Tilburg, 2000), the METU Conference (Ankara, 2000), the ESSID Summer School (Corsica, 2001 and 2002), the 
ETYC Doctoral Course (Strastourg, 2002), the 2nd EPIP Workshop (Maastricht, 2003) and the SEGERA Conference (Roskilde, 2004). I thank Maria Brouwer, William Cowan, Michiko Lizuka, Aija Leiponen, Stephen Maurer, Stan Metcalfe, Andrea Mina, Omit and Eitan Raz, Suzanne Scotchmer, Astrid Szogs, Patrick Waelbroek and Marc var Wegberg and the participants of those conferences for useful discussions, suggestions and comments.

This book could have not been printed without a great help from my friends: The cover" of the book was talentedly designed by Efrat Fridenzon-Harison. Bas Strathof offered his indispensable help in Latex and provided me with the tenplate of the book. Derk-Jan Heslinga proofread the Dutch summary.

I thank Judith and Kees Zijlstra for their companionship and friendship. During those years, the Zijlstra frumily has become an inseparatable part of my life in the Wether ands. Judith and Kees were keen on offering me their hospitality, and help when reeded. Their friendship and open heart have been a source of support and comfort throughout my years in the Netherlands.

My greatest gratitude goes to my family: To my parents - Aliza and Miron, and to my brother and sister - Barak and Avital. You fully supported me, encouraged and inspired every step of my work, while sharing with me hardships of the distance between the Netherlands and Israel, some worries and many joys. This book is dedicated to you. 


\section{Contents}

1 Introduction 1

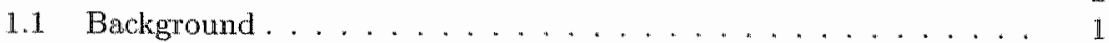

1.2 Outline of the Thesis .................

2 Intellectual Property Rights and Innovation: Introducing Economic Rationale into Legal Regimes 5

2.1 Introduction . . . . . . . . . . . . . . . . 5

2.2 Do IPRs Reward Innovation and Technological Change? An Eiconomic Outlook on the Dimensions of the Patent System . . . . 8

2.2 .1 Background ....................... 8

2.2.2 Economic Representation of the Patent Regime ...... 9

2.2.3 Trade-offs in the Structure of Patents and the Enhancement of Social Welfare ................ 15

2.2.4 Embedded Assumptions in the Neo-Classical Analysis of Patents...................... 19

2.3 Appropriating Innovation on Creative Grounds: IPRs and Prospect Theory ........................... 23

2.4 The Role of Copyrights in the Economy . . . . . . . . . . . . 24

2.5 Further Considerations ................. 26

3 The Role and Performance of IPRs as Knowledge-Propelling Regimes

3.1 Introduction . . . . . . . . . . . . . . . . 29

3.2 Disclosure vs. Exclusion: Implications of Mobility and Ownership

of Technical Know-How . . . . . . . . . . . . . . . 31

32.1 Background ........................ 31

3.2 .2 Structural Considerations ..................... 35

3.2 .3 IPRs and Anti-Competitive Behaviour of Firms . . . . 38

3.2.4 Compulsory Licensing: Enforcing the Utilization of PatentProtected Knowledge ................. 40

3.3 The Role of IPRs in Developing New Technologies: Empirical Find-

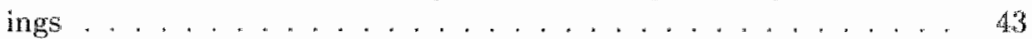

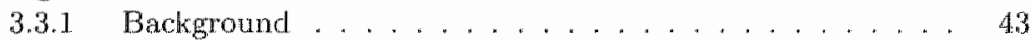

3.3 .2 Strategic Use of Patenting ............... 46

3.4 Conclusions . . . . . . . . . . . . . . . . . . . 54

4 Revealing Obscure Sources: The Paradoxical Evolution of Software Appropriation Regimes $\quad \mathbf{5 7}$

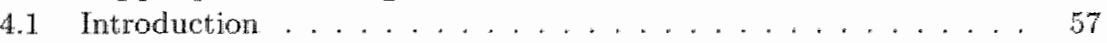

4.2 Evolution of Software Intellectual Property Regimes . . . . . . . 59 
4.3 Software Patents . . . . . . . . . . . . . . . . 62

4.3 .1 Backgronnd .......................... 62

4.3.2 Are present IPRs an under-protective regime? ...... 64

4.3.3 Are present software IPRs an ower-protective regime? . . 65

4.4 Copyrights ........................... 67

4.5 The Creativity Paradox: How IPRs are Challenged by the "Open Source" Mlovement . . . . . . . . . . . . . . . . . . 69

4.6 From IPR Protection toward Communal Benefits . . . . . . . . . . 71

4.7 Conclusions . . . . . . . . . . . . . . . . 75

5 On Substitution of Intellectual Property and Free Disclosure: An Analysis of R\&D Strategies in Software Technologies $\quad 79$

5.1 Introduction . . . . . . . . . . . . . . . . 79

5.2 Intellectual Property us. Disclosure: Description of the Model . 84

5.3 A Model of a Myopic Firm . . . . . . . . . . . . . . . . 85

5.4 Fonward-Looking Firms . . . . . . . . . . . . . . . . 89

5.5 Illustrating the Dymamics of Prices of Proprietary Sources . . . . 92

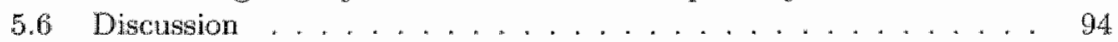

5.7 Conclusions . . . . . . . . . . . . . . . . . 97

5.8 Chapter Appendix: Symbols Used in this Chapter . . . . . . . . 99

6 Designed for Innovation: The Structure of IPR Regimes and $\begin{array}{ll}\text { the Evolution of Information Technologies } & 101\end{array}$

6.1 Introduction . . . . . . . . . . . . . . . . . 101

6.2 Methodology ... . . . . . . . . . . . . . . . . . 104

6.3 The Model . . . . . . . . . . . . . . . . . . . . . . . . 108

6.3 .1 Description . . . . . . . . . . . . . . . 108

6.3 .2 The Market . . . . . . . . . . . . . . . . . 109

6.3.3 Finms and Technical Change............. 110

6.3 .4 Innovation via Independent R\&D . . . . . . . . 111

6.3.5 Patents, Imitation and Release of New Products . . . . 112

6.4 The Simulation . . . . . . . . . . . . . . . . . . . 114

6.5 Results ............................... 114

6.6 Conclusions . . . . . . . . . . . . . . . . . . 120

6.7 Chapter Appendix: Symbols Used in this Chapter ........ 123

7 Owning Technology: The Structure of Intellectual Property Ownership in Software Technologies

7.1 Introduction . . . . . . . . . . . . . . . . . . . 125

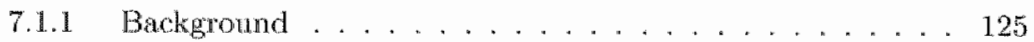

7.1 .2 What Do Patents Reveal? ............... 127

7.2 Aims of the Chapter . . . . . . . . . . . . . . . . 128

7.3 Methodology . . . . . . . . . . . . . . . . . . . . 129

7.3 .1 Definitions. . . . . . . . . . . . . . . 129

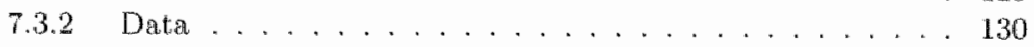

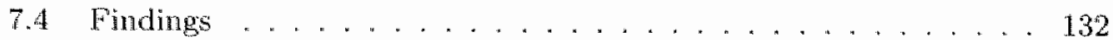

7.4.1 The Structure of Patent Omnership: A Comparative Analysis 1.32

7.4.2 Assessing the Quality of Software Patents . . . . . . . . 135

7.4 .3 Generic vs. Specific Use Patents. . . . . . . . . . . 139

7.4.4 The Evolution of Open Sonrce and Software Patenting . . 144

7.5 Conclusions ......................... 146 
8 IPRs in a Knowledge-Based Econony: A New Frame-of-Analysis 149

8.1 The Challenge: Forming a Legal Framework of Software IPRs . . 149

8.2 Markets for Goods and Ideas and How They Differ. . . . . . . . 150

8.3 Software Applications as Economic Goods . . . . . . . . . . 153

8.3.1 Manifold Dimensions of Software Products and Technologies 153

8.3.2 The Textual Nature of Computer Prograns . . . . . . . 156

8.3.3 Software Applications as Computational Machines . . . . 158

8.3.4 Programming as Construction of Industrial Designs . . . 163

8.4 The Rise and Fall of Metaphors in the Technological and Juridical

Courses ......................... 165

8.5 Re-Drawing a Fine Line Between Ideas and Expressions . . . . . 167

8.6 Conclusions......................... 169

9 Conclusions $\quad 171$

$\begin{array}{ll}\text { Appendices } & 191\end{array}$

$\begin{array}{ll}\text { A Proof of Propositions } 5 \text { and } 6 & 193\end{array}$

B Distribution of Software, Cryptography and Image Analysis Patents 


\section{List of Tables}

3.1. The share of firms applying various sources of information for in novation 48

4.1 Taxonomy of the development of software IPRs, 1950s-1990s . . . . . 60

5.1 Licensing terms of frequently-used Open Source licenses . . . . . . . 83

7.1 The distribution of patent classifications ............ 131

7.2 Major assignees in software patents, 1980 2003 . . . . . . . . . 134

7.3 Chow Test for structural changes in the reference year . . . . . . . 140

7.4 Cross-citations by citing and cited classes . . . . . . . . . . . 143

7.5 The ratio of cross-citations to pattents by citing and cited classes . . 143

8.1 Potential hazards and factors of failure in software markets . . . . 155

B.1 Distribution of patents by year and by class . . . . . . . . . . . 196

B.2 Distribution of patents by year and by class (cont.). . . . . . 197 


\section{List of Figures}

2.1 Market prices, firm's profits and deadweight loss ........ 12

3.1 Major appropriation methods in European firms . . . . . . . . . 45

3.2 Firm's channels of learning ................... 45

3.3 Relative importance of secrecy and lead-time-product innovation . 46

3.4 Relative importance of secrecy and lead-time - process innovation . . 47

3.5 The share of patents in recently-evolving technologies ...... 47

4.1 Guidelines for software patenting ............... 63

4.2 Number of Software Patents in the U.S. . . . . . . . . . . 64

5.1 Illustration of the single period model . . . . . . . . . 87

5.2 Minimal price of a proprietary feature a function of the degree of disclosure ... . . . . . . . . . . . . . . . . . 94

5.3 The level of subsidy as a function of the degree of disclosure . . . . 95

5.4 Myopic firm's one-period profits in various pricing strategies of proprietary features ...................... 96

6.1 Possibilities of patenting and releasing new features . . . . . . . 113

6.2 Average technical quality under different IPR regimes . . . . . . 118

6.3 Variance of the technical quality under different IPR regimes . . . . 118

6.4 The share of developing firms over time . . . . . . . . . . 119

$7.1 \quad$ No. of patents per annum, $1980-2003 \ldots \ldots \ldots \ldots . \ldots \ldots 3$

7.2 Ownership of patents by individuals and firms, 1980-2003 . . . . 136

7.3 Ownership of patents by firms, $1980-2003 \ldots \ldots \ldots 136$

7.4 The structure of patent ownership over time . . . . . . . 137

7.5 The average number of citations within five years from grant date. . 141

7.6 The probability to be cited within five years (different technologies) 141

7.7 The spotting age of patents (different technologies) . . . . . . . 142

7.8 The reference year of patents (different technologies) . . . . . . . 142

7.9 Technological classes with significant increase in the number of patents,

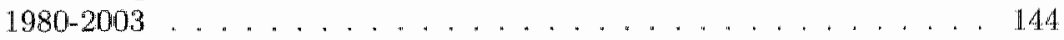

7.10 The evolution of Open Source projects and patenting in corresponding

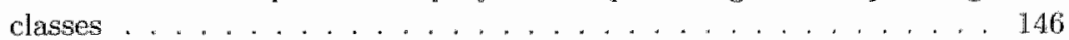




\section{Introduction}

\subsection{Background}

The inclusion of algorithms, business inventions and mathematical formulave in the scope of patentable subject matter and the exponential growth in the number of software patents that were approved by the USPTO after the approwal of its Guidelines in 1996 have raised significant doubts whether patents are granted to software inventions whose novelty and contribution to the state-of-the-are of technology are sufficiently novel.

Contradicting opinions on the contribution of patents and copyrights to foster imnovation in software technologies persist. Legal and economic scholars indicate that the present legislative framework, which provides inventors with long term, expansive rights over technology has distorted the balance between incentives to imnovate and monopoly rights. Further, if a significant number of software patents are granted to minor improvements, as some scholar suggest (e.g. Merges, 1999), assignees are provided with wide exclusive rights over technologies in retum to disclosure of relatively insignificant advances. In the short term, low-quality patents may restrict the entry of competitors to neighbouring market niches with superior technologies.

In complex technologies, such as software which integrates a large number of computational elements to achieve a required functionality, patents can potentially block development of products that use one or more essential components (Merges and Nelson, 1990). Algorithms, mathematical formulae and sub-rontines are the building blocks of computer programs that accomplish particular tasks that are essential for their operation. Therefore, software products encompass high degrees of interoperability between the final product and other programs and between the elements that construct it. When invention is recognized patentable and granted exclusive rights, patent-holders can prevent competitors from entering the market 
with product that use similar or improved features. Consequently, when a particular element cannot be used in computer programs without infringing legal rights and cunnot be substituted, the functionality of the program might be crippled or even not be attained at all.

In some cases software patents fail to provide sufficient degree of knowledge disclosure in return to monopoly rights. Then, the ability of second comers to review and to learn from prior inventions and to build new inventions upon it is fairly restricted. Similarly, if patent claims (i.e. the potential uses of the patented invention) are general and obscure, the scope of protection is wide and covers new applications that were not envisioned by inventors when the patent application was filed and those domains will be excluded from other inventors in advanced phases of the technology. Moreover, if patents lack sufficient nowelty and disclosure, they become "obvious" to practitioners and hence their quality encompasses lower levels of innovative added value and contribution to the public's welfare. Syrowik (1996) suggest that the examination of software patents by the USPTO suffers from those problems and as a result the balance between private and public interests has changed. Application of a different legal scheme that limit the scope of claims of software patents to particular applications and data structures can restore this balance (Schumm, 1996; Witek, 1996).

Our empirical andysis indicates that the structure of ownership of software patents is highly concentrated, as every year large numbers of patents are granted to a small group of assignees, all of them are multi-national firms that operate in. the electronics and ICT sectors. However, since the establishment of the Guidelines by the USPTO the structure of ownership has become more fragmented, as larger amount of small patent-portfolio holders (mostly SMEs and individuals) apply for and granted patents over their software inventions.

Granting broad exclusive rights (as defined by the patent claims) for long periods to inventions whose contribution to innovation is marginal is likely to hamper entry of new dewelopers and firms to the market and in the long run can lead to stagnation of the technological trajectories in the software industry. Nevertheless, the predictions of academic scholars and industrialists could have barely been fulfilled had the market followed a different trail in reaction to software patenting.

Our findings reveal that since the 1960s the U.S. legislation of software IPRs has lingered after the development of new software and information technologies by more than a decade. As a result, legislative changes suffered from two major sources of inefficiencies: First, policy adaptations were presented long period after the technical change had occurred, hence regulating new technologies with older legislative frameworks. Second, when IPR policies were modified due to technical 
developments, new technical paradign would have already been introduced to the market, bence creating another source of inefficiencies. Consequenty, the quality and the innovative value of software patents gradually deteriorated during the 1980 s and the early 1990s. However, since the enactment of the Guidelines in 1996, the quality of software patents is increasing and recent patents are more often cited as prior art.

The Open Source movement challenges the traditional IPR regimes by providing alternative incentive mechanisms for software developers that are based on reputation rather than on exclusive rights. Open Source development is based on disclosure of the source code. Programmers remove their ownership rights from their contributions to enable further development of applications. Open Source projects attract growing numbers of developers and many firms adopt it as their favourite mode of development, although their creative outputs are disclosed at a zero price tag. The thesis presents the dynamics of Open Source communities and elaborates whether policy-makers should integrate the Open Source mode of development as a substitute or complementary approach to IPRs.

\subsection{Outline of the Thesis}

Chapter 2, Invellectual Property Rights and Innovation: Introducing Economic Rationale into Legal Regimes, reviews the economic role of IPRs and their impact on the market. The chapter presents various legal-economic theories by which the structure of the legal regime and the public and private benefits that it provides can be analyzed.

Chapter 3, The Role and Performance of IPRs as Knowledge-Propelling Regimes, proposes a conceptual framework for analyzing the role and functionality of IPRs. The frame-of-analysis is based on insights from the evolutionary economics literam ture discussing the effects of technical knowledge and disclosure on innovation and technological change.

Chapter 4, Revealing Obscure Sonces: The Paradoxical Evolution of Software Appropriation Regimes, discusses how software IPRs evolved vis-à-vis the development of information technologies. We elaborate the role of patents and copyrights in protecting software and whether software IPRs have formed an over or under. protective regime. We also discuss the success of the Open Source movement to establish an alternative regime that is based on removal of IP claims from the source code and the dynamics of developers' communities.

Chapter 5, On Substitution of Intellectual Property and Free Disclosure, aims at revealing the economic rationale underlying Open Source development and how this mode can strategically be used by firms. By constructing an analytical model of the market, we identify the optimal share of source code that should be disclosed 
and deweloped as Open Source to maximize profits and how it is affected by the pricing decisions of firms.

Chapter 6, Designed for Innovation: The Structure of IPR Regimes and the Evolution of Infomation Technologies, constructs a dynamic model of the software market that explores links between different structures of the patent regime affect. market dynamics and technical change over time. The chapter provides insights or the relations between patent duration and novelty criterion and the degree of competition and the performance of technologies.

Chapter 7, Owning Technology: The Strocture of Intellectual Property Ownership in Software Techologies, studies the structure of: ownership of U.S. software patents and how it was affected by changes in IPR policy. Further, the chapter evaluates how the quality and the irnovative walue of software patents have been influenced by structural changes in the legal regime and reveals links between software patenting and the emergence of Open Source projects.

Chapter 8,IPRs in a Knowledge-Based Economy: A New Frame-of-Aralysis, discusses the economic nature of software and computational processes. We compare between the schemes of IPRs that were established for protecting computer programs and those that protect their physical equivalents (i.e. computational machines). Then, we propose a new conceptual framework for legal and economic analyses of software products and technologies.

The importance of the U.S. experience is emphasized in the light of the propasal of the Direcize on the Patentability Computer-Implemented Inventions (COM (2002) 92 Final) that aims at expanding the scope of the legal regime of software IPRs in the E.U. beyond the prior legislation from 1992." Chapter 9, What Can Europe Learn from the U.S. Q, presents the fundamental issues and challenges that policy-makers in the EC and in the Member States will confront with the imm plementation of a new regime that regulates IPRs for software and information technologies. The chapter provides essential guidelines for drawing a benchmark between the U.S. experience and the proposed E.U. legislation.

Finally, Chapter 10 provides conclusions and policy implications.

\footnotetext{
${ }^{1}$ Directive on the Legal Protection of Computer Programs (91/250/EEL).
} 


\section{Intellectual Property Rights and Innovation: Introducing Economic Rationale into Legal Regimes}

\subsection{Introduction}

IPRs are long-living institutions and were enacted centuries before the emergence of digital technologies. Copyrights were initially constituted in the 15 th century by the city council of Venice to provide incentives for authors and to prevent free rendering of their works. The roots of the patent system allso evolved during the same period when rulers in England and Venice granted letters with monopoly rights over production of inventions to the inventors. ${ }^{1}$

The raison d'etre of IPRs and the objectives to be attained by establishing those legal regimes have virtually not changed since then. Pattents provide economic incentives to inventors (individuals or firms) by granting them monopoly rights for limited periods over improvements of present techniques or breakthroughs in tedinology. ${ }^{2}$ The procedure of patenting new inventions involves submission of an application to the patent; office, evaluation by a professional referee ("patent examiner") and approval of a patent grant if the invention is found novel and exceds a minimal inventive step in technological terms. "In return for property rights over patented technologies, inventors are required to disclose to the pubm

\footnotetext{
Machlup and Penrose (1950) and Dawid (1993) provide a detailled review on the evolution of IPR regimes. Granstrand (1999; pp. 28-31) presents historical chronology of their devellopment.

${ }^{2}$ Patent protection is granted for twenty years from filing an application in the US and in the EU. Copyrights are obtained for the author's lifetime plus seventy to ninety years post mortem atetoris.

${ }^{3}$ There are no legal standerds for inventive step or non-obuicusness of inventions. Both definitions are open for wide interpretations by patent examiners and by Court. However, those terms represent qualitative measures for significant improvements beyond the state-of-the-art of technology for which inventions are recognized patentable.
} 
lic domain the techincal know-how for which they are awarded protection. The knowledge is organized by the patent office according to pre-defined categories (and search criteria) and is completely available for use by the public. Although the rationale behind patents and copyrights is similar, literary and artistic works differ from technical inventions, as they are automatically included in the scope of copyright protection when published and do not require any examination process to be considered intellectual property.*

IPR regimes aim at protecting diverse genres of knowledge, products and works and consist of different legal means, among which patents and copyrights are paramount from both judicial and economic standpoints. "For long periods IPRs. were considered as efficient regimes for fostering innovation and technical progress, embracing economic incentives for innovative individuals and firms, although IPRs, in particular patents, faced continuous attempts to curtail the privileges which inventors were granted by Law. The solicitations of the anti-patent movement finally won a victory when the patent system in the Netherlands was abolished in the late 19th century. After cancelling the patent regime no noticeable changes in innovative and technological output were experienced by the Dutch economy. Whether any foreseen benefits associated with complete abolishment of patent protection eventually happened remains unclear (Lerner, 2000). However, it was the only achievement ever won by the patent opposition movements, and it was short-lived, as the Netherlands had to revise its policy less than forty years after the changes took place in order to comply with the Paris Convention whose terms were adopted by many other nations at the same period.

Although complete removal of IP protection did not prove useful for the society, petitions against wide and long lived patents are continuously heard up to the present. Their nature, however, has turned from a general opposition rejecting all lorms of patents to controversy over specific technologies, mainly those that hawe recently deweloped, such as ICT and biotechnology, on practical grounds of assuring stable patterns of technological evolution and free access to knowledge, or on ethical grounds demanding wider allowances for low cost production of patentprotected drugs and medical equipment for domestic use in poor countries. The economic benefits and perils beyond the policies of legal protection as intellectual

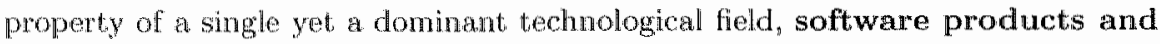
information technologies, stand at the core of this thesis.

While common analyses of IPRs compare the level of legall protection granted

\footnotetext{
${ }^{4}$ Registration of original works in the Copyright Office is optional but not obligatory to obtain copyright protection over them. Yet, the procedure is inexpensive and can prove helpfull in cases of dispute.

"Trademarks and industrial designs are other mechanisms of IPRs, but they play a less significant role in the evolution of technologies.
} 
by variety of national regimes, the contribution of the legal regime to ensure stable technological trajectories and innovation in the long tem can be measured wrough different features of the system and through historical perspectives on appropriation. Assessment of the enforcenent of property rights by national authorities and by Courts was conducted by analysing patent litigation cases in the 19 th century in the U.S. The analysis of those early U.S. cases reveals a positive correlation between effective reinforcement of Patent Law by the juridical system and effective patterns of technical change. However, a more efficient approach that does not include only on the revemues of patent-holders but also comprehends broader econ nomic effects of legislation on innovation and competition in technological markets was taken by Court in the late stages of forming the U.S. patent regime through the reforms of the $1850 \mathrm{~s}$. Being aware to the delicate balance between social and private interests in patent litigation lawsuits, Court considered the effects of patenting on social welfare, avoiding an already-prominent approach by which the public generally benefits when inventors are granted broader monopoly rights (Khan, 1995).

Those empirical observations are supported by the conclusions of analytical models, which evaluate the links between the strength of patent rights, mitation by rival firms and the motives of patentees to embark on legal proceedings against the infringers of their patent rights. However, the success of patent-holders to recover their damages from unauthorized reproduction of the protected inventions is not guaranteed and depends whether Court recognizes that rival products fall within the scope of protection of living patents. Therefore, the patent-holder's decision to engage in a patent litigation game and to submit a lawsuit against an infringer may prove unworthy. However, the possibility to prove infringement increases as wider protection of intellectual property is granted to innovators and, hence, the probability to fail in Court decreases as the patent regime becomes. broader (Waterson, 1990). A primary finding is that if the legal costs in cases of patent litigation increase, rivals are deterred from releasing product versions that fall within the scope of patented inventions. Following this conclusion, stricter measures of jurisdiction and enforcement would reduce the loss of social welfare as a result of (deadweight) litigation costs.

Though existing for centuries, legal and economic scholars started analysing

\footnotetext{
G Ginarte and Park (1997) define an index of patent, rights to measure changes in the levell of legal protection in 110 countries world-wide over a period of thirty years on tho basis of the scope of patent protection, nembership in intermational patenting ongatzations and agrements, provisions for loss of protection, enforcoment mochanisms and patent duration. Ostergard (2000) assesses the globall changes in the degree of protection of various IPR regimes between 1988-1994 on the basig of enforceability, administation, international treaties and the relative signifonce of each regimes for applicants though three different indices (Rapp \& Rozek, Sherwood and Seyoum).
} 
systematically the effects of different IPR regrimes on markets and economies only in the 1950 s. $^{7}$ Since then, studies on IPR thave become an integral part in evaluating rational innovation systems, policies and legal mechanisms designed to enhance economic growth through innowation and technical change in constantly-changing markets and technological lendscapes.

A prominent concern shated by policy makers, acadenicians and industrialists is whether IPR legislation indeed succeeds in preserving the necessary balance be tween the interests of the public, i.e. knowledge disclosure, and those of inventors, i.e. monopoly over creative output, to maintain stable patterns for developing new technologies. Further, misapplying ill-defined policies of IPRs may result in opposite effects than meant, hampering both innovation and technological progress.

The second section discusses the mainstream body of legal-economic studies, i.e. reward theory, that represents monopoly rights, granted by IPR regimes, as incentives to innovate. Particular references are made to the dimensions of the patent regime. The third section elaborates the function and the role of the patent regime from the prospect theory perspective. We devote a special discussion to copyrights and their economic significance in the fourth section. Finally, the weaknesses of the neo-classical models are discussed, in need of an alternative framework for evaluation of IPR regimes from a bird's-eye perspective.

\subsection{Do IPRs Reward Innovation and Technological Change? An Economic Outlook on the Dimensions of the Patent System}

\subsubsection{Background}

Patents, along with copyrights, are the major institutional means employed to obtain legal protection for intellectual endeawours. ${ }^{8}$ Patents are used to protect. inventions arising from technological advances in processes and products. Three criteria define minimal measures to judge whether new inventions are patentable:

- Utility: the technical know-how disclosed in the patent file must enable its further exploitation, either in applications that are explicitly mentioned in

\footnotetext{
Tmportant contributions in the frst stages of the economic research on IPRs were made by Penrose (1951) and by Machip (1958); path-breaking analyses of patents in various industrial sectors were carried out by Schmookler (1950).

Licensing and trade secrecy are additional features of IPR regmes that are treated by a separate body of economic literature (see, for example, Friedman et. al, 1991). They sarwe different roles: the fomer increases the rents accuing to an inventor without reducing his property lights, the latter prevents intellectual property from spilling out of the firm, for exanphe through employees moving to rival firms. Unlike either patents or copyrights, both of them are implemented through bilateral contracts either between two firms or between at firm and its employee.
} 
the patent claims, or in new products that can potentially be developed by the industry.

- Novelty: patent is granted for an invention that carries a required level of originality over the existing body of technological knowledge in the particular field world-unde.

- Non-obviousness: invention is recognized patentable if it entails a minimal, non-trivial inventive step, which is approved by a "person skilled in the art." (official examiner who has the necessary knowledge and skills).

If all those three criteria are satisfied, a patent is granted for the invention.

Intellectual property rights are essentially based on a balance between two sources of value. Public welfare is furthered when new knowledge is disseminated and widely used, both in production of goods and in production of further knowledge. Private incentives to innovate are high when the inventor is able to reap the rewards from his efforts. On the one hand, the inventor is granted a temporary monopoly over an invention and its derivative applications, thereby gaining protection from unauthorized exploitation of his technical know-how and a strong incentive to innovate. On the other hand, if technical knowledge were disclosed for public use, its accessibility would stimulate the generation of knowledge spillovers and the transfer of technical know-how throughout the economy. Accordingly, IPR legislation aims to optimize social welfare and to strike a balance between monopoly and disclosure.

The economic merits are largely affected by the design of the patent regime and may vary in their responses to different market conditions and strategic consideram tions. Firm's decisions to imitate existing products or to create new technologies, to invest in R\&D activities or to license the rights to apply inventions and technical know-how that are legally protected by other firms, to compete in technological markets or deter rivals from doing so are largely affected by the design of IPR regimes and by the opportunities to use them for their own profit. The lollowing section reviews the various dimensions of the patent system and their influences on innovation and research activities. The section also includes a critical overwew of the concepts and the boundaries of constructing analytical models of the patent regime and its influence on economic activity.

\subsubsection{Economic Representation of the Patent Regime}

Illustrated in a stylized way, patents create a three-dimensional structure ol monopoly rights over segments of the technological realm and over time. The patent regime can be clescribed and assessed according to its length (duration), breadth (scope) and height (a measure of disclosure or a "minimal inventive step" over the stateof-the-art of scientific and technical knowledge). Following this view, much of the 
economic rebearch on IPRs is geared toward assessment of direct effects caused by maxginal changes in one of the dimensions of IPR regimes."

Patent length determines the duration of legal protection (and the duration of monopoly rightz). In the U.S. and in the E.U. patent protection lasts for twenty years. In contrast to breadth and disclosure, which are both qualitative dimensions that may silgnificantly vary among patent offices and examiners, patent lifetime is an absolute measure and therefore can serve as a 'pure' attribute in economic malyses of patent regimes. Consequently, setting new patent length and evaluating the effects on firms' activities and innovation are relatively simple and straightforward activities.

Nordhaus (1969; Ch. 5) was the first to highlight the significance of the design of the patent regime by examining the links between the length of patents (as a measure for the degree of protection granted to inventors) and the consequent incentives to innovate. His synopsis was later expanded (and criticized) by Scherer"s work (1972). Both works aim at recognizing the nexus between patent length, frm's profits and innovation, whereas innovation is illustrated by the invention possibility function (IPF) that represents productivity or innovative output as st function of R\&D inputs.

The model is straightforward and its dynamics are explained as follows: Assume that technical inventions reduce the production costs of existent goods. ${ }^{10}$ However, if the invention is patented, it can be used only by its inventor. Consequently, only the patent-holder is able apply the new technology and reduce his costs, whilst other firms are unable to compete in price (patent infringement and unauthorized use are assumed not to exist). The inventor dominates the market: and charges the monopoly price, which is lower than the competitive price that was present before the discovery of the new technology (prices will decrease to a new competitive level when the patent expires). Therefore, firms are able neither to adjust their prices to the price charged by monopolist nor to adopt the new technology and so will be driven out from the market by price competition for the patent duration (assuming that no other non-infringing invention will take place at the same period).

The dymamics of the model are illustrated in Figure 2.1. Initially, the cost of producing one unit of product is $\bar{c}$. After a cost-reducing invention is made, the cost per unit falls to the price level c. Two conclusions emerge from this graphical presentation of the market pre- and post-introduction of a patented invention. First, the deadweight loss (denoted D.W.L. in the graph) increases

\footnotetext{
${ }^{9}$ This section reviews the attributes of the patent regime, but the structure of the copyright system can be illustrated in a similar way.

${ }_{10}^{10}$ Quality improvements and product differentiation are not included in this stylized form of presentation.
} 
when the elasticity of demand increases. ${ }^{11}$ Second, the patent-holder controls the use of the new technology and sets the monopolistic price, $c_{m}$, higher than the new, (potentially) competitive price level and lower than the pre-imvention competitive. price, hence $\underline{\mathrm{c}}<c_{m}<\bar{c}$. During the patent lifetime the patentee becomes a sole producer in the market and obtains a considerable share of the market.

A major assumption of the model upon which both works base their findings and even conclude upon the optimal length of patents, refers to the correlation between R\&D expenditure and imnovation (defined as the invention possibility function by Nordhaus). What are the terms in which innovative output should be signified and what is the precise relationship between R\&D expenditure and innowation are both the subjects of fierce controversies among economists.

Nordhaus (1969) represents innovative output by reduction in unit production costs as a result of implementing new invention. The volume of firm's investments in $R \& D$ is therefore associated with cost-saving. Furthermore, Nordhaus assumes a convex invention possibility function with diminishing returns to $\mathbb{R} \& D$ expenditure at any point. ${ }^{12}$ Scherer (1972), on the other hand, does not revolutionize those views (e.g. by differentiating between industrial sectors in assessing this puzuling link), but rather relaxes some of Nordhaus" assumptions by solving the model for a number of variants of the basic R\&D-cost reduction curve. The first is characterized by an inflected function with increasing returns in lower levels of $R \& D$ expenditure and diminishing returns in higher degrees of investment ("Scurve"). The second introduces discontinuity in cost reduction for th threshold level of R\&D ("stair-step" function). In a reply, Nordhaus (1972) suggests that, for a continuous IPF (finite) optimal patent life exists when the elasticity of cost. reduction with respect to $R \& D$ is greater than 1 . Further, he rejects the feasibility of the latter case, stating that "to my knowledge, there is no firm exidence on the degree of curvature of the IPF" (pp. 429) Interestingly, the possibillity of negative correlation between $\mathrm{R} \& \mathrm{D}$ and innovation (mainly in high degrees of $\mathrm{R} \& \mathrm{D}$. investments) has never been mentioned innovation studies. This phenomenon is far from being an academic exercise and previously was identified in other ecomomic fields where the organization of the $\mathrm{R} \& \mathrm{D}$ process largely affects its ontput.

From the perspective of the innovative agent who follows the assumptions of those models, longer patent lifetime is desirable, since patent protection stretches the time in which her technology is novel in the market from product lead-time. Hence, patent-holders generate revenues over longer periods, without being threat-

${ }^{11}$ "This result implies low royalty fees to minimize the deadweight loss as a result of patent rights. Implications of this finding regarding compulsory licensing policies are further discussed in the next chapter.

${ }^{12}$ Traditionally, the invention possibility function is defined as: $Q=\beta \cdot(R D)^{\alpha}$, where $\alpha<1$ and $\beta>0$ are constant (Nordhaus, 1969; pp. 22-26). 


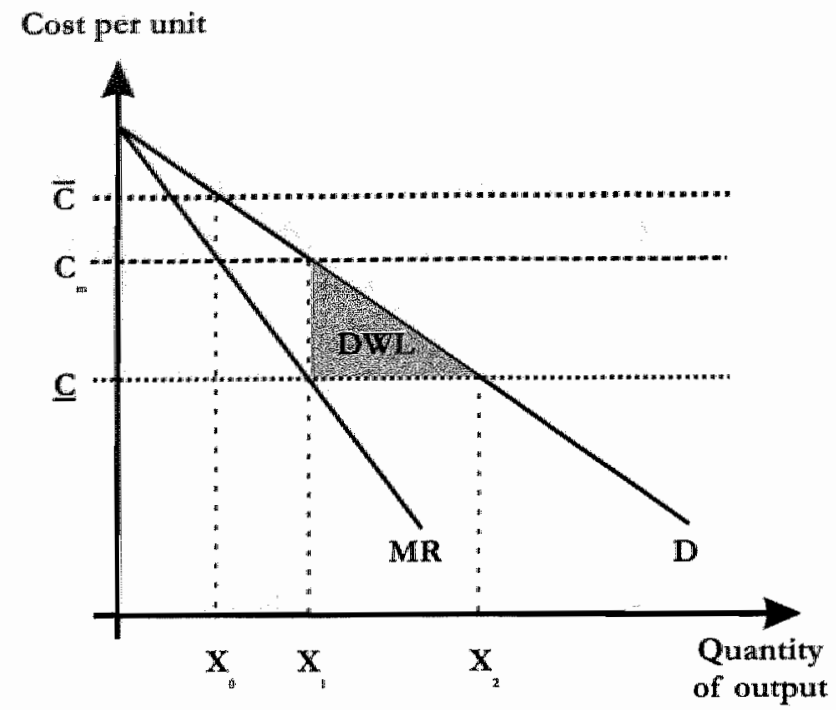

Figure 2.1. Market prices, firm's profits and cleadweight loss at the presence of cost-reducing technology (based on Scherer, 1972).

ened by imitation and introduction of rivals goods in the technological emvironment of the patented invention.

While Nordhaus and Scherer study the behaviour of a monopolist inventor and the modes in which his profits are affected by different patent durations, the conclusions on the behaviour of firms change dramatically in a competitive environment. Firms that decide to invest in R\&D in a competitive enviromment face two sonrces of uncertainty. First, the risk of failure in accomplishing the development project successfully and the consequent loss of financial resources. Second, competition against rival inwentors is characterized as a patent race, in which monopoly is granted to the "first-to-patent" firm, pre-empting rivals from commercial exploitation of similar inventions, even if those were completed successfully. In this "winner-takes-all" competition between firms, longer patent life infuences at fim's decision to increase its R\&D expenditure. Consequently, the increased investment in R\&D will enhance the firm's know-how and will curtail (with probability) the period of discovering new imventions, thus enhancing the imovative output of the frm (Kamien and Schwartz, 1974 ).

When the development process is positively correlated with R\&D expenditure (i.e. the technical progress increases and the development time decreases with RCD), Frms increase their R\&D expenditure (Chou and Shy, 1993). If the expenditure on R\&D is taken as a fixed share of the revenues, long term patents would improve the terms for investment in RLD ensuring a stable stream of income during the patent lifetime and generating ongoing imovative efforts. Hence, not only 
inventors but also innovation is rewarded by longer patent duration.

However, results opposite to the conclusions of the models presented above may dominate markets with high $R \& D$ intensity. Long duration of patents may restrain the development of new invertions and pre-empt the establishment of new frms, as inventors would prefer the purchase of monopoly rights and to guarantee themselwes a secure and stable strean of revenwes; rather than invest im new R\&D activities. Further, if inventors regard their patent rights as a "milking cow" and do not re-invest in $\mathbb{R} \& D$, longer patent duration would enrich investors and would not stimulate establishment of new firms and development of new technologias. thus retarding innovation and economic growth in the long run.

In an attempt to strike the balance between social and private benefits in diverse technological and economic scemarios, Arditti and Sandor (1973) propose to revolutionize the patent regime by implementing a variable patent duration. However, this solution seems to be infeasible from the legal standpoint and its implementation would entail considerable juridical, administrative and enforcement costs. Moreover, successful implementation is difficult, since determining the dem sirable patent duration depends on precise estimation of the rate of return from patented inventions ex-ante. A potential solution for the problem of estimating the social value of patents can be achieved by calculating the average rate-of-return on patent and R\&D costs of existing inventions in similar techmological classes. However, this policy tool method proves inappropriate and even misleading for judging the value of patent applications in their early phases of submission to the patent office in order to derive the granted duration, as inventions have to be sufficiently novel to obtain a patent and significantly different from existent products. Moreover, inventions may differ in their nature, varying from "improvements" of present technologies to technological "breakthroughs". Therefore, a versatile patent policy that determines the unique duration of patents by interpolating the value of granted patents may result in large biases in the case of new technologies. ${ }^{\text {"ta }}$

In comparison to patent duration, the definitions of breadth (scope) and disclosure are inconchusive and therefore suggested modifications in both dimensions and the assessment of their impact on the market are difficult to attain. Patent breadth (scope) refers to the coverage of subjects that can be patented and later protected from introduction of rival products similar or close to the invention. Patent breadth is determined by the technical know-how disclosed in the patent description and by immediate and potential applications that are described in the patent claims. The technical knowledge includes background of the inven-

\footnotetext{
13. Diversification of IPR regimes by policy makers, applying sun-geteris legislition to protect different genres of products, has become a common practice mainly in the EU. Yet, considering the unpredictable manners in which technologies evolve (especially recently), those policies are open to periodical remssessment and revision.
} 
tion, description of the blueprints and detailed duscussion of the invention and its operating.

For example, U.S. patent no. 6,697,960 describes "method and system for recovering data to maintain business continuity" that is based on configuration of local and remote disks and eliminates the use of magnetic media for backup of dignitally-stored data. The patent builds upon (and cites) U.S. patent no. 6,446,175 on storage and retrieval of data on tape backup system. Although the purposes of both inventions are similar (data backup in remote business sites, as described. in the background sections of both patents), the method and system applied in patent no. 6,697,960 are sigmificantly different from the description and the claims of earlier patents (such as patent no, $6,446,175$ ) and therefore do not fall within their scope of protection.

Inclusion of advanced exploitation of the invention, as mentioned in the claims, is extremely important for inventors, as it provides them property rights over anticipated applications of the patented knowledge. Wider breadth permits inventors to obtain dominance in larger market shares by excluding rivals from implementing the patented technology in a wider wariety of products and by charging larger numbers of users of the protected technology with royalty fees.

Patent breadth closely affects innovation and development of new products influences the structure of technology markets. Extension in the breadth of patents. implies higher rewards to imnovators, when other dimensions of the regime remain unchanged, as exclusive rights are granted to inventors over wider technological domains than before. ${ }^{14}$ However, an opposite effect of wider breadth is an increasing difficulty to patent. Wider coverage of patent protection expands ownership rights of patent holders, therefore introducing more constraining conditions to new patentiees. ${ }^{15}$

Generally, when wider patent breadth is put into practice, product wariety falls, as patent-holders pre-empt introduction of similar products and variants of thei" protected inventions. Increasing breadth reduces product variety, directs consumers" preferences to a smaller range of goods and enables patent-holders to charge monopoly prices for their products, by pre-empting introduction of clones and goods alike bearing a competitive price-tag. The aggregate effect is an increase

"4the breadth of patents can be expanded by Court's decisions in specific cases or, more generally, by Patent Offices taking a more liberal approach towards applications that have not; been recognized patentable before. For example, mathematical algorithms have officially become patentable in the U.S. in 1996 (USPTO, 1996). Business methods can be patented in the U.S. since 1998 (State Street Bank and Trusted Company w. Signature Financial Group; 149 F.3d 1368, Fed. Cir).

${ }^{15}$ In most cases inventions are characterized by sequential improvement upon existent fechnologies, rather by breakthroughs. Therefore, extension of patent breadth forces new inventors to license technological donains that previously were considered public domain, reducing their bargaining power in front of incumbent firms. 
un consumers' deadweight loss and in producers" surplus.

Patent height defines the minimal degree of technical knowledge created by the inventor that should become available for the public when patented. Freight is associated with the degree of novelty and non-obviousness of patents, distimguishing patentable subject matter from marginal improvements upon existent patents. As intellectual property is revealed when patent applications are submitted, rivals may improve their products more easily than before and esitablish new technologies on the basis of information disclosed in patents, hence competing with the patentee with superior products. Hence, firms aim at the minimal degree of disclosure that satisfies the patent examination guidelines, in onder to acheve a profound position in the market. By contrast, policy makers aspire to increase the level of overt know-how that becomes available for public use. When patent. height is relatively low, there is a small difference between innovation and firm's behaviour in free markets and in patent protected regimes. Surprisingly, application of intermediate degree of height generates the opposite effect than expected. Rivals increase their expenditure on R\&D to exceed the required degree of novelty and to enter the market. Yet, their products are sufficiently close to the patented technology to compete with it in the same class of products, hence reducing the revenues of patentees. Therefore, from an innovator's standpoint, patenting becomes a desirable practice only when relatively 'high' patents are granted (Van Dijk, 1996).

The legal definitions of patent breadth and height are somewhat vague and depend mostly on the expertise and on the judgement of every patent examiner. Therefore, modifications in the "size" of breadth and length and evaluation of their effects on innovation and on firm's behaviour are difficult to accomplish. Hence, the main economic literature on IPRs typically estimates the impact of patent breadth and height on innovation and on the diffusion of new technologies by constructing conceptual framework-of-analysis (Merges and Nelson, 1990) or by illustrating through analytical models the links between the patent system, R\&D investments and technological markets (review of the literature on the design of IPR regimes is provided in Tirole, 1988; Ch. 10).

\subsubsection{Trade-offs in the Structure of Patents and the Enhancement of Social Welfare}

An optimal structure of the patent regime aims at maximizing social welfare of consumers and innovators is measured by minimal deadweight losses, oniginating in two major sources:

1) Advances in technology are protected by patents by inventors and are introduced to the market at higher (monopoly) price. Consumers may choose to adopt 
the new technology or to purchase low grade technologies, already present in the market and umprotected by patents, at a competitue price. However, if consumers are sensitive to price, they will prefer technically inferior substitutes outside the scope of patents of the adwanced technology which, had it not been protected by IPRs, would have been offered at a competitive price:

2) Patents oblige consumers to purchase protected products at a monopoly price and prevent them from acquining low cost substitutes that fall within the scope of patents. As a result, broader patents namow the variety of products from. which consumers are free to choose their preferred technology and enable patentholders to introduce their goods at higher prices than the competitive price.

Klemperer (1990) concludes that narrow, infinitely lived patents are desirable when consumers" preferences are indifferent among variety of patented and unprotected products (i.e. type of inefficiency is marginal), while wide and short-lived patents are more desirable when consumer's decision whether to purchase one of the products or none of them are equally important. Between those poles lies an infinite range of designs of the legal regime in which longer patent duration substitutes for narrower breadth, and vice versa to maintain a similar dlegree of incentives. Finally, the patent structure that optimizes social welfare is chosen. ${ }^{16}$.

Those findings persist when imitation is costly (Gallini, 1992). Setting sufficiently broad patents that increase imitation costs prevents rivals from "inventing around" existent patents and introducing minor improvements of protected technologies to avoid infringement. The optimal length is sufficiently short to deter amitators from implementing patented know-how during the patent lifetime and provides inventors with a predetermined level of rewards. Curiously, setting longer patent duration provides higher incentives to inmovate. However, firms that are pre-empted from using patented technologies for long periods may enter the market by developing non-infringing and competitive products, capturing shares of the monopoly revenues. ${ }^{17}$

Gilbert and Shapiro (1990) share similar notions with Klemperer, investigating the trade-ofl between patent breadth and length and demarcating the structure of the legal regime that minimizes deadweight loss and sustains a predetemined reward. Their work focuses on determining the optimal breadth of infinitelylived patents. Infinite duration is justified as the optimal length of patents that maximizes social welfare, represented by the summation of inventor's profits and

\footnotetext{
${ }^{16}$ Technically, Klemperer (1990) identifies the breadth that minimizes the ratio of total social costs to profits, $\left\{w \mid M i n, \frac{s(w)}{\pi(w)}\right\}$ and devises the corresponding patent length $\bar{L}$ for which the innovator obtains steady incentives, $V(\bar{L}, \bar{s})$

${ }^{17}$ Under those circumstances, inventors would prefer to charge licensing fees lower than imitation costs, precluding their rivals from developing non-infringing substitutes and generating a secondary stream of revenues.
} 
consumers' surplus. The model introduces sochl welfare in tems that are equiralent to the second source of inefficiencies in Klemperer's model, while product differentiation and the choices of altermative products by constmens (creating the first source of inefficiencies) are not included within their model. Therefore, in the model, an increasing patent breadth is associated with an increased deadweight loss, as consumers avoid purchasing the patented product at a non-competitive price.

However, Gilbert and Shapiro's model is to an extent restricted and addresses only a limited sphere of reallife scenarios, as the effects of patent breadth on the cost of products and the liberty of consumers to choose among altermative goods of the same class are not included in their interpretation. The model suffers another major shortcoming, assuming negative correlation between inventor's profits and welfare at any given degree of the profits (i.e. $\left.\frac{\partial W(\pi)}{\partial \pi}<0\right)$. Presumably, this relationship seems to be straightforward if social welfare is limited only to the benefits of consumers. A higher degree of market power of the patentee and increase in the deadweight loss of consumers that result from broadened patent protection. IHowever, if the definition of social welfare includes both consumers" well-being and inventors' profits, as Nordhaus (1969) and Scherer" (1972) follow in their analyses, broader patents balance the decrease in consumers' welfare (higher deadweight loss) by increasing the producer surplus of inventors, thus maintaining the level of social welfare in the market. Therefore, and in contrast with Gilbert and Shapiro's work, finite-life patents produce higher societal value than longliving ("infinite") patents.

Analysing the trade-off between length and breadth of patents is far from being trivial, as some of those models suggest. First, the reward (or the planned incentives) to inventors camot be accurately predicted, but rather be determined ex-post and the links between expected incentives to innowators, engagement in R\&D projects and successful accomplishment of inventions and their patentability. Second, sectors are chanacterized by different modes of innovation (i.e. discrete, cumulative, chemical and science-based inventions) and may react, diversely to changes in the patent regime and therefore require further theoretical and empirical investigations on the links between incentives to innovate (provided by legal or means), and innovation (Merges and Nelson, 1990).

Models that measure the trade-off between different dimensions of the patent system follow the essence of reward theory, canalysing how changes in patent length and breadth are applied simulteneously to maintain fixed revenues, also interpreted as firm's incentives to innovate, at the lowest possible social costs. Other models assess the correlation between the various dimensions of patents and identify tradeoffs and alternative designs of the regime. However, patent breadth and height 
are imperfect substitutes, embodying diverse purposes and market responses when both are simultaneously modified. Where patent breadth characterizes the range of features of a given technology that can be imitated, height defines the improvement that is recognized patentable and non-infringing. The effects of the dimensions on the market are essentially different, as the expense of improving technology (by conducting R\&D at some degree) is typically higher than the costs of imitation. Further, in terms of product variety, breadth is assaciated with horizontal product differentiation, while height measures dissimilarities of products along a similar quality ladder (Van Dijk, 1996). ${ }^{\text {is }}$

Where stylized rnodels reflect a simplified image of a complex reality, empirical fradings provide a supplementary wiew to affirm indications that otherwise would remain within the limited boundaries of the theoretical exercise. "The first challenge that economists face while analysing the dimensions of IPR regimes is to assess the influence of patent breadth and height on imnovation, market structure and adoption of new technologies by applying quantitative methods. Trajtenberg (1989; 1990) employs patent citations to measure the "magnitude" of inventions and applies this method to evaluate the links between patenting and innovation in tomography scamners.

A second challenge is to define empirically the state-of-the-art of technology and a measure for patent height, to avoid granting patents for technologies in presence and for minor improvements in existent technologies. Bibliometric methods applied to explore and to measure the intensity of co-publication in scientific research by analysing citations of scientific papers in patent records (Mairesse and Turner, 2002) may be further exploited to assess the novelty and the nonobviousness of the technical know-bow disclosed in patents. Lerner (1994) assesses the elasticity of patent breadth and the value of firms in the biotechnology sector by employing the number of subclasses under which a patent is classified as an indication for its breadth. His observations stand in one line with the findings that were brought earlier in the theoretical literature (in particular with the results of Klemperer's model). Significant correlation was found between increase in the breadth of patents and higher valuation of the patent-holding firms. Those results support the arguments that stand at the basis of the incentive theory: The stronger IPRs protection is (i.e. through granting broader patents to inventors), the higher are the incentives to innovate (as reflected by the value of the firm). Lener also concludes that relatively broad patents were granted by the USPTO

\footnotetext{
${ }^{18}$ Although Van Dijk mentions the feasibility of a combined model of patent breadth and height, it seems that the order of biases in representing the trade-off between both dimensions is significant. Inevitably, his analysis is restricted to adjusting the height and we effects on market structure and on social welfare, ignoring other aspects of the patent system.
} 
in early stages of development of biotechnology and later, since 1988, the breadth of patents was significantly narrowed. The results stggest that the value of intelNectual assets increases with wider breadth not necessanly due to the potential to develop variety of commercial applications on the basis of patented inventions, but rather due to the ability of patentees to pre-empt inventors from entering broader thechnological areas in the legally-protected environment of their patents. A second important result that Lerner's analysis yields is the link between patent breadth and the "uniqueness" of patents. Wider breadth of patents becomes more valuable in the mature stage of technological trajectories, when technological fields are massed with a multitude of competing firms that own broad portfolios of patents. The explanation of this result is almost straightforward. Large numbers of patents may emerge in any technological domain that accommodates high concentration of firms performing $R \& D$. As a result, the possibility to dominate larger technological vicinities by broader patents increases. Nevertheless, technical markets in which large numbers of firms operate and many patents are awarded bear a high degree of risk for new entrants and innovators from incumbents that already own core technologies in the form of intellectual property. Consequently, wider breadth may encourage new entry in the short run and in the long term will mitigate competition. $^{19}$

Through controlling the length, the breadth and the height of patents, separately or altogether, agents take rational and, therefore, uniform decisions on their patenting behaviour, R\&D expenditure, on imitation and invention strategies and on the licensing terms between patent-holders and licensees.

\subsubsection{Embedded Assumptions in the Neo-Classical Analysis of Patents}

A comparative benchmark of the literature on the patent regime, its dimensions and proposed optimal design reveals that the models of IP $\mathrm{R}$ regimes share a common frame-of-reference and some fundamental assumptions:

\section{1) The economic aims of IPR regimes:}

The neo-classical approach recognizes IPRs as legal mechanisms that are geared to prevent market failure as a result of under-investment in R\&D: Firms are deterred from allocating financial resources for development of new technologies unless their inventions are safe from reverse-engineering, rendering and duplication

\footnotetext{
${ }^{19}$ Patent breadth may be changed in particular cases by Court applying the doctrine of equivalents. The doctrine enables extension of the legal coverage beyond the breadth of the claims on a case-by-case basis "if two devices do the same work in substantially the same way, and accomplish substantially the same result, they are the same, even though they differ in name, form, or shape" (Machine Co. v. Murphy, 97 U.S. 120, 125; 1991). Analysis of the history of the doctrine and the legal imaplications of the recent: Festo decision are brought by White (2002).
} 
by rivals (Arrow, 1962). Consequently, neo-classical studies on the function of IPR neginus as means to enhance economic growth typically aim at discowering aptimal designs of the patent system that maximize social welfare (summing up the inventor's profits during the patent duration and the consumers? surplus in the following period) and minimize the social costs in terms of deadweight loss from monopoly rights and R\&D investments.

Following those arguments, industrial policies that aim at providing an enviroment in which innovation advances at a rapid and stable pace through implementation of IPR regimes do so by constructing a regime that satisfies the optimal degrees of the length, the breadth and the height of patents and maximizes social welfare in the short and in the long-term. However, most analyses neglect the inter-dependencies or substitution between the three dimensions of the patent system.

The assumption of market failure that stands at the basis of the reward theory advocates the use of extensive exclusive rights (e.g. monopoly over patented inventions) where other incentive mechanisms fail, thus contradicting the principal aim of knowledge transfer and diffusion of new technologies, leading to a quast-efficient regime. ${ }^{20}$

\section{2) Stability of market structure ower time:}

The assumption embedded in the basis of neo-classical models of the patent regime is that markets reach stability at a certain equilibrium point in which cconomic terms remain unchanged. The final state of the market is predictable and can be determined ex-ante by social plamers if the actors and links underlying the economic system are clearly identified and economy that reaches the desirable equilibrium will not deviate from it. Following this argument, by identifying the structure of the market and its initial conditions and by setting the magritude of the various dimensions of the regime, policy makers are able to steer the market towards a long term stability at a desired optimum. Conseguently, the level of sociall welfare can be maximized ex-ante by determining the optimal structure of the legal negine.

\section{3) The essence of imovation:}

Innovation is described as a sequence of discrete inventions that do not relate to each other from the technological or economic standpoints. Typically, the economic benefits of inventions are associated with reduction in the unit production costs and, under the assumption of homogeneous economic goods, product diversity does not exist. Although recent models consider product diversity as the relative positions of goods on the quality ladder and, consequently, invention

\footnotetext{
20 The Fair Use doctrine attempts to resolve the imperfections of the patent regime, defining exemptions to exclusive rights over inventions that are applied in scientific and non-profit use.
} 
reduces the costs of "climbing up" along it (see, for instance, Horowitz and lad, 1996), this analytical representation of technologies reflects reality only in part, leaving out the diversity of tastes and preferences whilst matching consumers and products. Introduction of new inventions tends not to include in the scope of analysis further effects, such as fostering introduction of new products and bechnologies who build upon existent goods, development of new product varieties and quality improvements.

However, Scotchmer (1991) describes innovation as cumulatwe in essence. Both technical improvements and breakthroughs are achieved through a continuous and gradual construction of new know-how upon previous inventions. Hence, technical progress is typically achieved when innovators are "standing on the shoulders of giants".

The two ways in which innovation is characterized, either as a process that compounds of discrete technological improvements or as an sequence of inventions, reaches beyond the purposes of academic discussion. Understanding the emergence of the innovative process may largely affect the course of IPR policies. In particular, the structure of exclusive rights granted to early inventors and to their followers may infuence the market organization of core inventions and of their technological offsprings. If innovators are granted weak protection for their discoveries and technological breakthroughs, firms will prefer investing in improving existing products on entering research and development of new technologies that can easily be rendered. However, if early inventors are provided with wide exclusive rights over their inventions in, their followers will be preempted from introducing advanced products and improvements. Consequently, late stages of development may be hampered by the legal regime. Scotchmer (1996) examines how the division of profit between inventors of basic technology and the "secondgeneration" applications (and consequently the incentives of firms to engage in basic of applied R\&D). She concludes that IPR policies that favour granting stronger exchusive rights to basic technologies and restricting the patent rights which are provided to second -generation inventions would increase the profits of early inventors (e.g. by licensing out their patents to a larger number of developers).

\section{4) Homogeneity of agents:}

The economic actors that operate in the market, including users, developers and distributors of technologies, are identical in thein preferences, technical capabilities and knowledge and therefore share similar decision-making mechanisms and economic rationale, leading to the formation of an anticipatted market equilibrium.

\section{5) Homogeneity of technologies and products:}

Most of the analyses assume that technologies share similar merits and are 
identical in theix market behaviour. The neo-classical body of literature largely looks at "genenic" technologies, which are similar in their diffusion patterns, in the efferency of $\mathbb{R} \& D$ investments and in their innovative trajectories. Clearly, though, the nature of innovation differs between technologies and industrial sectors and so does the use of patenting by firms. ${ }^{21}$

\section{6) Insignificance of knowledge externalities from patenting:}

The neo-classical approach typically assume insignificant knowledge externalities from patenting that bear only minor effects on innowation and technical change. R\&D expenditure and accidental inventions are perceived in the majority of patent models as the fountainhead of innowation, while the role of knowledge disclosure through patenting in the innovation process is excluded from the scope of most of the analyses, including those of knowledge transfer between firms and other actors, e.g. uniwersities, public research and strategic collaborations. Horstmann et. al. (1985) elaborate the signalling effects of patents in a multi-stage game and conclude that the equilibrium propensity of firms to their inventions decreases when the profitability of competitors increases due to further exploitation of the disclosed know-how. More recently, Verspagen and De Loo (1999) measure knowledge spiliovers from patents between sectors and Maurseth and Verspagen (2002) assess their impact on the economy. ${ }^{22}$

If the market indeed behaved as a homogeneous and stable system as described above, application of a uniform legal regime would be sufficient to achieve sustainable trajectory of inmovation. A single, "optimal" patent system that adequately addresses the needs of a wide variety of technologies will be sufficient to maximize social welfare through innovation is a straightforward conclusion.

This commonplace perspective on IPR regimes emphasizes the role of patents in promoting unvestments in research and development in firms and increasing the level of social welfare by sustaining the propensity of inventors to innovate. However, opponents of wide IPR provisions often comment that originality and creativity exist regardless of any economic incentives and novel endeavours are initiated even under difficult economic terms, as anecdotes in techmical and artistic fields demonstrate fone may think for example of the Open Source movement and its equivalent phenomena, permissive shaxing of music and books, mainly those that are published by new artists). Yet, a stable stream of profits from patent-

\footnotetext{
${ }^{21}$ Empirical studies on the links between innovation and appropriation reveal significant differences between sectors in firms' propensity to protect their inventions by patents: while the majority of pharmaceutical firms would have not developed or introduced new products at the absence of patent protection, abolishment of IP protection in other sectors, such as office equipment, vehicles and textiles, would have only a minor impact on firms' behaviour (Mansfield, 1986).

${ }^{22}$ The effectiveness of patents as sources of knowledge at the firm's level are discussed in Chapter 2.
} 
protected products along the duration of the patent providas continous sotrce of expenditure for R\&D activities and, consequently, development of new products and technologies.

\subsection{Appropriating Innovation on Creative Grounds: IPRs and Prospect Theory}

A widely accepted perspective on the economics of intellectual property, which differs from the neo-classical standpoint, is prospect theory. The theory explains national policies that aim at producing social benefits by granting rights over public property to individuals and firms in return for private investments in development and exploitation of public resources and royalties. In many nations, however, governments are not interested in or are unable to exploit public resources and prefer to transfer the property rights to private firms in return for licensing fees, royalties, investments in domestic industries and regiond development (general review and analysis of the theory of property rights appears in Barzel, 1997). Kitch (1977) draws parallels between the right to use public resources to generate profits in a defined manner within a certain geographical area (for example, rights over mining or operating fishery boats) and the provision of intellectual property rights to inventors, i.e. the right to exploit commercially the "technological prospects" that they discover. Kitch argues that patents allow inventors in discovering and producing technological advances within a particular field, hence developing it without risking their investments in $R \& D$, as their competitors are forbidden from duplicating the patent-protected inventions and from producing rival goods. However, Beck (1983) criticizes the rationale of Kitch's interpretation of the patent system on various grounds: Property rights over prospects (e.g. land) are exclusive rights granted not only for the physical asset, but also for any future use of the prospects developed later by right owners. Jin comparison to property rights, patents grant exclusive rights ower present inventions and do not provide the patentees with any control over future applications of their patented technologies. If patent claims are very broac, Courts may limit their scope and enable the release of new inventions that are build upon existing patents. Hence, future developments of the technological domain can also be accomplished by new entrants, other than the owners of patents. Further, if future development of a technological prospect can be accomplished during the patent lifetime only by patent-holders, as prospect theory suggests, other inventors would be prohibited from entering (or "trespassing") into this feld. Followirig this argument, we may assume that patenting technologies in their early stages provides patent-holders with monopoly not only over their own inventions, but also over technological advances. Consequently, other inventors would not participate in R\&D on the basis 
of existing patents, unless their eforts are coordinated with patent-holders and they obtained a "right of entry". Howewer, this view does not comply neither with reality nor with the objectves of thit patent system.

Kitcli's analysis suffers also similar weaknesses as those mentioned for the reward theory. First, whereas the rights over prospects is bounded by both geographic borders and use, i.e. the mining license is restricted to a certain zone and cannot be expanded geographically or to other types of use of the land, such as agriculture or construction, this is not the case in innovation. Whereas the value of a mining area is determined by a given amount of prospects underground, the significance of irventions and the value of patents may dramatically change in warious stages of the diffusion of technologies on the basis of commercial success, licensing and citations in other patents and by exploitation of the technology in unexpected ways. ${ }^{23}$ Second, both the prospect theory and the reward theory relate to the role of market failure and under-investment in imnovation, due to the difficulty to appropriate revenues from technical knowledge as a non-rivalrous good. On this grouncl, Kitch highlights the commonalities between the uncertainties to generate economic benefits from developing physical resources and the inability to predict whether investments in R\&D in a technological terra incognita will truly fulfil the expectations of inventors and become profitable.

In an attempt to analyze the patent system and to assess to what extent the current regime fosters innovation and technological advance, Kitch (1977) suggests a path-breaking analogy of property rights over intellectual endeavours and rights granted for physical prospects, such as land use or fishery. Although both regimes are based on provision of (temporary) exclusive rights as incentives for development efforts, this doctrine suffers major shortcomings due to major dissimilarities between the economic properties of prospects and technological know-how. In particular, prospect theory fails to reflect the cumulative nature of innowation. Patenting technologies in their early stages can largely be interpreted as a barther for development of new inventions in techmological domains, wather than as exclusive rights that protect the claimed applications and the disclosed know-how.

\subsection{The Role of Copyrights in the Economy}

Different from patents, copyrights aim to protect artistic and literary works, such as books, photographs and phonograms. Copyright legislation worldwide is based on the guidelimes of the Berne Convention. The Berne Convention defines a min-

\footnotetext{
${ }^{23}$ For example, it is hard to imagine that anyone in the beginning of the 1970 s, including the patentees, had fully reognized the commercial potential and the value of patents on. the Cohen-Boyer process of recombinant DNA, which became a major keystone in the exolution of the biotechnology industry.
} 
imal term for protection of the author's lifetme plus fifty years, which car be extended when rules are written at the national level. ${ }^{24}$ The (non-limiting) scope of coverage by copyrights includes not only literary and artistic works but also the derivatives of copyrighted works, such as translations and adaptations. The derivative artefacts enjoy copyright protection equal to the terms of protection that original works enjoy. The Convention also enables an optional protection for official, legislative and administrative texts, lectures, folklore works and even mailing addresses (WIPO, 1998), 25

The incentive mechanisms underlying copyrights are not less complex than those that are at the basis of the patent system. Since generation of artistic and literal works differs in essence from technical inventions and does not, encompass similar degrees of investments in $\mathbb{R} \& D$ as technology requires, the insights of the reward theory that justify long-term monopoly rights to elevate the scales of art production do not necessarily apply in the case of cultural goods. Towse (1999) interprets the economic function of copyrights as a risk-sharing mechanism between publishers and authors: publishers invest in the distribution and promotion of creative works and share agreed part of the profits with authors in return to the right to reproduce their work. The model may explain the rationale of copyrights in cultural industries, in which creation and dissemination are carried out separately by the authors and producers, but can hardly characterize sof ware development, where most of the applications are developed within firms and marketed by them.

From a moral point of view, copyrights are indeed another form of appropriation mechanism, which ensures "incentives to create" new artistic works to authors and creators of other cultural genres, such as choreagraphy and photography. However, major conflict between copyrights and the nature of artistic and literary works is emphasized by the nature of those products. Property rights emerge where scarcity of resources exists and, hence, investments in developing them may prove insufficient. ${ }^{24}$ Copyright-protected goods seem not to suffer any source of scarcity: written books or composed music will be generated by their creators under a wide range of market terms, therefore giving higher weight to the rational rewarding authors" creative efforts ex-post.

In their seminal paper on the economics of copyrights, Landes and Posner (1989) highlight the distinction between (abstract) ideas, which are excluded from the legal scope of copyrights, and the tangible expressions for which legal protec-

\footnotetext{
${ }^{24}$ Copyrights are granted for author's lifetime plus a term of seventy years in the EU and ninety years in the U.S.

${ }^{25}$ U.S. jurisdiction has not followed this extension, as the Feist doctrine demonstrates.

${ }^{26}$ In the case of patents, scarcity of resources problens can be formed as a result of under-investment of firms in $R \& D$. The patent regime aims at providing exclusive rights to inventors to prevent market failure in developing new products and technologies (Arrow, 1962).
} 
tion is guaranted, on the basis of originality, stating that:

since the costs of developing a new idea are likely to be low in most cases relative to the potential reward from licensing the idea to others, there would be a mad rush to develop and copyright ideas... with minimal expression. [Consequently, although the development of new ideas would be accelerated, the dissemination of ideas minght not be." (Ibid.)

Looking at the impact of changes in the design of the legal regimes on technology markets, scholars see only mimor benefits to society from extending the term of copyrights, at the expense of high social costs. Critique of the extension by twenty years the duration of copyrights was submitted to the US Supreme Court. by a group of legal and academic scholars stating that the modified doctrine encompasses only marginal incentives for authors and creators to generate aew works, but significantly increases the social cost of monopoly. Hence, the extended term may hinder innovation by liniting the right to use earlier material in new works for a longer period (Akerlof et. al, 2002). Common opinions hold that the protection of different genres of creative endeavours is fundamentally divided between patents on copyrights. Analysing IP doctrines that protect a certain technology or product jointly by patents and copyrights, Reichman (1994) argues that integrating both regimes to protect different tedmical functiomalities and merits does not necessarily guarantee complete protection and appears to be under-protective in some cases. However, under other market conditions the dual protection creates an overlap between both legal blankets, covering a similar subject matter, which may be over-protective in favour of market incumbents, providing them with excessive ownership rights over technologies. Since the publication of his work, an increasing variety of legal regimes that merge patenting and copyright protection. or adopt selected aspects of each system, were established by legislators (e.g. in several EC Directives on knowledge-based industries). Alternatively, firms design public licenses, custom-built to the characteristics of new products, to maintain wide and rapid diffusion of their technologies and products ${ }^{27}$

\subsection{Further Considerations}

The "Graditional" faculty of the economics of IPR regimes" 28 have concentrated in studying the immediate and short-tem effects of the legislative framework,

${ }^{2 \pi}$ Bessy and Brousseau (1998) find a positive correlation between the diversity of licensing agreements, as appropriation mechanisms additional to the use of IPRs, and higher levels of technical knowledge acquired by heenses in various industrial sectors. In the particular context of information technologies, Perens (1999) proposes a model of public licensing strategles to enhance the diffusion and use of software applications.

${ }^{2}$ Here, I notably refer to the special issue of RAND Joumal of Economics from January 1990. 
mainly those of patents, on innovation and techmical change. Innovation is analyzed in most cases as a single-period process where sequential contributions and breakthroughs and different genres of technology are treated evenly. In realify, however, innovation is a dynamic process whose effects are not limited to selected markets but diffuse to other technological domains and mushroom new products and technologies in neighbouring technical fields to that of the invention.

The development of new products and technologies is indeed a puzaling process, whose underlying mechanisms are to a large extent obscure. What are the sources of inmovation and the imputs that may enable the foster of creativity and do technological breakthroughs emerge in laboratories and research units are issurs whose solutions are still far from completely understood. "The pace of innovation, i.e. the technical progress that a single invention produces and contributes to fostering later stages of research, is umpredictable and cannot be easily associated with exogenous parameters, such as with R\&D expenditure or with one of the dimensions of the patent system.

The innovation is typically characterized by wider veriety of products with higher quality and lower price-tags. Diffusion of advanced technologies and products into daily use signifies an increasing social. welfare, as households purchase similar or technically-improved goods at lower prices. Similarly, frms that are anthorized to implement the state-of-the-art of technology will generate further inventions and technological progress. Instead, most studies identily social welfare benefits with minimizing deadweight loss and by drawing causalities between $\mathbb{R} \& \mathrm{D}$, innovation and reward within a static frame-of-analysis. This body of literature hardly refers to the dynamics of diffusion processes. Indeed, enduring the application of stronger IPR regimes and granting innovators increasing levels of monopoly rights may consequently increase their rewards from succesfully-commercialized inventions, but may hamper the pace of innovation in the long run by restricting the use of progressive techniques in research and development of new products. 



\section{3}

\section{The Role and Performance of IPRs as Knowledge-Propelling Regimes}

\subsection{Introduction}

The economic role of $\mathbb{P R}$ regimes and their impact on technological markets are broadly discussed in the previous chapter. However, the complexity underlying the economics of IPRs, the ties between legislation and innovative output and their application within firms" strategies call for a systematic evaluation of the role of IPRs in the economic system. Further, the impact of the IPR regime and knowledge disclosure are not necessarily restricted to provision of direct incentives for innovators, but also generate a wider array of effects that stem from knowledge spillovers and from their contribution to technological learning in firms. Whether there is a need for governing emerging technological markets by enacting new IPR rules and by extending present doctrines to include them in their scope of protection or should economies be left unregulated to market powers and to the "invisible hand" is among the main concems that policy designers face. Issues of policy changes should be assessed within an adequate framewok that includes the short-and long-term goals of economic policies, major inputs and outputs and institutions that are involved in the imovation process. Hence, technologies and markets influence and are affected, to an extent, by the forms of institutions and regulatory fameworks.

The inpact of long duration monopoly rights on innovation goes beyond momentary effects as the many neo-classical economic analyses suggest. Economies and markets usually react to legislative changes after long periods in different ways due to the different difusion phases of the technology. For example, the consumption behaviour of early adopters differs from the behaviour of consumers of mature technologies. Consequenty, frms' strategies that are based on IPRs (e.g. strategic patenting) may significantly be altered as technology evolves. Consequently, 


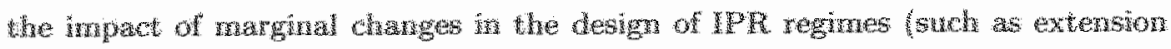

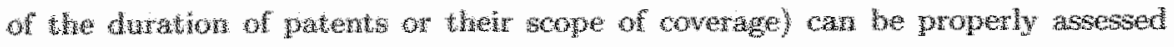
ex-post after long durafon of mplenentation of wew policies, rather than through wallysis of a momentary sirusathon.

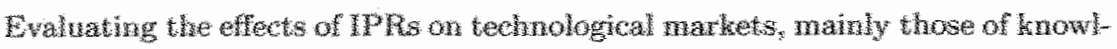

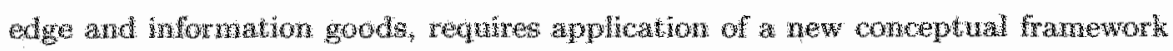
that differs from the conventona economic insights. This chapter draws a rame-

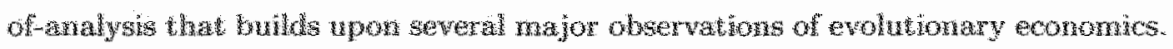
The hrst the percephon of the ecomomy as dyname aystem whose responses to external shmin, snch as changes in reguhtion, shond be assessed in a wider perspective than their influence on the "return-on-wwention" and NCD inwestments by fus in a given period. Hsted, narkets, institutions and techologias co-evolwe over inne and may closely (or loosely) interdet with each other. If regklation, for example, is atered, frms and techologies will react in ans adaptwe way, often wht a time lag from the introduction of the attered polvy. Simitarly,

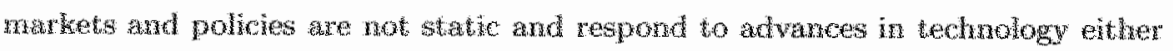
by modifying stretegies of hrms and consumer's behawion or by dictating new reles.

Second, the dynamics of knowledge formation and its links to innovaton and

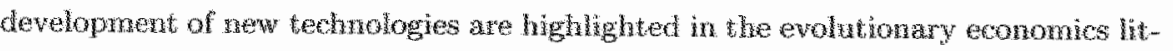
erature. Ow andysis wins at dentifyng the prevaling thmensions of $\mathrm{PR}$ regines that infuence the fommation and the mobitity of techical knowledge and, hence, affect the pace and the patterns of imovation and tewneal development an mormation techalogies. IPRs may cortribute to technological progress, but wisapplication of appropriation polices may impede technological adwances in the long run. Therefore, IPR policies should consider the links between structural factors of the legal regime and processes of innovation, introduction of new products and creation of novel know-how.

Generic laws of IPRs that apply general legislation to a wide variety of technologies and products are favoured by policy makers and practitioners on sum generis laws, uniquely formed to meet the needs of each technology and product. From the social welfare point-of-view, the costs of administrating and enforcing TPRs and the expenditure on training new attorneys and examiners decrease as the legal doctrine becomes more general, due to similarities in the legal procedures that regulate a variety of products and technologies. However, a general doctrine may suffer significant shortcomings, granting over- and under-protection to various components of information technologies. Of major importance are the scales of knowledge cisclosure and novelty required to obtain a patent in comparison to monopoly rights that are granted to inventors. Those dimensions play a 
Disclosure vs. Exclusion: Implications of Mobility and Ownership of Technical

major role in developing stable patterns of inmovation and in forming competitive and innovative markets. However, negative effects of over-protective IPR regimes are associated with monopoly rights over creative endeavours and may result in acquiring competitive advantage through legal practices, rather than through innovation and creativity. Further, IPRs are mostly enacted as a generic set of rules that address a wide variety of technologies. Rarely, IPR laws are talored to fit the needs of specific technologies. The adequacy and the weaknesses of the regime to assure a prominent development of technical knowledge and advanced products are discussed in the following section.

\subsection{Disclosure vs. Exclusion: Implications of Mobility and Ownership of Technical Know-How}

\subsubsection{Background}

The primary perspectives of evolutionary economics emphasize the role of knowledge disclosure and dissemination as a principal device beyond innovative and technological virtue. Knowledge creates further knowledge and opens new avenues for further development and introduction of new products through a process of cumulative improvement of existent technologies:

"Most inventors stand on the shoulders of giants, and never more so than in the current evolution of high technologies, where almost all technical progress builds on a foundation provided by early innovators" (Scotchmer, 1991).

Entrepreneurial and innovative output usually takes the form of incremental improvements on the basis of prior innovation and it is seldom characterized by breakthroughs or accidental discoveries. Technologies commonly emerge from long and systematic processes of research and development and technological learnirg, where the capabilities of the firm are gradually constituted (Dosi, 1988). Firms are able to recognize the value of new information (either externally acquired or developed in-house), to assimilate it and to exploit it in their products only if they already possess a sufficient level of technical capabilities, which enable them to process and to synthesize it into their organizational knowledge base. "The absorptive capacity of firms is greatly affected by the present level of their competences and the capacity of their technical know-how (Cohen and Levinthal, 1990). If firms acquire essential knowledge and capabilities earlier, they will be able to compete more efficiently in the market and to "catch-up" with advanced technologies of their rivals. However, in the extreme case, if the firm lags behind competitors in possessing and assimilating knowledge assets, it would not implement recent technical advances and in the long run it will fail in competing on price and quality with other firms. 
Another important property of technical knowledge is its evolution and transfor in an "epidenic" manner. The exposure of firms to new technologies expands as knowledge spillovers occur within and among different sectors. Knowledge spillovers are also generated from the mobility of labour between firms, from reverse engineering rival products and rom imitating existent technologies and from schentific and technical publications.

The disclosure of know-how to the public domain expands the population of firms that apply it in their products. Information that has previously been kept secte within companies is published and other inventors are capable of experimenting with new techniques, enhancing their technological competences and, consequently raising their innovative output. The provision of property rights over inventions provides firms with incentives to do so. IPRs assure the safe revelation of trade secrets and protect their applications of the disclosed knowledge by Patent Law. Had other products that sufficiently differ from the technology of the originating firm been developed by other inventors, they would be recognized non-infringing and may be patentable by themselves.

The preparation of patent applications forces firms to organize and to present their knowledge in a standard and rigid format. The process of knowledge codification in firms encompasses substantial benefits, which may result in costs reduction of business processes and in increase of organizational efliciencies (Cowan and Foray, 1997).

First, acquisition of particular know-how may turn out to be unnecessary if shares of the information have already been augmented by the firm and can be easily retrieved. Knowledge can be transferred and communicated within organizations through explicit forms of representation. By codifying know-how, firms are able to enhance the capabilities of their employees and to reduce transaction costs associated with the acquisition of knowledge. However, accessibility of employees to know-how becomes possible only if it is dissemimated in an 'explicit' format, such as in a form of patent records. Hence, investments in re-acquiring already existent knowledge can be removed and funds can be reallocated to R\&D activities, enhancing both the efficiencies of fims and social welfare.

Second, codification reduces the effects of asymmetric information and increases coordination within and among firms. For example, when knowledge that was previously kept by technical persomnel is distributed to other units in the firm, such as marketing and strategic planning, workers may utilize it in different directions, such as initiating new projects and evaluating plans and operations. In a

\footnotetext{
${ }^{1}$ Difterent forms of legislation, e.g. tracle searecy and the Fair Use doctrine, aim at protecting entrepreneuns by limiting the How of know-how, technical information and expertise to their competitors.
} 
similar way, firns cooperate in order to integrate their technological competences and different genres of knowledge to develop advanced products."

Third, codification of knowledge that previously has existed in a tacit form enables easier commodification and commercial explotitation of it in fimal goods. Knowledge is not kept anymore within the domain of individuals and can be used by others regardless of any properties of its previous owners. By transforming knowledge that previously has been based on personal experience of workers to routines, firms are able to standardize and to control organizational processes and increase the volume of production and the quality of products (Nelson and Winter, 1982; Ch. 5). For example, identifying the "right conditions" of temperature and moisture of paper mash was an essential skill of machine operators in paper mills and remained tacit for many years. Measuring (i.e. codifying) the parameters of the chemical process and developing sensor-based equipment enabled a dramatic increase in the efficiency, quality and stability of paper production. ${ }^{3}$ However, the decision to codify specific knowledge prospects is not necessarily driven by motives of transferring knowledge from a tacit to an explicit form for the sake of easier representation, but imwolves economic considerations of costs and benefits by firms. Knowledge codification is a costly process that requires investments in working hours, capital resources and information technologies, it is undertaken by the firm only if it is economically justified (Cowan et. al., 2000). The process may be accomplished successfully only if the organizational environment supports efficient sharing, storage and retrieval of knowledge.

As this argument goes, IPRs (and patents in particular) may be perceived as mechanisms to promote codification and approximation of state-of-the-art, tacit knowledge. Otherwise the innovative information would be kept secret within the domain of its creators. More generally, patents provide firms with a framework for representing their tacit knowledge (as well as measuring the efficiency of their R\&D teams). Further, learning form patents has become easier than ever before as patent records, blueprints, and cletaled descriptions of the inventions and the claims are browsable online by the interested party."

The application of information technologies for accessing patent databases and retrieving information is very beneficial from a social welfare standpoint. Search costs of patentees, patent attorneys and firms have significantly decreased as a

\footnotetext{
${ }^{2}$ For a review of inter-firm research collaborations since the 1960 s in variety of industrial sectors, see Hagedoorn (2002).

${ }^{3}$ Similar processes fostered the development of advanced production methods in the fast food industry by codifying the tacit knowledge of machine operators.

${ }^{4}$ During the last years patent offices world-wide made significant investments in digitisation of patent databases and in construction of Internet-based communications and interfaces to access their contents online. See, for example, the USPTO website in: www. nspto.gov.
} 
result. Futher, the publication of technical detals in patent records reduces information market asymmetries and uncertainty, consequently fostering the formation joint ventures between firms and efficient allocation of capital investments im R\&D projects. Nevertheless, patenting embraces substantial costs for the society: the use of know-how is restricted by law for long periods and firms are prohibited from learning by following the knowledge base of patented inventions. ${ }^{5}$

While rewand theory and prospect theory indicate that the major aim of the patent system is to provide "incentives to innovate", evalutionary theory suggests that its primary goal is to provide inventors with "incentives to disclose" knowhow on nowel inventions, which otherwise would have remained within the firm's domain.

Cohendet and Meyer-Krahmer (2001) suggest a different perspective on the links between IPRs and innovation, emphasizing the role of patents in knowledge production processes. The existence of trust between collaborating firms is perceived as the primary motive behind the decision of firms to apply patenting as their preferred appropriation method. If the level of trust and cooperation between busimess partners of the venture is low, specialized know how can easily be acquired from other parties and, hence, inventors rely on patent protection to safeguard their intellectual assets. When trust between parties exists business partners benefit from reciprocal exchange of knowledge and patents function as "access rights" to codified information and serve as a signalling device for the value of inventions or as indicators of reputation and imnovative qualities of potential associates. Although trust seems to be a key factor in patenting decisions of firms, their motives are affected by far more complex considerations that are geared towards obtaining market dominance and technological leadership by implementing legall means. However, trust cannot be used as a criterion to determine the design of IPR regimes. It is notoriously difficult to quantify (even on an approximate scale) and therefore it imposes further uncertainties and abstraction into a system which is already complex. Nevertheless, trust can provide new insights on the merits of IPR regimes and their links to the business environment but can hardly establish any measures for articulating new policies or for reforming the patent system.

Paradoxically, although IPRs aim at fostering knowledge disclosure and innovation on the basis of patented know-how, IPRs limit other parties from freely exploiting knowledge and to some extent even restrict new inventors from intro-

\footnotetext{
${ }^{5}$ Following Roche Products, Inc. \%. Bolar Pharmaceuticals Co. (733 F.2d 858, Fed. Circuit, 1984), testing the feasibility of producing patented inventions when patents are valid (in order to enter the market when they expire) was recognized infringing. For review of Fair Use of patented inventions vs. the Experimental Use exemption, see Grossman (1990).
} 
ducing advanced technologies that build upon disclosed know-how by providing inmovators and authors with monopoly rights over creative endeavours. Preserving the balance between knowledge disclosure and its exclusion from free use is a primary challenge for policy makers and regulators.

\subsubsection{Structural Considerations}

The legal realm of intellectual property rights offers various means for protection of novel technological and artistic artefacts. Patents, copyrights, and trade secrecy are different methods for protecting intellectual endeavours, where, on the other pole, licensing, fair use doctrine and anti-trust laws foster information flow and utilization of legally protected know-how.

Legal and economic scholars are concerned with different aspects of IPR regimes. The present length, breadth (and less-ofter the height) of patentis are often criticized as over-protective and as pivotal encumbrances for developing technologies (see the discussion above). Industrial organization studies, the chief body of economic literature on the design of IPR regimes, is based on static analyses that aim at evaluating how marginal changes in the determinants of patents and copyrights affect the market and the behaviour of firms and at discovering the optimal magnitude of each dimension under different market terms. However, IPR regimes are not uniformly shaped across nations and industries and vary in systematic attributes. Therefore, a closer look into patent regimes world-wide reveals further policy considerations beyond issues of the three-dimensional structure of the regime, which stand in the scope of international harmonization efforts. ${ }^{6}$ Other attributes of the patent system (i.e. the structural factors of the regime, such as the ownership of a patent by the "first to file" or by the "first to invent" among competing inventors), which are second-in-importance to length, breadth and height, are far from being administrative fine-tunings and can significantly affect the pace of innovation and the strategies of firms in the short rum.

A major difference between the U.S. patent system and other intermational regimes refers to the ability to challenge monopoly rights that were granted to patent applicants by others. In Europe and Japan the "first to file" patent applications will obtain the patents rights over inventions, where in the U.S. patents are granted to the "first to invent". What seems as a minor wariance in legal definitions is a meaningful difference that influences the risks of innovators and

\footnotetext{
SSome of the aspects of the following discussion may apply also to copyrights. However, the structural and legislative properties of the copyright regime signifcanty differ from those of patents. Following characteristics and the goals of each regine, it is reasin able to assume that the impact of modifying the configuration of patents on inmovation and technical change will be far more significant than equivalent modifications of copyrights.
} 
the introduction of new technologies (and consequently their diffusion). According to nom-U.S. Patent Laws, if a patent were approved, the first to apply for it will receive the ownership rights of the protected invention. In the U.S., the first to develop a patented invention can regain the rights over it, even if the patent has already been granted to the earliest applicant. Therefore, in the $\mathbb{E} . U$. and in Japan the validity and the novelty of patents can be challenged by other parties, but the ownership rights of applicants cannot be put to question, while in the U.S. paterts can be pended within a year from issuing if other applicant proves that she preceded the patent-holder in developing the litigated invention (even though she was late in submitting the patent application).

The impact of the U.S. legistation on patenting decisions of firms can formally be described as a non-cooperative game between patent applicants and rival developers with asymmetric information. Assuming that the applicants cannot obtain information about $R \& D$ operations in rival firms, rivals are able gain knowledge on new patent applications virtually at no cost from the USPTO databases. Generally, inventors awoid revealing information on their technologies in early stages of development and prefer trade secrecy on patenting, unless patent applications on the very same inventions are submitted by rival firms.

Some developers may prefer to delay their patent proceedings from strategic reasons until another applicant is granted with a patent over the same invention. Then, they can submit a "first-to-invent" appeal and obtain the patent rights, regardless their position in the patent race as followers of the earliest applicant. By appealing to the UPSTO after firms have already been granted patents and made substantial investments in production facilities and in $\mathrm{R} \& \mathrm{D}$, inventors are able to suspend the introduction of new products by their competitors and to aggravate their losses in the first phase of commercializing new technology. Consequently, the risk of patenting in the U.S. is significantly high in comparison to other countries and firms often delay the submission of patent applications. Ordover (1991) anam lyzes international patent systems and concludes that that European and Japanese innovators, having to follow the first-to-file doctrine, are persuaded to apply for a. patent earlier than U.S. applicants, as a failure to submit their patent applications before competitors will result in a loss of (potential) monopoly rights over their inventions. Theoretically, the U.S. policy may result in lower degrees of social welfare than obtained in other states, as inventors may delay their patent applications (and consequently the disclosure of technical know-how) and the introduction of new technologies, considering the risks of engaging in patent litigation with competing firms. Therefore, the competitive behaviour of firms and their rivals in European and in Japan typically follows the dynamics of patent races, whije the decisions of U.S. fims involve other considerations, such as the technological level 


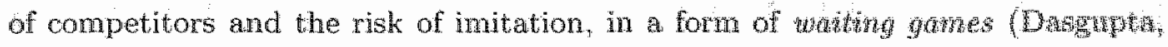
$1988)$.

A second structural difference between the Japanese regime and the US. ard European patent systems refers to the onthe of patent records and particutinly to the structure of the specified clans. The U.S and European legistation enable patentees to include multiple clains within a single patent and therefore to protect wide range of present and future applications of the invention within a single patent. The Japanese system requires submission of a separate patent for every single component of the invention or for any particular application of the invention. The structure of the U.S. and the European patent systems provide inventors with broader legal coverage than the Japanese regime does (even when inwentors apply for multi-patent protection, following the orders of the llapanese Patent law), as patent records in the U.S. and in the E.U. are far more open for legal interpretation of their scope, while Japanese applicants are required to "anticipate" and to apply for patents for all the beneficial uses of their inventions (Karjala, 1990; Brueckman, 1990). From an economic standpoint, the Japanese Patent Law exhibits a more restricted form of exclusive rights by "fencing out" smaller shares of technological domains than in the U.S. and European doctrines. Therefore, the Japanese patent system applies a munificent approach towards dissemination of technical knowhow and diffusion of new technological advances over granting wider exclusive rights to patent-holders. Nevertheless, from a social welfare perspective, setting up appropriation policies that build upon the Japanese patent system may suffer significant shortcomings. Single-claim patents involve higher legal costs for the firm and for the patent office. Moreover, when the breadth of patents is narrower than in other international patent regimes, the risk of disclosing largely applicable technical know-how increases, resulting in lower propensity of firms to protect their inventions by patents.

Although the European and the Japanese patent systems do not significantly differ from the U.S. regme, both regimes propose alternative standards and should be considered as a basis for future reforms in the U.S. patent regulation. Application of narrower patent claims or even single-clam patents and a minimal inventive step in new patent policies are likely to foster the entry of new firms to markets that previously were dominated by patent-holders. By implementing policies that modify both legal measures, new entrants will be able to compete with incumbent firms by introducing new products based on existing knowledge and yet are sufficiently differ from patented inventions. 


\subsubsection{IPRs and Anti-Competitive Behaviour of Firms}

The legal framework of anti-trust laws had been formed to ensure free competition and, in this context, to provide legal means for assuring that entrepreneurs can develop and distribute rival techmologies and products. Anti-trust authorities attempt to guarantee that monopolization of a market does not hinder either market or technological competition. Contrary to anti-trust doctrine, patents and copyrights provicle monopolistic power to inventors of technologies and to creators of artistic and literary works for relatively long periods. Ownership of a technology is guaranteed to the holders of the rights with no constraints, as in most countries no legal guddelines for compulsory licensing of patents or copyrighted works exist. Jurisdiction declines to state that refusal of patent holders to license patented technologies is a violation of anti-trust doctrine, even when patent-holders deliberately rule out any use of their technologies by other frms. Although patents and copyrights are often criticized as inappropriate methods of fostering innovation and technical change (in the case of patents) and other sorts of creative output (in the case of copyrights), both regimes are still the most dominant institutional means for protecting intellectual property. This issue is furthermore amplified by the views that patents and copyrights are over-protective, providing high degrees of monopolistic power over inventions and works in new and core technologies and in cultural industries, hence impeding innovation and competition in these mankets.

It is indeed striking how fundamental prospects of IPRs are inconsistent with the main characteristics of competition law, as the two legislative systems are long-living regimes. Anti-trust policies aim at preventing the formation of monopolles and restricting their infuence on consumer choices and competition, thereby assuring the emergence of new, inventive entrants in the market. IPRs, in turn, wim at generating incentives to foster inwowation by granting monopoly power over tedhological fields, and thus can be seen to be in direct conflict with competition law. Being aware of the conflict long ago, the U.S. Supreme Court had stated that "since patents are privileges restrictive of a free economy, the rights which Congress has attached to them must be strictly construed"?

The relations between competition law and intellectual property rights are not as straightorward as it seems. Gallini and Trebilcock (1998) suggest that it is possible to reconcile the two regimes by perceiving competition laws as promoting inventions by ensuring free-competition and market entry in the long run, while IPRs encourage innowation in the short run by offering monopoly rights over technological advances (hence providing inventors with incentives to innovate). This conclusion has to be treated carefully. A closer look at the evolution of technolo-

\footnotetext{
United States wasonite (Supreme Court, 1942).
} 
gies suggests that permitting monopolistic market structures and the consequent pricing of products reduces the demand for technology in the short run, and therefore deters both technological diffusion among users and learming-by-doing and learning-by-using effects among firms (Arrow, 1962b; Rosenberg, 1982). Lower scales of technological learning, which are significant for generating technological advances, may slow down the pace of imnovation in the long run.

Typically, anti-trust authorities prohibit mergers or acquisitions that create technological monopolies, since to avoid the formation of barriers to entry, but under some circumstances monopoly over technology is permissible by anti-trust. laws. The case of the acquisition of Wellcome by Glaxo demonstintes the efficiencies of monopoly in developing new technologies. The firms had received FDA approwal for a new migraine reatment with oral application. The acquisition of Wellcome by Glaxo was denied in its first stages by competition athorities in the U.S. to prevent a monopoly in migraine-treating drugs. However, the decision was revised and the acquisition was finally approved when Glaxo successfully proved that its rivals performed only marginal R\&D activities in this technological field and had no tangible basis to enter the new market (Tom, 1998). The high costs of R\&D for developing pharmaceutical products and drugs create high barriens to entry such that technological monopolies are within the natinal structure of the industry. Since this acquisition was not going to tip any competition over this market segment, and since regardless of whether the acquisition took place other firms were unllikely to enter (due to the high $R \& \mathbb{D}$ costs) the acquisition was permitied to proceed.

Although the tension between anti-trust laws, deterring monopolies over trechnological markets, and IPRs forming monopolies over technological fields has not been resolved, both the EU legislation and the US law avoid application of compulsory licensing. The European Court of Justice stated that "refusal to grant a license, even if it is the act of an undertaling holding a dominant position, cannot in itself constitute abuse of a dominant position". "The U.S. Court has expressed a similar opinion that the refusal by patent holder either to license or to use its patent is not an anti-trust case. The degree of complexity to which the tension between anti-trust legislation and IPRs has evolved is amplified when technologies of the New Economy are considered. Software technologies, Internet-based communications and accessibility to database contents being applied by vast numbers of users via the Internet or while being massively distributed, generate network effects. "Lock-in" to a single technology and its implementation as a market standard (Arthur, 1987) questions the role of competition authonivies in markets in which technological merits and not necessarily business strategies of firms lead io

${ }^{8}$ RTE B Anor v. Commission of the European Communities (1995). 
moropolistic position.

Policy makers, aspiring to encourage knowledge spillovers between inventors and other firms, have faced opposite opinions about IPR regimes and enforcement of Competition Law when cone technologies are dominated by monopolies. How variations in the patent regime, such as those presented above, contribute to innovation satisfy the goal of economic growth is still a puzaling affair. Although Ordover (1991) supports mplementation of structural changes that ypically follow the desigm of the Japanese regime in the U.S., the legal and administrative costs involved in modifying the patent system might exceed the benefits. However, some of the structural attributes reviewed above should not be ignored instantly, but shond be considered while forming new IP policies or while revising the present legislation. "The application of some of those structural changes in the existing regimes may foster knowledge disclosure and competitiveness in markets that were previously dom nated by monopolists. Finaly, further inquiry is needed to determine the motives of firms that initialize a litigation process in order to stop patents from being granted to rival firms. Further empirical inquiries of litigation cases and opposition to patents are therefore necessary to broaden the legal and economic kmowledge an ways firms apply those less-spotted prospects of the patent system as strategic means.

\subsubsection{Compulsory Licensing: Enforcing the Utilization of Patent-Protected Knowledge}

Systems of IPRs are commonly perceived as major institutional tools in innovation policies mainly in fostering disclosure of technical know-how, which otherwise could have remained within the firm's domain. Interestingly, scholars highlight alternativo means to promote innovation and knowledge disclosure. Public procurement, prizes granted to the first-tio-invent an essential technology (e.g. discovering medical drugs) public research contracts are common examples (Wright, 1983; Dasgupta and David, 1994; Davis, 2004). Another mechanism that is inherent in the pettent system is compulsory licersing. A wide implementation of compulsory licensing is advocated on occasion as a balancing instrument against excessive monopoly pricing of inventors. In practice, however, it has been enforced only in a small number of occasions world-wide. ${ }^{\text {to }}$ Compulsory licensing is

\footnotetext{
A leap loward in the study of patent litigation and objection processes was recently made by Graham et. al. (2002), studying reextmination of patents in the U.S. and in Hurope. Howewer, them analysis is concerned with dafferent issurs than those mentioned here, such as the rate of opposition and the outcomes of patent re-examination by the patent offices un various industries.

10 The TRIPs agrement permits compulsory licensing in cases of "national emergency a other ciromstances of extreme urgency or in cases of public non-commercial use" (Axticle 3 llib), ag, production of low-price, generic versions of anti-HTV drugs for developing
} 
closely associated with anti-trust policies and their legislative framework, known as Competition Law, which is discussed below.

The enactment and enforcement of compulsory licensing raise legal and ethical difficulties, questioning the rights of patent-holders to own intellectual assets for long periods and the legitimacy of governmental intervention. However, from an economic standpoint, the benefits of implementing compulsory licensing may overcome the drawbacks in a variety of market conditions and technological spheres. ${ }^{11}$

Compulsory licensing enables regulators flexibihity to intervene in to revise patent policies. Yet, it provides them with a set of exemptions that restrict the practice of patent rights by their holders when the balance between monopoly rights and market power is heavily distorted. By applying compulsory licensing measures, substantial welfare losses (i.e. deadweight loss) and slower adoption of technologies due to a non-competitive structure of the market can be avoided. The "neo-classical" deadweight loss results from granting inventors excessive exclusive rights over technology. In the lack of compulsory licensing measures, inventors protect their monopolistic position by strategically patenting a wide range of applications and later determining monopoly prices for them. However, if inventors were obliged to share their exclusive rights with other firms and be paid royalty fees the market would become competitive and the prices of goods would be lower than monopoly price. The profits of inventors having to compete with other firms would decrease in some degree. However, under compulsory licensing revenues are generated from royalty fees and from a mark-up $\rho^{*}$ on goods produced at the cost of $\underline{c}$ (Tandon, 1982). ${ }^{12}$

A second social benefit from compulsory licensing is a rapid diffusion of new technologies, as firms are able to introduce competitive products at, a lower price without infringing the rights of patent-holders (as long as royalty fees are paid). In order to prevent situations in which patentees charge expensive royalty fees to preserve their monopoly, compulsory licensing should be accompanied by other anti-trust measures, such as public control over royalty rates. ${ }^{135}$

Further, compulsory licensing prevents abusive use of monopoly rights by patentees. Inventors are granted rights ownership over cone technologies and standards for long periods and are free to license them at any cost. Consequently, patent-holders do not dominate only the protected technology but also a wider

\footnotetext{
countries.

${ }^{11}$ Ethical, moral and political aspects of the compulsory licensing are left outside the scope of this discussion.

${ }^{12}$ Formally, $c \cdot\left(1+\rho^{*}\right)<c_{m}<\bar{c}$, where $\bar{c}$ is the pre-invention market price, $c_{m}$ is the monopoly price and $\underline{c}$ is the post-invention competitive price. $\rho^{\text {* }}$ denotes the royalty fee per product unit determined by the regulator $\left(\rho^{*}<1\right)$.

${ }^{13}$ Compulsory licensing is positive from the firm"s learning perspective, onabling development that gradually builds upon patents without infringing them.
} 
scope of dowhstream products. Compulsory licensing removes the monopoly power of single inventors and opens new opportunities for developing the technology further by other firms. Yet, inmowators are rewarded for their efforts by royalty payments from licensees.

Licensing core inventions with low royalty fees may prove a desirable strategy for the frm. If patented inventions become accessible to a wider population af firms, the technology will diffuse rapidly and will become a market standard, broadly used by consumers and firms. In the long run, if its technology becomes successful, the innowatung firm will occupy larger market shares and generate higher revenues from royalty fees. Alternatively, the firm can grant exclusive rights over patents to a small group of licensees at high fees per firm. It is difficult to predict ex-ante whether licensing patents to a srrall group of firms or to many licensees or keeping the technology proprietary is more profitable. However, when an inwention becomes widespread as a core technology or produces strong network effects, low rates of royalty fees will assist its adoption and will increase the total profits of the firm. The case of Cohen-Boyer patents exemplifies the advantage of licensing with low royalty fees. In 1973, Stanley Cohen of Stanford University and Herbert Boyer of the Uniwersity of Califorma discovered the process of recombinant DNA, a first keystone for the new scientific field. The first patent application was submitted by Stanford University in 1974, and in 1976 Cohen and Boyer founded Genentech, which became the first biotech firm. Since the patents for the Cohen-Boyer process were registered, licensing agreements have generated more than $\$ 140$ million in royalty fees. The successful implementation of non-exclustive licensing terms, which strengthened the evolutionary path of the biotechnology industry by charging (relatively) low royalty fees for the Cohen-Boyer process thus helped establish new trajectories that continue to employ this technical knowledge. Three characteristics distinguish the recombinant DNA as a technological and commercial success story. First, the invention was at that period a unique technology, having no competing methods to conduct a similar process and products. Second, the techrology that was presented was imexpensive to use and easy to implement. Third, most importantly, the Cohen-Boyer process was a core technology that served as the foundation for a wide range of applications and opportunities for developments in the established field of molecular biology (NRC, 1997). Further, the licensing strategy of the Cohen-Boyer patents emphasizes the importance of assessing the elasticity of technological diffusion with regards to royalty fees, mainly in core technologies. If high fees behave as barriers for entry of firms to markets of developing techmologies, the variety of applications and use will be small in relation to markets in which innovators charge lower royalties and the patented technology more rapidly and widely spreads. 


\subsection{The Role of IPRs in Developing New Technologies: Empirical Findings}

\subsubsection{Background}

The social value of IPRs and their rationale is based on promoting knowledge production and diffusion of new technologies, as technical advances have a central importance in economic development and growth. A question that is often heard in this context, yet remains unsettled, is how important are IPRs for nourishing innovation and technical change?

The sources of innovation and the links between institutional and organizational factors involved in research and development of new technologies and the innovative yields of firms had been explored in a series of innovation studies since the beginning of the 1980s. Von Hippel (1982) studies the impact of appropriability and $\mathbb{R} \& D$ expenditure on innovation empirically. Levin et. al. (1987; hereinafter the "Yale Survey") examine the reliance of firms on IPRs as a method of accuiring better protection for their technical know-how and observe that firms prefer to safeguard intellectual property by applying strategic and contractual methods other than legal means, such as trade secrecy and lead times. Arundel compares the preferences of American and European firms to use various appropriation methods (i.e. secrecy, lead times, patents, etc.) for protecting their intellectual assets. His findings are consistent with those of Von Hippel and Levin eb. al. Lead-time and secrecy together are more important than patenting as a means to protect property. They are from $10 \%$ (Switzerland) to 120\% (Western European and Irish companies) more common than is patenting. ${ }^{14}$ Moreover, firms stated that superior sales and services, learning curves of new technology and lead times were the most preferred means for appropriation against competitors. Patents were among the least common methods in use (see Fig. $3.1 \& 3.2$ ).

The second goal of IPRs is to encourage the diffusion of knowledge. Put in a different way, "if new innovations are not widely used, the system will be less beneficial than one with less creativity, but where the materials created are more broadly disseminated" (Besen and Raskind, 1991). Patent documents enter the public domain and become "transparent" to anyone to search for novel technical information and ideas. Nonetheless, there is a strong tendency among firms, particularly among SMEs, not to use patents as a source of technical knowledge ${ }^{15}$ Hence, a second important issue in the examination of IPR regimes refers to the significance of patents in technological learning of firms and whether patents and

\footnotetext{
${ }^{14}$ The results of studies conducted in Japanese firms were similar to those presented here.

${ }^{15}$ Innovation 8 Technology Transfer, Vol. 1/00, January 2000, p. 15.
} 
copyrights live up to the expectations of policy makers as a major source of knowhow for innowators.

Comparing the contribution of various information sources to the process of innovation, high technology firms were found to rely on knowledge acquired from patent records and (copyright-protected) publications only as a marginal source from which to acquire technical knowledge (McFetridge, 1995).

Earlier innovation surveys by Von Hippel (1982) anid Levin et. al. (1987) found that hims retrieve technical know-how mainly through recruited employees, affiliates, trade shows, conferences and professional literature. Patents have taken b lower position as firms" channels of learning (see Fig. 3.3). Arundel (2000) strengthens their conclusions grading knowledge disclosure via patent records as the least important source of information for innovative activities in European frms after customers, suppliers, trade fairs and competitors. Moreover, firms prefer to protect their intellectual assets by applying other means than IPRs, such as lead-time and trade secrecy. Low and medium technology firms give higher importance to patents and copyrights than high technology companies, but in both cases firms give lower priority to their use as appropriation methods (McFetridge, 1995; See Table 3.1). The results of recent innovation surveys conducted by Arundel (2000; 2001) in the European ICT industry and by Hanel (2002) in Canadian firms affirm the conchsions of earlier studies:

Firms apply IPRs to dominate substantial segments of evolving markets and technological trajectories in initial stages of development.

The importance of various appropriability mechanisms to firms may vary considerably anong different industries, between firms in similar sectors and even between product and process inventions at the sarne firm. Therefore, firms usually implement IPR strategies that are based on a combination of different appropriability methods for various purposes. For example, firm may protect various components of a chemical product by patents while keeping essential substances undisclosed to prevent their rivals from "inventing around" them substitutes that are analogous in their technical functions but are sufficiently-diverse to be noninfringing and patentable. Industries commonly rely on combination of various appropriability mechanisms, such as applying both secrecy and lead-time for the same products. When some of those mechanisms are jointly implemented, they generate unique "appropriability strategies" that are especially formed or adapted to the technological environment and to conditions present in the market. Secrecy and lead-time are implemented among large populaces of firms in many different industrial sectors, while the other means are less widespread and are applied only in particular sectors. 


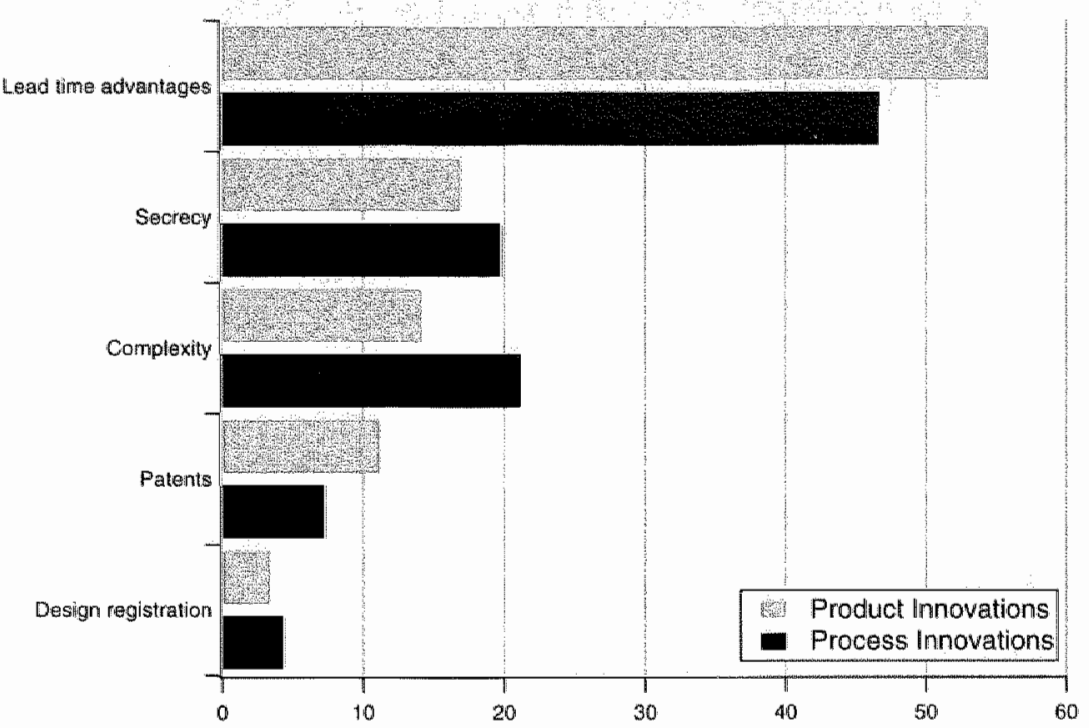

Figure 3.1. Major appropriation methods in European firms (Source: Arundel, 2001).

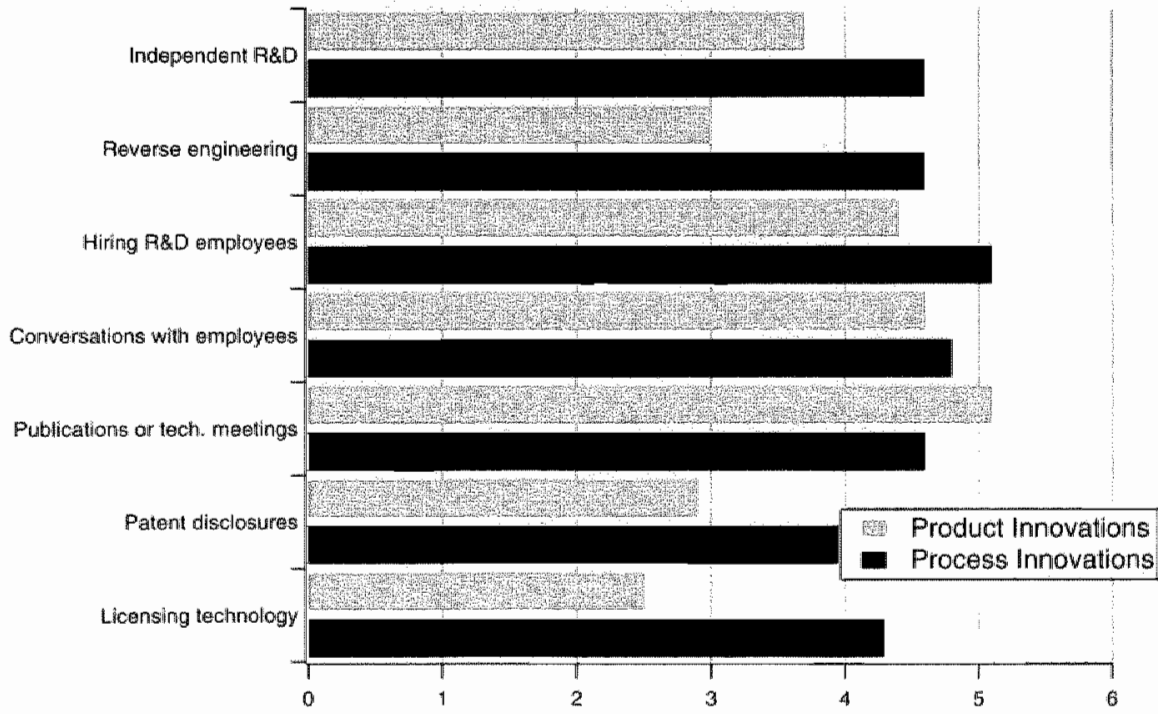

Figure 3.2. Firm's channels of learning (scaled by importance) (Source: Levin et. al. 1987). 


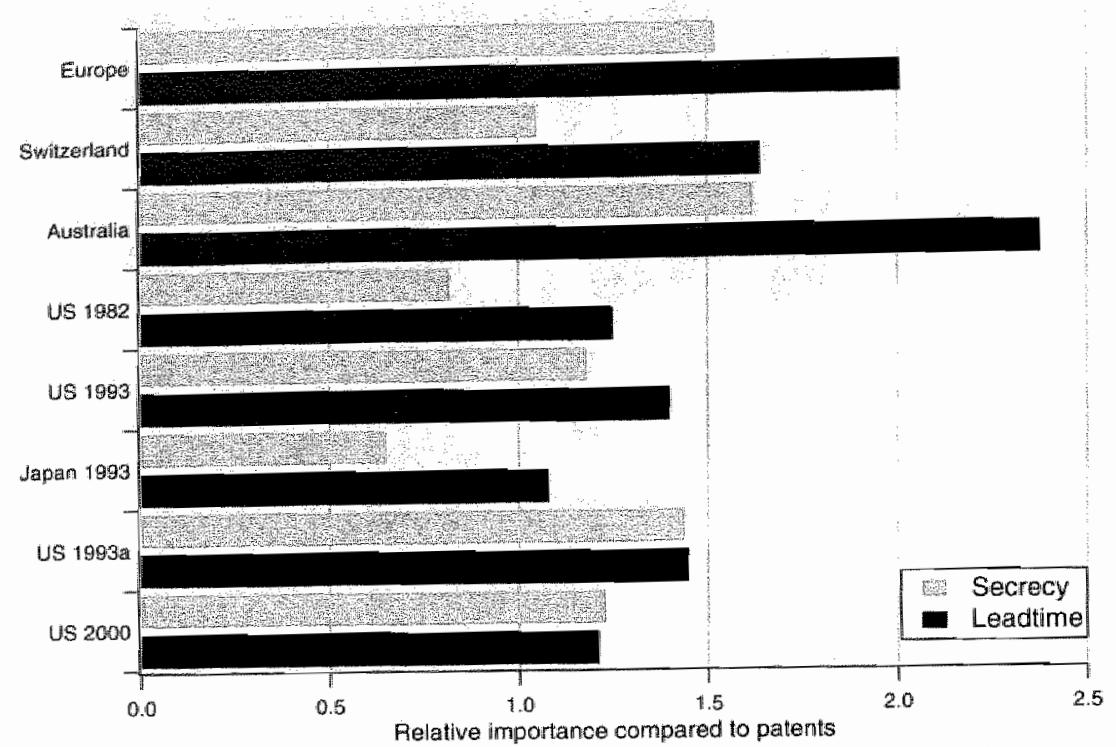

Figure 3.3. Relative importance of secrecy and lead-time for earning competitive advantages from product innovation (Source: Arundel, 2000; Cohen at. al., 2000).

\subsubsection{Strategic Use of Patenting}

Patents are among the less prelerred appropriability mechanisms and involve considerable legal costs. ${ }^{16}$ Nevertheless, patent statistics in the U.S. shows a stable growth in the number of patents in "traditional" classes and dramatic increase in patenting recent technologies during the last decade (See Fig. 3.5). Those dynamics of patenting behaviour indicate a rising propensity of firms to protect their intellectugl endeavours by patents.

Therefore, a presumed contradiction between the low propensity of firms to patent their inventions, as appears lrom the results of innovation studies, and the steadily growth in the number of patents emphasizes the issue:

Why do firms patent if patenting is costly and second-in-importance as a means for appropriating their revenues?

The link in question between the increasing number of patents and their contribution to social welfare has become a major policy concem after recent reforms in the U.S. patent system that extended the scope of protection to include recentlymevolving technologies. Legislative changes have taken place despite broad public opposition and criticisms by legal scholars and econornists (see, for exam-

\footnotetext{
${ }^{16}$ The average cost of patent application is estimated by 6,900 dollars (www imvention.com). To compare, the average filing cost in the EPO is around 8,000 Enros (EC's IPR Helpdesk).
} 


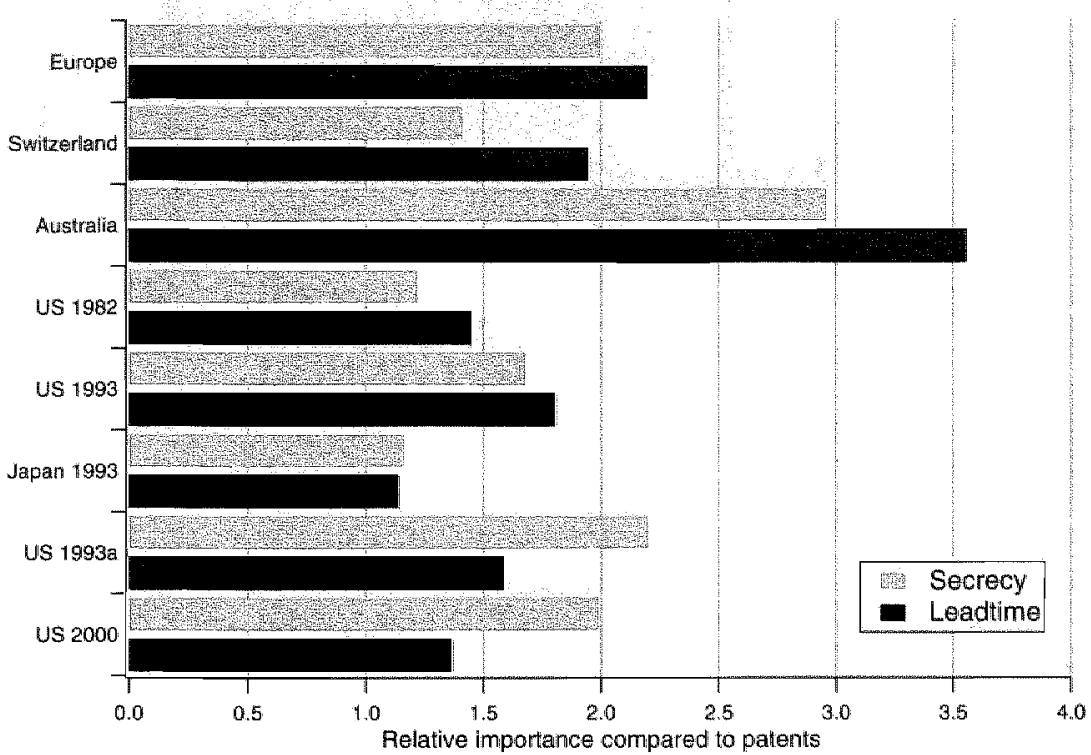

Figure 3.4. Relative importance of secrecy and lead-time for earning competitive advantages from process innovation (Source: Arundel, 2000; Cohen et. al., 2000).

\section{Percentage of} all patents

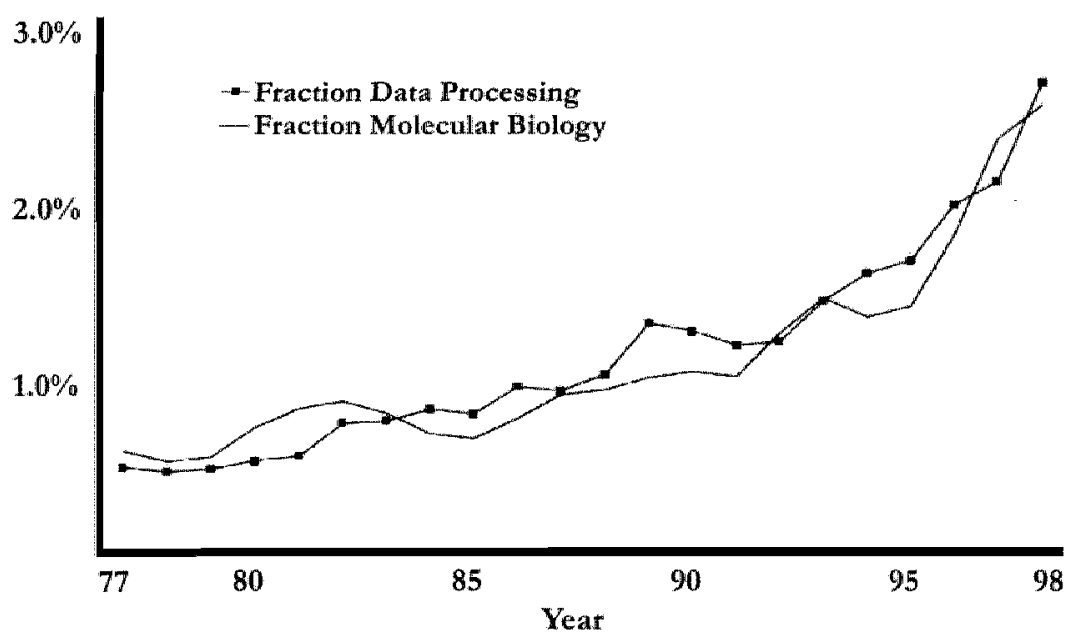

Figure 3.5. The share of patents in recently-evolving technologies (Source: USPTO; brought in Jaffe, 2000). 


\begin{tabular}{|c|c|c|}
\hline Santre & High Toehnalogy E inms & Medum/Low Technology Firms \\
\hline Aflinates & $71 \%$ & $100 \%$ \\
\hline Trade showss and conferences & $70 \%$ & $56 \%$ \\
\hline Literabue & $68 \%$ & $46 \%$ \\
\hline Discevssions gith other frims & $32 \%$ & $26 \%$ \\
\hline Reverse engineering & $8 \%$ & $1 \%$ \\
\hline Copyrighted material & $3 \%$ & $7 \%$ \\
\hline Industrial designs & $3 \%$ & $7 \%$ \\
\hline Platit breder's rights & $3 \%$ & $1 \%$ \\
\hline Paterits & $2 \%$ & $13 \%$ \\
\hline Thtegrated cirevit designas & $2 \%$ & $3 \%$ \\
\hline
\end{tabular}

Table 3.1. The share of firms applying various sources of information for innovation (Source: McFetridge, 1995).

ple: Eisenberg, 2000; Gallini, 2002). Of a particular concern are the manners in which patents correspond to the original purposes of the system shaped by the carly legislators "to promote the progress of science and useful arts" (U.S. Constitution, Article 1, Section 8). However, the application of patents as part of business strategies of firms created a controversy over the success of the patent system in promoting innovation in new and leading industries, such as computers, pharmacenticals and biotechnology.

Patenting choices are not necessarily geared at securing monopoly revenues, as reward theory suggests. The propensity of firms to patent is influenced by many factors in the general context of their business environment, such as the structure of the market, ownership of patent rights over core inventions by other firms and the nature of technology and its diffusion patterns. Further, as this argument goes, patenting decisions cannot be distinguished from the competitive behaviour of the firm and its rivals. Generally, minimal disclosure of knowledge in return to maximal protection by patent is most desirable from the firm perspective. ${ }^{17}$ Empirice reveal that strategic patenting, methods in which firms employ patents to gain competitive advantage against rivals and to preempt new entrants from operating in their market niches is important.. ${ }^{18}$

Granstrand (1999) classifies the underlying reasons for the decisions to apply for a patent into several categories.

- Pre-emption of new entrants from operating in defined and related technological fields.

\footnotetext{
${ }^{17}$ By maximal protection we mean the longest duration and the widest scope of patent that can be approved by the examuners of the patent office.

${ }^{18}$ The interisive use of strategic patenting as a part of the business strategy of the firm is a long process that requires to adapt its culture to conceive the present and the future value of its intellectual assets, and to form links between the legal unit and its R\&D and business departments to support new organizational processes (Granstrand, 1999).
} 
- Blocking rivals from obtaining competitive advantage being "the first to patent" (monopolistic competition and patent races between firms). ${ }^{10}$

- Build-up of portfolio of the technical assets of the frm to be traded or exchanged in cross-licensing agreements with complimentary technologies and for "signalling" investors with potential value before IPO or with commercial opportunities to exploit the technology of the firm.

The Carnegie-Mellon survey (Cohen et. al, 2000) identifies multiple reasons beyond the decisions to apply for patents: protecting intellectual assets from being cornmercially exploited by other firms, blocking rivals from patenting related inventions, defending the firm against patent litigation lawsuits and adwantageons position in cross-licensing negotiations. Firms indicate that the primary motive beyond their patenting activities is to preclude rivals from copying their inventions. This is followed by the use of patents to inhibit competitors from protecting complement technologies ("patent blocking") and to prevent infringement lawsuits by the "first-to-apply" for a patent (thus patent races taking form of patent litigation practices). Therefore, firms patent to enable free use of their own technologies without being sued by other firms that were faster to patent similar technolom gies, thus preempting the firm from its market. Similar patenting behaviour and strategic considerations are prominent in the semiconductor industry, where the increasing propensity of producers to patent and the consequent growth in the number of patent grants) do not reflect any significant change in R\&D expenditure over time.

Cohen et. al. (2000) distinguish between "complex" and "discrete" inventions by the amount of patentable features that are embodied in each product. Discrete technologies are characterized by a small number of patentable elements. Products are relatively distinct and compound a weak degree of complementarity between different technical features. Firms that operate in markets of discrete products often base their strategies on "inventing around" leading products and developing substitutes that would potentially compete with patent-holders without infringing their patent rights. Therefore, firms that hold the rights on core technologies usually extend their patent portfollios to cover a wide range of applications to protect product substitutes that do not fall within the scope of their patents (i.e. non-trivial inventions). Moreover, expansive IP portfolios reduce the possibilities of other firms to "invent around" patented inventions. Alternatively, firms enter the market after patents have expired with their own product versions. In this case, both competition and product variety are enriched after a long period of the patent lifetime.

\footnotetext{
${ }^{19}$ Patent races are associated with welfare loss as firms duplicate their R\&D efforts, but one a single firm obtains monopoly rights over the invention.
} 
On the other pole are complex technologies, which are identified by integration af technologies and strong interdependence between the variety of their features. The complexity of the products and the technologies rises from two different sources: First, a large number of components are integrated in the final product and a lack of one of the necessary elements would prevent its successful development and production. Second, a firm $\mathrm{S} \& \mathrm{D}$ activities depend on its ability to use patented inventions that are essential for the development of new products. If patents over complementary inventions are held by different firms, separate negotiations between each frm and right-holder are required to obtain access to the technology. Refusal of one of the firms to license its invention would put to s halt R\&D and production of new goods.

The case of Polaroid Corp. $v$. Eastman Kodak Co. demonstrates the concerns and the risks of firms that invest in developing complex products that require integration of various technologies, particularly when some components are already patented by rival firms. Polaroid Corporation, a leading innovator and patentholder of numerous patents of instant photography, submitted a lawsuit against Kodalk Corporation for infringing twelve of its patents relating to instant cameras. Court found that seven of Polaroid patents were walid and were infringed by Kodak actions (i.e. production and marketing of similar products). Consequently, Kodak. awarded Polaroid over 900 million dollars in damages for infringing its patents (U.S. District Court of Massachusetts, 16 USPQ2d 1481). Further, Kodak was prohibited from competing with Polaroid in the instant camera and instant film markets. The results of the ruling were harmful to Kodak's commercial activity and business development, affecting it in three major areas. First, the company was obliged to abandon its investments in $\mathrm{R} \& \mathrm{D}$ and in production of instant cameras, thus worsening its Iosses beyond the damages that were determined by Court. Second, the firm thad to abolish its plans to expend the market, thus losing a major expected source of income that restricted its future activities and vulnerability to changes in the business enviromment. Third, since Kodak's proclucts were available in the market already for several years and the firm was prohibited from producing and supplying films for instant cameras, it had to compensate the owners of those products for having to abolish them. Fourth, the ruling affected the pattern of techmology development and innovation, hindering Kodak and other firms but Polaroid from furthering the features of the new technology or competing with advanced products in the instant cameras and instant films markets.

Following the lessons of Polaroid $v$. Kodak, frms are trying to obtain wider exclusive rights via "defensive patenting". Those rights serve both purposes of trading access rights to patented inventions with other firms (Jaffe, 2000) and as basis for a solid intellectual property portfolio that aims at threatening rivals from 
submitting patent litigation lawsuits, being able to initiate cotuter action of the same sort (Hall and Ziedonis, 2001). ${ }^{20}$ According to the Camegia Mellon survay, obtaining stronger bargaining power in inter-firm negotiations (e.g. cross-licensing agreements) seem to be less important in "discrete" industries than it is in high technology sectors due to weaker degrees of complementarity between inventions:

Patenting as a means to gain reputation, an internal measure for the performance of $\mathrm{R} \& \mathrm{D}$ personnel or for generating royalty revemues are generally less valued motives beyond firm's decision to patent. Manufacturers and developers of "complex" products use technologies of their own and those whose patent rights belong to other firms. This dependence fosters cross-licensing of patent rights between firms, as technology builds on present inventions. This is significant in negotiations taking place between producers of electronics, vehicles, computers, etc. In case of enforcing other frms to negotiations in cross-licensing agreements, patents function as "bargaining chips" Inventions can be related one to each other in two ways: as substitutes or as complementary inventions. When substitutes are considered, patenting operates to block competitors from being the first to acquire monopoly rights over inventions. When the technology presents a patterm of complementary inventions, patenting is driven mainly by strengthening the negotiating position of the firm.

Firms that operate in "discrete" industries (such as chemicals) are generally driwen by the propensity to block competitors from patenting substantive prodwcts. Therefore, a strategy that is based on discovering and patenting substitute technologies fortifies the competitive position of the firm and weakens the dominance of its rivals. In "complex" industries (e.g. telecommunication) motives to patent are mainly about forcing rival firms to collaborate and to trade access rights to their inventions in return for been granted the rights to use the firm's patents. Hence, patenting large number of complementary technologies in the field enables the firm to construct patent portfolios and to create dependence of other firms in using its patents as a basis for negotiations over mutual licensing of patent rights.

Under particular market conditions and merits of the technology, firms prefer to avoid protecting their inventions by patents and implement other means of appropriation. In some cases, high degree of disclosure of novel techniques of the firm, required to obtain a patent, enables its competitors to "invent around" the patented invention relatively with ease. Hence, a firm that operates in "complex" industries would prefer to keep core technologies covert to prevent other firms from developing technological substitutes that compete directly with the firm's core technologies. At the same time, patenting less significant components,

${ }^{20}$ In some cases, firms find their techrologies diffcult to patent and choose to dischose then via professional and scientific journals, thus obtaining reputation while applying "defensive publication" to prevent rivals from patenting similar and related inventions. 
which are essential for producing the frm's goods but iwolve smaller degrees of knowledge disclosure prevents other firms from competiug with complementary products. However, in "discrete" industries application of integrative strategy of patents and trade secrecy is more complicated and in some scenarios impossible. Consequently, firms must assess the rusks of revealing their core krowledge and competences to rivals: whether their products can be easily reverse-engineered and hence should be patented and how easily their know-how can be learnt and be transformed into advanced products (thus maintaining secrecy). Other major reasons for awoiding patenting include the difficulty of proving the novelty of inventions, patent application costs and the legal costs of defending firm's patents in Court. ${ }^{21}$

Since the Yale survey in the early 1980s, scholars observed major changes in firms" preferences to apply various appropriability mechanisms. First is the emerging use of trade sectecy in itself or within appropriability strategies that combine various methods. Along with increasing numbers of patent applications, and with wiclespreading opposition to recent patent policies, firms have recognized the benefits of secrecy. Indeed, secrecy encompasses some risk that novel technologies will be revealed, ${ }^{22}$ but its main advantages are minimal disclosure of advanced knowledge (particularly in firms whose unique competences and know-how are perceived as core assets) and the low costs of enforcing it. This trend, characterized by the rise of secrecy as a prominent mechanism of appropriability of inventions is troublesome for innovation, as advances in technology are not distributed among larger technical and scientific communities and knowledge spillovers are formed. Consequently, the diffusion of technical knowledge is impeded and may result, in the long run, in lower levels of innowation followed by an economic slowdown. Second, firms have shifted from patent races to patent portfolio races in order to secure wider applications to their core inventions (by patenting around them) and to obtain large amounts of patents in important fields, to be traded later with rivals in return to rights to use their patented inventions (i.e. patents serving as "bargaining chips" in licensing negotiations). Third, firms that operate in complex technological fields are motivated to patent as many technologies in their use as possible, otherwise they may fail to produce any goods that implement wide range of inventions if patent-holders refuse to license any of their patented inventions.

On the other hand, patent portfolio races may contribute to social value, encompassing two positive impacts from the social planner's perspective. The

\footnotetext{
21 The decision of avoiding patenting due to high costs of legal procedures, i.e patent applications and litigation suits are typical to SMEs, both puting a heavy financiat burden on the firm.

${ }^{22}$ The risk and the damages of unauthorized disclosure by employees can be limited. to an watent, by commact.
} 
probability to accomplish successfully licensing agreenents in complex industries increases when a small number of firms holds wide shares of the technology than many frrms hold small fractions of the technology in patents. Moreover, the costs of coordinating and negotiating the terms of licensing agrements increase with the number of the patentees whose access rights are necessary for the firm.

Additionally, firms are encouraged to disclose technical knowledge in the process of establishing of patent portfolio. Otherwise, if the knowledge stays within the firm's domain, it would not be able to gain exclusive rights over it and to trade it for access rights to other firms" technologies.

Comparing the results of the Yale survey (1987) with those of the CarnegieMellon survey (2000) reveals only modest changes in firms' behaviour and in their appropriability strategies, although the technological agenda and IP legislation, mainly in knowledge-based products, have substantially changed during the $1990 \mathrm{~s}$. The importance of secrecy as an appropriability mechanism among firms in all sectors has increased and has become the second most-preferred method after lead-time (previously, leaming curves were positioned after lead-time). Lead-time remains first in importance with a marginal change in firms' propensity to implement it. Surprisingly, the relative effectiveness of patents as an appropriability mechanism has not dramatically changed and even declined, although patenting has become easier than ever, as the scope of pattents has been extended to include new technological fields and patient records and application manuals have become accessible online by all users.

The Carnegie-Mellon survey highlights three prominent patenting strategies that common among firms in all sectors:

- Firms apply for "block to play" patents to prohibit rivals from developing technologies that are similar or close to those of the firm and to secure their technologies from patent litigation suits by first-to-patent competitors. Consequenty, this strategy enables firms to expand their technological domains and to invest in R\&D without running the risk of being excluded from exploiting their inventions in later stages. Although "block to play" patents involve unnecessary social costs (that otherwise could have been devoted to R\&D) and hamper other firms from applying patented inventions, particularly in cases of "sleeping patents" that were never used by their patentees, firms entering new technological fields are prom vided with suitable environment for innovation without risking their investments in R\&D.

- "Patent fences" do not aim at blocking other firms from obtaining a stronghold position in cross-licensing negotiations, but rather they are directed to fortify a dominant position in the market by owning monopoly rights for core inventions and technologies in their domains, where competitors may invent around 
firm-owned patents to trespass them legally; and by excluding other firms from using thom by means of intellectual property.

- "Player" strategies refer to patenting for blocking and cross-licensing purposes with no intention to obtain royalty revenues from licensing in the course of action. "Player" strategies are widely used in firms that operate in complex industries and are less popular among producers of discrete products, due to the linited scope of the applied technologies and among large patent portfolio holders in most sectors due to their ownership rights that are preferably practiced through fericing rival firms instead of negotiating access rights.

The use of the "block to play", "patent fences" and "player" strategies varies between. firms that operate in different industries and among producers of "discrete" and "complex" products (see Table 3.1). Mast firms in discrete industries usibally construct "patent fences" to annex technological areas and to impede development of competing products (i.e. substitutes), since the capability of firms to generate revenues directly from licensing their patents is relatively weak, unless in exceptional cases firms hold patents over "core technologies". Cross-licensing negotiations between firms seldom occur in discrete-technology markets. In other discrete industries, where patents are mainly implemented to generate monopoly rents and royalby lees during the patent lifetime with relative ease, "block to play" strategies are often used by firms. In complex industries patents serve as bargaining chips to obtain an advantageous position in cross-licensing agreements and as means for generating licensing revenues. Hence, firms that own large patent portfolios choose to apply "player" strategies to preempt competitors from entering: the market and to gain rights to use complementary technologies, where possible.

\subsection{Conclusions}

Knowledge dissemination is a primary instrument in promoting the development: of new technologies. Usually, inventors do not develop new products in a void, but gradually further prior inventions. However, empirical studies indicate that patents are widely used for strategic means (e.g. blocking rivals from entering the market or" as "bargaining chips" in cross-licensing megotiations), rather than as meellanisms for distributing novel know-how. The motives of firms to apply for patents are lax from the goals of policy makers and for the rationale of their originators.

The conclusions of those studies indeed present grave concerns regarding the contribution of IPRs to innovation and technical change and maintaining the balarce between private interests and public benefits in the patent system. 
Further, the main issues over IPR regimes spawned a series of related debates. The success of IPRs to achieve sustainable development of technologies in various industrial sectors and market conditions by providing inventors with monopolistic position is continuously being questioned by legal and economic scholars.

In addition to the traditional roles of IPRs, i.e. provision of incentives for innovation and for knowledge disclosure, patents (and to a lesser extent copyrights) promote the codification of know-how by fims. IPRs provide incentives to transform knowledge prospects into standard formats of presentation that can be judged by practitioners for its utility and novelty to be applied later by other firms.

The technical contents can further be exploited in other products on be published in technical manuals and "cookbooks", which may be protected by copyrights. Yet, patents provide larger economic incentives for knowledge codification and disclosure than copyrights, as the form of exclusive rights cover also the technical applications of the protected technology, rather than its published description that can be protected as a literary work by copyrights.

The findings of various innovation studies suggest that the perception of patents as an exchsive solution for issues of intellectual property ownership, technological development and imnovation is misleading. The role of IPRs, in particular the functions of the patent system should be reviewed within a wider context that. includes the behaviour and strategies of firms, institutionally supported mecham nisms of kmowledge transfer and the peculiar merits of different technologies and industries. Therefore, any analysis of IPRs cannot be accomplished adequately without considering the market dymamics of the technology.

'The empirical evidence emphasizes the use of patents by firms for non-innovative purposes, i.e. pre-empting competitors from entering new techological markets by forming legal barriers around technological domains, over their expected operation as a source for technological learning. The findings reflect major concerns whether the extant IPR regimes fulfill their primary role in fostering creativity and disseminating technical and literal endeavours or eventually hinder them. Firms may strengthen their positions in the market against entry of corrpetitors by patenting and commencing patent litigation procedures, due to high fixed costs of juridical procedures. Indeed, those legal practices are found to be more common in large firms than in SMEs. However, the consequences of those stratlegies, if broadly employed by market incumbents, may prove perilous to innovation and technical change, nipping in the bud inventions that mushroom in small-size firms. To emphasize, firms have other means for commercial exploitation of intellectual assets and technical knownow and, indeed, they employ them for this purpose. Patents are commonly used only as legal means to capture rents from innovation and in 
sorne industries they play insignificant roles.

Apart from following the original intents of the founders of the patenting system, i.e. protecting directly patented inventions from being imitated by competitors and securing the revenues of inventors, firms use patents for objectives that had not been anticipated by the originators of the regime and, in some scenarios, which may even contradict its fundamental goals. Firms that operate in discrete industries (e.g. chemicals) commonly use patents as strategic means by building patent fences around their cone inventions. Those patents usually aim at cowering the range of potential substitutes of core inventions, which may be developed by other firms to compete with the original products by reverse-engineering their compounds on the basis of the disclosed information. Later, if the process significantly differs from the patented procedure, a new patent is granted, although the end products are similar in structure and function. A complete protection of market segments acquired by the firm is gained by avoiding licensing the patents on product substitutes to other firms, although sometimes those patents are not. even commercialized by patent-holders (therefore this sort of patents is named "sleeping patents"). In other cases, patents are widely used to protect the firm and to threatien its rivals against litigation lawsuits. From a social welfare standpoint, defensive patent applications against offensive ("blocking") patenting of competitors is undesirable. Firms are engaged in costly legal processes of patent applications (which otherwise were not: submitted to the patent office), litigation and protection from infringement lawsuits. Moreover, those purposes are far from the aims of the patent system and in some cases even contradict them.

Finally, comparing the results of the Yale survey with those of the CMS reveals only limited changes in the decisions of firms to use various appropriability mechanisms, although legistation has experienced dramatic changes since the 1980 s (e.g. the establisiment of the Court of Appeals for the Federal Circuit and substantial extensions in the scope of patents to include gene sequences, computer programs and algorithms). Recent studies suggest that the effects of structural changes in the patent system on technological development and economic growth are fainly restricted and both goals are largely affected by the nature of technologies and by patenting strategies of firms. 


\section{Revealing Obscure Sources: The Paradoxical Evolution of Software Appropriation Regimes}

\subsection{Introduction}

The rise of the information society results in enormous changes throughout the economy. The "health" of information sectors will be central to the future economic growth of every country. While the information sector encompasses many different industries, information goods are pivotal. Ont of a great variety of information goods, the paradigm example, probably, is software. Indeed, software is now incorporated into so many "other" goods, that it may be the most pervasive sub-sector of the new economy. Its growth certainly attests to a widespread diffusion - in the OECD countries in the 1990s software sales (excluding bundled operating systems) have been growing at roughlly $11 \%$ per annum; $12 \%$ if bundled operating systems are included (OECD 2000). Besides this immense growth in sales, we see also enormous amounts of piracy. Losses of sales due to piracy are estimated to be in the neighbourhood of 11 billion USD annually (SPA, 1997, 1998; SIIA, 1999). As one can imagine, piracy of this magnitude is accompanied by claims by software vendors that it threatens the development of the industry as a whole.

Since the mid-1.980s regulators have been seriously concerned with issues of infringement of intellectual property rights in relation to information goods and software in particular. The US has been leading the way in deternining legal doc trine for protecting the software intellectual property with European and Japanese legislation typically following (Karjala, 1990; Brueckmann, 1990).

A basic definition for protection of intellectual property in the US legistation distinguishes "idea" from "expression". Patents are granted only for technological 
advances that permit the practical solution of specific problems in the fied of technology and fulfil the fundamental terms of being an "ider", that is utilization by the application of the technical know-how in products and processes, nowelty and ron-obviousness of the invention. Copyrights aim to protect creative endeavours consisting of artistic and literary works and their derivatives which are original by themselves and cannot be technologically utilized (although copyrighted works can be presented or performed publicly). Nevertheless, careful examination of the US Patent Office guidelines for computer-related inventions (USPTO, 1996) leads to consideration of computer programs as hybrid legal entities which may warrant protection by both regimes, since on the one hand, algorithms, processes and ideas involved in a computer program can be patented, and on the other hand, other elements and concepts of software, such as interfaces, code lines and finall copies of software products can be protected by copyrights (Reichman, 1994; Nichols, 1.998).

Advances in the technological frontiers of software and information systems raise questions about the ability of the current doctrine to preserve the balance between the guarantee of property rights for inventors of software technologies, and economic inefficiencies from monopoly powrer.

Recently, the EU has expressed particular concern over the rise in illegal reproduction of digitized works for private use, facilitated by technical advance in communication platforms, and their increased difusion (EU Green Paper, 1995). However, implementation of IPR regimes to diminish unauthorized duplications in the short-mun should be judged not only by their ability to protect the interests of owners of software copyrights and related rights, but also by their ability to avoid pitfalls caused by over-protection that may lead to fragmentation of the Internal Market in the long-run.

In many ways the growing medium of the Internet as a distribution channel can loster new types of infringements of intellectual property rights. The share of data communication equipment as a percentage of the total OECD IT market almost doubled in the $1990 \mathrm{~s}$, increasing from $2.6 \%$ in 1990 to $5 \%$ in 1997 . The number of world-wide Internet hosts grows rapidly $(37.7$ million hosts in July 1998, an increase of $23 \%$ over January 1998) (OECD, 2000). Additionally, the volume of cone copyright industries in the US economy was estimated to have a value-added of 254.6 billion dollars in 1994 , representing $3.78 \%$ of the GDP. The revenues from online software sales were estimated to be $10 \%$ of the total revenue of the copyright industries in 1996 (approximately 0.5\% of the US GDP) and were predicted to triple by the end of 2000 (OECD, 1998). While the scope for legal distribution of copyrighted material over the Internet seems enormous, so does the scope for illegal distribution, as the recent Napster case shows (or is alleged 
to show).

The growth in development and use of software products, their contribution to the New Economy and the projected emergence of new software markets in electronic commerce have led policy makers and software publishers to re-assess present regimes and their ability to cope with violation of software as intellectual property.

\subsection{Evolution of Software Intellectual Property Regimes}

Software patenting and copyright legislation has passed through several stages of modification from the 1960 s to the $1980 \mathrm{~s}$. Until the mid-1980s applications to register patents for software-based processes and computer program algorithms were rejected, following US Patent and Trademark Office (USPTO) policy guidelines. The USPTO justified its decision with the argument that novelty could hardy be established in the dynamic field of software development. Furthermore, historically; patent protection has been given to mass-marketed commodities, thus excluding computer programs as they were distributed only in small volumes. As a result, until the late 1970 s the software industry relied mainly on trade secrecy contracts and licensing agreements (Branscomb, 1990; Samuelson, 1993).

A shift away from the perception of IPRs as germane mostly to mass-produced physical goods began with the parallel development of the Personal Computer and the shrink-wrapped software ${ }^{1}$ market in the mid 1980s. Sone computer programs have become mass-consumption goods, as computer applications are now distributed through a variety of channels for purchase (except for, by and large, operating systems which tend to be supplied with hardware, as in the 1960s). This reduces the force of the USPTO's previous rationale. So we see that since 1986, the US Patent and Trademark Office has considered software goods and software-embedded products as patentable.

Policy guidelines, in contrast with the previous period, have considered software goods (and embedded software technologies) as legal entities that are owned by their creators and can be protected through intellectual property rights. The new guidelines have preserwed the traditional distinction between an "idea" and "expression", eryabling software technologies to obtain patent protection as do other types of technical advances.

Table 4.2 shows the gradual evolution of the software industry in terms of the nature of software, typical users, IPR mechanisms and regulation. What we can

1 Software products that are plyysically distributed in packages, accompanied with licensing agreements for their use. 
observe from this table is a gradual move awdy from the open system of the 1950 s and 1.960 s toward the closed system that appears to be emerging today.

\begin{tabular}{|c|c|c|c|c|}
\hline Period & $\begin{array}{l}\text { Software Appli- } \\
\text { cations }\end{array}$ & User Profile & $\begin{array}{l}\text { Type of Protec- } \\
\text { tion }\end{array}$ & Fegulated by.. \\
\hline $1950 \mathrm{gm}-1960 \mathrm{~s}$ & $\begin{array}{l}\text { Bundle of hord- } \\
\text { ware \& software } \\
\text { for central ma- } \\
\text { chines }\end{array}$ & $\begin{array}{l}\text { Researchers \& Aca } \\
\text { demics. }\end{array}$ & $\begin{array}{l}\text { No protection: in- } \\
\text { formal exchange }\end{array}$ & No Regulation \\
\hline $\begin{array}{l}\text { Early 1960s- } \\
\text { Late 1960ss }\end{array}$ & $\begin{array}{l}\text { More diverse and } \\
\text { complex program } \\
\text { for Central Com } \\
\text { puters }\end{array}$ & $\begin{array}{l}\text { Researchers, Aca- } \\
\text { dlemics \& Earlier } \\
\text { Market }\end{array}$ & $\begin{array}{l}\text { Trade Secrecy and } \\
\text { Licensing }\end{array}$ & $\begin{array}{l}\text { Fair Use Law } \\
\text { Trade Secrecy and } \\
\text { Contract Law }\end{array}$ \\
\hline $\begin{array}{l}\text { Late 1960s } \\
1970 \mathrm{~s}\end{array}$ & $\begin{array}{l}\text { Commercial ven } \\
\text { dure sofware } \\
\text { projects, based on } \\
\text { scientific research }\end{array}$ & $\begin{array}{l}\text { Industry \& Aca- } \\
\text { demics }\end{array}$ & $\begin{array}{l}\text { Trade Secrecy and } \\
\text { Licensing; Patents } \\
\text { and copyrights re- } \\
\text { jected }\end{array}$ & $\begin{array}{l}\text { Fair Use Law } \\
\text { Trade Secrecy and } \\
\text { Contract Law }\end{array}$ \\
\hline $1980 \mathrm{~s}$ & $\begin{array}{l}\text { Personal Comput- } \\
\text { ars ( } \mathrm{PC} \text { ) and in- } \\
\text { dustrial processes/ } \\
\text { equipment }\end{array}$ & $\begin{array}{l}\text { Industry, Business, } \\
\text { Academic \& Home } \\
\text { users }\end{array}$ & $\begin{array}{l}\text { Trade Secrecy } \\
\text { Copyrights } \\
\text { Patents } \\
\text { ishrink Wrap" Li. } \\
\text { censing }\end{array}$ & $\begin{array}{l}\text { Copyright Act ("ex- } \\
\text { pression"), Patent } \\
\text { Law '(tidea"), Berne } \\
\text { Convention }\end{array}$ \\
\hline $1990 \mathrm{~s}$ & $\begin{array}{l}\text { Personal Comput- } \\
\text { ers and Internet } \\
\text { (World Wide } \\
\text { Web) / LAN / } \\
\text { WAN }^{\text {di }}\end{array}$ & $\begin{array}{l}\text { Industry, Business, } \\
\text { Academic, Home } \\
\text { and Net users }\end{array}$ & $\begin{array}{l}\text { Hybrid character of } \\
\text { software; Intema" } \\
\text { tionen Copyrights } \\
\text { and Patents Laiks; } \\
\text { New economic mod- } \\
\text { els (as "Sharing" } \\
\text { and "Bundling") }\end{array}$ & $\begin{array}{l}\text { EU "Green Paper" } \\
\text { (EU, 1995); TRIPs } \\
\text { Agreement (WTO, } \\
\text { 1995); Suggested } \\
\text { Sur Generis" Law } \\
\text { for Software Link- } \\
\text { ing, Web Caching } \\
\text { and Browsing - "on } \\
\text { a case by case" } \\
\text { basis ruling. }\end{array}$ \\
\hline
\end{tabular}

Table 4.1. Taxonomy of the development of software IPRs, 1950s-1990s

(Based on: Samuelson, 1993; Reichman, 1994; Holdeness, 1998; Morisson, 1999).

"Adapted to software IPRs by CONTU (National Commission on New Technological Uses of Copyrighted Works, 1980).

${ }^{b}$ A change in U.S. Patent and Trademark Office (USPTO) policy occurred after the U.S. Supreme Court's decision in Diamond vs. Diehr, 1981, by which software involved in an industrial process can be considered patentable.

"See Whelan ws. Jaslow ("Whelan "Test") for the "expression/idea" ruling.

"I IAN - Local Area Networks; WAN - Wide Area Network.

"Sui Generis: "of its own kind", used to describe something that is unique or different.

Emerging legislation and rulings appear to be a continuation of the regime developed for physical goods, with analogies drawn between various aspects of software, and both traditional technologies are artistic artefacts. This incremental approach has intensified the debate over IPR protection. Indeed, the main 
issue, debated but untesolved, is the ability of current IPR regimes to address the technical changes presented by information goods. Several suggestions have been proposed to strike the right balance between incentives to innovate (thought. extremely important by software industry investors) and freedom of knowledge or information diffusion (thought vital for technology transfer, knowledge spillovers and further innovation). These suggestions frequemly appear when new challenges are felt by the market, and are contrasted with inappropriate and in some aspects archaic, economic models (Reichman, 1994).

A striking aspect of this evolution is that software is being treated as both patentable and copyrightable. Previous techno-economic paradigms built a dichotomy between copyrights and patents as regulatory mechanisms. Patents apply to the ideas and processes underpinning the inventive step, whereas copyright applies to the expressions of creative works, basically in literary or artistic forms. But as noted above, the USPTO guidelines divide the protection given to software, such that algorithms and processes are patented, while interfaces, code lines and final products are copyrighted.

The legal overlap between software patents and copyrights to protect the same product is claimed to be over-protective, and likely to result in a monopolistic dominance of technological know-how in software development. IPR regimes aspire to promote high levels of creativity, both for "art" (copyrighted works) and "utility" artefacts (patented inventions). As new technologies present new ecom nomic paradigms, implementation of both regimes is claimed to supply a broader protection than the one which IPR regimes originally aimed to provide (Menell, 1989; Samuelson et. al., 1994; Reichman, 1994; and others). Examination of aircraft and radio industries in their infant stages shows that patents registered by market dominators created barriers to entry for new inventors and potential market entrants, thus slowing the pace of innovation at a stage critical for development (Nelson, 1994).

Mackaay (1994) expresses a concem for the sofware industry stemming from similar phenomena. He argues that software innovation is hampered by existing intellectual property regimes which supply a broad protection, and do so for lower levels of creativity than is appropriate for this (relatively) new industry. His explanation is that the adaptation of the legal regime of intellectual property rights lags technological changes and fails to keep up with changing peculiarities of new and rapidly changing technologies. While developed in the context of software, this argument, will obviously apply to any rapidly changing industry, but it is especially strong when the industry is at the heart of a shift in technological paradigm.

The following sections review legal madus operandi employed to protect soft- 
ware goods, the issues and constraints of the existing methods of software IPRs.

\subsection{Software Patents}

\subsubsection{Background}

From the very first stafges of computer and software techollogies, US industries have dominated global software markets. This trend continues as US holds a share of $47 \%$ of the global packaged software markets and $36 \%$ of the global ICT markets (OECD, 2000). Hence, US legislation has prevalled in the formation of software IPR regimes since the first commercial applications were released and has been determining the attitude towards patent protection world-wide.

The most important event in software patenting in the US, later infuencing legislation in the EU as well as in other parts of the world, occurred in 1986. A verdict given by the Supreme Court in Dianond ws. Diehr found a rubber curing process involving a software element in the chemical process patentable, and thus approved the patent claims. The verdict was important in two ways. First it created a precedent by permitting a piece of software to be patented. Second, it defined a distinction between the patented "ideas" and the non-patented (but copyrightable) "expressions" embedded in software technologies and goods.

In 1996, the USPTO wrote guidelines to steer the evolution of software IPRs (officially in the US and de facto in most other countries). The Patent Office adopted an evolutionary rather than a revolutionary approach and so has created its software policy based on existing IPR legislation and rulings. Notwithstanding, part of the examination procedure has been adapted specifically for software inmovations and clearly shows an attempt to accommodate the hybrid aspect of software as both an "idea" and "expression". The procedure is illustrated in Figure 4.1.

In the European Union, the EU Council Directive on the Legal Protection of Computer Programs (91/250/EEC) presented guidelines for future legislation and instructions for adaptation of national software. IPF regimes by the Member States on the basis of key principles adopted from US ruling. The terminology for legalization is taken from US guidelines, and a similar distinction beween an "idea" and an "erpression" exists." According to the Directive, the legal term "icomputer programs" includes, both the source code and preparatory designs (similar to the SSO principle). ${ }^{3}$ The aim of software patenting is to protect ideas and principles embedded in software that are not covered by copyrights (as also stated in the

2 Diferences between the Directive and the US cloctrine mostly relate to the broader permiselons for reversi engineering allowed by the Directive.

3 "The "structure, sequence and orgarization" of a computer program enjoy copyright protection, as do final softwane products (also known as the "Whelan test"). 


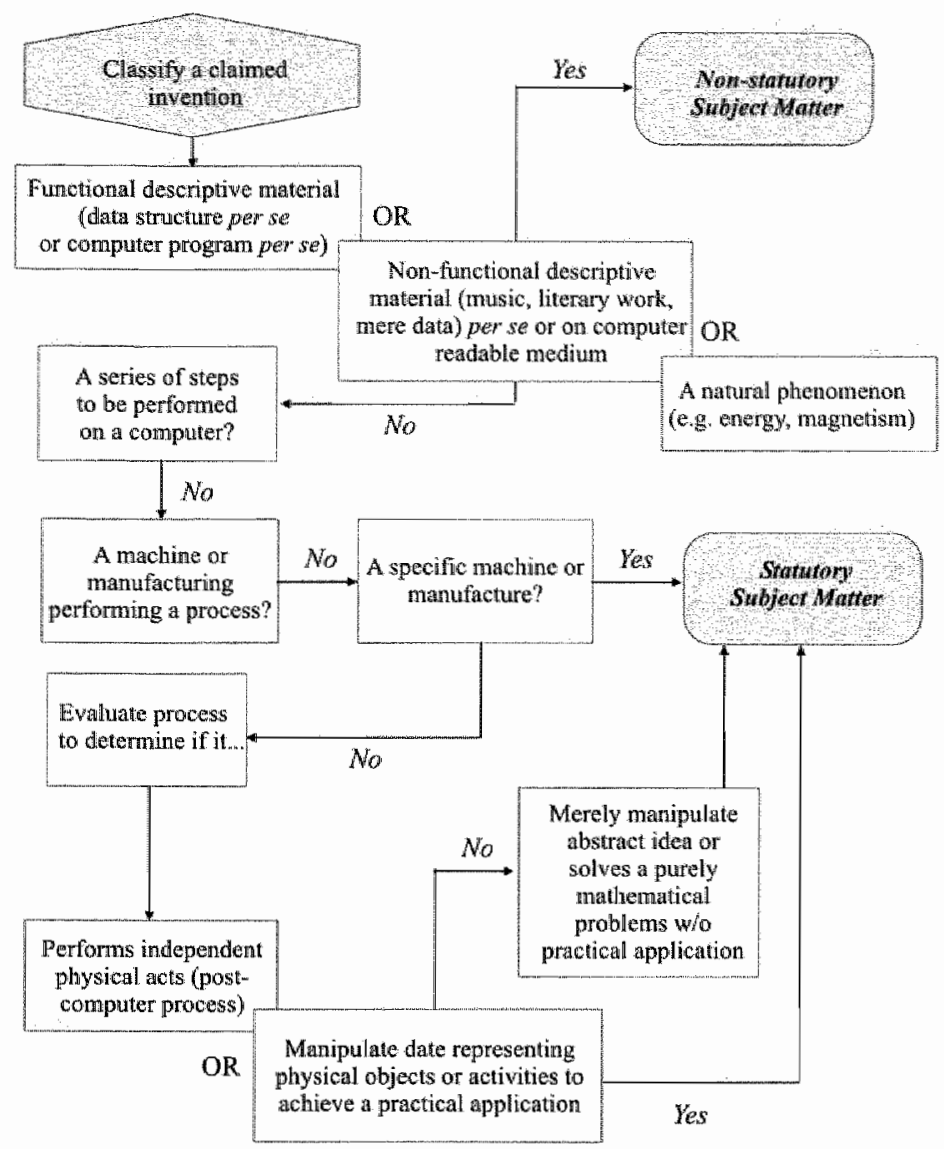

Figure 4.1. Guidelines for software patenting (Sonrce: USPTO, 1996).

USPTO guidelines; see Figure 4.1). With the adoption of major parts of the US doctrine, the $\mathrm{EU}$ has consequently left the door open to the emergence of legislative issues in the protection of software similar to those that have emerged in US (Brueckmann, 1990).

As shown in Figure 4.2, patenting has become a much more common method by which software developers protect their technological advances. Note that numbers of software and software-related patents have been increasing rapidly since 1992." An annual growth rate in the number of patents in class 395 ("information processing system organization" - - the major class for software-application patenting), between 1992 and 1999 was on average $33 \%$. To compare, the equivalent annual growth rate in the total number of US patents between 1992 and 1999 was $6.3 \%$.

\footnotetext{
4 Stolpe (2000) mentions in his survey that the vast majority of software puthlishora in Germany prefer protection of their products by legal means such as an application of technical methods against unauthorized use.
} 


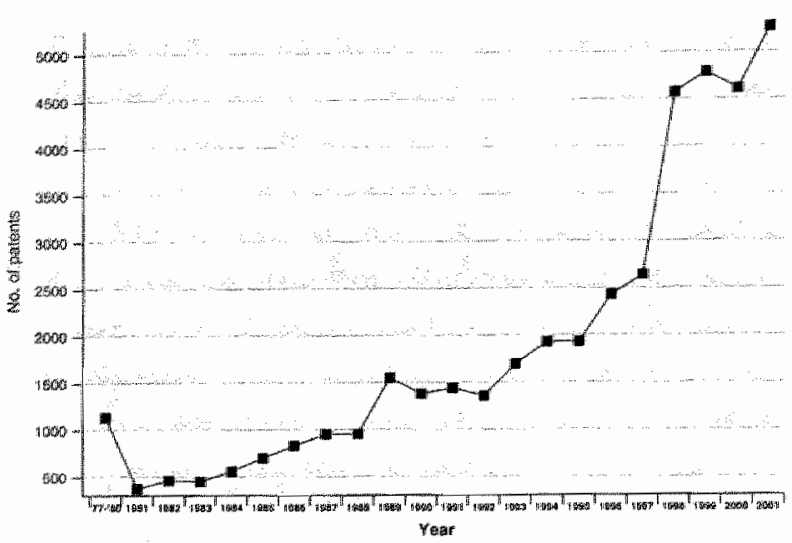

Figure 4.2. Number of Software Patents in the U.S., 1977-2001 (original classifications only) (Source: USPTO, 2002).

While it has been possible to patent software technologies for more than a decade, arguments for, and in particular against the present doctrine have been heard throughout this period. However, scholars differ in their opinions about whether the present statutory regime is over-or under-protective and what possible consequences may be for the software industry and its technological trajectories. Most importantly, debate continues regarding the design of any regime to replace the present legislation in order to guarantee efficient protection and incentives while avoiding monopolistic impediments to innovation. ${ }^{5}$ Nevertheless, from this debate we may conchude that, to some extent, drawbacks of current over-protective regimes outweigh the advantages arising from implementation of a strengthened legislation.

\subsubsection{Are present IPRs an under-protective regime?}

Advocates of strengthened IPR regimes argue that protection should be increased in order to guarantee incentives to innovate (Clapes, 1993) and to protect small firms against predatory imitation by large firms (Heckel, 1992). Other arguments based on effective resource allocation clam that the scope of patent protection should be broadened, that is, a single patent should provide protection in a wider technological sphere, in order to allow co-ordination between inventors and to allocate efectively resources and investments in R\&D as new entrants adopt agreed technological standards for development of advanced applications (Cohen, 1999). Furthermore, protective regimes not only co-ordinate efforts to innovate, but also encourage firms to introduce products early in order to achieve advantageous mar-

\footnotetext{
3 Contrast, for example Schumm (1996) with Cohen (1999).
} 
ket positions of "first-movers". The firms are thus forced to increase their R\&D efforts and to accelerate the pace of innovation.

Even technological lock-in is seen as a reason for stronger IPRs. A lock-in to single software platform is an advantage and a contributor to standardization. Consumer's choice of a single technology from several available technologies is infuenced not only by its technical merits, but also by the number of users that have adopted it. As the number of users increases, so does the possibility for interaction using a single standard ("network externalties"). Market standards a]low "secondary markets" (application developers) to devote more resources to development of a wider variety of applications for a single (standard) platform, instead of allocating resources for development of similar functionality for rival technologies, interfaces and converters (Farrell and Saloner, 1992).

Standardization is certainly valuable in creating static efficiencies: economies of scale in production, installed base economies and network externalities. In software, in particular, scale economies in the production of complementary applications are important. Giwen the possibility that a market will standardize on an inferior technology (Arthur; 1987; Arthur, 1996; Farrell and Saloner, 1985), the 'static efficiencies' argument is easy to justify only if "any standard is better than none". But this neglects dynamic issues and makes perhaps an unrealistic assumption that the quality of a platform technology does not restrict the technical qualities of its complementary applications.

\subsubsection{Are present software IPRs an over-protective regime?}

As innovation and diffusion both have social value, if the relative social values change, in principle the regime should be changed in response. For example, if the social value of knowledge diffusion increases, then the IPR regime should be altered to facilitate (or place fewer restrictions on) the diffusion, which will necessarily be at the cost of incentives to innovate. One can argue that in the case of soltware (and information goods in general) this has indeed happened.

Net benefits of diffusion increase if the cost of diffusion decreases, all else equal. This has clearly happened with the growth of the Intermet as a distribution chand for all sorts of information goods.

Software is in many ways a "general use" technology. That is, it is an input to or a component of many other technologies or goods. In particular it is a very important input into the generation of further innovation. Thus, if it were widely diffused, it would have very large positive effects on further knowledge creation, and would reduce costs of production of many goods in the economy. 
It may also be the case that the costs of strong protection have increased. That is, while the net benefit of the monopoly given to innovators is still strong at the individual level, it is less so at the social level. The argument here is that a legal monopoly prevents entry. When a technology is changing rapidly, entry is vital in continuing innovation. An over-protective regime prevents just the type of entry that causes and is caused by rapid advance (Samuelson et. al., 1994; Davis et. al., 1996).

As a classic example of a general use technology with the potential to create extremaly strong market power consider the merge-sort algorithm. The mergesort method is an algorithm for effective classification and sorting of objects (such as records in a database). It was presented in the beginning of the 1970s, and since sorting is used in very many applications, it has become a very common and widely-used algorithm in computer science and throughout the software industry. Had its inventor registered a patemt for the mathematical method, most of today's software development, activities and products would have been dominated by a single person. We can easily imagine the harmful influence of a monopoly, had it been granted to a merge-sort patent, on today's software development and innovation, as no altermative has been invented (Schumm, 1996). ${ }^{6}$ This suggests a new test for examination of software claims. Patenting an idea or an algorithm should be accompanied by claims for future applications of the algorithm, which would be an integral part of the patent scope. Thus, patent protection wrould be limited to future applications that were mentioned in the claims. Disclosure of technical know-how allowing implementation in unclamed fields would then be achieved. Although the proposed test does not restrict broad claims from being registered, it is an initial attempt to improve the present situation in which wide allowances are granted to software inventions by limiting the scope of protection to explicit applications that were registered in the patent claims.

These sorts of arguments suggest that if it were possible, software should have a less restrictive IPR regime than many other goods. Sui-generis regimes may be (politically) difficult to create, but at this point in time, since the regime is now being constructed, there is an opportunity to resist calls for stronger protection or, alternatively, to demand compulsory licensing.

\footnotetext{
"One could argue that the presence of a patent would have prompted "work-around" innovation. "This seems unllikely. Given how pervasive is the use of sorting, and how time-consuming it is, incentive to find efficient algorithms are very strong even in the absence of a need to work around a petent.
} 


\subsection{Copyrights}

As in the case of patent regulation, the US is leading the way in revising copynght regulations to fit the new technologies. The rights of the owner a copyriglnted work are well defined in section 106 of the Copyright Act, approved by the United States Congress in 1976. Its definitions include the right for reproduction of a copyrighted work by its right holder, the right to prepare derivative works that are based upon the copyrighted material, the right for distribution of the work, and the right to perform and display it publicly. Additionally, an eligible work must be presented on or in a tangible medium to receive copyright protection (Diotalevi, 1998).

Copyrights are considered as a, "half baked cake" when used to protect software from misappropriated use. The copyright system is being adjusted in light of the hybrid character of computer programmes, and to complete and complement the changes taking place in patent regulations. Nevertheless, software copyrights have not yet successfully addressed the character of the technology in general, and are frequently examined in Court on a "case by case" basis. Reichman (1994) argues that application of copyrights to protect software products in an overlap with patent ("utility") protection of the embodied ideas and algorithms, as eventually legislated in most of the countries, may lead to an over-protective ("narrow") regime. Reichman advocates a suigeneris law that would be tailored to the technical characteristics of software goods and reduce the level of protection that software currently enjoys.

A major juridical test was created by the precedent of Whelan vs. Jaslow, and it drew explicit guidelines for software copyright infringements. In Whelan, the Third Circuit ruled that copyright protection would be available for the "structure, sequence and organization" of a computer program, thus nicknamed the SSO principle. The SSO principle significantly widened the scope of software copyrights, formerly granted only for the source code. ${ }^{7}$ The Court concluded that copyright protection that follows the SSO principle is essential to supply enough incentives for investment in software development. Moreover, the "Whelan Test" presicribes the perception of functionality of a computer program module as an uncopyrightable part, different than other aspects of software, which are copyrighted as an "expression" (Samuelson, 1993).

Criticism published after the ruling objected to the decision as over-protective. The monopolistic dominance over patented technical know-how was argued to contrast, with the incremental evolution of the software industry, based on knowledge transfer and technological spillovers, and the term of copyright protection was

\footnotetext{
7 The statements and instructions that a programmer writes while creating a program.
} 
also indicated as unnecessarily outstretched compared with the average life-cycle of software applications (Menell, 1989). Indeed, interpretation of the ruling led to a conclusion that a new computer program, applying what are by now relatively common procedures and user interface design, such as word processor fonts ${ }^{8}$ and methods for real-time date input may violate the SSO princtele. Thus, onners of rights may not only dominate software technologies by obtaining patents, but also software designs for elongated periods by copyrighting.

In the EU Menber States, legislation is applied nationally, under a uniting legal framework stuplied by WIPO's Berne Convention. ${ }^{10}$ For example, the Dutch law is based on the Copyright Act (1912), which was modified in 1985 according to the Paris Act of Berne Convention. " Although the Directive for Legal Protection of Computer Progeams contained explicit guidelines for adaptation of national regimes (software copyright regimes, in porticular), there are substantial gaps in policy implementation which have slowed the legal harmonization among Member States. Two examples of such gaps seen in the Dutch case illustrate the tension between national legislation and the "Fortress Exrope" regime.

A report on the Implementation and Effects of Directive 91/250/EEC on the Legal Protection of Computer Programs, submitted to the European Commission. (COM (2000)199), found that the Dutch policy for software IPRs differs from the instructions of the Directive by prescribing a wider scope for "expression" which is unclearly defined (EU, 2000). The explicit definition by which ideas and principles embedded in software do not enjoy protection by Copyright Law has not been enacted, and the formal distinction between "idea" and "expression" appears to be somewhat vague in the Dutch legislation.

The second gap concerms differences in restrictions on de-compilation of software goods between the Directive and the Dutch law. ${ }^{2}$ Article 4 in the Directive includes the following limitations for de-compilation of computer programs:

1. "The permanent or temporny reproduction of a computer program by any mears and in any form, in part or in whole. Insofar as loading, displaying, running transmission or storage of the computer program necessitates such reproduction. such acts shall be subject to authorization by the right holder.

[This would include for example making a second copy on a hard drive.]

2. The translation, adoptation, arrangement and any other alteration of at

* Adobe Systems ws. Sowthern Softwane (Federal District Court, 1998) - fonts were approved to be copylighted subject matter.

- Interactue Network ws. NTN Communacontions (Califormia Court, 1995) - "real thime data feed" methods were approwed to be protected by copyrights.

10 WTPO -.. World Intellectual Property Organization; WTO - World Trade Organiza tion.

11 By Stratsblad no, $307(30.5 .1985)$.

12 Notice that the Dinective has an extremely broad defintion of "de-compilation". 
The Creativity Paradox: How IPRs are Challenged by the "Open Source"

computer program and the reproduction of the nesults thereof, without pregudice to the rights of the person who alters the program.

[This would include for example translating the dialogue boxes from English to Dutch.]

3. Any form of distribution to the public, inchuding the rental of the orginal computer program or of copies thereof. The first sale in the Community of a copy of a program by the right holder or with his consent shath exhaust the distribution. right within the Community of that copy, with the exception of the right to control further rental of the program or a copy thereof." ( $\mathrm{EU}, 1991)$.

[This would include, for example, re-selling a piece of software if it had previously been installed, even if it is now completely uninstalled.]

These are all Directive limitations on de-compilation. However Article 6 of the Directive makes an exception aimed at increasing innovation and product development: de-compilation of computer programs is permitted if the purpose is to achieve interoperability of the software with other applications (a process prohibited by US law). The Netherlands did not validate this exception, thus restricting the scope for software de-compilation. It is worth mentioning, however, that the report considers the overlap between software copyrights and patents as. non-problematic, as it is mostly concerned with a guarantee of broad scope of protection for software goods (EU, 2000). Hence, the authors of the EC's report on the implementation of the Directive on the Legal Protection of Computer Programs hold an opinion that expansion of software IPRs by the application of a more protective copyright regime, despite an overlap in legal protection between patent and copyright regimes, is the favoured decision.

\subsection{The Creativity Paradox: How IPRs are Challenged by the "Open Source" Movement}

The rapid development of the Internet accelerated in the 1990 s and confronted software users, developers and authorities with a wide variety of problems. The intellectual property rights regime, developed in an era in which physical goods dominated the economy, was in some ways not in keeping with the new realities of intangible, information goods, the ease of their reproduction, and, with the Internet, the ease and geographic scope of their distribution. One aspect of the evolution of software, and information goods in general, has been an altempt to commodify them in such a way that they fit into the old IPRs paradigm. Thus, one movement has been towards applying strong property rights, such as patents, in this area. The natural evolution would seem to favour the development of "closed" software platforms, offered to the market with absolutely minimal disclosure of the embedded knowledge. As we have seen, software patenting both as a means of 
protecting property and as a strategic means to preempt new entrants has become more and more widespread.

By contrast, though, since the beginning of the 1990 we witness al significant increase in developmert of Open Source systems, which are publicly offered with a free use license (e.g. Linut, Apuche and Sendmail). Why do software developers and software firms offer their creative output at zero-price, even though current, legislation allows software developers more means to claim property rights than even before?

Software IPRs have been developing in an evolutionary rather than a revolutionary manner, thereby tending to force the technological agenda to fit out-moded legal pattems. Even the current resolution, an extension of the "idea/expression" doctrine to inchude computer programs and algorithms, first enacted in the US and later adopted in part elsewhere, attempts only to adapt existing IPR regimes by providing developers with a dual protection by patenting embedded ideas and copyrighting final products. Like any other patenting, software patenting aims at. promoting innovation and knowledge disclosure by granting exclusivity over inventions to their creators, here, "fencing off" new algorithms and techniques from the public domain. But legal scholars, economists and even programmers themselves, continuously criticize the current regime as jeopardizing further developments in $1 \mathrm{CT}$.

As a good, software causes difficulties for current IPR regimes. In addition, new modes of software production do not fit well either. A growing body of empirical literature and anedotal evidence implies that as a production technology, Open Source maty be extremely effective. ${ }^{1.3}$ The stability of open source software, and the speed with which developers respond to things like security problems argue that Open Source as a mode of production has many advantages. But whereas properties of software production are complex and not entirely known, Open Source development has brought to the fore far more complex issues that challenge current IPR policies and legal paradignus. Open Source development, an approach which explicitly eschews traditional notions of intellectual property rights, relies on a free disclosure and reciprocal exchange of technical know-how, ideas and code lines within a virtual community, fully accessible for distribution and use by all web-surfers. The Open Source community has rejected the application of patents and copyrights in favour of its own parallel "regime", based on variantis of public licenses which differ in terms of distribution, use and obligatory disclosure of advances in source code (e.g. Copy-left. MPL and the BSD license), but which in general treat innovative ontput as a relatively public good, available

13 See, for example, the exponential growth of websites using the Apache server and the success of the Open Source community in providing its users with continuous technical support (Lakhani and von Hippel, 2000). 
to be wsed by whomever sees value in it. ${ }^{4}$ Traditional means (of legal monopoly e.g.) of appropriating value from innovation do not apply. Rents cannot be extracted through the market for the good itself as it appears from the innovative process. Similarly traditional means of control of the technology do not apply. If the core of the technology is in the public domain, the locus of control has necessarily to be created and maintained in some non-traditional way. Traditional property rights have been central in both cases. The challenge now is to develop a new system in which the values of open-ness are maintained, but in such a way that incentives can remain, and in which control of the technology is not: usurped by those that feel threatened by it. ${ }^{15}$

\subsection{From IPR Protection toward Communal Benefits}

Since the mid-1990s, two major trends in software economics have arisen. The first. argued for strengthening intellectual property rights for software and information goods, whereas the second approach presented a progressive attitude, commonly known as Open Source, by which legal modus operandit to protect software goods and innovation should be only minor. In order to understand the background for the emergence of the two approaches the technological evolution which led to those changes should be first introduced.

Issues of intellectual property rights, copyrights and patent protection for software-embedded processes and later explicitly for software goods, appeared after the verdict in Diamond ws. Diehr (Supreme Court, 1986) in which software elements were recognized patentable. During the beginning of the 1990s, the US Patent Office (USPTO) decided to examine its guidelines for protecting software goods. The result of its efforts defined progressively more toleranti allowances for patenting.

The main change in the USPTO policy is the ability to patent algorithms, which enabled the patenting of advances in software technologies (the "idea"), ws at part of developed software, whereas the final product is protected by the Copyright. Act (the "expression") (USPTO, 1996). Hence, since the Courts verdicts and legal guidelines determined legal methods for protection of software goods ideas, processes and algorithms have come to be protected by patent law. Consequently, the number of patents in the category of "intormation processing" (the majo: classification for software application patenting) has rapidly grown between 1992 1999 .

\footnotetext{
${ }^{14}$ In many cases, Open Source licenses protect thernselves from modification of terms by applying copyrights for this purpose; See Perens (1999) for a review of primery Open Source licensing methods.

${ }^{15}$ Imagine what could happen if Microsoft decided to create "its own wersion" of Limux.
} 
The other approach, the Open Source movenent; was established in order to integrate and to coordinate an aggregation of skills of computer developers. While this movement was begun in the 1970s in academic institutes and public laboratories, the extensive diffusion of the Internet has changed dramatically the scope and feasibility of the movement and has wrolved larger parts of the population in open source development. This model involves the full life-cycle of software development in a cumulative and communal manner and is nicknamed the "Bazaar model", in which the programmers are invited to take part at any time." The model is named to contrast with the prevailing methodology in the software industry "the Cathedral model", in which "closed" development teams have well-defined areas of responsibility coupled with stuctural processes and procedures for testing, debugging and non-frequent releases of versions (Raymond, 1999). The "Bazaar model" allows communities of users and developers to create a dynamic process, in which products are opened to changes, freely implemented and frequently updated, mastered and enriched by their users. In order to assure that programmers disclose their advances back to the community, and those are shared as public domain, unique schemes of "public licenses" were formed when the first, open source projects were launched ( $C P L, M P L, G N U$ and others).

Numbers of Open Source applications have been growing exponentially since the beginning of the 1990s. The technological diffusion of the Internet has fostered the formation of programming teams over the Internet via discussion groups and message boards and has orientated talent toward joint development of networkbased applications. To illustrate, USA Today predicts that the share of Linux, an Open Source operating system and a common example of a successful bazaartype development, will be doubled within two years and exceed a $9 \%$ market share. ${ }^{17}$ The Open Source Apache is the leading platform for Internet communication servers. It is estimated to have captured $57 \%-60 \%$ of the market for Internet hosts. ${ }^{\text {s }}$

The success of the "Bazaar model" to attract skilful programmers that prefer to devote time, efiorts and original developments "with no reward" to a virtual community is still puzzling. The rise of the Open Source movement is far more impressive when one considers the potential rewards that Open Source developers could have acquired during the Internet gold-rush of $1995-1999^{19}$ by commercial

\footnotetext{
16 The stages of the model include: development of the source-code, debugging, testing and quatity assurance, documentation, wesion release and a contimuous development of related fatures (as software "patches").

17 Avalable at: htp:/www. usatoday,com/life/cyber/tech/cthot6.htm

18 Based on estimations of friktomi and the NEC Pesearch Imstitute

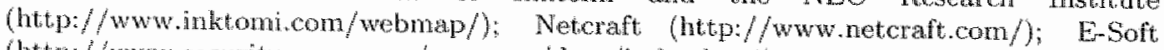
(htp://www.securityspace.com/s_survey/data/index.htmil).

19 "The "Internet gold-rush" turned to be an "Internet bubble": a frenzy runaway of
} 
exploitation of their source codes and by the new legal guidelines that protect them from being "stolen" by others.

Economists and social scientists have recently begun to examine the rationale behind the "altruistic" behaviour of sofware developers, sharing their intellectual and professional output at "no cost" with other users. Initial conclusions distinguish among contributors to Open Source projects and divide them to three groups:

- Participants in Open Source community are involved mainly in soltware documentation and testing via regular use. Their incentives include satisfaction and expertise in state-of-the-art software technologies.

- Programmers develop source code of Open Source applications. They benefit to a large extent, from adoption of relevant procedures and algorithms in other projects in which they are involved, and from relationship with other actors in their professional circles. Their incentives also include "learning by doing", gaining expertise from development of new software and from knowledge spillovers by other programmers in the project.

- Project leaders initiate development of Open Source applications mostly as a "call for solution" of engineering problems they confront in commercial projects they perform (for example: development of unique email protocols as a part of communication project). Later, when the number of participants and their interest in the project exceeds a critical mass, and the initial specification expands, project leaders continue to coordinate the development efforts or hand over their role to one of the active participants. They are driven by reputation and by recognition in the "Open Source" community and among software firms and by the ability to signal future trends in the ICT market and to recruit genuine programmers to their commercial activities.

(Raymond, 1999; Lerner and Tirole, 2000)

One aspect of a firm's decision to embrace Open Source involves the expectation that by disclosing the software technology to the public domain, other complementary activities, offered by the firm, can be conmercially exploited and will expand through a rapid diffusion of the proposed technology. Further, a firm disclosing its source code expects that its product would gain a dominant position in the market, enjoying both technical superiority on proprietary products as Open Sources are being nourished by a wide community of skilled users which creates a technological spill-over to proprietary products, and rapid diffusion due to a minimal "price tag".

investors from high technology stacks and the crash of many software firms, between March and December 2000. 
Hence, release of a source code for free use is perceived as a method to foster adoption of core technologies and to turn them to a market standard. Small and nedium fims that cannot compete with market leaders may apply the Open Source strategy to mprove therr position in the market and extensive implementation of their technologies. Red Hat Linux is an example for a successful business model, which is fully bassed on Open Source applications. The company distributes Open Source applications, which can be downloaded for free from the Internet, but provides its customers full guarantee and technical support. Red Hat acquires the source code at no cost, tests and improves the sofware, and then sells it in the market. Although Red Hat Linux may be installed and used for free (both are permissible by Linux licensing terms), most of its customers prefer to buy an original copy of the software, as an "insurance preminm", and enjoy the firm"s guarantee (Young, 1999).

Examining Red-Hat's success, one should cautiously conclude about the possibilities of other firms to profit by adoption of a similar model for their business activities. Indeed, Open Source software is available to distributors at no cost and in many cases offers consumers superior solutions than "closed applications", 20 and their application as a purchased copy reduces the implementer's risk. However, the formation of communal cooperation in development of advanced applications and their use by computer experts and, recently, by home users questions the need for extensive frameworks of intellectual property rights in software technologies and whether legal protection by patents and copyrights may be reduced. ${ }^{21}$

Under this type of business strategy, or on this rationale for creating some open source, a firm must be able to create both open and proprietary software. To maintain the second class, there are two possible strategies: to deploy property rights, or to enforce trade secrecy. If the second, combined with network externalities, is a possilaility, and this sems quite feasible in software technologies, then traditional IPR policies will be inappropriate for the software maket. They would be inappropriate for proprietary software in that they are unnecessary to create incentives to innovate. But more interestingly, they are inappropriate in open Sonrce because they do not provide the structure (in fact they hamper it) that Open Source needs to thrive. If the open source production mode continues to bave the technological successes it has enjoyed in the past, it provides a strong argument against the current trends in sofware IPRs.

20 Users are able to copy parts of open source systems for implementation in other systems, modify them according to their needs or distribute them to athers at no cost.

21 Not only do software producers hardly rely on IPR regines to prevent unduthorized duplication, most of them rarely implenent technical means for this purpose (Stolpe, 2000). 


\subsection{Conclusions}

Patents and copyrights are well-known methods to guard technological advances and creative arts. However, these regimes are traditional in the sense that both were articulated when technological advances in physical goods were the nom.

Since the 1960 s we see the emergence of a new techological paradigm, namely knowledge-based economies, often called the weightess economies. Knowledgebased goods are based in large part on intangible modes of distribution and use rather than on physical elements of technology in the final product. In recent years the growth of patent applications in these new industries shows a growing attempt by innovators to strengthen legal rights over their ideas.

The development of the personal computer and the Internet, common repre sentatives of knowledge-based technologies, as well as other new technologies that evolved, have not only opened new scientific and technological avenues but also initiated a debate around the contribution of patents, copyrights and licensing strategies to obtain continuous innovation. Although technical contents differ, some arguments in the debates on the nature of IPR probection are shared.

First, the success in preserving the balance between monopoly and disclosure of technical know-how to the public is under doubt. On the one hand, the possibilities for unauthorized duplication, distribution and use of information goods imply that. legal provisions are to some extent under-protective. On the other hand, network. effects leading to the emergence of single technology as a market standard create monopoly over technology empowered by legal regimes.

Second, as information goods have become accessible world-wide, mainly by the Internet as an infrastructure for global communications and retrieval of contents, information providers, such as sofware publishers, database producers and news agencies have confronted vast scales of copyright violations.

Third, opposite effects that emerge from the development of technological means which restrict accessibility to information, compounded with impacts of strengthened protection by recently formed regimes (e.g. the US Patent office for software patenting and the EU Database Directive), have been argued to put scientific and technological advance, mainly in public and academic research institutes, at stake by monopolizing the content.

Fourth, and most importantly, policy makers around the globe attempt to resolve these issues by applying old legislative frameworks of IPRs to new technologies. Misapplication of current IPR regimes to the evolving technologies may be the result. Moreover, policy changes that aim to provide adequate protection to technologies are often approved a decade or so after radical changes in technology have taken place, whereas in the meantime technology continues to evolve, 
presenting further puzzles.

As stated in the beginning of the chapter, regulations are found to be far from being water thight against sofware piracy. The nature of software goods, as well as other intangible gaods, confronts policy-makers with evolving needs of the software industry not only to explore new methods for enforcement, but mostly to adapt the current regimes to the technological dynamics.

At the same time that higlily protective legal intellectual property regimes for software have been criticized as destroying the balance between incentives to invent and the diffusion and use of technological knowledge, alternative models of intellectual property use, based on the tradition of Free or Open Source, in which openly avalable software is used the basis of a profit-making venture have developed. ${ }^{22}$ Recent research in economics has attermpted to explain the rationale for participants, both firms and individuals, in Open Source. A development method, which originally started with the Free Software Foundation to foster an endogenous growth in innovation for software technologies (Stallman, 1999), has developed to become a profitable business model, in which a reliance on legal intellectual property regimes is (almost) prohibited, by legal means.

The Open Source model indeed demonstrates a creativity paradox. Inventors of software technologies could take advantage of incentives provided by intellectual property rights based on traditional IPR regimes by creating rights of propriety and thus an advantageous market position. Nonetheless, new developments succeed technologically and commercially where these incentives are ignored, and where IPRs are not implemented and software is freely disseminated.

The Open Source development, mode not only seems to be a paragon for software production, but also dramatically weakens the argument that strong property rights are necessary to create incentives for inventors to innovate in software technologies. Open Source communities demonstrate how technologicall advances and progressive conmunication platforms can efficiently foster innovative efforts, in m. way not taken into account in traditional models of innovation and property rights. The Open Source movement, at the same time producing rapid innovation of good technologies and avolding application of traditional IPR regimes, suggests strongly that software IPRs is a case of the tragedy of the anti-commons: Software is "a resource [that] is prone to underuse... when multiple owners each have a right to exclude others from a scarce resource and no one has an effective privilege

22 In contrast to nuay opinions in the field for these mainstrean views sec Reichman, 1994; Sammelson et. al., 1994; Schumm, 1996), Cohen (1999) argues for a stromger IPR regine. The idea is that if property rights were stronger, dominant standards for core technologies would emerge nome quickly, and by reducing resourcess expended on comm peling technologies, more resources would be available for more rapid dewelopnent of applications. 
of use" (Heler and Eisenberg, 1998), ${ }^{23}$

Finally, although the echoes of fomer debates in software economics have not yet dissolved, technological developments in the field and progressive communication platforms may confront us, due to evolving abilities and functionality, with new levels of complexities, far from the traditional economic and legal models, as currently known.

\footnotetext{
${ }^{23}$ Other known "tragedies" which arise from extension of traditional IPR regimes to include knowledge-based technologies in their scope of protection are genetic expressed sequence-tags patenting (Heller and Eisenberg, 1998) and the EC Directive for the Legal Protection of Databases (David, 2000).
} 

(1) 


\section{On Substitution of Intellectual Property and Free Disclosure: An Analysis of R\&D Strategies in Software Technologies}

\subsection{Introduction}

Since the beginning of the 1990 s, we have seen a significant increase in the development of computer programs as Open Source applications, publicly offered with a free-use and distribution license. Open Source applications cover a wide variety of fields from operating systems and communications to desktop publication programs and Enterprise Resource Planning packages (prominent and widely implemented examples are Linux, Apache, Open Office and Sendmail)."

Part of the success of the Open Source movement is explained by the rapid growth of the Internet as a communication network between users and developers. The design and programming of new applications progresses online. Users continwously download updated versions, test them and indicate faults in their operation or propose additional features to develop (Raymond, 1999; Jeppesen and Molin, 2003). "The architecture of the Internet and the connectivity of wast numbers of users enable communities of software developers to coordinate widely distributed programming efforts and skills online. Those skills are tumed into a contimuous improvement of computer programs and solid technical support at virtually no cost (Lakhani and von Hippel, 2000).

While the early modern history of computer software involved consideralble open source development, mostly in the academic milieu. In recent decades, particularly since the rise of the personal computer, commercial programs dominate

\footnotetext{
${ }^{1}$ Listed Open Source initiatives and active projects in a variety of fields can be found in http://sourceforge.net/.
} 
Whe hon's share of software markets and Open Source moved to the fringe of the industry. However, in the past few years major firms have decided to integrate Open Source methodologies in part of their projects. Cowan and Jonard (2003) explain Netscape's decision to disclose the source code of its browser arguing that "W] hat the Internet may have done is to create a large enough community of "collaborators" to make the gains from collaboration outweigh the costs perceived in loss of proprietary control (which may, of course, include lass of narket power, technological secrets, trade secrets and so on)."2 A recent example is the release of the source code of IBM's Eclipse project, a new software platform on which information systems are built, in November 2001 . It was a proprietary software that was developed at the cost of forty million dollars (Industrial Computing Magazine, November 2001).

Despite an extensive legal framework which permits software developers to appropriate rents from their programs and inventions, 3 many developers prefer to offer their creative output at zero revenue. Firms that supply Open Source as part of their business model expect to raise their profits and to increase their market shares by disclosing their core asset for free use, modification and re-sale by removing any intellectual property claims from it. Other firms disclose their source code and technology and establish industrial consortia to maintain them to prevent competitors from "hijacking" substantial market shares with their own proprietary standards (Rice, 2003). Firms, in particular, small and medium enterprises apply Open Source to gain a competitive adwantage by fostering the diffusion of their technologies and by expanding the installed base of users. Bonaccorsi and Rossi (2003) indicate that although Microsoft succeeded in establishing a dominant position in the desktop market and disrupting wide diffusion competing Open Source applications, Open Source software obteined a stronghold in the web server market. Altematively, a firm's decision to embrace Open Source involves the expectation that by disclosing contents of their technology to the public domain, complementary services (a.g. implementation and technical support) can be conmercially exploited and will expand through a rapid diffusion of freely-offered contents. Red Hat Linul is a prevalent example for a successful business model fully based on Open Source soltware. The company distributes Open Source applications which could be downloaded for free from the Internet, but Red Hat provides its customers full guarantee and technical support. Red Hat acquires

\footnotetext{
${ }^{2}$ The explanation is supported by an e-mail from Eric Hahn, Executive Vice President. and Chief Technology Officer at Netscape, stating that Netscape's decision was inspired by writings about the Opern Source mode of development (Raymond, 1999; pp.76).

${ }^{3}$ Increasing numbers of software patents submitted and approved by the United States Patent and Trademark Office (USPTO) and the rising number of lawsuits over patent disputes in information technologies reflect a wide adoption of IPRs as stratregic means by software companies (Granstrand, 2000; Cowan and Harisont, 2001).
} 
the source code at no cost, tests and improves the softwere, and then sells it in the market. Although Red Hat Linux may be installed and used for free (both are permissible by Linux licensing terms), most of its customers prefer to buy an original copy of the software, as an "insurance premium", and enjoy the firm's guarantee (Young, 1999).

As the use of software applications expands, so do their "production externalities": Knowledge spillowers that foster technological advance increase with the level of openness of the source code, as skilled users integrate new features into the base program. Therefore, when increasing the numbers of subroutines that are made public, the technical quality and the performance of the product is more likely to rise, as the scales of labour involved in designing and programming new features and improwing existing code-lines increase. External programmers can join the development process and contribute their skills and know-how. Further, by "outsourcing" other tasks of R\&D to Open Source communities (e.g. documentation, quality control and bug fixing), software firms are able to reduce their development, costs. ${ }^{5}$ However, the major drawback in a frm's decision to adopt Open Source methodologies is the remowal of intellectual property claims from disclosed features, as a precondition for involving external programmers in the development process. Consequently, the revenues from open versions may become lower than revenues that are obtained from proprietary wersions. Hence, many software firms choose an alternative strategy and distribute their products as hybrids, in which part of the source code remains proprietary and the other is made open by disclosing their code-lines or by customizing the licensing terms of their products (McKelvey, 2001). For example, the Sun Community Source Licensing (SCSL) for its Java-based applications integrates both Open Source and proprietary policies acconding to the use of those products. Users can download the Java. developers" kits and use it at no cost. However, licensing fees are charged when they acquire the source code of the standard environment and modify it for their own purposes."

The development and the distribution strategy of firms closely affects the licensing terms of software. Those terms regulate whether fragments of the Open

\footnotetext{
"Results of several benchmark studies comparing the main variables of performance and stability in Open Source vs. proprietary applications have shown superiority of the Open Source Linux over its proprietary rival, Windows 2000 (see for instance: Rothman and Buckman, 2001; PC Magazine, 2001; PC Magazine, 2002).

${ }^{5}$ Software firms had long ago reduced their testing costs by introducing beta versions of computer applications to potential users before releasing the final products to the market.

6"The Open Source model shares similar concepts with other business models, such as shareware, in which products versions with partial or downgraded functionality are offered at no cost. Howewer, the main difference is that Open Source requires disclosure of the source code and hence users are able to adapt the software to their needs by modifying it or by adding new features.
} 
Source code can be applied within proprietary programs, can be modified or redistributed and whether the type of license is "viral" (i.e. programs that apply part of the source code should be protected by the same type of license) or has non-restricting terms (see Table 5.1). The licensing terms, in turn, infuence the conditions and restrictions for developing and distributing future "generations" of the technology and releases of new product versions. The dissemination and use of derivative and complementary applications, in which parts of the code are embedded, are subject to the same license of the original program. However, in some cases analytical modelling can be far more complicated than the generall model presented here, considering the "viral" characteristics of licensing terms and the opposing views on the links between Copyleft licenses and their contribution or impediment to innovation. From a developers' standpoint, Reese and Stenberg (2001) perceive Copyleft licenses as a hindrance to cooperation between Open Source programmers due to their exclusive scope. Copyleft licenses (primarily the GPL license) require that every piece of source code that was made executable should be disclosed to the public and code-lines covered by Copyleft terms cannot be integrated into other programs if their licensing terms impose "ffurther restrictions" or lesser degrees of disclosure. The extensive scope of disclosure restricts the subsequent use of Copyleft protected programs by firms, and. presents "no notion of proportional fairness. The quid pro quo [i]s in reality a quodque pro quo."7 Consequently, Copyleft protection discourages participation of commercial programmers in the development process (the authors argue that. contributions of software developers employed by firms are the most prominent in. Open Source projects). Lessig (2002) holds ar opposite view on the benefits of Copyleft licenses to Open Source projects and innovation in software technologies, analyzing the structure of competition in the Open Source market. He argues that Copylef licensing terms foster innovation by disclosure of improved versions and maintein incentives to initiate new Open Source projects. If changes in the source cade of Open Source software were left undisclosed, rivals could have abtained it fon tree, improve it and redistribute the program as a low cost proprietary product that directly competes in the original application. Smith (2002) proposes balancing measures between private and public interests, by which application of Copyleft terms would be limited to software that is developed by public institutes for non-private use.

In the model that follows we assume that Open Source programs are distributed under permissive terms of 'X-license' that enable free use, commercialisation, development of new features and application of a 'mixture' of free, open

\footnotetext{
${ }^{7}$ Quid pro quo - something given in return for something else; Quodque pro quo everything in retum for something.
} 


\begin{tabular}{|l||c|c|c|c|}
\hline License & $\begin{array}{c}\text { Code can } \\
\text { be used } \\
\text { in non-OS } \\
\text { programs }\end{array}$ & $\begin{array}{c}\text { Modifications } \\
\text { taken } \\
\text { without } \\
\text { disclosure }\end{array}$ & $\begin{array}{c}\text { Software } \\
\text { re-licensed } \\
\text { by anyone }\end{array}$ & $\begin{array}{r}\text { Privileges for } \\
\text { the original } \\
\text { copyrght-holder } \\
\text { over modifications }\end{array}$ \\
\hline$G P L$ & $\mathrm{X}$ & & & \\
LGPL & $\mathrm{X}$ & $\mathrm{X}$ & & $\mathrm{X}$ \\
BSD & $\mathrm{X}$ & $\mathrm{X}$ & $\mathrm{X}$ & \\
NPL & $\mathrm{X}$ & $\mathrm{X}$ & $\mathrm{X}$ & \\
MPL & $\mathrm{X}$ & & \\
$\mathrm{X}$-License & & & & \\
\hline
\end{tabular}

Table 5.1. Licensing terms of frequently-used Open Source licenses (Source: Perens, 1999).

and proprietary software. By using the model as a baseline case, future research may assess the impact of the various licenses present in the open and free sofware community (e.g. GPL and BSD) on the development of information techologies.

A positive effect of free dissemination of software products, which even exists in software piracy, is the increasing number of users that choose to adopt them (i.e. the installed base of computer programs). Firms may benefit from disseminating unprotected versions since the demand and the propensity to pay higher revenues for legally-purchased copies increase with the total number of licensed and unlicensed users of their products (Conner and Rumelt, 1991; Shy and Thisse, 1999). However, this strategy would succed only if the elasticity of substitution between paid and unpaid use is larger than 1, i.e. the growth in profits from purchased copies exceeds the losses from illegal duplication. Yet, research on the economic effects of software piracy and unauthorized use examines software programs mainly as final goods (i.e. compiled software packages), overlooking the other type of benefits source code disclosure involves. Whereas the success of proprietary software and its endurance to changes in the market is recognized by "locking-in" the majority of consumers to a single market standard over rival applications, the success of Open Source projects is not measured by the same token. Rather, Open Source programs succeed by attracting many agents who implement them, provide technical support to other users and produce new and improved versions on a continuous basis.

On the supply side, various scholars suggest that developers participate in Open Source projects and disclose their intellectual and professional ontput to the public at "no cost" are driven by behavioural determinants, such as self satisfaction or "altruism", rather than by a more "traditional" economic rationale."

\footnotetext{
${ }^{8}$ Although it is reasonable to assume that professional programmers would prefer
} 
Others argue that new opportunities to "soctalize" with members of online communties who share common interests and background and the reputation gained in professional circles are the main motwes behind partaking Open Source (Lemer and Thole, 2002). However, whether one social factor is more dominant than the others, common observations mention that the development of open sources is essentially not affected by any changes in the market and can be represented in economic terms as a non-elastic supply of skills. ${ }^{9}$

In the following sections, we look at the underlyng dynamics of software markets, where producers of software platforms and major applications (such as operating systems or Internet communication servers) are able to choose different degrees of disclosure, in terms of technical quality and profits. Our model analyzes how different degrees of source code disclosure affect the performance of softwere products and technologies and the profitability of their producers. Section 2 describes a model of R\&D in software firms where a short-sighted firm applies level of disclosure that optimizes single-period profits.

Section 3 expands the model and analyzes how disclosure influences long-term profits and social welfare and whether both measures correspond to each other. Section 4 expands the scope of the discussion and illuminates potential strategies in some common market scenarios. Finally, we compare between markets of myopic and forward-looking firms, where similar degrees of disclosure generate different levels of profitability and future investments in R\&D and draw conclusions on the links between software disclosure, technical quality and profits.

\subsection{Intellectual Property vs. Disclosure: Description of the Model}

Soltware products and technologies are composed of different technological features, various components that execute information processing and computational functions that are involved in the operation of computer programs. Software features are commonly integrated to a single, coherent application and do not overlap either in their functionality or tasks.

The essence of the model is based on a firm's decision to disclose part of its source code to improve its profits. Since the disclosed features are freely disseminated and used, the firm must "compensate" for its disclosure through increased

developing in their spare time commercial applications rather than free sofware, in any Opun Source community roughly half the dewelopers are professional programmers (Hertel et... $\left.a_{k, 2}, 2003\right)$

The phenomenon of Open Source communities is more likely to be found in information technologios rather than in electronic engineering or biotechnology, since new entrants are not required to make Ungh capital imwestments in hardware in order to participate in "ploduction" of new computer programs. 
revenues from the remaining proprietary features. Open source features become avaibule to both users and rival firms, thus we can assume that revenues are not generated here. Again this assumption is a way of simplifying the model. If the software market has a monopolistic competition structure, profits are made through product differentiation. But thinking in Lancasterian terms, if two products share a feature, there is little ability for the two firms to differentiate using that feature. Thus the ability to differentiate, which is central to the ability to eam profits, depends on having features that other products or firms do not have. "This is captured in a very straightforward way by assuming that frms eam no tevenues on anything developed as open source (since competitors can exsily copy them): their revenues must come from the features which difterentiate their products from the competitors. This approach implies that software is hybrid in that parts of it are open and other parts are closed. Hybrid software may be relatively uncommon, but some important examples exist. The new Macintosh operating system is an example of a hylbrid product: the heart of it is based on a BSD Unix version (called Darwin), on top of which is a proprietary user interface. The Lindowsos is another example for an operating system that was built on the basis of Debian Linux. The system offers compatibility to Windows applications (which does not exist in Linux versions), graphic and user interfaces similar to WindowsXP and advanced features (e.g. anti-virus, anti-spam filters and WiFi detector). At the same time, the model can be interpreted as representing a firm's portiolio of software. Some products are offered as open source, and others are proprietary. This avoids the issue of hybrid packages per se.

The model presents a stylized version of a real-world "software consumption" behaviour, in particular as regards the demand side. Since the links between revenue and openness are in principle unclear, we look instead for bounds on revenue response, such that open source becomes a viable development mode. While this makes the model appear simplifed and quite unrealistic in a way, it captures the basic motivations of firms to develop their products as open or proprietary versions and avoids the difficulties involved in a fully-blown demand side.

\subsection{A Model of a Myopic Firm}

Nordhaus model of technical change (1969, Ch. 2) describes liow the quality and the performance of technology expand when new features are added, either by the firm's R\&D or by users. Technical quality signifies the performance of technology and can be represented as a position on a "quality ladder" (Grossman and Helpman, 1991). Following this definition and Nordhaus" model, firms cortinu- 
ously mprove the technical quality of their products by investing in R\&D. The incremental change in the techncal quality of sofware is denoted $R$ in our model.

Assume for simplicity that development of new features involves no risk. Therefore, development of features accomplished by users substitutes for R\&D of the firm, if the code-lines of this feature were disclosed.

The model acdresses the problem of a single firm. Given the costs of the two modes of development, and the relationship between openness and revenue, the firm maximizes profits by choosing the degree of openness, $\alpha \in[0,1]$ (the complementary share of the tecknology, $1-\alpha$, remains proprietary and developed by the firm in-house). ${ }^{10}$ Initially we examine the case in which revenues do not respond at all to openness, and then ask about conclitions on the relationship between reverue and openness that would encourage or discourage firms to open their source.

The cost to the firm of developing a new feature is $\bar{c}$ if it is developed in-house and $c_{1}$ if accomplished through Open Source communities. Since Open Source programmers carry out major tasks, without compensation from the firm, $\mathrm{c}_{1}<\overline{\mathrm{c}}$. Consequently, the R\&D expenditure of the firm includes the cost of developing proprietary features, $\bar{c} \cdot(1-\alpha) \cdot R$, and the cost of Open Source features, $c_{1} \cdot \alpha \cdot R$.

The revenue of a single proprietary feature is a function of the level of disclosure, $\Psi(\alpha){ }^{11}$ Revenues are generated only from fieatures that are distributed as proprietary sources, $(1-\alpha) R$. One-period profits of the firm are achieved by subtracting its development costs on Open Source and proprietary features from its revenues.

The firm maximizes its one-period profits, $\pi$, by evaluating the trade-off between R\&D expenditure on Open Source features vs. its expenditure on proprietary features and the revenues that are achieved:

$$
\pi=(1-\alpha) \Psi(\alpha) R-\left[\bar{c}(1-\alpha) R+c_{1} \alpha R\right]=(\mathbb{1}-\alpha) \Psi(\alpha) R-\left[\bar{c}-\alpha\left(\bar{c}-c_{1}\right)\right] \cdot R
$$

Figure 5.1 illustrates the mechanism graphically, showing the consistency requirements among the variables. Given the change in the technical quality of

${ }^{10}$ At one extreme lies full protection by IPRs and consequently full ownership of the technology. At the other extrene technology is developed only by public communities and, hence, can be freely copied, disseminated and installed. In reality, however, full disclosure is more of a descriptive expression rather than an existing state, as part of the technical know-how always remains tacit within the domain of its inventors. The scenario of complate protection is far from reality as well as firms disclose essential software components to developers of complimentary applications and reveal their technical specifications. We assume that the technical know-how obtained from the share of proprietary software is only marginal.

"If a firm inchudes some proprietary and some open source features in its producti, rivals can duplicate the non-proprietary features in their own versions of the good. Thus, ignoring the possibility that, users are interested in "bundles" rather than features, a firm. can only extract revenues on its proprietary features. 


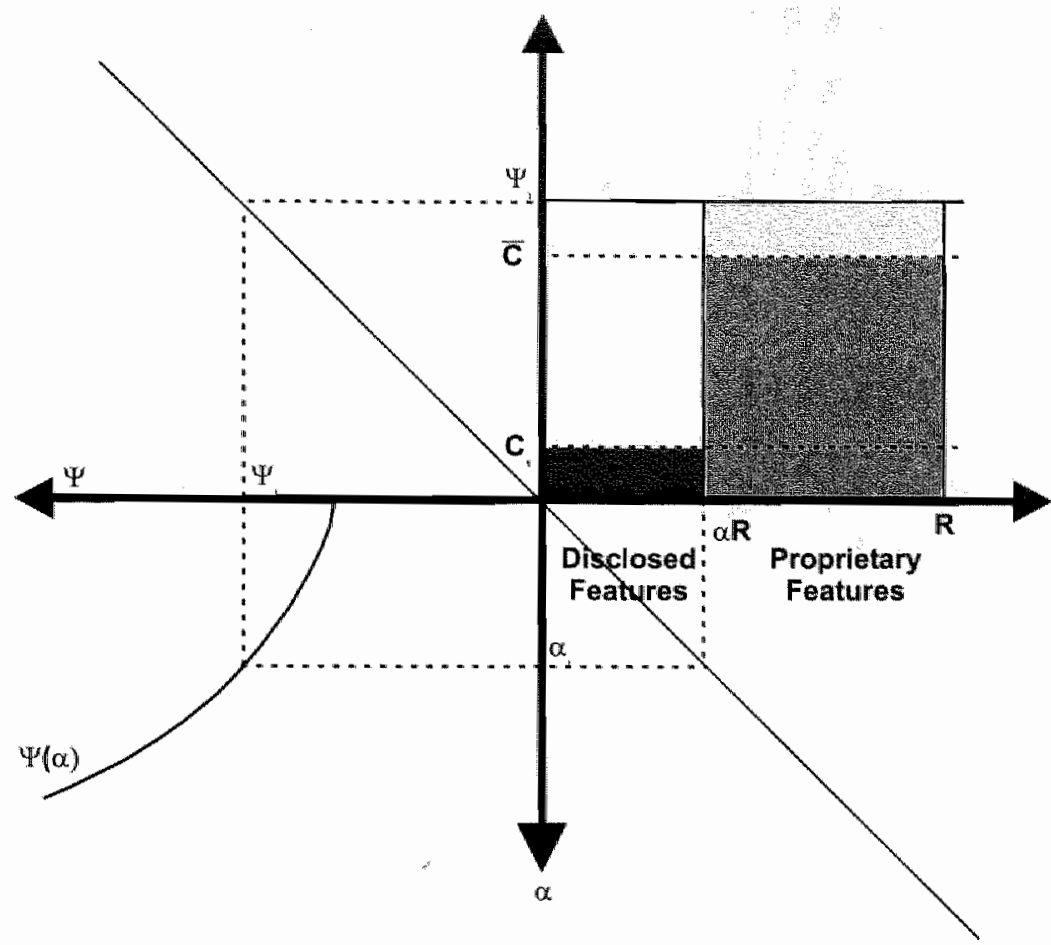

Figure 5.1. Illustration of the single period model.

For a given $R$, changes in $\alpha$ change both the proportion of $R$ on which the firm receives revenue, and, through $y(\alpha)$, the revenue "per" feature" for those features.

software, $R$ (the horizontal axis in the north east quadrant), a firm chooses a degree of openness $\alpha_{1}, \alpha_{1}$ is the argument in the revenue equation, $\Psi(\alpha)$, and the revenue is determined in the south west quadrant. The revenue, $\Psi_{1}$, determines profits in the following way. Rewenue is generated only on closed software, and is defined as $\Psi_{1} \cdot\left(1-c_{1}\right) R$ (light grey plus medium grey). Total costs are the sum of open development costs (dark grey) plus closed costs (medium grey). Thus profits are the difference between profits on closed software and open development, costs (light grey minus dark grey). Increasing $\alpha$ can increase the revenue per feature, but it will decrease the quantity of software on which the firm earns revenues. This captures the firm's basic trade-off.

A marginal increase in the degree of disclosure has three effects on the costs and gains of the firm:

(1) Revenues decrease by $\Psi(\alpha) \cdot R-(1-\alpha) \frac{d \omega(\alpha)}{d \alpha} \cdot R$ as the firm expands the non-remunerative segment of the product;

(2) the total costs of Open Source development increase by $c_{1} \cdot d a \cdot R$, and 
(3) the costs of in-house development decrease by $\bar{c} \cdot d \alpha \cdot R$.

Solution of the frm's problem depends heavily on revenue responsiveness to openness. First we examine the extreme case in which revenue does not respond to openness.

Differentiate Equation 5.1 to find the cumulative effect on the profits of the firm:

$$
\frac{d \pi}{d \alpha}=-\Psi(\alpha) \cdot R+(1-\alpha) \frac{d \Psi(\alpha)}{d \alpha} \cdot R+\left(\bar{c}-c_{1}\right) \cdot R
$$

Proposition 1 When the revenue per module is ficed $(\Psi(\alpha)=\Psi)$, the optimal strategy is to keep ald software features proprietary.

Proof. From Equation 5.2: $\frac{d \pi}{d l * x}<0$ when $\frac{d w(\alpha)}{d \alpha}=0$, so $\alpha^{*}=0$.

If revenues do not respond to openness, the firm would prefer to keep its features undisclosed. However, an observation in today's software market is that firms are changing (notably, increasing) the degree of openness in their software development. In the extreme, they can extract no revenues from Open Source software. Thus, a change in the degree of openness must be accompanied by a change in revenues of proprietary features to maintain the level of firm's profits. Following Equation 5.2, we identify the conditions on revenue responsiveness for which (partial) openness is applied by the firm.

Proposition 2 If $\frac{\partial \Psi}{\partial t x}>\left[\frac{1}{1-\alpha} \cdot\left(\Psi(\alpha)-\left(\bar{c}-c_{1}\right)\right)\right]$ at $\alpha=0$ and $\Psi(1)>\left(\bar{c}-c_{1}\right)$ then $0<\alpha^{*}<1$.

Proof. Find the terms in Equation 5.2 for which $\frac{d \pi}{d \alpha}>0$ for $\alpha \rightarrow 0$ and for $\mathrm{C}=1$.

An interesting benchnark then is the relationshp between $\alpha$ and $\pi$ such that prohts do not change as chunges.

Difterentiate Equation 5.1 and set to zero. Re-armang:

$$
\left.W(\alpha)\right|_{a=\alpha_{i}}=\left.(1-\alpha) \frac{d W(\alpha)}{d \alpha}\right|_{\alpha=\alpha_{1}}+\left(\bar{c}-c_{1}\right)
$$

Or:

$$
\left.\frac{d \omega(\alpha)}{\mathrm{w}(\alpha)+\left(\alpha-\alpha_{1}\right)}\right|_{\alpha=\alpha_{1}}=\left.\frac{d \alpha}{1-\alpha}\right|_{a=\alpha_{1}}
$$

By integrating the terms in Equation 5.4, we obtain a revenue function for stable profits.

$$
w^{*}(a)=\left(\bar{c}-c_{1}\right)+\frac{w}{1-a}
$$


where $\Psi_{0}$ is constant. By substituting Equation 5.5 into Equation 5.1 we can generate the non-negative profits constraint: $\Psi_{0}>\mathbb{C}_{1}$.

Following this line of discussion we can state

Proposition 3 If $\Psi(\alpha)$ is continuous and $\Psi\left(\alpha^{*}\right) \gtrless\left(\bar{c}-c_{1}\right)+\frac{c_{1}}{1-\alpha^{*}}$ then a frm operating with $\alpha=\alpha^{*}$ will increase (decrease) its level of openness,

Proof. As discussed above.

We can summarize these results briefy. If revenue is unresponsive to openness, software is only ever released as a proprietary product (Proposition 1). Further, if revenue responds slowly to openness, source code stays closed. However, if revenue is highly responsive to openness, the firm would open its source code. But since no revenue on fully open source is generated, part of the features remain proprietary (Proposition 2). When there is an exogenous change in the relationship between revenue and openness, Proposition 3 describes the conditions on the change such that a firm will increase or decrease its degree of openness.

\subsection{Forward-Looking Firms}

We extend the model to include intertemporal dynamics, keeping the basic terms and definitions of the previous model unchanged. ${ }^{12}$ Define $R(t)$ as the increment of quality of software in period $t$ from the addition of new features either by the users or by the firm. The frrm decides ex ante what share of features, $a \in[0,1]$, is developed as open source. The revenue received for a single proprietary feature changes with the degree of disclosure. In this dynamic seting of the model, we re-interpret $\Psi(\alpha)$ as the present discounted value of the gross revenue from a closed-sonrce module or feature. Thus, $\Psi(\alpha(t)) \cdot R(t)(1-\alpha(t))$ is the present discounted value (PDV) of the revenue from the technical advance in period $t$ :

$$
R V(t)=(1-\alpha) \Psi(\alpha) R(t)
$$

The total axpenditure of the firm on R\&D in period $t$ is allocated between development of open and closed sources:

$$
R D(t)=\alpha R(t) \cdot c_{1}+(1-\alpha) R(t) \cdot \vec{c}=\left[\vec{c}-\alpha\left(\bar{c}-c_{1}\right)\right] R(t)
$$

\footnotetext{
${ }^{12}$ The dymamics of the wo models represent, the behaviours of myopic and nom-myopic firms, as the forward-looking firm captures a multi-period problem in which the frm 1 einvests its profits in R\&D. Following this rationale, one cals also interpret the costs and the rewerues in the basic version of the model as present walues of cash flow.
} 
Assume that a constant share of firm's profits in each period, $\rho \in(0,1)$, is invested in $R \& D$ in the following period. ${ }^{13}$ Therefore, the total investments in R\&D are determined by the profits of the firm in the preceding period, $\pi(t-1)$, so $R D(t)$ is:

$$
R D(t)=p \cdot \pi(t-1)
$$

Subtract the cost of R\&D from the revenues of the firm (Equation 5.6) to obtain the PDV of features introduced in period $t$ :

$$
\pi(l)=(1-\alpha) \Psi(\alpha) R(t)-\left[\vec{c}-\alpha\left(\bar{c}-c_{\mathbb{1}}\right)\right] R(t)=(1-\alpha) \Psi(\alpha) R(t)-\rho \pi(t-1)
$$

Substitute Equation 5.7 into Equation 5.8 to obtain $R(t)$ as a function of the degree of openness, $\alpha$, and firm expenditure on R\&D in period $t$ :

$$
R(t)=\frac{R D(t)}{\bar{c}-\alpha\left(\bar{c}-c_{1}\right)}=\frac{\rho \pi(t-1)}{\bar{c}-\alpha\left(\bar{c}-c_{1}\right)}
$$

Substitute $R(t)$ into Equation 5.9 to obtain an intertemporal link between the firm's profits in successive periods:

$$
\pi(t)=\left[\frac{(1-\alpha) \Psi(\alpha) \rho}{\bar{c}-\alpha(\bar{c}-c)}-\rho\right] \pi(t-1)
$$

The firm's goal is to maximize the present value of its stream of profits. If $\delta$ is the discount factor, its objective function is

$$
\Pi=\sum_{t=0}^{\infty} \delta^{k} \pi(t)
$$

Equation 5.11 and 5.12 show that we can use a simple induction argument to find optimal levels of $\alpha$. In each period the firm's problem is identical to that of the previous period. The profits of last period $\pi(t-1)$, serwe only as a scaling facton in the optimization problem of period $t$. On the assumption that the system converges to a steady state, a simple induction argument shows that $\alpha^{*}$ is constant.

Differentiating $\pi(t)$ with respect to $a$ :

$$
\frac{\partial \pi}{\partial \alpha}=\frac{-\mu(\alpha) c_{1}}{\left(\alpha c_{1}+(1-\alpha) \bar{c}\right)^{2}}+\frac{(1-\alpha) \frac{\partial \psi}{\partial \alpha}}{\left(\alpha c_{1}+(1-\alpha) \bar{c}\right)}
$$

Following Equation 5.13 we can state

Proposition 4 If $\Psi(\alpha)$ is constant then $\alpha^{*}=0$.

${ }^{13}$ Empirical evidence supports the assumption that R\&D is a fixed proportion of profits. The intensity of R\&D in the French software and information sector is estimated to be $14 \%$ of their sales and is relatively stable over time (Abi-Saad et. al., 2001), 
Proof. If revenues are fixed with respect to $\alpha(\Psi(\alpha)=$ const.), then from Equation 5.13 we see that $\frac{\partial \pi}{\partial \alpha}<0$ and it is optimal for a fim to keep hll of its software proprietary $\left(a^{*}=0\right)$.

This proposition contains the apparent result that firms do not open their source in the short run, in order to make rapid advances, and then reap benefits in the future by closing their source. This is explaned by the fact that firms never generate revenues on modules that were developed in the open paradigm. Any module developed as open source is avalable to all competitors, and thus if there are potential revenues to that feature, all competitors will offer it, thus eliminating it as a source of product differentiation, and so eliminating revenues. Only features developed as closed source contain potential revenues. Rapid advances today do not result in higher revenues tomorrow in this model. For this sort of investment to be possible, the model would have to include some secondary effects of rapid advance, perhaps working through network externalities and a sufficiently rapid increase in installed base that there are market share effects. ${ }^{1.4}$

If the change in revenue per feature compensates for the change in the total income of the firm from modifying the open/closed mix (i.e. changing $\alpha$ ) then it is possible that it may be optimal for the firm to open its source. From Equation 5.13 follows:

Proposition 5 (a) If $\Psi(0) \geq\left[\frac{\partial \Psi(0)}{\partial \alpha} \cdot \frac{\bar{c}}{c_{1}}\right]$ at $\alpha=0$ then $\alpha^{*}=0$.

(b) If $\Psi(0) \geq\left[\frac{\partial \psi(a)}{\partial \alpha} \cdot \frac{\bar{c}}{c_{1}}\right]$ at $\alpha=0$ and $\Psi^{\prime}(1) \leq 0$ at $\alpha=1$ then $0<\alpha^{*}<1$.

Proof. See Appendix A.

Finally, in parallel with the analysis of the myopic firm, setting $\partial \pi / \partial \alpha=0$ in Equation 5.13 and solving for $\Psi(\alpha)$ gives

$$
\Psi^{*}(\alpha)=\left[\bar{c}+c_{1} \frac{\alpha}{]-\alpha}\right] \cdot \Psi_{0}
$$

If Equation 5.14 holds, then $\alpha^{\prime \prime} \varepsilon(0,1)$. "This gives us directly the following proposition.

Proposition 6 If $\Psi(\alpha)$ is continuous and $\Psi\left(\alpha_{1}\right) \gtrless\left[\bar{c}+c_{1} \frac{\alpha_{1}}{1-\alpha_{1}}\right] \cdot \Psi_{0} a t a=\alpha_{1}$, $a_{1}(0,1)$, then the firm will increase (decrease) its level of openness.

Proof. See Appendix A.

Propositions 2 and 5 , and Propositions 3 and 6 give different results for optimal amounts of openness and the critical openness-revenue relationship. These

\footnotetext{
14. On this issue see, for exarrple, Givon et al. (1995) and Laffont eb, al. (1998).
} 
differences are driven by the fact that in the myopic case (Propositions 2 and 3 ) the degree of technical advance is fixed each period and the R\&D expenditure varies, whereas in the non myopic case, since R\&D expenditures are determined by lasit period's profits, the reverse is true.

Notice that if revenues are fixed with respect to openness, technical advance is at a minmum $\left(\frac{\partial \pi}{\partial r}<0\right.$ in Equation 5.13 ; and technical advance each period, $R(t)$, is determined by profits the previous period: $R(t)=\rho \pi(t-1))$. However, if the goal is to maximize technical advance, the optimal development mode is entirely open source, which is approached if revenues increase rapidly with openness. It is almost certainly the case, though, that maximizing technical advance is suboptimal due to its effects on accelerating depreciation. Generating an interior amount of openness is desirable from a policy maker's perspective (driven by the view that some intermediate rate of technical advance will maximize social welfare) and has to be supported by a complimentary pricing mechanism whereby the effective revenue to a firm from an advance in its software's technical quality increases with openness, but only to a point. This is likely to be a non-trivial policy problem.

In the model developed above, it was not possible for a firm to capture revenues from anything developed in the open source mode. It could be, though, that due to reputation effects or packaging effects, a firm may be ablie to generate revenues on these features. This can be captured in the model by introducing the parameter $\Psi_{1}$. It is reasonable to assume that while $\bar{c}>c_{1}$ similarly $\bar{\Psi}>\Psi_{1}$. Clearly, if $\bar{\Psi}-\bar{c}<\Psi_{1}-c_{1}$ then the optimal strategy for any firm is to embrace open source for all of its development. The more interesting case is when $\bar{\Psi}-\bar{c}>\Psi_{1}-c_{1}$. In this case the analysis follows in a straightforward way, re-writing the revenue definition in Equation 5.6 as $R V(t)=\left(\alpha \Psi_{1}(\alpha)+(1-\alpha) \Psi_{2}(\alpha)\right) \cdot R(t)$. Still, however, no interior solution exists when revenues do not change with the degree of openness.

\subsection{Illustrating the Dynamics of Prices of Proprietary Sources}

The decision on the level of disclosure is largely affected by the pricing policy of the firm. In former sections of this chapter, we discovered that the firm's profits are closely correlated with the marginal price to disclosure ratio. Hence, the firm's pricing policy has a major effect on both the firm's strategy and profits. The pricedisclosure curve for forward-looking firms (Equation 5.14) is illustrated in Figure 5.2. For most values of $\alpha$, the marginal price of proprietary features increases very moderately. As a approaches 1 (full disclosure), the price increases very steeply. Further, the minimal price of proprietary features changes with the cost of in-house and Open Source R\&D. When the cost of developing software within 
the firm increases in comparison to the cost of Open Source projects, it would be harder for the firm to recover its expenses and it would choose to distribute larger proportion of its features as proprietary software. When the cost of developing Open Source features is closer to the cost of in-house R\&D (i.e. the ratio $\frac{E}{c_{1}}$ decreases), the the prices of proprietary features increases very rapidly for smaller values of $a$ and the firms would choose to disclose larger parts of its source code.

As concluded in Section 2 and 3 above, when the degree of disclosure increases, the price for proprietary features increases too (for both myopic and far-sighted firms). From a social welfare perspective, this is a conflicting situation. On the one hand, policy makers attempt to foster the diffusion of advanced technologies to increase the level of social welfare (in terms of the technical quality of the technology in use). Software developers are willing to offer larger shares of their products as Open Source in return for charging higher prices for a smallen share of proprietary features. However, higher prices will reduce the demand for advanced proprietary features and will hinder the adoption of the technology by many users who will favour partial functionality and less expensive products. On the other hand, policy makers perceive disclosure as a positive effect on innovation and technical change, as individual knowledge is shared among other users and firms. Further, Open Source communities can carry out trivial tasks and enable firms to utilize their resources by allocating more personnel to R\&D. Provision of price subsidy for proprietary features can increase both the diffusion of the technology and knowledge spillovers from Open Source products. The level of subsidy as a share of the price of proprietary features, $s(\alpha)$, can be determined as follows:

$$
s(\alpha)=\frac{\Psi(\alpha)}{\Psi(\alpha=0)}-1
$$

When the price of proprietary features increases, so does the subsidy $s(\alpha)$ for any value of disclosure. The subsidy curve shifts to the left as $c_{1}$ increases towards $\vec{c}$, and vice versa, suggesting that the subsidy will be higher when firms choose to develop more features in-house. Alternatively, this subsidy can deploy public support to Open Source communities to develop free-use alternatives.

The analysis of the links between disclosure, price and single-period profits in Section 2 reveals negative correlation between disclosure and profit when fixed prices are chosen (see also Fig. 5.4a). Howewer, when the price of proprietary features is selected as a function of $\alpha$, the result is a non-linear profit function,

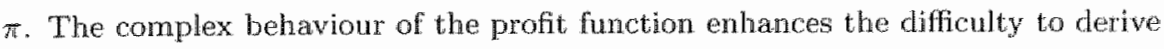
generic "rules of thumb" that will help policy-makers in steering the strategies of software firms, as non-linearity exists even in simple scenarios where the price $\Psi(\alpha)$ is a linear function of $\alpha$ (Figures $5.4 b$ and $5.4 c$ ). In some cases, as stated in 


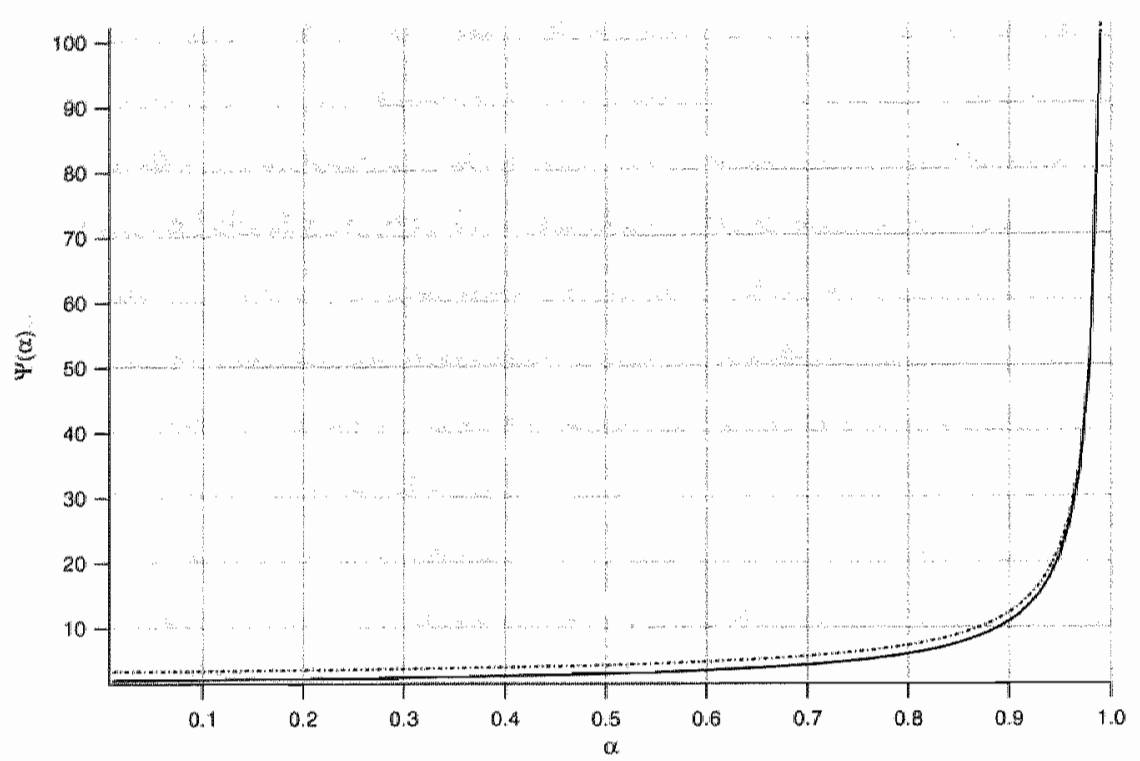

Figure 5.2. Minimal price of a proprietary feature as a function of the degree of disclosure for different ratios of development costs: $\frac{\bar{c}}{c_{1}}=2$ (continuous line) and $\frac{\bar{c}}{c_{\mathrm{l}}}=3.33$ (broken line)

Proposition 5(b) and exemplified by Fig. 5.4b, an intermediate level of disclosure (i.e. a software "hybrid") provides maximum profits, whereas full protection or" complete openness are less profitable.

\subsection{Discussion}

We have seen the strong result that in the model as described: The negative relationship between the degree of openness and profits implies that a profit maximizing firm will kep all its code proprietary. Yet, application of Open Source methodology gains popularity among commercial firms, which publicly release the source code of their products. What is their rnotivation?

In the model as developed, the increment to technical quality, $R(t)$, is determined simply by R\&D expenditure and the degree of openness since open source and proprietary soltware have different costs. But if open source has an independent effect on quality, if it is more reliable for example, as some suggest, then this would support an increase in revenue as the degree of openness increases.

A second explanation has to do with quantities. Implicitly, $\Psi(\alpha)$ is the revenue attributed to the current increment in technical quality. If an increase in openness increases sales, then $\Psi(\alpha)$ increases with $\alpha$. This is made stronger by the observation that for software goods, marginal cost is essentially zero, so average costs fall with output. The motivation for a firm to open its source code (apart 


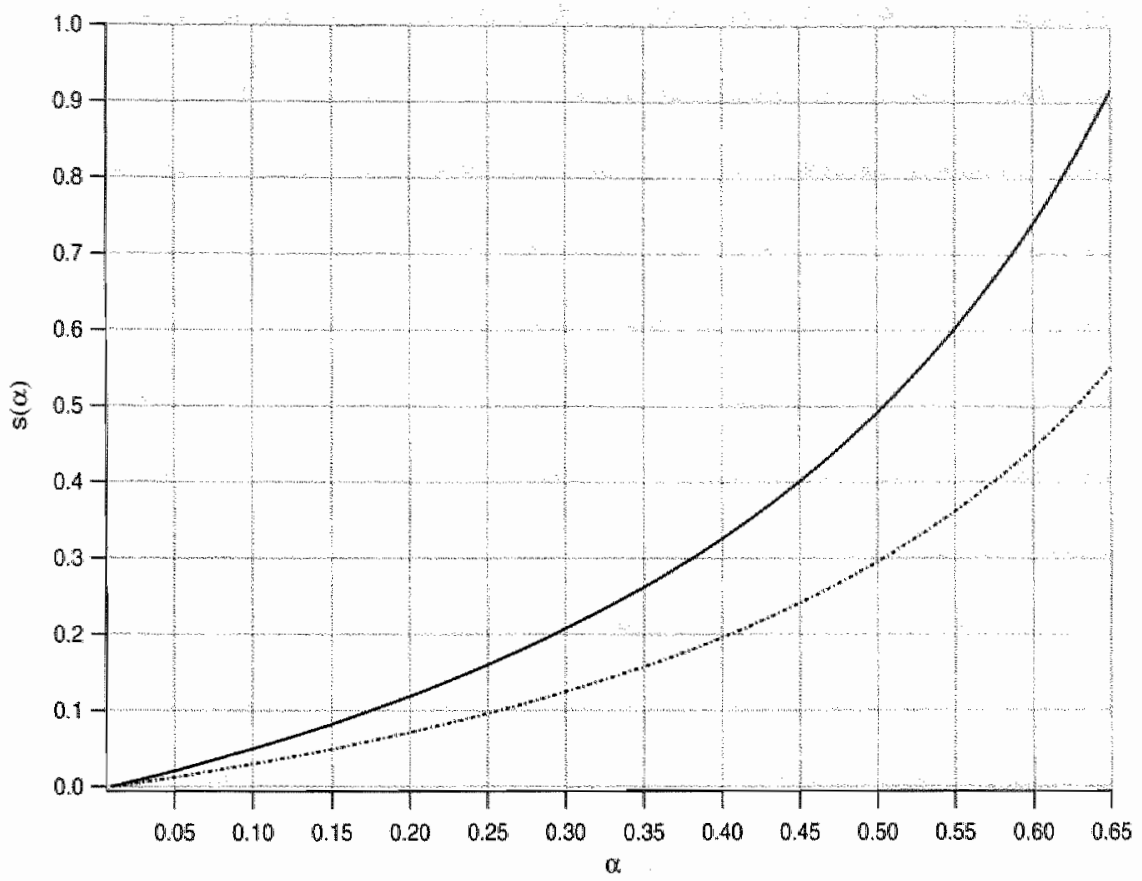

Figure 5.3. The level of subsidy as a function of the degree of disclosure for different ratios of development costs: $\frac{\bar{c}}{c_{l}}=2$ (continuous line) and $\frac{\bar{c}}{c_{1}}=3.33$ (broken line). $s(\alpha)=$ the increase in the price of proprietary feature.
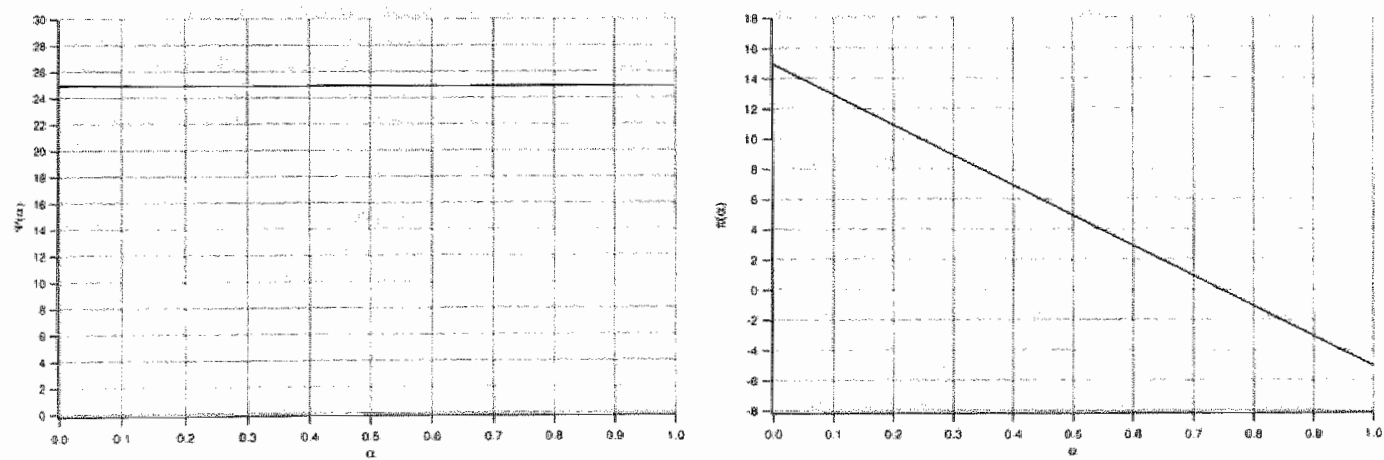

(Fig. 5.4a) 

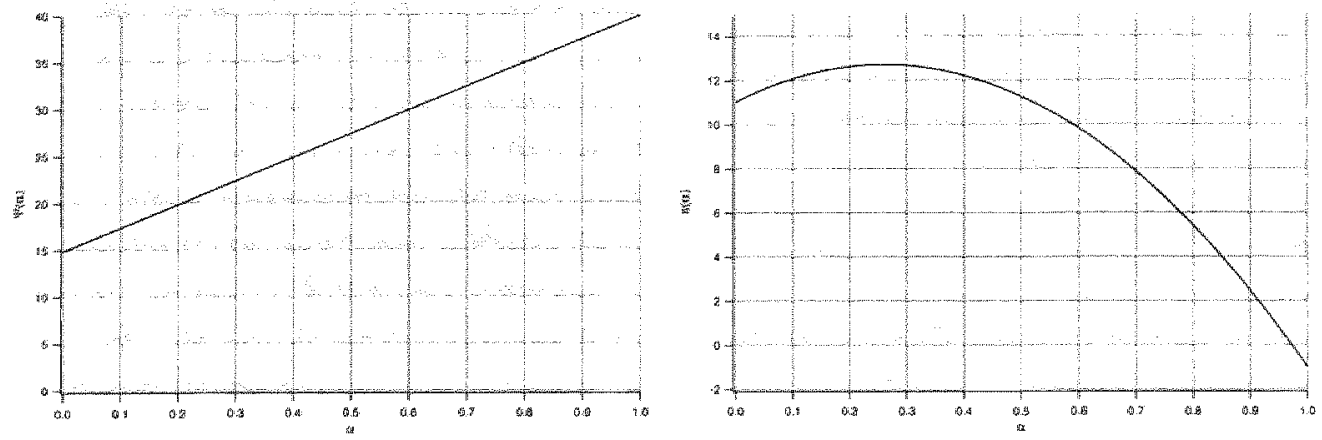

(Fig, 5.4b)
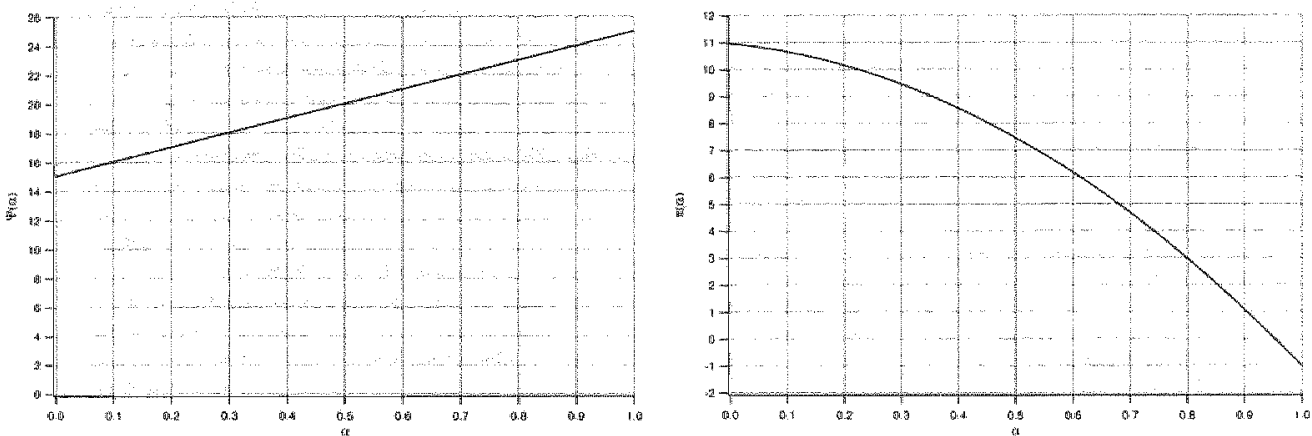

(Fig. 5.4c)

Figure 5.4. Myopic firm's one-period profits ( $\pi$ ) in various pricing strategies of proprietary features $(\Psi(\alpha))$ : (a) fixed price; (b) price increases with disclosure; (c) Price increases with disclosure (different set of parameters).

from potential threats from the Justice Department), can be to increase sales. In a larger model, in which network externalities would play a role in a competition for market share, firms are more motivated to choose Open Source strategies, as an incrasing market share could have the positive effect of locking a competitor out of the market and providing a monopoly in the future.

This chapter has presented a lower bound on the responsiveness of revenues to the degree of openness for software firms that choose strategic application of Open Source for their products. Critical in this bound is the difference in the costs of developing a module as open versus closed source for the firm. It is important to remember here, that open source development is not free, even though a significant proportion of the inputs are. We obtain a knife-edged result such that if the revenue increases rapidly enough with openness, the optimal strategy changes from entirely proprietary to a strictly positive degree of openness. Like most knife-edge results, this one is extreme, but it does suggest that following certain environment, changes in which it becomes possible to capture more revenues from open source or a reduction in the costs of open source development, we would 
expect to see firms that have historically been developing only proprietary software moving aggressively towards open source. ${ }^{15}$ We have seen this strong move from proprietary software to open source with, among others, IBM's Eclipse, Netscape's Mozilla project and Sun's move from Star Oftce to create Open Oflice. Using this idea as a base for further analysis, it is possible to purste the investigation of open source as a firm strategy. Understanding why firms engage in this strategy then devolves to understanding the mechanisms by which this strategy increases revenues or how the responsiveness of revenues rises above the threshold.

\subsection{Conclusions}

IPR regimes for software techmologies have evolwed since the mid 1980 s, aiming to resolve issues of piracy and unauthorized use by expanding the guidelines of traditional legislation, i.e. patents and copyrights, and by including information. technologies in their scope of protection. However, along the same period, alternative models of intellectual property use, based on the tradition of Free or Open Source, in which a rapid diffusion of unprotected software is used as the basis of a profitt-making venture have developed. The existent body of literature explores positive externalities in software piracy and infringements of intellectual property in computer programs. For example, emergence of network effects generates higher utility for users and expands the diffusion of software products among legal users and their propensity to pay for the product. However, this faculty of thought treats computer programs in a form of final products (i.e. compiled software packages) and does not evaluate the role of knowledge spillovers in advancing the technology, had the source code of computer programs made accessible to skilled users. Our model includes "production externalities", contributions of users to the technical quality and functionality of the software, positively comelated with the degree of openness. The model analyzes the relations between softwane protection, its price and firm's profits in markets of myopic and forward-looking firms. The first part of the model presents new insights on the links between openmess and firm's profits. When a fixed-price policy is applied for proprietary features, the correlation between disclosure and profits is negative. Firms would prefer to migrate from in-house development to open-source methodologies if higher profitability were guaranted. The model supports the rationale that firms prefer to apply the "bazaar model" of Open Source on the traditional modes of software development only if they expect ligher rewards than the gains from distributing proprietary products. Hence, our model approves the strategic rationale beyond firm's decision to disclose its main asset, the source code, in particular condi..

\footnotetext{
15 Note that incentives of firms to invest in R\&D are not endogenized in thigh model.
} 
tions. Further, when the price of proprietary features does not change with the degree of openness, complete protection is favourable in terms of firm's profits and technological performance. However, price dyramics depend on the difference between the costs of developing software as Open Source or in-house, among other attributes of firm's strategy. The closer those casts become, the higher the price of proprietary features is at any degree of disclosure. These results emphasize the complexity of the behawiour in markets of software technologies. Policies that aim at fostering technology by modifying pricing, R\&D costs and disclosure may divert the technological trajectory to different directions than meant. Hence, innovation. and technical change in ICT require an implementation of diverse and implausible approach towards software openness, rather than application of a general and somewhet sophistic framework. Another important lesson is associated with the nse fiscal tools to foster higher degrees of innovation and technical quality in software products. As the firm impels towards maximizing its profits in the short and in the long run, higher degrees of technical quality of soltware are achieved at the cost of lower openness of the source code. However, policy makers may maintain the pace of technological development by implementing subsidy schemes that elewate the demand of users for the non-disclosed share of the technology. By reducing the prices of proprietary features, e.g. by subsidizing directly the price of proprietary features, endowing firm's R\&D in return source code disclosure or by establishing free-software consortia, technology would progress more rapidly, as skilled users would devote skills and efforts to promote technical performance and quality of software technologies. 


\subsection{Chapter Appendix: Symbols Used in this Chapter}

\section{Parameters:}

$\bar{c}$ - Cost of developing a new feature in-house by the firm.

$c_{1}$ - Cost of developing a new feature via Open Source communities.

$\rho$ - Share of revenues invested in R\&D.

$\delta$ - Discount factor.

\section{Variables:}

$\alpha$ - Degree of software openness.

$a^{*}$ - Optimal degree of software openness.

$R$ - Incremental change in the technical quality of software.

$\Psi(\alpha)$ - Revenue of a proprietary feature.

$\pi$ - Firm's profits.

$R(t)$ - Incremental change in the technical quality of software in period $t$.

$R V(t)$ - Present discounted value of the revenue in period $t$.

$R D(t)$ - R\&d expenditure in period $t$.

II - Present value of firm's stream of profits.

$s(\alpha)$ - Subsidy for an Open Source feature. 
मै।

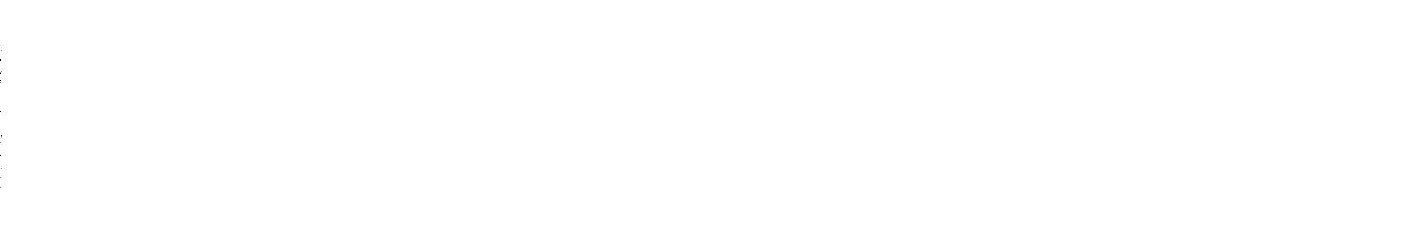
.

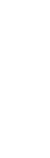

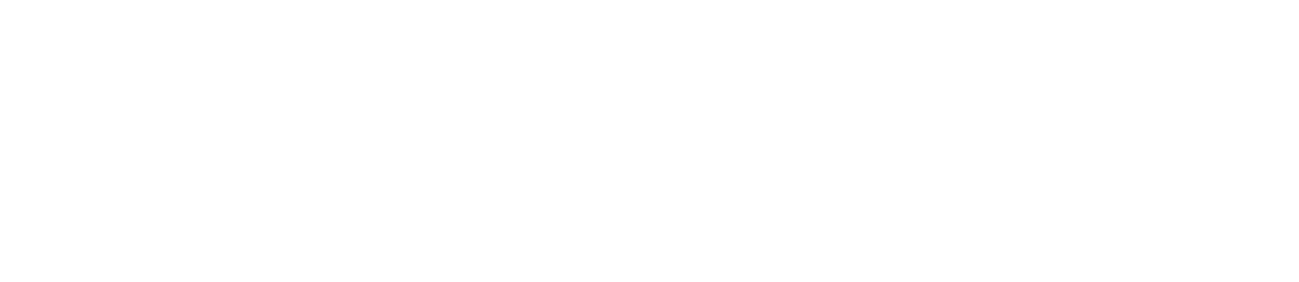


Designed for Innovation: The Structure of IPR Regimes and the Evolution of Information Technologies

\subsection{Introduction}

Innovation in software and information technologies is characterized by an ongoing process that produces variety of goods that differ in quality and performance. Most information technologies develop in a cumulative manner, as recent technical knowledge gradually builds upon prior know-how and is continuously applied in new products and contexts, whereas scientific and technological breakthroughs rarely occur (Scotchmer, 1991). "Empirical evidence describes the development of: most technologies as an evolutionary rather than a revolutionary process (Freeman and Soete, 1997). Technological breakthrowghs seem to be rave exceptions rather than the norm in the majority of techological fields.

The impact of innovation extends beyond new product versions and largely affects incumbent techrologies. In many technologies, including ICI, innovation. is described as a process of creative destruction in which new lechnologies evolve on the ruins of their technological predecessors (Schumpeter, 1975; pp. 82-85). Introduction of products with advanced features, higher quality and improved performance remowes older versions from the market.

Software developers contimuously release improved software versions during short and fixed periods. Major shares of users, in turn, upgrade their installed

The process of imnowation in other industrial sectors, such as consumer electonics (Wade, 1995), telecommunications (Maloney and McCormick, 1995) and autoriobiles (Kim. 1998) is similar to technological advance in information techologies. Howewer, mnovation in other industries, such as glass fabrication, is character of techological discontinuties (1.6. more significant and less fraguent improvenuents of the technology) (Anderson and Tushman, 1990). 
versions when improved applications are introduced. ${ }^{2}$ Alternatively, users can replace the installed software with rival programs.

The effects of sequential innowation and creatiwe destruction and their contribution to social welfare are somewhat ambiguous from the social planner's standpoint. On the one hand, continuous diffusion and implementation of improved products enhance economic efficiencies by providing better technical prospects, quality and performance. On the other hand, adoption of new technologies and. disposal of older products entail significant social costs.

The influence of creative destruction on the market is emphasized or restrained by the application of different IPR regimes. Theories of technological diffusion and economic growth show the significance of IPRs in stimulating innovation through disclosure of technical know-how and knowledge spillovers between firms (e.g. Mansfield, 1986; Dosi, 1988). The positive impact of the legal regime on innovation and technical change is encapsulated in fostering disclosure of novel technical knowledge through patenting.

Those desirable effects of the patent system on innovation and technologicall learning of imnovators ane offset by provision of temporary monopoly in the form of property rights over inventions for a long period. Firms, other than the patent-holder, are prohibited from exploiting protected know-how or even from introducing improved product versions, unless they significantly differ from patentprotected technologies. Consequently, firms that are engaged in R\&D activities enter patent races against rival developers, in which the first to innovate dominates the technology (and potential markets) for the patent's lifetime. Other firms can enter similar technological markets with competing products without infringing patent-holders' rights if they succed in "inventing around" patent-protected inventions and in developing distinguished product features that lie beyond the scope of existing patents. Alternatively, similar products can be released by rivals after patents expire, or via licensing protected inventions.

The case of software patents is of a particular interest. The inclusion of software and algorithms within the scope of patents by the USPTO propelled a contimuous debate on the contribution of patents to innovation and economic growth. The effects of the frequent changes in the patent policy were linked also to other sectors of the knowledge-based economy where computer programs are extensively used and may have major impact on the trajectories of recent technological developments, e.g. multimedia (Mansell and Steimmueller, 2000; Ch. 7), electronic commerce (Kuester and Thompson, 2001) and bioinformatics (Schonfeld and Restaino, 2002).

\footnotetext{
${ }^{2}$ In many cases, users must upgrade the software in use to maintain technical support.
} 
Further, intellectual property rights in software and infomation technologies have developed reactively rather than promactively. Legislation was adapted to single precedents and frequently lagged by more than a decade after technological advances (Cowan and Harison, 2001). As the "old" patent system has incrementally been modified in an attempt to fit to the characteristics of emerging technologies, historical effects created a regime partially mal-suited to the needs of new products and technologies (Dawid, 1993). Yet, the main issue whether IPRs may elevate or impede technological diffusion and innovation in software remains unresolved.

In the large body of legal literature on IPRs, contradictory arguments over the contribution of IPRs to inmovation persist. On the one hand, empirical evidence indicates high rates of software piracy world-wide, which result in lower levels of revenues and R\&D expenditure. On the other hand, imitation and reverseengineering entails the advantages of acquiring broader knowledge over a large number of product features. ${ }^{3}$ Moreover, patent protection of software technologies contributes to emergence of concentrated market structures. If firms cannot develop new features that exceed the patent-protected level of the technology, they are not allowed to release their products to the market. Firms that patent early inventions can prempt rivals from entering the market by suing them for infringing their patent rights, even though those firms have never exploited any protected inventions. Legal and economic scholars often argue that the development of information technologies is offset by a long patent duration and by a lack of novelty in many software patents that were issued by the USPTO. The value of patents is largely influenced by the ability of firms to gain exclusive rights over a variety of technologies and to control the access rights of competitors, and not necessarily by their innovative or technical properties. Consequently, peutentaholders are granted monopoly rights over a wide range of applications of their invention and minor changes in the structure of software patent claims can become a major vehicle for raising the value of patents, as "by understanding the clam styles... the practitioner can spend a few extra dollars and a few additional hours when initially drafting and prosecuting a software patent application to derive millions more dollars in walue from an issued software patent." (Witek, 1996).

Proposals for alternative regimes have aimed at balancing incentives for innovators against knowledge disclosure and at overcoming major shortcomings in the design of the present legislation by offering voluntary dismissal of intellectual property claims (e.g. the Open Source movement) or by modifying the existing Law. Samuelson et. al. (1994) propose enactment of swi-generis regimes, specially formed to provide software technologies and products with aclequate legal

\footnotetext{
See discussion in Chapter 3.
} 
protection. Marges (1999) applies a different approach and suggests to reform the adminustrative organization of the patent system and the examination process of patent applications in the USPTO with minute alterations of the present legislation to enhance the quality of software patents and to red uce the "error rate" of issuing inwalid patents.

The chapter aims at developing a coherent view of market dynamics and innovation by constructing a dynamic model of the market. The model simulates the interactions between sofware producers and users and their choices while developing and adopting new products. First, we review the methodology and provide formal presentation of the model. Then, we present the results of the model and assess the influence of different legal regimes on the pace of innovation, the market structure and the emergence of a domimant techmology. Finally, we draw conclusions and policy implications regarding the suitability of different IPR regimes to promote innovation in software and information technologies.

\subsection{Methodology}

We apply a multimeriod model to identify the links between the design of the patent regime and the evolution of software technologies and the market dynamics. Those attributes are projected and analyzed under different structures of the market and alternative designs of the legal regime.

In contrast to much of the literature on intellectual property rights and technology diffusion, this study emphasizes the heterogeneity of software users, and explicitly incorporates the technical performance of the technology into the decisions of both users and software producers with different levels of R\&D expenditure and technical know-how. Releases of new products and technologies create waves of creative destruction, as consumers prefer purchesing updated product versions over older generations of the technology (Aghion and Howitit, 1992).

On the supply side, firms can introduce their own product versions by devel oping them in-house or by legally imitating rival products (i.e. without infringing. valid patents of their competitors). Firms also patent their inventions if they achieve sufficient degree of technical novelty.

The design of the patent regime is defined by patent length (the duration of exclusive rights over inventions) and height (the minimal degree of technical advance required for granting new patents). The model represents the functionality and performance of software products through the level of their technical quality.

Among the key parameters that may largely affect both market dynamics and technical change is patent length. From an economic standpoint, patent length signifies the period in which exclusive rights over technical know-how are granted 
to patent-holders and in which patented knowledge, though disclosed to the public, cannot be applied by others. Lacking means to protect inventions and to appropriate from them, two types of market failure may appear: First, inventors would apply trade secrecy to protect their know-how and, hence, would impede the diffusion of new technologies. Second, frms failing to protect their inventions from imitation would choose to reduce or even to terminate their investments in R\&D.

The model builds upon insights from several literatures. First, zoftware innovation is highly evalutionary in that it tends to come in versions or generations, each being a modification of its predecessor. Consequently, early computer programs are substituted by advanced applications, and new products ofter dominate the whole market (Evans et. al, 2002). The technical quality of product features is described by a quality ladder, a continum on which products are represented and can be compared according to technological merit. A similar representation of products on a quality ladder appears in O'Donoghue et. al. (1998), where higher R\&D expenditure shortens the time between inventions. However, our model is loyal to the characteristics of the software development process and differs from O'Donoghue et. al.'s model in several aspects: Inventions and product improvements (albeit minor) are contimuously generated and released, whereas in O'Donoghue et, al. the time between inventions depends on firm's investment in R\&D.

In our model the firm's investments in R\&D are taken as a share of its revenues, and the size of technical progress increases with R\&DD expenditure. Consequently, decreasing revenues are followed by lower degrees of R\&D expenditure. This can result in lower innovative output of the firm in the short term. In the long term, lower levels of R\&D investments induce slower development of innovation and advanced technologies. Hence, the intensity of competition and the market share of the firm may largely affect its revenues and R\&D investments and the technological advances that the firm achieves. ${ }^{4}$

Our model captures the essence of product variety and the complexity of software technologies by defining a product as a set of multiple features. Every feature is positioned on a separate quality ladder. To compare, O'Donoghue et. al.'s model represents each product as a point on a single quality ladder. Products may have a relative advantage in some features while other features may be technically inferior to those of other products.

Innovation and firm's learning are of a continuous and cumulative nalure. Knowledge is accuired by firms, cached, and serves as a basis for generating new

\footnotetext{
${ }^{4}$ Conner and Rumelt (1991) base their analysis of piracy of software on a similar perception of the market.
} 
technological competences and advanced product features. The evolution of the technology is described in the nodel as an incremental process, in which technology endogenously develops through diffusion of improved product versions. ${ }^{5}$

Patents have a major impact on firm's strategic and competitive behaviour. Its abllity to compete with new product versions is restricted by the patent regime. Technical achievements and advanced product features can be produced as long. as no patents are infringed. Economists usually emphasize the role of patents in providing incentives to innovate in return for knowledge disclosure (see for example David, 1993). However, Green and Scotchmer (1995) suggest that a somewhat different approach should be taken while examining the effects of the patent regime on technologies characterized by cumulative and sequential innovation. In those techmologies, the profits of second-generation producers, who improve upon existing goods, generate higher profits than the inventors of those products. In many cases, second-generation producers directly compete with the inventors with advantageous product versions. Hence, the patent system functions as a profitsharing mechanism that ensures that inventors will be able to recoup their costs from second generation producers who benefit from their know-how. Thereupon, "W]hen innovation is cumulative, an important incentive problem is to ensure that each innovator is rewarded enough to take account of the benefits conferred on future innovators.. Intellectual property law has a rich set of policy levers, both for providing profit and for governing the division of it." (Scotchmer, 2005; pp. 170-171) Following this argument, the dimensions of the patent regime can be interpreted as follows: The minimal inventive step of patents ${ }^{6}$ provides the firstinventors with the right to block competitors who build upon their inventions and enables them to recoup their $R \& D$ investments, while patent length determines the period in which they are able to deter rivals from using and improving upon them. Despite recognizing cumulative innovation as a long term process that varies and significantly changes the technological landscape over time, most studies, inchuing those of Green and Scotchmer (1995), O'Donoghue et. al. (1998) and Denicoló and Zanchettin (2002) examine the innovative process via equilibrium-based models with homogeneous agents and two stages ("periods").

A large literature in industrial organization is used as a basis to represent the effects of IPR protection on different aspects of competition. Models of the patent regime provide a conceptalal framework through which use of IPRs to manipulate market position can be observed. Gilbert and Newbery (1982) explore within a

\footnotetext{
"A similar model was developed by Silverberg and Verspagen (1994) to assess how innovation and learning affect economic growth. Bessen and Maskin (2000) assess the influence of stronger and weaker patent a egimes on the development of software in markets with two symmetric firms.

${ }^{6}$ Scotchmer (2005) uses the term leading bneadth to describe the same parameter.
} 
static frame-of-analysis the relations between the structure of patent rights, the use of preemptive patenting to block new entrants, the level of R\&D expenditure and the resulting technical progress. Reinganum (1983) furthers Gibert and Newbery's basic model and compares $\mathrm{R} \& \mathrm{D}$ investments of an incumbent nonopolist (whose market position is empowered by patents or by other means) with those of a potential entrant ("challenger") in a game theoretic model with a stochastic inventive process. She concludes that incumbents are likely to invest in R\&D less than new entrants, due to their dominant position in the market. Hence, provision of expansive patent rights to incumbent frms would lower their propensity to develop new products and would preempt other firms from competing in the market and furthering technology. Klemperer (1990) and Gilbert and Shapiro (1990) present a neo-classical model with a tradeoff between patent length and breadth and discover the optimal patent design for different degrees of monopoly revenues (i.e. the innovator's expected "reward"). Green and Scotchmer (1995) assess the potential effects of the patent design (in terms of length and breadth) on the structure of the market and argue that broader scope enables first-inventors to proceed to developing the next stage of innovation without fearing fierce competition, as rivals are deterred from producing improved product versions that will infringe existing patents. Further, Merges and Nelson (1994) conclude that "there [is no] reason to believe that more narrowly drawn patents would have damped the incentives of the pioneers and other early comers to the field. In cumulative systems technologies, superior design, production, and marketing rather than strong patent protection, are the principal source of profit." (Merges and Nelson, 1994; pp. 21)

Our study develops a different approach that incorporates the essence of innovation in software technologies as a long term and cumulative process with the strategies of firms that operate within a technological, IP-protected environment. Therefore, the effects of legislation on innovation and market dynamics are investigated over long periods. The model is based on a dynamic framework that includes heterogeneous users and firms. Products include a set features anch represented through a set of quality ladders, which ensures variation of products, consumers" preferences and firms' choices. Innovation is represented as a long term and continuous process, in which technology gradually evolves over multiple periods, hence capturing events that are beyond the timeline of other models. Finally, the model explores how various structures of the patent regime and the market (defined by the number of fims) affect the evolution of information technologies.

The model provides a test-bed to explore the impact of different IPR regimes on the development of technology within a large variety of market terms and to assess how the evolution of information technologies is affected by the structure 
of the market and by the legal regime. The model entertains the possibility that regulators can change the dimensions of patents to enhance the degree of technological progress. It can also be employed to produce benchmark analyses of various designs of the patent regine under different degrees of competition.

\subsection{The Model}

\subsubsection{Description}

The model represents economy that includes several firms. Each firm continuously dewelops a single product that competes in quality and price. Technology is represented as a set of technicall features, and products are described by the technical quality of their features.

Demand arises from a large population of heterogeneous consumers with diverse preferences for the various product features. Preferences of users are represented by a vector of perceived qualities, the value given to product features by users. ${ }^{7}$ Users maximize utility by repeatedly choosing between upgrading the product in use and purchasing another product. They decide which software to use by comparing prices of products and the technical properties with their own preferences. ${ }^{8}$ The utility of consumers increases when the "distance" between the quality and their own preferences is lower, or" when the price decreases."

Every period firms improve one feature, which is selected by a rule of thumb based on an address model: Each firm calculates the average preferences of users and compares them to the quality its own product. Then, it chooses the least advanced feature in comparison to the average preference. Firms can improve the technical quality of features through internal R\&D, imitation, or application of patented know-how whose protection has expired. The amount dedicated to R\&D is taken as a fixed share of the revenues in the last period. Quzulity improvements are positively correlated with the amount of R\&D. Every period firms distribute installation versions and product upgrades and determine different prices for them.

Firms patent their inventions if they are sufficiently novel. We assume that the costs of patenting are marginal. Products with improved features are released when they do not infringe patents of other firms or when they are sufficiently novel (and then they are also patented). Otherwise, firms are prohibited from

\footnotetext{
${ }^{7}$ For example, some users would prefer purchasing a product, with detailed graphic interfaces, while others find those feature less important than advanced communication protocols.

${ }^{8}$ In some cases, newwork externalities are important for choosing technology. However, in this model they are ignored for the sake of simplicity.

DThe distance is determined by summing up the difference between user's preferences and the technical quality of features.
} 
disseminating products with improved features and must keep them as part of their internal know-how.

The following section provides formal presentation of the modal.

\subsubsection{The Market}

The model consists of $M$ firms. Each firm produces and distributes one product with $J$ technological features. $Q_{i j}(t)$ denotes the technical quality of feature $j$ of firm i's product that is released to the market in period $t . q_{i j}(t)$ measures technical know-how that remains in-house and is not embedded in its product. Hence, the total know-how of the firm is $\overline{Q_{i, j}}(t)=Q_{i j}(t)+q_{i j}(t)$.

Firms determine two price levels for their products: $\overline{p_{i}}(t)$ for installation version and $\underline{p}_{i}(t)$ for the upgrade. $\overline{p_{i}}(t)$ is bigger than or equal to $p_{i}(t)$, as the firm decides. Formally:

$$
p_{i}(t)=\left\{\begin{array}{ll}
\overline{p_{i}}(t) & , \text { if } I_{n}(t) \neq I_{n}(t-1) \\
\underline{p_{i}}(t) & \text {, if } I_{n}(t)=I_{n}(t-1)
\end{array} \quad\right. \text { (user changes the product in use) }
$$

where $l_{n}(t)$ is the product used by consumer $n$ in period $t$.

On the demand side, $N$ consumers with heterogeneous preferences repeatedly choose one of the products. Every period users may change the product in use or upgrade it. Each consumer's preferences are defined by vector $\vec{V}_{n}=\left(V_{n_{1}}, V_{n_{2}}, \ldots, V_{n_{J}}\right)$. Heterogeneity enters here as different consumers have different preferences, formalized by set of $\vec{V}_{n}$ and distributed as $J$-variate nomal.

The decision which product to adopt is taken on the basis of quality and price. Users measure the distance $d_{i n s}(t)$ between their preferences and the quality of products or altematively, the extent to which their "desires" are not satisfied:

$$
d_{i n}(t)=\sum_{j=1}^{J}\left[V_{n j}-Q_{i j}(t)\right] \quad, \forall V_{n j j}>Q_{i j}(t)
$$

The utility that consumer $n$ derives from product $i$ is based on the distance between her preferences and the quality of the product (Eq. 6.2) and on the price (Eq. 6.1):

$$
U_{n, 1}(t)=\sum_{j=1}^{J} V_{n j}-d_{i n}(t)-p_{i}(t) \quad, \forall n \in N
$$

Consumer $n$ chooses product $I_{n}(t)$ that maximizes her wility. Therefore: 


$$
I_{n}(t)=\arg \max \left[U_{n}(t)\right] \quad, \forall t \in I, n \in N
$$

The revenues of firms are directly determined by the purchasing decisions of useris ( Fing. 6.4):

$$
R_{i}(t)=\sum_{n=1}^{N}\left[p_{i}(t) \cdot w_{n_{2}}(t)\right]
$$

Where:

$$
\left(\omega_{n}(t), p_{i}(t)\right)= \begin{cases}\left(1, \overline{p_{i}}(t)\right) & , \text { if } I_{n}(t)=i \text { and } I_{n}(t) \neq I_{n}(t-1) \quad \text { (change of product) } \\ \left(1, p_{i}(t)\right) & , \text { if } I_{n}(t)=I_{n}(t-1)=i \quad \text { (upgrade) } \\ (0,0) & , \text { if } I_{n}(t) \neq i \quad \text { (otherwise) }\end{cases}
$$

\subsubsection{Firms and Technical Change}

Technology continuously evolves by building upon prior inventions. Firms develop new competencies that result in new features that are acded to recent product versions or kept as proprietary know-how within the organization.

Every period firm $i$ improves the least advanced feature, $j_{i}^{*}$, by comparing product quality to the average preferences of users, $\overline{V_{j}}$ :

$$
j_{i}^{*}(t)=\arg \max \left[\overline{V_{j}}-Q_{i j}(t-1)\right] \quad, \forall \overline{V_{j}}>Q_{i j}(t-1)
$$

Where:

$$
\overline{V_{j}}=\sum_{n=1}^{N}\left[V_{n j} / N\right] \quad, \forall j \in J
$$

The firm can further the quality of its product in one of the following ways:

(i) carrying out independent research and development (see section 6.3.4),

(ii) legal initation of rival products (see section 6.3.5).

or"

(iii) acquisition of knowledge from expired patents (see section 6.3.5).

Firms compare the expected quality improvements that can be achieved in each way and choose the optimal method to acquire knowledge. Denote the maximal expected improvement $E \Delta Q_{i j}(t+1)$.

The pricing mechanism is based on the expected improvement in the firm's product and in the products of its rivals. First, the firm predicts the expected 
quality of its product in the following period by summing up the present quality level and the expected improvement in quality. Second, it assesses the quality improvemerts of its rivals, taking into account their expected investments in RSD (a fixed share of their revenues), their ability to imitate rival products or to learn from patents. Third, it calculates the utility of the "average user" from purelasing other firms' products. Finally, the firm determines a competitive price, for which the utility from purchasing its product will surpass the maximal expected utility gained from using other products. Each firm repeats this process for users of its product ("loyal users") and for consumers of rival products ("potential custoners").

Formally, the price of new product is determined as follows:

$p_{i}(t+1)=\sum_{j=1}^{J} \overline{V_{j}}-\overline{d_{i}}(t+1)-\max _{k \neq \neq} E U_{k}(t+1)=\sum_{j=1}^{J} Q_{i j}(t)+E \Delta Q_{i j}(t+1)-\max _{k \neq i} E U_{k}(t+1)$

We assume that the costs of production and distribution per product mit are equal to zero. R\&D expenditure is taken as a fixed share of the revenues, $\rho<1$.

From Equation 6.5, the expenditure of firm $i$ on acquisition of know-how is

$$
R D_{i}(t)=\rho \cdot R_{i}(t-1)=\rho \cdot \sum_{n=1}^{N} I_{n}(t) \cdot p_{i}(t)
$$

and its profits are

$$
\pi_{i}(t)=(1-\rho) \cdot R_{i}(t)=(1-\rho) \cdot \sum_{n=1}^{N} I_{n}(t) \cdot p_{i}(t)
$$

\subsubsection{Innovation via Independent R\&D}

Technological progress is positively correlated with R\&D expenditure (Klette and Griliches, 1998) and the onemperiod progress rate is normally distributed (Arora. et. al., 2003): $:^{10}$

$$
\left.\xi_{i j_{i}^{*}}(t) \sim N\left(f_{a}\left(R D_{i}^{\beta}\right), \zeta\right)\right) \quad, \forall i, j
$$

where $\beta$ is the elasticity of innovation with respect to R\&D.

New inventions increase firm $i^{\prime}$ 's internal know-how by $\xi_{i i_{i}^{*}}(t)$ :

\footnotetext{
10rThe simulation runs are based on $\beta=0.65$, estimated for computers and office aquipment by Arora et. al. (2003).
} 


$$
q_{i j}^{*}(t)=q_{i j}^{*}(t-1)+\xi_{i j} j_{i}^{*}(t) \quad, \forall i, j_{i}^{*} \in J
$$

Product quality improves when advanced features are produced on the basis of in house knowledge and relexsed without infringing patents:

$$
Q_{i j}(t)=Q_{i j}(t-1)+Q_{i j}(t)
$$

The firm then begins in augmenting new know-how, therefore $q_{i j}(t)=0$.

\subsubsection{Patents, Imitation and Release of New Products}

The model simulates a market with firms that operate under different patent regimes. Firms protect new inventions by patents when their technical quallity exceeds the minimal inventive step over the most advanced technology. Products are released to the market when they do not infringe living patents (i.e. when other firms' patents have expired, when the firm was granted patents over the features or when they are sufficiently novely. Otherwise, technical know-how is angmented and remains proprietary within the firm. Firms can improve their products by developing them in-inouse, by imitating unproteced features of their rivals or by implementing knowledge disclosed in patents that have expired.

Both patent duration, $L$, and the minimal inventive step, $s$, are exogenous parameters, determined by regulators. Sirnulations cover a range of designs of the legal regime with $L=0 . L_{\max }$ periods and $s=0 . s_{\text {max }}$ quality units. We then compare the resulting patterns of quality, $Q_{i y} \mid\left(L^{*}, s^{*}\right)$, under different patent regimes.

A feature can be protected by several patents, each patent being granted over and protecting a particular part of the techology, $\left[Q_{p_{\text {min }}}, Q_{p_{m a x}}\right]$, for $L$ periods. ${ }^{11}$

Patenting is possible if inventions are sufficiently novel, i.e. when the technical quality exceeds the inventive step over the patented quality level, either when former patents are still valid or have already expired. Formally, firms can patent technical advances when $Q_{i j}(t-1)+q_{i j}(t) \geq Q_{j p_{\text {rax }}}+s$. When a patent is granted, the firm can embed it in its product and release an improved version to the mariket.

A firm can release product with minor improvements when that firm improves upon product features which it patented before (i.e. $Q_{j w_{\max }}<Q_{i j}(t)+q_{i j}(t)<$

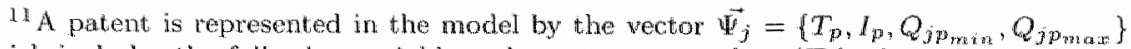
which includes the following variables: the patent grant date $\left(T_{p}\right)$, the index of the inventing firm $\left(Q_{p}\right)$ and the protected technological parcel $\left(\left[Q_{j p_{m i n}}, Q_{j p_{m a x}}\right\rangle\right)$. We assume no difference between the grant, cate, $T_{p}$, and the application date.
} 


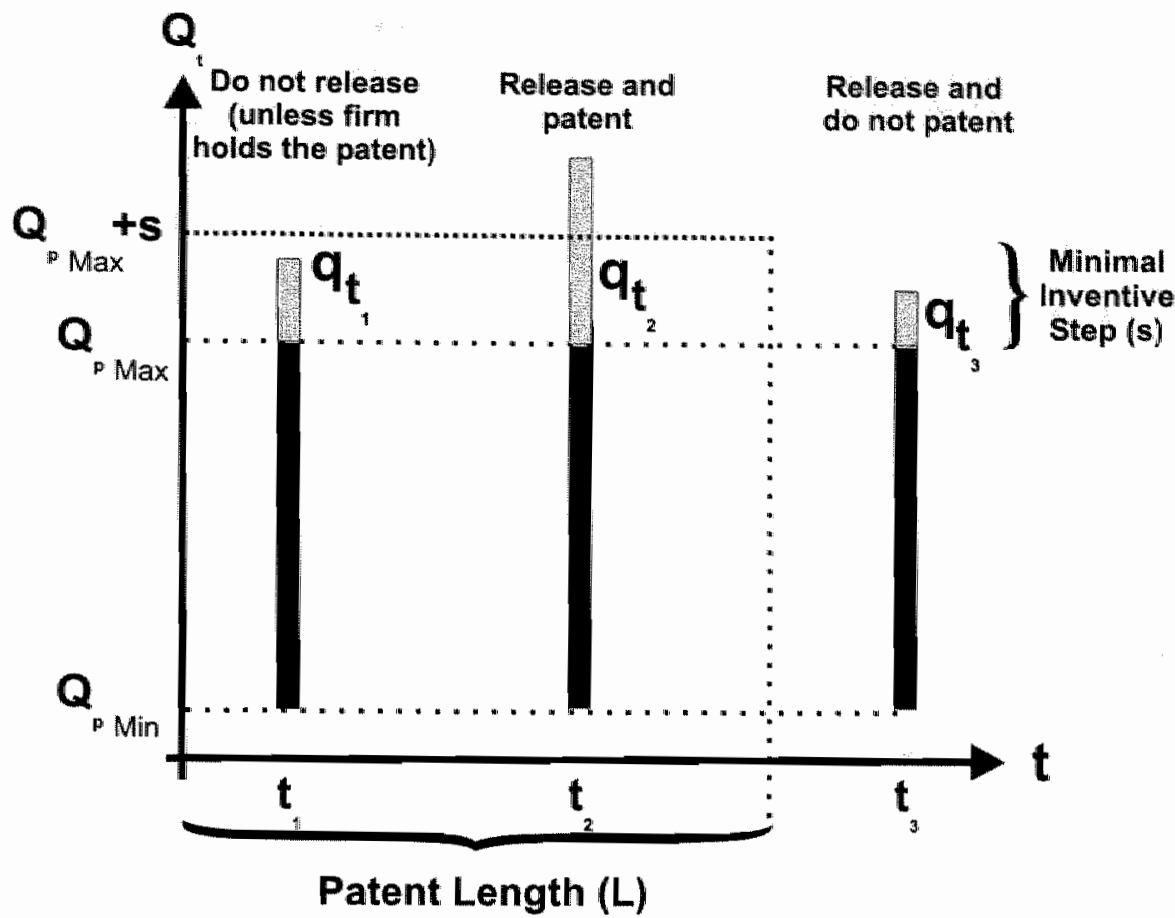

Figure 6.1. Possibilities of patenting and releasing new features.

$Q_{j p_{m a x}}+s i=I_{p}$ ) or when patents held by rivals have expired (i.e. $Q_{i p_{\text {max }}}<$ $\left.Q_{i j}(t)+q_{i, j}(t)<Q_{j p_{\text {max }}}+s \mid t>T_{p}+L, i \neq I_{p}\right)$. When an improved version. of product $i$ is released, the quality of feature $j$ increases. Formally: $Q_{i j}(t)=$ $Q_{i j}(t-1)+q_{i j}(t)$. Otherwise, the technical quality remains unchanged.

Fig. 6.1 illustrates the possibilities of firms to protect inventions by patents and to use them in mew product versions. Assume that a patent over a feature was granted to Firm $A$ in period $t=0$. The quality segment protected by the patent is $\left[Q_{p_{\text {min }},}, Q_{p_{\text {max }} x}\right]$ (dark bar). Firm $B$ develops a competing product that improves Firm A's good by $q B$ units (gray bar).

We consider three possible scenarios that involve Firm A's patent and Firm B's product:

In the first scenario, Firm B invents within the period of patent protection (e.g. in period $t_{1}<L$ ) and its invention fails to present sufficient degree of novelty, i.e. $Q_{B}\left(t_{1}\right)+q_{B}\left(t_{1}\right)<Q_{p_{\text {mat }}}+s$. Firm B can neither release an improved product without infringing Firm A's patient, nor protect its invertion.

In the second case, Firm $B$ produces a sufficiently novel invention with a quality level that exceeds the minimal inventive step, $Q_{B}\left(t_{2}\right)+q_{B}\left(t_{2}\right) \geq Q_{p \text { prat ax }}+s$ before Firm A's patent expires (e.g. in period $t_{2}<L$ ). Firm $B$ will receive a new patent that protects the segment $\left[Q_{2} \mathrm{y}_{\max }+s_{1} Q_{B}\left(t_{2}\right)+q_{B}\left(t_{2}\right)\right]$ for the period 
$\left[t_{2}, t_{2}+L\right]$. Firm A will be prohibited from introducing a product with quality level $\left(Q_{\text {prom }}+B_{3} Q_{B}\left(t_{2}\right)+q_{B}\left(t_{2}\right)+s\right]$ as long as Firm $B$ 's patent is valid.

In the third case, Firm $B$ invents after Firm A's patent has expired (e.g. in period $t_{3} \geq L$ ). An improved version of Firm B's product can be released, but it cannot be patented if its quality does not exceed the minimal degree of novelty, $s$.

\subsection{The Simulation}

The set of results describes the evolution of technologies and the innovative output of firms under various structures of the patent regime and the market. The results of the model were obtained for 1000 consumers with normally-distributed, heterogenous preferences. The series of simulation runs were accomplished with five, ten and twenty firms to explore how the links between the patent regime and the level of technical quality vary under different scales of competition. Each firm produces a product with fifteen technical features. Following the statistics on R\&D expenditure in French software firms (Abi-Saad et. al., 2001), we set the share of revenues dedicated to $R \& D, \rho_{3}$ equall to $15 \%$.

The results were recorded for different patent durations that vary from zero to thirty periods and for inventive step that varies from one to fifty quality units. Since quality improvements are normally distributed, they produce some degree of a Gaussian noise. We apply nonparametric kernel regression as a statistical smoothing technique that reduces the noise-to-wave ratio. The kernel regression implemented a bivariate box-smoothing filter with an optimal bandwidth to guarantee high degrees of accuracy of the data transformations. ${ }^{12}$

\subsection{Results}

Figures $6.2 \sim 6.4$ describe the results of the simulation model on three-axes. The independent variables (inventive step and length) are represented by the $(x, y)$ axes. The dependent variables (average quality, quality variance and the share of developing firms) are described by the gray scale.

Analyses of the average quality of product. features reveal strong links between the different dimensions of the patent regime and the evolution of technology under warious market structures. Fig. 6.2 illustrates the average quality in markets with five, ten and twenty firms. The effects of different structures of the patent regime on technology are more significant in competitive markets than in less competitive economies. Comparing Fig. $6.2 \mathrm{c}$ with Fig. $6.2 \mathrm{a}$ and $6.2 \mathrm{~b}$, we can state:

\footnotetext{
3)

${ }^{12}$ A detaled description of the method is found in Bowman and Azzalini (1997; Ch.
} 
Proposition 7 Qwality rises with the number of competing frrms.

The impact of differences in the design of patents on technical quality is found to be insignificant in markets with a small number of firms (Fig. 6.2a). Innovation is infuenced, to some extent, by different structures of the legal regime in markets with intermediate levels of competition (Fig. 6.2b). However, the structure of patents has prominent effects on innovation and technological development in competitive markets (Fig. 6.2c), which are described and analyzed in the course of the discussion. In this respect, Fig. $6.2 \mathrm{~b}$ illustrates an intermediate situation between markets with minor degrees of competition, where patents have small impact on firms, and competitive markets, where the impact of the regime is stronger.

Following the comparison between the average quality levels obtained under different structures of the patent regime, we observe that

\section{Proposition 8 :}

a) Quality increases when patent duration decreases, ceteris paribus.

b) Quality increases with minimal inventive step, ceteris paribus.

Proposition 8 stands in contrast to the widely-accepted rationale and of the patent system offered by reward theory. Reward theory suggests that firms' investments in $\mathbb{R} \& D$ increase with patent duration and, consequently, the technical quality improves. The results of the model indicate that patents with shorter duration are better suited to support technological development. The highest scales of technical quality of products are achieved when short patent durations (one to three periods) are applied for any degree of the inventive step. Reward theory suggests that extended patent term increases the incentives of firms to engage in $\mathbb{R} \& D$ activities, as inventors will generate monopoly revenues over longer periods, will be able to recoup their prior investments in $R \& D$ (see Nordhaus, 1969; Scherer, 1972; Nordhaus, 1972). The results of our study illustrate how the negative effects of elongated monopoly over technologies overturn and exceed the benefits of long term revenues and protection. Using Nordhaus' terminology to describe the impact of the legal regime on innovation, extended patent duration narrows down the invention possibility function of firms rather than expanding it as Nordhaus suggested. Further, one may recall the debate between Klemperer (1990) and Gilbert and Shapiro (1990) over the desirability of infinitely-living patents. From the results of our analysis we conclude that long, or even intermediate patent durations would hamper innovation; the highest degree of technical quality is achieved when short-termed patents are applied.

Patentability of small improvements (i.e. patents with small inventive step) impedes the pace of innowation, as firms are deterred from exploiting their own 
technological advances for long periods. Consequently, firms that operate under this structure of the patent regime are poor performers in terms of achieving high levels of technical quality, in comparison to other markets. Hence, legislation that enables patenting of small technological advances harms innovation in the long run, rather than contributes to it.

Proposition $\mathbf{9}$ When patent length increases, the minimal inventive step should increase to matritain the level quality.

And similarly:

Proposition 10 When the minimal inventive step decreases, patent duration should be shortened to maintain the level of quality.

Fig. $6.2 c$ provides an interesting result by revealing close links between patent length and the minimal imventive step. Intermediate levels of technical quality are achieved when short term protection with small inventive step is applied. Those degrees of quality remain unchanged if the minimal inventive step increases when the duration is extended. Those findings highlights a trade-off between patent length and imventive step. Klemperer (1990) and Gilbert and Shapiro (1990) suggest that narrower patent scope substitutes for longer patent duration, and vice versa, to maintain the amount of incentives (and revenues). However, their analyses refer to the breadth of patent claims and to possible extension of patent protection to neighbouring technologies and applications, rather than to patenting large or minor technological advances. Van Dijk (1996) discusses another tradeoff between patent breadth and inventive step ("height") and possible designs of patient regime that yield optinal degrees of innovation. Therefore, the findings of the model, stated in Propositions 9 and 10 , affirm the presence of another tradewoff between patent, length and inventive step, overlooked by other studies.

The variance of technical quality serves as a measure for the degree of competition between firms and for their ability to "catch-up" with rival technologies. Fig, 6.3 illustrates how the quality variance in each market differs under various patent regimes (dark regions represent high scales of quality variance). Following the results of the analysis, we can state:

Proposition 11 Technical quality decreases and its variance increases as markets become less competitive under long-term patents with small inventive step.

Merges and Nelson (1990) argue that higher levels of competition are necessary to produce technological progress. Rivalry between firms maintains the 
diversity of products and techniques and fosters the creation of new goods, upon which advanced features can be furthered or devised. Their views are supported by empirical exidence from the early days of the radio and aviation industhes. Therefore, they advocate the enactment of a patent regime that does not impede entry of firms and assures ongoing competition with incumbent firms. The authors arrive to the same conclusion as Proposition 11, despite the differences between software and physical products in the nature of goods, frequency of new releases and product life cycle.

As Proposition 11 indicates, high levels of variance in the quality of products appear when long-living patents are granted to minor advances (upper-left corner of Fig. 6.3). This result persists for any number of firms that operate in the market, but is stronger as the number of firms increases.

The differences between products are influenced by the design of the patent regine and do not result from diverse strategies of product differentiation that firns apply (firms use the same average consumer profille and rules to determine which product features should be improved). Longer patent term and smaller inventive step foster introduction of more diverse products. However, Fig. 6.2 reveals that the scales of technical quality under this patent regime are significantly lower than under different patent designs. The graphs indicate the emergence of non-competitive market structures, assisted by strong IPR regimes, as firms are able to monopolize larger fragments of the technology for longer periods. Patents with long duration and small inventive step impede the efforts of firms to follow technological leaders and, over time, to introduce their own advances and produce negative externalities for innovation.

Following the behaviour of firms under different structures of the regime (Fig. 6.4), we conclude:

\section{Proposition 12 :}

a) The propensity of firms to imitate (to innovate) increases (decreases) with the minimal inventive step.

b) The propensity of firms to imitate (to inmovate) decreases (increases) with patent lifetime.

When the duration of patents is shortened and/or the inventive step increases, i.e. patenting becomes more difficult and patents protect inventors for shorter periods, the number of developers goes down and more firms would prefer imitating rival products on investing in developing their own technologies (Fig. 6.4).

Further, following Fig. 6.4, when small improvemenis are protected by patents for long periods (i.e. $L$ is high and $s$ is relatively small), internal R\&D is favoured 


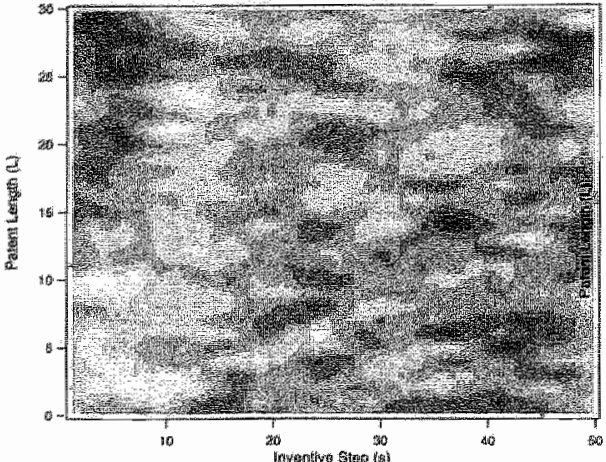

(5 firms)

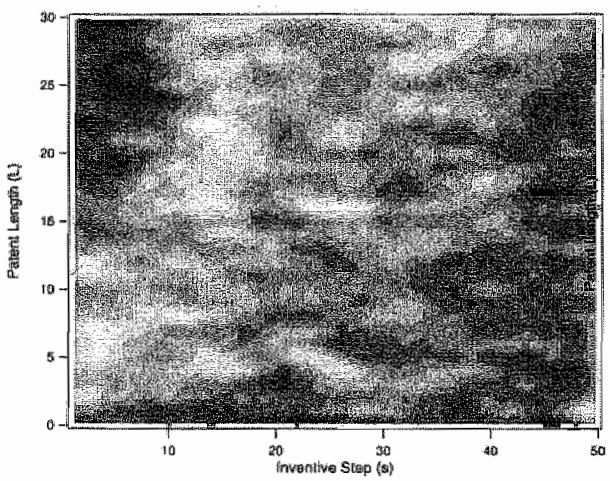

(10 firms)

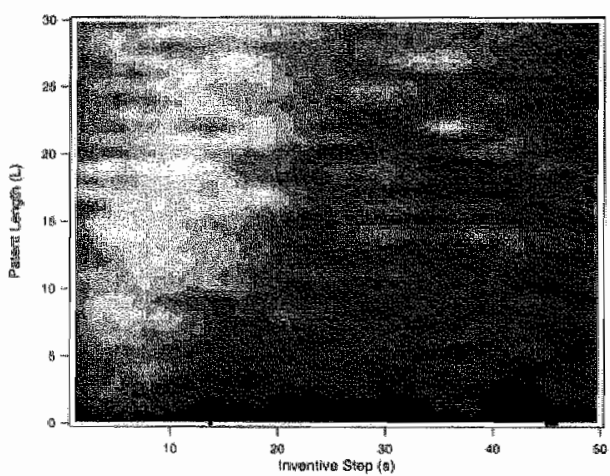

\section{(20 firms)}

Figure 6.2. Normalized average technical quality under different IPR regimes after 50 periods.
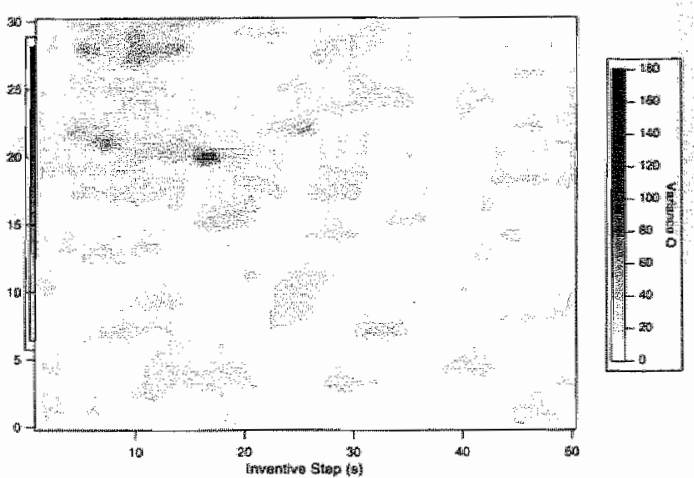

(5 firms)

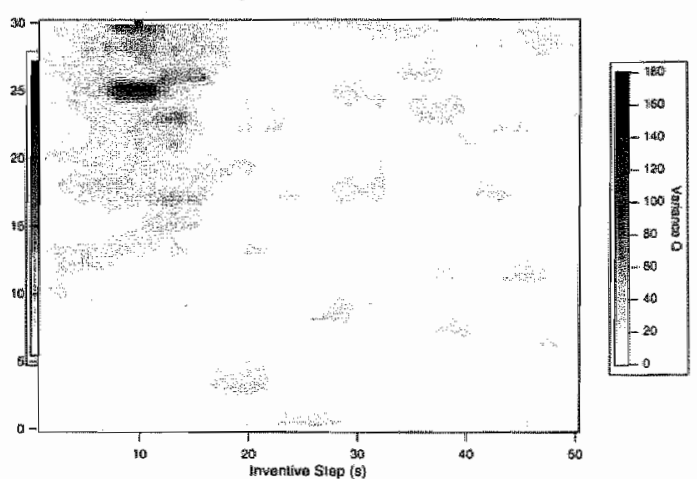

(10 firms)
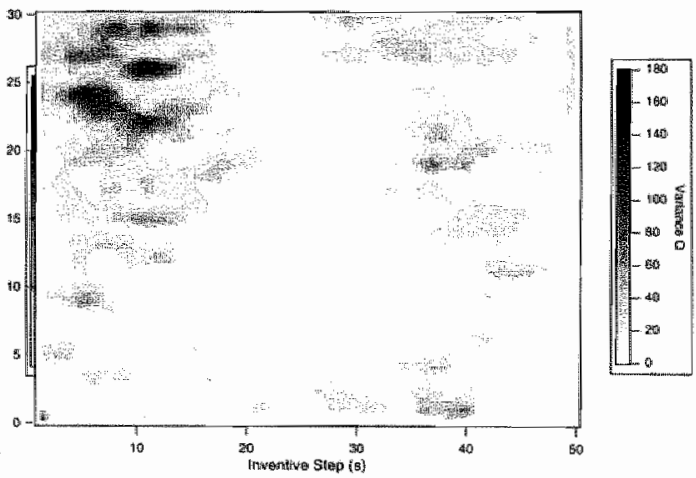

\section{(20 firms)}

Figure 6.3. Variance of the technical quality under different IPR regimes after 50 periods. 

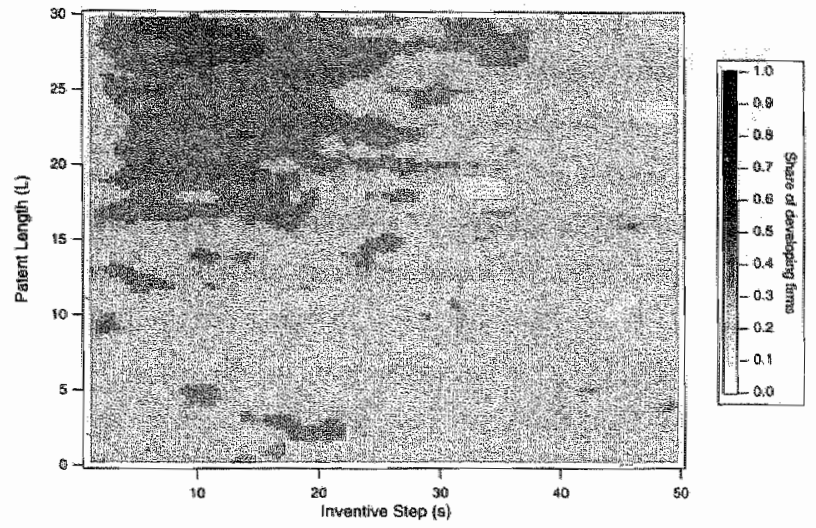

(5 firms)
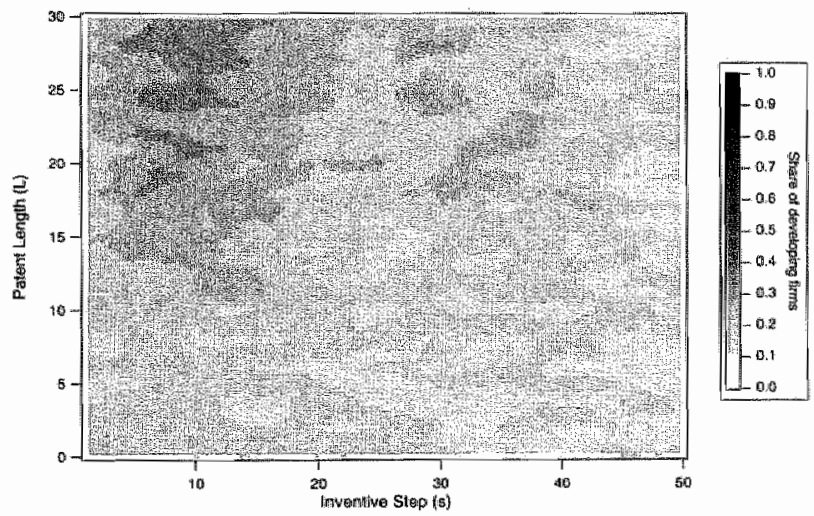

(10 firms)

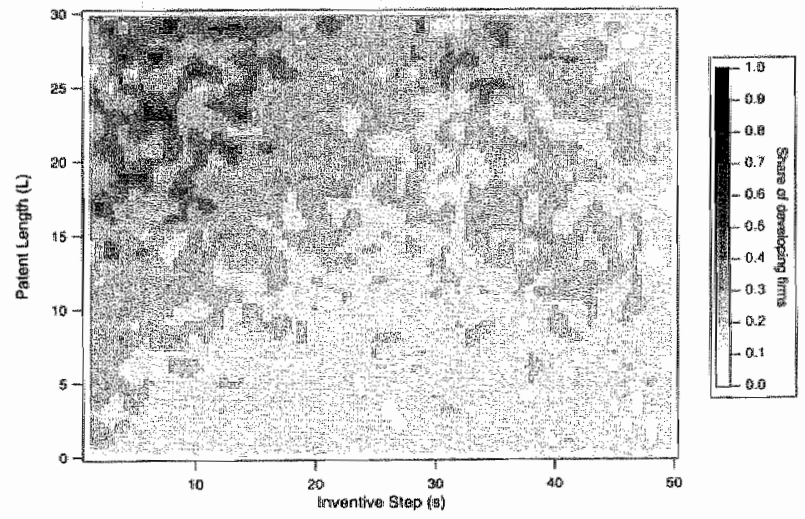

\section{(20 firms)}

Figure 6.4. The share of developing firms over time $(t=1.50)$, 
over imitation. The propensity of firms to patent increases when the inventive step decreasses, even though rival frms are able to exceed smaller inventive step to overcome vallid patents and to be granted patents for their own advances. In this case, the previous patent-holder can continue to compete efficiently with the new patentee as the "second-best" (since the differences in technology between the two firms can be relatively minor, considering the small inventive step), while preempting technological laggards from acquiring dominated market shares.

\subsection{Conclusions}

The clapter evaluates how alternative structures of the patent regime affect innovation in information technologies by using simulation of the market and the patent regime. On the one hand, lack of protection fosters knowledge spillovers and development of superior technologies by riwals. However, high scales of imitation remove part of a firm's revenues and lower its propensity to invest in R\&D. On the other hand, stronger patents provide higher incentives to innovate, but restrict the access to recent developments.

Following the results of the model, we conclude that firms operating under less protective regimes are more innovative and produce higher quality products, despite imitation by the majority of firms. On the extreme, if patents are granted to minor improvements and protect them for long periods, rival firms will be preempted from introducing advanced product versions and from furthering the technology. This regime is clearly over-protective, as it provides excessive monopoly rights over inventions and results in inferior technological performance of firms in comparison to less protected markets.

Interpretation of the results of the model leads to an inevitable conclusion that "real world" patents, whose duration is twenty years (both in Europe and in the U.S.) most probably hamper the development of technologies at any degree of the inventive step. The inclusion of software within the scope of protection of patents during the 1980 s has slowed down the pace of development in information technologies. However, complete ebolition of patent protection for software technologies $(L=0, s=0)$ is not desirable and may yield non-optimal degrees of Innovation. "The results suggest that the performance of firms under the Open Source mode of development is superior to the present regime, but it is less efficient than under short-term patents. Finally, patent protection granted to minor technological advances for long periods retards the evolution of technologies in the long run, even though more firms prefer developing their own technologies in-house on imitating rival products.

The desirable design of IPR regime consists of a short patent lifetime and intermediate-to-high level of the minimal inventive step. Under those conditions, 
imventors enjoy protection of significant technological advances rather than o limited protection of rare breakthroughs. Moreover, exclusion of minor improvements from the scope of patents and a shortened duration of patents enable firms to access and to implement novel know-how. Consequently, both competition and technologicall progress are enhanced in the long run.

The results also suggest that the incentives of firms to innovate are positively correlated with the degree of protection provided by the legal regime. Imitation is the least preferred method under a strong regime (i.e. long patent duration and small inventive step), as imitators are limited in their possibilities to acquire recent developments and to leap-frog over technological leaders by first legally imitating them. When firms operate under weaker IPR protection, their propensity to distinguish their products by in-house development decreases and imitation is more often chosen. Hence, $R \& D$ producing firms can achieve better competitive pasitions in the market than can imitators under a strong patent regime.

When the market contains a large population of firms, each firm confronts fierce competition and in order to survive has to distinguish itself by continuously "reinventing" its own product. Policy makers can then provide incentives to imnovate by creating stronger protection schemes. Those means should be carefully applied when market competition intensifies, e.g. when large number of firms join the market, as stronger patents may clecrease the level of technical quality.

The results of the model support application of weak patent regimes in early stages of the technology, when large numbers of frms pursue new technological opportunities and compete mainly by releasing adwanced product versions. At this stage, application of strong IPRs may create a sequence of monopolies over inventions. Firms with broad patent portfolios will gradually exclude other firms from the market. As the level of competition decreases, the remaining firms will increas ingly turn from imitation to R\&D. In latter stages of the technology, when a small number of firms remains in the market, strong IPRs will provide major incentives to accomplish continuous development by the remaining firms by ensuring a stable stream of revenues over time. This regime is favourable for increasing the pace of innovation and technical change, despite steadily growing market concentration and higher barriers for entry.

The links between competition and innovation are particularly interesting in light of Schumpeter's observation that large and monopolistic firms are well-suited to produce innovation. Their profits that are generated by practicing dominant position can finance costly R\&D activities. However, the resultis of the model are in contrast to Schumpeter's arguments and suggest that monopoly over technology accommodated by strong patents rights is likely to impede the pace of innovation. Those results call for further investigation of the contribution of IPRs 
to development of new technologies in less competitive markets.

The model inchudes several assumptions that assist in identifying major effects of the patent regime on innovation in a system which is altready very complex. However, those assumptions can be relaxed or modified in advanced versions of this model. First, we assume that R\&D expenditure is taken as a fixed share of firm's revenues. In practice, firms may adopt different strategies to determine their investments in R\&D. Second, the pricing mechanism is based on the distance between the technical quality of products and on the average preferences of users. However, firms apply price discrimination strategies to attract different users (e.g. offering "student packages" with a lower price tag), rather than base their pricing on the preferences of the "average user". "Third, we assume that the technical quality and the prices of products have equal importance in purchasing decisions of different consumers. In reality, some users are more sensitive to the product price than others (compare, for example, the purchasing decisions of private users and corporations). 


\subsection{Chapter Appendix: Symbols Used in this Chapter}

\section{Parameters:}

$M-N$ nuber of firms (products).

$J$ - Number of product features.

$N$ - Number of consumers (users).

$i$ - Firm's index.

$j$ - Feature's index.

$n$ - Consumer's index.

$\rho$ - Share of the revenues invested in R\&D.

$L$ - Patent length.

$s$ - Minimal inventive step.

\section{Variables:}

$Q_{i j}(t)$ - Technical quality of feature $j$ of product $i$, released to the market in period $t$.

$q_{i j}(t)$ - Technical know-how associated with feature $j$ and remains undisclosed within firm is domain.

$\bar{p}_{i}(t)$ - Price of an installation version of product $i$ in period $t$.

$\underline{p_{i}}(t)$ - Price of an upgrade version of product $i$ in period $t$.

$V_{n j}$ - Consumer $n$ 's preference (value) of feature $j$.

$\overrightarrow{V_{j}}$ - Average consumers' preferences.

$V_{m i}(t)$ - Consumer $n$ 's utility from using product i in period $t$.

$d_{i n}(t)$ - The distance between consumer $n$ 's preferences and product $i$ 's quality in period $t$.

$\omega_{n}(t)$ - Consumer $n$ 's buying decision in period $t$.

$I_{n}(t)$ - Product used by consumer $n$ in period $t$.

$R_{i}(t)$ - Firm $i$ 's revenues in period $t$.

$\pi_{i}(t)$ - Firm $i$ s profits in period $t$.

$R D_{i}(t)$ - Firm $i$ 's R\&D expenditure in period $t$.

$j_{i}^{*}(t)$ - Feature selected by firm $i$ for improvement in period $t$.

$\xi_{i j_{i}^{*}}(t)$ - Technical progress of feature $j_{i}^{*}$ in period $t$.

$\beta$ - Elasticity of innovation w.r.t. $\mathbb{R} \& \mathrm{D}$.

$\left[Q_{p_{m i x} i x}, Q_{p_{m a x}}\right]_{j}$ - Patent-protected segment of feature $j$.

$T_{p}$ - Patent grant date. 


\section{Owning Technology: The Structure of Intellectual Property Ownership in Software Technologies}

\subsection{Introduction}

\subsubsection{Background}

This chapter aims at exploring how the structure of ownership of patent rights in software technologies has changed over time in comparison to other technologies. We analyze how changes in the U.S. patenting policy have affected the structure of patent owmership and reveal similarities and differences between patents over generic inventions and over specific applications. Finally, we analyze the relations between Open Source and proprietary software by comparing the development of public domain projects with patent records in relevant classes.

Intellectual property is the main source of value and profits in software firms. Software products, information goods and source code of programs gemerate major shares of nevenues in information technologies. Users' installed base, licensing agreements and technical support are among the other assets of software producers. Yet, valuations of firms" assets often overlook the real value of their intellectual property or reflect only a small fraction of it, as value estimates of intangible goods are notoriously difficult to accomplish. ${ }^{1}$ Similarly, the scales of lost revenues as a result of unauthorized reproduction and use of computer prograns and software packages ("software piracy") are difficult to assess. Piracy rates, i.e. the share

\footnotetext{
${ }^{1}$ Aboody and Lev (1998) discuss the conflicts between different estimates of value of computer programs, software development projects and information systems, determined by a variety of existing accounting standards. OECD (1998) and Vosselman (1998) highlight the challenges imvolved in measuring and comparing investments in intangible goods in industrialized nations and attempt to solve the problems by presenting a new frame of analysis with harmonized definitions.
} 
of users of hlegal coples of commercial software, serve as a simple indicator to evaluate the scalles of urathorized use of computer programs. They can be easily obtained through users" surveys and questionnaires or by validating their unique electronic signatures when they are connecting the producers' servers. Piracy rates are often used by software producers in order to demonstrate lass of potential income as a result of illegal reproduction and use of software packages. Statistics showing significant levels of piracy supports the sottware industry's pleas in favour of stronger $I P R$ regimes. For example, piracy figures, published by the software industry, indicate that over $90 \%$ of copies of commercial applications used in some developing economies, $35 \%$ in Europe and $25 \%$ in the U.S. are illegally reproduced. The estimated loss of revenues of software producers is approximately 1.2 billion dollars (SIIA, 2001; SPA, 2002). In reality, the loss of potential revenues is significantly lower than those figures. Had Copyright Law been fully enforced, part of the users of unauthorized copies would have chosen to implement alternative and less costly applications instead of the products in use. In economic terms, the elasticity of substitution between legal and illegal copies is lower than 1, and depends on the price of legal copies. ${ }^{2}$

Elements of computer programs are also vulnerable to imitation and reproduction, mainly by competitors. Fragments of source code, algorithms, interfaces and operational features can inexpensively be copied or reverse-engineered to produce software clones with similar functions and a lower price tag. However, technically imitation and reverse-engineering of software elements is more complex than reproduction of additional copies of the final product. Consequently, it is far more difficult to observe and to prove violation of IPRs over origimal elements of computer programs than infringement of software copyrights (see Chapter 8). Nevertheless, IPRs fulfil a major role in appropriation strategies of software firms.

Since the changes in IPR legislation in the U.S. and the expansion of the scope of patents and copyrights to protect software-based inventions, firms can safeguard their main sources of income (i.e. the source code, the final products and elements embodied of programs) more easily by legalistic means. Moreover, patents are used as important strategic means by IT. firms not only to protect their intellectual property but also to preserve market shares and revenues. Those phenomena are largely observed as increasing numbers of patent applications and grants for software and computer-based inventions and by the rapid growth of patent portfolios held by software firms.

Changes in legislation have influenced the market dynamics. By re-shaping the environment in which firms aperate, IPR legislation has also affected their

\footnotetext{
${ }^{2}$ Indeed, in developing countries, where the prices of sotware are above the income level of many users, piracy rates are significantly high.
} 
decisions and business practices. A prominent effect of frequent changes in the IPR regime and the growing numbers of litigation cases in which softwane firms were involved was to increase the degree of uncertainty, which in turn influenced firms" operations, including their $\mathrm{R} \& \mathrm{D}$ investments, licensing policies and entry into new markets. Similarly, the propensity of firms to protect their inventions by patents, which involves disclosure of novel know-how, has varied not only due to the legal allowances to protect elements of software as intellectual property, but also according to the inature of competition in the market and the phase of technological development. In early stages of the technology, firms prefer to protect. technical advances by patents in order to gain dominance over broad shares of the market and over a variety of downstream applications, expected to appear as development proceeds. However, when technology reaches maturity, firms apply different strategies that are based on lead-time and learning curves of competitors to protect their inventions (see Chapter 3 for an overwiew of appropriation methods).

The strategic behaviour of firms can be explored by following the development of their patent portfolios. A firm's decision to protect its technology by patents or by trade secrecy, or even through disclosure of its source code, is influenced by changes in the market and by the decisions of its rivals. Consequently, the ways in which ownership of intellectual property evolves are closely linked to competition, emergence and decline of technologies and business models and changes in the regulation. Therefore, the structure of ownership of intellectual property can be used to analyze the responses of firms to historical changes in the market, such as shifts in the legal, technological and economic paradigms.

\subsubsection{What Do Patents Reveal?}

Patent data serve as a rich source of information on innovative activities of firms. Patent records provide a variety of quantitative indicators and a contemporary and historical outlook on research and development activities in firms, technological fields in which they operate, their innovative output and whether they have succeed in achieving substantial advances in technology. Patent data prowide information on innovation and the evolution of technologies in micro-, mesom and macro-economic levels. We can assess ex post the pace of innovation and technological discoveries, the extent to which innovation is cumulative and relations formed between technically close or adjacent technologies. It is important to acknowledge that patent records do not provide perfect indicators on the innovative actiwity of firms. Firms may prefer using strategies that are based on product lead-time and learning curves of competitors over patenting. Nonetheless we can use patents to analyze the innovative output of firms and the structure of patent 
ownership.

Patent records include the application date, in which the request for a patent was subnitted by the assignee. The application date is often taken as a proxy for the discovery date of inventions. ${ }^{3}$ Applications are approved if the degree of novelty is sufficient (i.e. if significant advance over the state-of-the-art of technology has been achieved). The grant date follows the application date and signifies the day the Patent Office approves the application and grants exclusive rights over the invention.

Patent records disclose the identity of inventors and assignees (i.e. holders of patent rights) and their geographical locations. Those data provide a wealth of information on kmowledge spillovers from public research institutes to frrms and among firms, between techmological fields (Jaffe and Trajtenberg, 2002) and between geographical regions (Verspagen and Caniels, 2001). Patent data can be coupled with other sources, such as financial data and inventors' surveys (Jaffe et. al., 1993), to reveal links between innovation and other dimensions of firms' activities and performance.

Patent records classify inventions by technological fields and provide a detailled description of the technology, its utility and applications. Since innovation is by essence cumulative and inventors "stand on the shoulders of giants" seeking aspiration and solutions in prior discoveries (Scotchmer, 1991), patent records include references to prior art - scientific and technical articles and preceding patents through which inventors have reached new discoveries. Patents cite previous patents ("backward citations") to define their scope and to avoid "trespassing" into other patents' domains. We can assess the importance of inventions and their degree of novelty by identifying which patents were more cited than others ("forward citations"). Patent citations also reveal how different genres of knowledge were used to produce new innovations and how existing know-how has diffused to new fields.

\subsection{Aims of the Chapter}

The main purpose of this chapter is to portray the structure of ownership of software patents. A second aim of this chapter is to reveal how firms adapt to changes in their legal enviromment and the extent to which their strategic decisions to protect their software inventions by patents were affected by the frequent changes in the legislative framework.

The research evaluates whether firms are consistent in their patenting behaviour over time and along different classes of the technology, particularly in

\footnotetext{
${ }^{3}$ Most firms submit their patent applications close to the discovery date to gain priority over competitors, i.e. to win the patent race.
} 
protecting multi-use (generic) technologies vs. targeted applications. We evaluate the inventive value and the "quality" of software patents and how changes in the patenting policy affected then. Finally, we explore possible links between Open Source and proprietary software by comparing the pace of development of selected Open Source projects with the structure of intellectual property ownership in related fields.

\subsection{Methodology}

\subsubsection{Definitions}

Different studies on patenting software and computer-implemented inventions, algorithms and business methods use diverse definitions of "software patents" and thereby include different patent classes in their analyses. Studies that build upon wider definitions of software patents apply bibliometric searches with related keywords to identify relevant patent records. However, those searches include also computational components that are applied in physical machinery. Wicler criteria encompass any patent with the term "software" in the description and the claims (e.g. OECD, 2002; Ch. 3). However, those studies include patents granted for programmable elements within different apparatus, such as electronic kitchenware, which should only doubtfully be regarded as software patents. ${ }^{4}$

Allison and Lemley (2000) include "pure" software patents in their study on patent litigation on the basis of the USPTO definitions of software, "electrical" and "computer related" patents. " Bessen and Hunt (2004) apply wide criteria that do not rely on the USPTO diefinitions for classifying software patents. Instead, the population of software patents in their study was identified by searching for software-related keywords and terms within patent records. The resulting research population is much broader than in other studies and includes patents that refer to any form of software components and algorithms that was recognized patentable due to the USPTO guidelines and the ruling of Diomond $v$. Diehr. However, the scope of this definition of software patents is far too broad and may include, for example, inventions that perform a series of steps, as many process patents describe, and may be associated in one way or another with the operation of digital. processors. Yet, the production of those inventions does not reserrible any form of

\footnotetext{
"Whether many of those patents are indeed "software patents" and hence should be included in empirical studies is open to different interpretations.

5 The authors do not disclose a list of the classes that were included in their analysis.

"The ruling stated that the "concept of software patent involves a logic algorithm for processing data that is implemented wia stored instructions; that is, the logic is not "hard-wired.". These instructions could reside on a disk or other storage medium or they could be stored in "firmware," that is, a read-only memory, as is typical of arnbedded software." (pg. 8).
} 
software development and programming and therefore it is weakly associated with any of the conflicts or the challenges related with software patents.

Graham and Mowery (2002) use a somewhat different method for the classification of software patents to assess their commencial value and to measure the propensity of software firms to protect their inventions by patents. Patents from eleven International Patent Classes (IPC) linked to software inventions were included. ${ }^{7}$ However, their research population is limited to 358 patents that were granted to 100 major U.S. firms between 1987-1997. Therefore, the results do not reflect the changes in patent legislation and in the USPTO's policy (in particular those of 1996) and major trends in software and information technology markets.

Our study includes virtually all U.S. software patents in ten technological clesses that are essentially associated with software, computer programs and algorithms and were gramted between 1980-2003. We are cautious in applying a conservative definition of software patents in our analysis that includes only "pure" software patents. It refers to methods of developing and operating computer programs and to information processing techniques. The population of this study encompasses patent records that are explicitly associated with software technologies and novel algorithms. We exclude patents that describe operation and control of physical apparatus. In most cases, those patients barely resemble any form of software or computational processes, even though many of them use some digital components. Otherwise, those patents would have been (re)classified by the Patent Office in one of the categories that are included in this study. ${ }^{8}$ The number of patents surveyed in this research is smaller than the research population of some other studies. The use of those definitions exhibits a higher degree of conformity to the classification of inventions that are part of the production of advanced software applications. The distribution of patent records in the USPTO classes that are included in our survey is described in Table 7.1. As each patent can be classified under more than one class, the total number of patent classifications presented in Table 7.1 is higher than the number of patent records."

\subsubsection{Data}

The chapter analyzes the changes in the structure of ownership of intellectual property in software technologies by using U.S. patent records that were granted between 1980 and 2003 . We compare the structure of ownership in software to two

\footnotetext{
The classes are: G06F/3-5-7-9-11-12-13-15; G06K/9-15; H04L/9.

Patents can be attributed to one or seweral technological fields, due to the technologies that are included in the invention. For example, U.S. patent no. $6,807,492$ is classiffed Class 703 (Data processing: structural design, modelling, simulation and emulation) and under Class 435 (Chemistry; molecular biology and microbiology),

${ }^{9}$ For example, a patent record that is classified under classes 703 and 705 is counted twice.
} 


\begin{tabular}{|c|c|c|}
\hline $\begin{array}{l}\text { Patent } \\
\text { Chess }\end{array}$ & USPTO Classification & No. of Palents \\
\hline 703 & Data processing: structural design, modeling, simulation, and emulation & 5270 \\
\hline 704 & $\begin{array}{l}\text { Data processing: speech signal processing, linguistics, language trans- } \\
\text { lation, and audio compression/decompression }\end{array}$ & 14584 \\
\hline 705 & $\begin{array}{l}\text { Data processing: financial, business practice, management, or cost/price } \\
\text { determination }\end{array}$ & 13484 \\
\hline 706 & Data processing: artificial intelligence & 6450 \\
\hline 707 & Data processing: dataliase and file management or data structures & 23303 \\
\hline 709 & $\begin{array}{l}\text { Electrical computers and digital processing systems: rimulticomputer } \\
\text { data transferring or plural processor synchronization }\end{array}$ & 26657 \\
\hline 710 & Electrical computers and digital data processing systems: input/output & 26426 \\
\hline 715 & Data processing: presentation processing of document & 6941 \\
\hline 717 & Data processing: software development, installation, and management & 7114 \\
\hline 718 & $\begin{array}{l}\text { Electrical computers and digital processing systems: virtual machine } \\
\text { task or process management or task managenent/control }\end{array}$ & 3446 \\
\hline Total & & 133684 \\
\hline
\end{tabular}

Table 7.1. The distribution of patent classifications.

other technologies: cryptography and image analysis. Those fields were selected as they are knowledge-intensive technologies, and in the beginning of the 1970s, early applications of cryptographic and image analysis techniques appeared at the same period when the use commercial software packages significantly increased. By contrast, though, patented inventions that are classified under cryptography and image analysis are usually embedded in tangible media or in machinery.

Lists of patents in each technological class and detailed patent records were obtained from the USPTO database. Complementary information on assignees, such as private/corporate ownership of patents, was obtained from Derwent Innovation Index. Finaly, patent records were sorted their by assignees. 10

The research population inchudes:

- 62000 software patents in ten patent classes granted to 20400 assignaes.

- 4000 cryptography patents (Class 380) granted to 2000 assignees.

- 5000 image analysis patents (Class 382) granted to 2900 assänces.

(Distribution of the number of patents by year and class is found in Appendix B).

By analyzing the patterns of patenting behaviour of firms and comparing them with the other two technologies, we discover how firme were affected by the frequent changes in the software patenting doctrine and how they adapted their:

Io Note that some of our analyses in this chapter distinguish between patents that are held by firms and those held by individuals. 
strategies to the legal environment. Moreover, while prior studies combine the variety of software patents into a single proxy, and therefore assume uniformity among technological classes, our study distinguishes between patents in different classses and analyzes how the patenting behaviour differs in separate areas.

\subsection{Findings}

\subsubsection{The Structure of Patent Ownership: A Comparative Analysis}

Since the mid-1990s, the number of software patents continuously increase exponentially. Not only that the total number of software patents constantly grows since 1980s, but also the scale of patexts per annum increased from dozens of patents in 1980 to over 18000 patents in 2003. Those figures are indeed striking when compared to other technologies, as "pure" software patents (patents included in classes that were surweyed in this study) account for $3.2 \%$ of the U.S. patents granted in 2003 (USPTO, 2004). To compare, the number of patents in cryptography and image analysis grew from similar scales, i.e. dozens of patents in 1980, to hundreds of patents per annum in the mid-1990s and their share in the total number of patents is marginal. However, the significant increase in the number of software patents since the beginning of the 1990 s has not affected the patenting behaviour of firms in other technological areas. Figure 7.1 demonstrates a moderate growth in the number of patents in image analysis and cryptography in comparison to soltware. ${ }^{11}$

This substantial growth in software patents since the mid 1990s has various origins; which has altered the dynamics of the market in the long run. Those phenomena were associated with changes in the strategic behaviour of software producers and other firms and the increasing value of intellectual property in software technologies, as much as they were linked to the rising exprectations for protit-making in IOT (later referred to as the "bursting bubble" of the Internet). Modifications in the legislative framework and Court's verdicts in major litigation cases gradualy expanded the opportunities to protect software inventions and algonitmms by patents ${ }^{12}$ and were followed by changes in the structure of ownership of patent rights.

Since the mid 1980s, firms have continuously adapted their strategies and appropriation methods to the evolving legislation and to contemporary jurisdiction. Whether changes in the structure of ownership of intellectual property were influenced by one factor or by all is doubted. The patenting behaviour of each firm is

\footnotetext{
${ }^{11}$ Rapid growth in patenting is also observed in other emerging areas of knowledgebased economy, such as biotechnology (Jaffe, 2000).

${ }^{12}$ See review in Chapter 4 .
} 


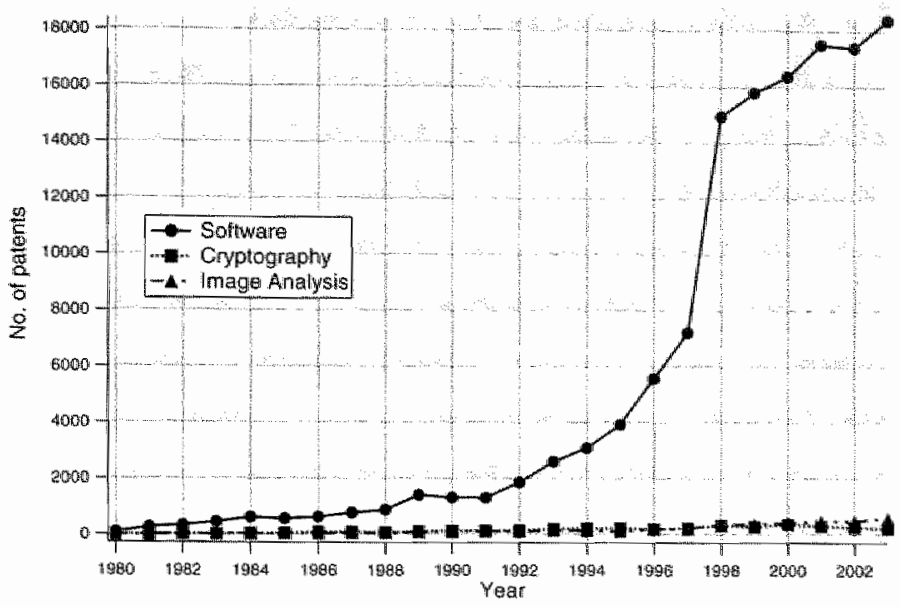

Figure 7.1. No. of patents per arimum, 1980-2003.

largely affected by other attributes, such as its size, its dominance in the market and its techuological competences. Yet, legislation has re-shaped the legall environment of firms and formed new set of conditions that has stered their strategies and patenting behaviour. Those legislative changes have also affected competition, as firms had to modify their market behaviour according to new passibilities of protecting their intellectual assets on in response to actions taken by rivals.

The changing legislation and the growth in the volume of software patents could have affected the emergence of one out of four possible market structures: First, incumbent firms could react to the changes in their business environment by expanding their patenting activities and by increasing the number of patent applications. Second, firms that had relied on different appropriation mechanisms could engage in patenting activity more than before. Third, the new guidelines enabled the protection of new inventions by patents and consequently have increased the volume of $R \& D$ investments. As a result, more discoveries were made and were granted patents. Fourth, the patenting activity in softwaremelated fields latas grown by increasing R\&D efforts coupled with patent-oriented strategies.

We compare the structure of patent ownership in software technologies, cryptography and image analysis for the complete population of patents granted between 1980-2003. We assess the general effects of the legislative changes on software patenting in general (patents owned by both individuals and firms) and on firms' behaviour in particular (patents held by firms).

The Lorenz curve presented in Figure 7.2 reveals a highly concentrated structure of ownership of software patents: $6 \%$ of firm and individual assignees hold $70 \%$ of software patents. The structure of patent ownership in the other two technologies is more fragmented: $21 \%$ of the assignees hold $70 \%$ of cryptography 


\begin{tabular}{|l||c|c|}
\hline Assignee & Share of firm-owned patents & Share of all patents \\
\hline \hline IBM Corporation & $12.9 \%$ & $10.6 \%$ \\
\hline Hitachi & $2.9 \%$ & $2.4 \%$ \\
\hline Microsoft Corporation & $2.5 \%$ & $2.0 \%$ \\
\hline Intel Corporation & $2.4 \%$ & $2.0 \%$ \\
\hline Fujitsu & $2.3 \%$ & $1.9 \%$ \\
\hline NEC Corporation & $2.0 \%$ & $1.7 \%$ \\
\hline AT\&T Bell Labs & $2.0 \%$ & $1.7 \%$ \\
\hline Sun Microsystems & $2.0 \%$ & $1.7 \%$ \\
\hline Hewlett-Packard & $1.9 \%$ & $1.6 \%$ \\
\hline Toshiba & $1.5 \%$ & $1.3 \%$ \\
\hline
\end{tabular}

Table 7.2. Major assignees in software patents, 1980-2003.

patents, and $30 \%$ of the assignees hold the same share of image analysis patents. Yet, cryphography and image analysis patents are not distributed evenly between assignees.

Figure 7.3 provides analysis of patents whose rights are held by firms and indicates a more polarized structure of IP ownership. The majority of software patents were granted to a small number of large firms, and only a small share was obtained by SMEs (6\% of firm assignees, or 522 firms, hold $80 \%$ of software patents). To compare, $27 \%$ of firm assignees (323 firms) hold $80 \%$ of cryptography patents. The same share of image analysis patents is held by $33 \%$ of firm assignees (511 firms). Further, the top ten software patent assignees include the Majors in ICT industries, with IBM as the largest software patent-holder. ${ }^{13}$ Those ten firms hold one third of firm-owned soltware patents, or $27 \%$ of all the patents (Table 7.2).

The Gini Coefficient measures the degree of concentration of patent rights held by various assignees and collapses the Lorenz curve to a single number. The Disordered Gini Coefficient is calculated as follows:

$$
G_{1}=\frac{2}{n^{2} \cdot w^{2}} \cdot \sum_{i=1}^{n}\left[\left(i-\frac{n+1}{2}\right) \cdot x_{i}\right], \quad 0 \leq G_{1} \leq 1
$$

where $n$ is the number of assignees, $x_{i}$ is the number of patents granted to assignee $i$ and $\bar{x}=\frac{1}{n} \sum_{i=1}^{n} x_{i}{ }^{14}$ The Gini Coefficient for patents owned by individuals and

\footnotetext{
${ }^{13}$ Since 1980 , IBM sustains its share of software patents at around $10 \%$ of the patents granted per annum. Since the late 1960s, soltware patents play an important role in IBM's appropriation strategies, in particular as "hardware producers in the U.S., with the notable exception of IBM, have received a diminishing share of their revenues from software production." (Steinmueller, 1996)

14 Alternatively, we can use the Ordered Gini Coefficient, $G_{2}=\frac{2}{n^{2} \bar{x}} \cdot \sum_{i=1}^{n}\left(i \cdot x_{i}\right)-$ $\frac{n+1}{n}$, if the data are sorted by a clecreasing number of patents.
} 
firms are significantly higher in sofware patents $\left(C_{s}=0.72\right)$ than in cryptography $\left(G_{c}=0.59\right)$ and image analysis $\left(G_{i a}=0.53\right)$.

The effects of the changes in the legal emwiromment of software firms on their R\&D and appropriation strategies can be revealed by following the direction in which the structure ownership of software patents has developed over time. The Gini Coefficient for the share of patents held by different assignees is calculated per grant year. Figure 7.4 presents the values of Gini Coefficient for software, cryptography and image analysis patents granted between 1980 and 2003 .

The results suggest that the structure of intellectual property ownership is highly concentrated in software in comparison to the two other technologies. Smaller numbers of assignees were granted wider exclusive rights over software inventions than in other knowledge-intensive fields. The structure of patent ownership in the three technologies became increasingly concentrated between 1980 and 1998.

Since 1999 the structure of ownership of software patents has significantly changed and has become more fragmented (as shown by decreasing values of the Gini Coefficient). Despite the potential effects of the legislative changes in the patenting policy on cryptography and inage analysis patents, those technologies have not been affected as software patents. The level of concentration of patent: ownership in both technological fields has continued to grow during this period, with some transient fluctuations.

Patents granted since 1999 exhibit a significant change in the structure of ownership of software patents. During the last five years, the concentration of ownership of software patents has steadily decreased, and by the end of 2003 the value of the Gini Coefficient has returned to the same level of 1988. Those figures indicate a more even distribution of patent rights between assignees. This result, can be associated with the new legislation and its effects on markets of soliware and. information technologies. New firms enter the market and increase the degree of competition. Other effects of the legislation are associated. with growing numbers of firms that apply patent-based appropriation methods to protect their R\&D investments and innovative output.

\subsubsection{Assessing the Quality of Software Patents}

The quality of patents is usually evaluated on the basis of their forward citations, i.e. by identifying which succeeding peitents ("patent chilcren") cite preceding patent records ("parent patents") as pror art. Patents are cited for two major reasons: First, citations indicate that the invention has built upon prior technical advances and it should be granted a patent, having proved its utility and novelty (patent applications cite scientific and technical publications for the same reason). 


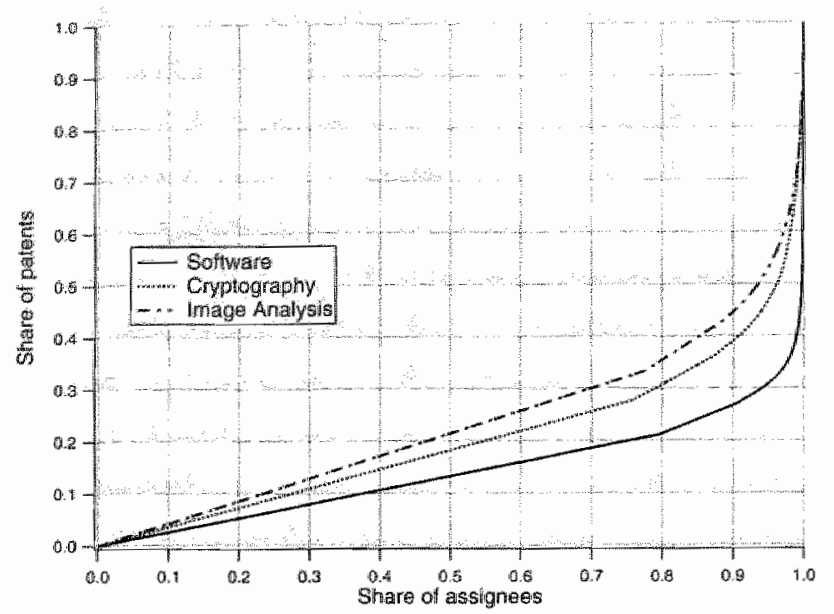

Figure 7.2. Ownership of patents by individuals and firms, 1980-2003.

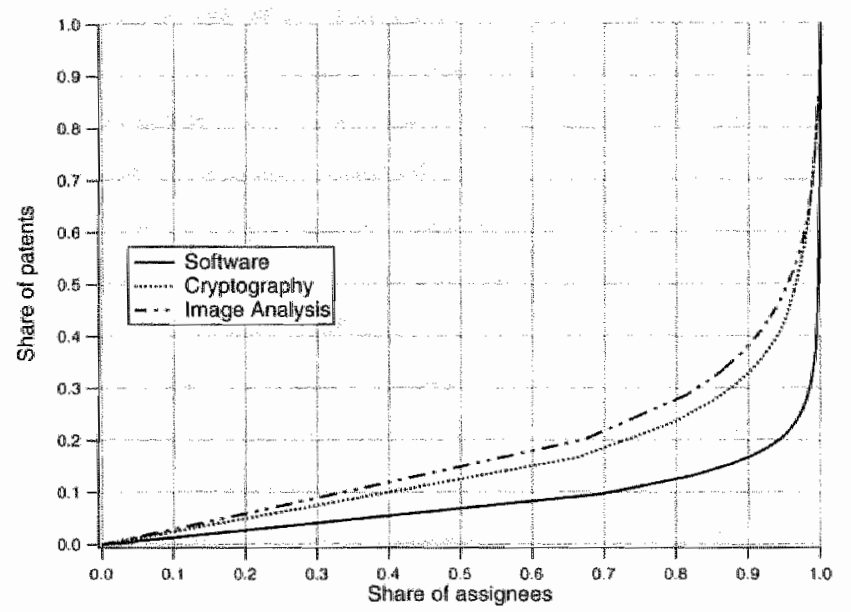

Figure 7.3. Ownership of patents by firms, 1980-2003.

Second, prior patents are cited to distinguish the invention from them. Inventors. draw border-lines between their own discoveries and protor ant to assure that no equivalence claims will be submitted by other patent-holders. Yet, the number of citations can be affected by the "density" of patents in neighbouring domains of the invention, by the crowding in effect of fims determined to win property rights over emerging technologies or by construction of as-wide-as-possible patent portfolios that serve as tradable currency in cross-licensing agreements (Jafie, 2000; Hall and Ziedonis, 2001). Therefore, forward citations can produce a variety of indicators that combine forward citations with other data within patent records. For: example, those data can be employed to assess the innovative value of a particular invention by counting its forward citations, or to measure knowledge spillovers 


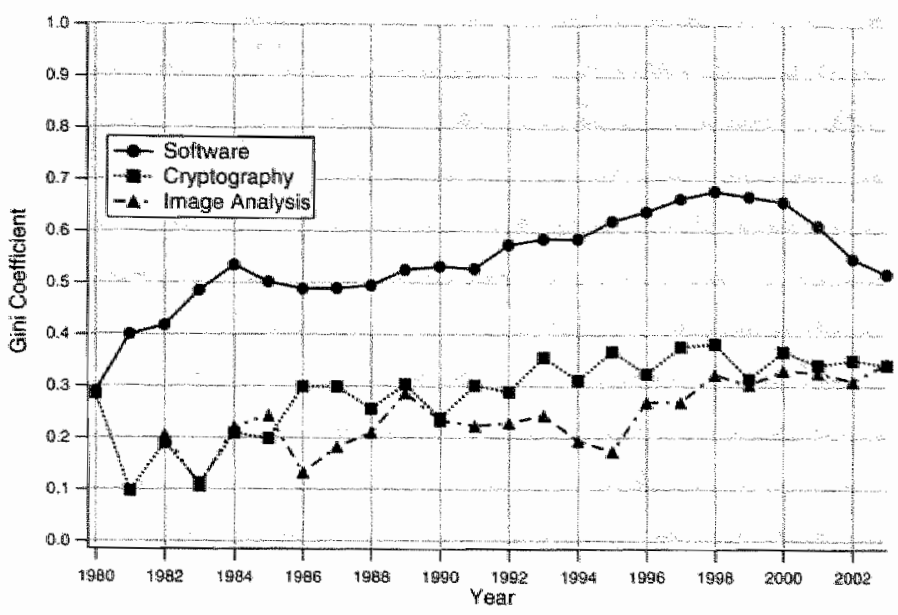

Figure 7.4. The structure of patent ownership over time.

from a technology, represented by a set of related patents, by comparing their citations by patents from the same technical class and from other classes (see for example, Hall et. al, 2001; Jaffe and Trajtenberg, 2002).

The quality of patents that were issued in different periods can vary substantially due to differences in patenting policies, in the examination guidelines (e.g. different utility and novelty criteria) or in the examination process (e.g. as a result of different training programmes of the Patent Office). In what follows, we wise the number of forward citations within five years from the grant date to evaluate how the quality of sotwware patents has changed over time. Further, we use indicators that are based on forward citations of software, cryptography and image analysis patents that were issued at the same time to compare their quality and imnowative value.

Figure 7.5 presents the average number of forward citations of software, cryptography and image analysis patents by the grant year of "parent patents". The average number of citations of software patents has steadily grown since 1981 , which might appear to indicate that the quality of software patents has also inproved over time. However, this result can be explained by the exponential growth in software patents, which increased the likelihood that a growing number of citations will be nade by following patents. Therefore, this measure has to be corrected by taking into account the number of patents granted in the same year as the "parent patent" (and could be cited too within five years). The probability of patents to be cited within five years, $P_{c}$, is calculated as follows:

$$
p_{c}=\frac{C P P}{N_{G} \cdot N_{A}}
$$


where CPP is the number of citations of the "parent patent" within five years from grant date, $N_{O}$ is the number of patents that were approved during the grant year of the "parent patent" and $N_{A}$ clenotes the total number of patent applications within five years.

Figure 7.6 presents the probability of patents to be cited within five years from grant date. ${ }^{18}$ During the whole period the probability of software patents to be cited was significantly lower than the probability of cryptography and image analysis patents. This result implies that the quality of software patents is lower in comparison to the other technological fields. However, the probability of software patents to be cited, which continuously decreased until 1996, has steadily increased since 1997. The other two technologies present similar results with sone exceptions, as the values of probability were fluctuating during the early $1980 \mathrm{~s}$ and patents granted for cryptographic inventions in 2000 are slightly less likely to be cited than patents that were granted a year before.

Two other measures illustrate the recent increase in the quality of software patents. The spotting age of patents defines the time between the grant date of "parent patents" (i.e. the date of disclosure of patented know-how) and application date of "child patents" (i.e. approximately the time of succeeding inventions). The average spotting age is used to assess whether recently-granted patents are more valuable than older patents. If indeed younger "parent patents" are more often cited, their innovative value surpass the quality of patents that were granted earlier.

The other measure is the reference year of patents. It signifies the year in which the most valuable patents were granted, i.e. the period in which the most cited "parent patents" mere granted. The reference year is calculated by subtracting the average spotting age from the application year of "child patents". If the reference yeal: increases with the application year (i.e. recent inventions refer to more recent patents), the quality patents has been sustained, as recent patents refer to new patented inventions. However, if patent applications that were submikted in subsequent years continuously refer to patents from the same reference yeur, the value of patents is cecreasing over time as more recent patents are less frequently citted.

Untill 1996 the spotting age of software patents has steadily increased, indicating that on average older patents held greater inventive value (or better quality) than recent patents (Figure 7.7). However, patent applications that were submitted after 1996 have cited significantly younger "parents".

The changes in the reference year of citing patents over time provide a con-

\footnotetext{
${ }^{1.5}$ The number of patent grants and applications for 2004 was estimated on the basis of $2000-2003$.
} 
plementary outlook on the quality of patents (Figure 7.8). From 1998 onwards, software patents depart from cryptography and image analysis patents and refer to increasingly newer patents. ${ }^{16}$ The decrease in the reference year of soltware patents, followed by an increase starting in 1999, clearly indicates a significant improvement in their quality since 1996 , as citing patents refer more often to those records.

The figures suggest major improvements in the value and quality of patents which were submitted after 1996. The occurrence of a structural change in the quality of patents is afirmed by the results of the Chow Test for structural change (Table 7.3), which examines the extent to which variations in the spotting age of patent applications from different periods are significant. Patent applications that were submitted after 1998 cite mostly patents that were granted close to or after 1996 and less frequently refer to older patent records. ${ }^{12}$

\subsubsection{Generic vs. Specific-Use Patents}

Ownership rights over software technologies may grant assigmees with excessive rights if those patents protect core inventions with a. wide range of applications in other fields. For example, encryption algorithms are generic inventions and have wide applications in a variety of fields, including secure communications, payment. systems and computer networks. The patentees of encryption algorithms, such as the IDEA and the $\mathbb{R C 5}$, can license them or can preempt any party from implementing them.

Analysis of software patents by class reveals major dissimilarities in the patenting behaviour of firms that operate in different, though close, technological areas. We aim at exploring whether patenting activity has increased in all areas, in generic classes or particularly where inventions are targeted toward specific uses. For example, substantial growth in the number of patents in generic technologies would indicate that the patent-holders over core inventions can dominate a wide spectrum of applications. This scenario may easily tum to a "tragedy of anti-commons" in software technologies, in which a small group of assignees are "fencing out" core inventions by obtaining patents over them and forbiding their use by competitors in new contexts and applications (Heller and Eisenberg, 1998). The risks of excluding large numbers of inventors from the market by ownership of property rights over wide technological areas are tangible in software

\footnotetext{
${ }^{16}$ Cryptography and image analysis patents seem to "catch up" with software paterts, as their reference years notably increase between 2000 and 2001 .

${ }^{17}$ Table 7.3 also shows a structural change in the spotting age of cryptography paterts in 1999. However, the origins of this recent development remain unclear, as no policy changes conceming cryptography patents or significant technological developments were reported.
} 


\begin{tabular}{|c|c|c|c|c|}
\hline Application year & & $\begin{array}{l}\text { Software } \\
\text { neference year }\end{array}$ & $\begin{array}{l}\text { Cryptography } \\
\text { reference year }\end{array}$ & $\begin{array}{l}\text { Image analysis } \\
\text { reference year }\end{array}$ \\
\hline 1985 & $\begin{array}{r}P_{r}>F \\
F\end{array}$ & $\begin{array}{c}0.3924 \\
1.06\end{array}$ & & \\
\hline 1986 & $\begin{array}{r}P P^{r}>F \\
F r\end{array}$ & $\begin{array}{c}0.3835 \\
1.09\end{array}$ & $\begin{array}{c}0.1563 \\
2.05\end{array}$ & \\
\hline 1987 & $\begin{array}{r}P_{r}>F^{a} \\
F\end{array}$ & $\begin{array}{c}0.6378 \\
0.58\end{array}$ & $\begin{array}{c}0.3242 \\
1.27 \\
\end{array}$ & $\begin{array}{c}0.3280 \\
1.27 \\
\end{array}$ \\
\hline 1988 & $\begin{array}{r}P r>F \\
F\end{array}$ & $\begin{array}{c}0.6130 \\
0.62\end{array}$ & $\begin{array}{c}0.4633 \\
0.91\end{array}$ & $\begin{array}{c}0.3472 \\
1.21\end{array}$ \\
\hline 1989 & $\begin{array}{r}\operatorname{Pr}>F \\
F\end{array}$ & $\begin{array}{c}0.7914 \\
0.35 \\
\end{array}$ & $\begin{array}{c}0.5527 \\
0.73\end{array}$ & $\begin{array}{c}0.3233 \\
1.29 \\
\end{array}$ \\
\hline 1990 & $\begin{aligned} P r>F \\
F\end{aligned}$ & $\begin{array}{c}0.8269 \\
0.30\end{array}$ & $\begin{array}{c}0.5937 \\
0.66\end{array}$ & $\begin{array}{c}0.1279 \\
2.31\end{array}$ \\
\hline 1991 & $\begin{array}{r}P r>F \\
F\end{array}$ & $\begin{array}{c}0.8420 \\
0.28\end{array}$ & $\begin{array}{c}0.5886 \\
0.66\end{array}$ & $\begin{array}{c}0.1695 \\
1.99\end{array}$ \\
\hline 1992 & $\begin{array}{r}p_{\gamma^{n}}>F^{n} \\
F\end{array}$ & $\begin{array}{c}0.8289 \\
0.29\end{array}$ & $\begin{array}{c}0.5714 \\
0.69\end{array}$ & $\begin{array}{c}0.3849 \\
1.11\end{array}$ \\
\hline 1993 & $\begin{array}{r}\text { Pr }>F \\
F\end{array}$ & $\begin{array}{c}0.7999 \\
0.34 \\
\end{array}$ & $\begin{array}{c}0.5750 \\
0.69\end{array}$ & $\begin{array}{c}0.5347 \\
0.77\end{array}$ \\
\hline 1994 & $\begin{array}{r}P r>F \\
F\end{array}$ & $\begin{array}{c}0.7460 \\
0.41\end{array}$ & $\begin{array}{c}0.6148 \\
0.62\end{array}$ & $\begin{array}{c}0.7719 \\
0.38\end{array}$ \\
\hline 1995 & $\begin{aligned} \operatorname{Pr}>F \\
F\end{aligned}$ & $\begin{array}{c}0.8519 \\
0.26\end{array}$ & $\begin{array}{c}0.5999 \\
0.64\end{array}$ & $\begin{array}{c}0.7704 \\
0.38\end{array}$ \\
\hline 1996 & $\begin{array}{r}P r>F \\
F\end{array}$ & $\begin{array}{c}0.8344 \\
0.29\end{array}$ & $\begin{array}{c}0.5491 \\
0.74\end{array}$ & $\begin{array}{c}0.4744 \\
0.89\end{array}$ \\
\hline 1997 & $\begin{array}{r}P r>F \\
F\end{array}$ & $\begin{array}{c}0.4619 \\
0.90\end{array}$ & $\begin{array}{c}0.7265 \\
0.44\end{array}$ & $\begin{array}{c}0.7396 \\
0.42\end{array}$ \\
\hline 1998 & $\begin{array}{r}P r^{*}>F \\
F\end{array}$ & $\begin{array}{c}0.0380^{*} \\
3.56\end{array}$ & $\begin{array}{c}0.9992 \\
0.01\end{array}$ & $\begin{array}{c}0.5795 \\
0.68\end{array}$ \\
\hline 1999 & $\begin{array}{r}P_{n}>F \\
F\end{array}$ & $\begin{array}{c}0.1882 \\
1.80\end{array}$ & $\begin{array}{c}0.0099^{* *} \\
5.76\end{array}$ & $\begin{array}{c}0.1430 \\
2.18\end{array}$ \\
\hline 2000 & $\begin{aligned} & P P_{r}>F F^{*} \\
& F\end{aligned}$ & $\begin{array}{c}0.1089 \\
2.37\end{array}$ & & \\
\hline 2001 & $\begin{array}{r}P r>F \\
F\end{array}$ & $\begin{array}{c}0.1194 \\
2.27\end{array}$ & & \\
\hline Tolal R-Square & & $92.1 \%$ & $86.0 \%$ & $97.0 \%$ \\
\hline
\end{tabular}

Table 7.3. Chow test for structural changes in the reference year of patents (*P $\leq 0.05, * * P \leq 0.01$ ). 


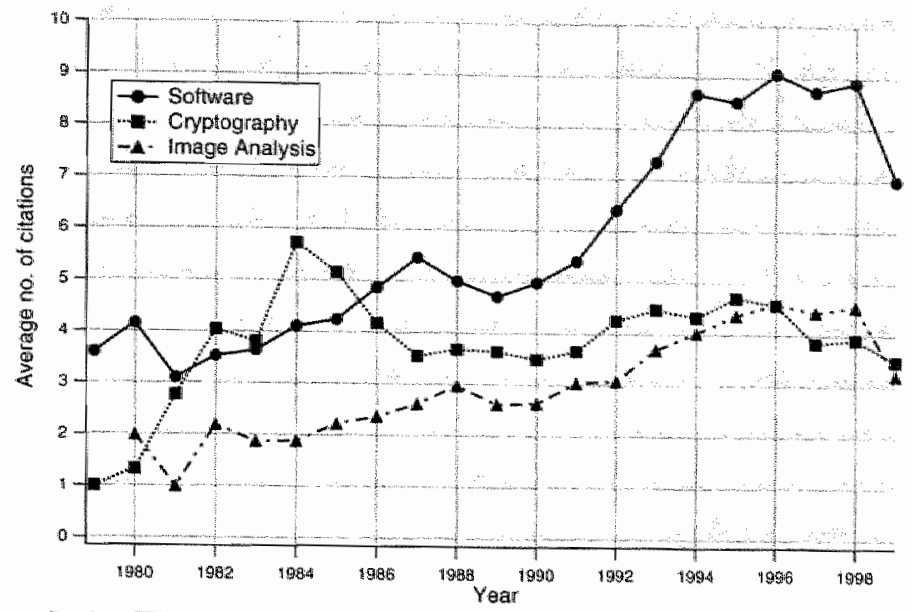

Figure 7.5. The average number of citations within five years from grant. date.

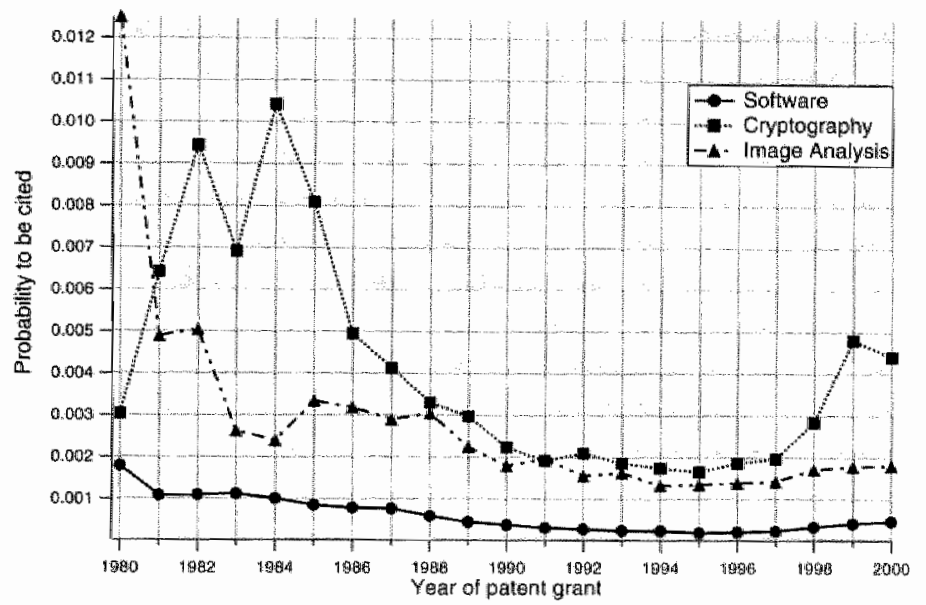

Figure 7.6. The probability of patents to be cited within five years.

and information technologies, due to interoperability and compatibility effects between different components of computer programs (David and Greenstein, 1990) and strong technological interrelatedness among software applications (Antonelli, 1993). However, if the majority of patents was issued to inventions with specific uses, the possibility that a small number of patents would form excessive monopoly rights over a large variety of technologies is comparatively small. In this case, assignees can exercise their monopoly power over a limited range of applications and. vertical markets.

The number of citations of sofware patents by other software-related classes is used as an indicator to explore the nature of patents in different areas of software 


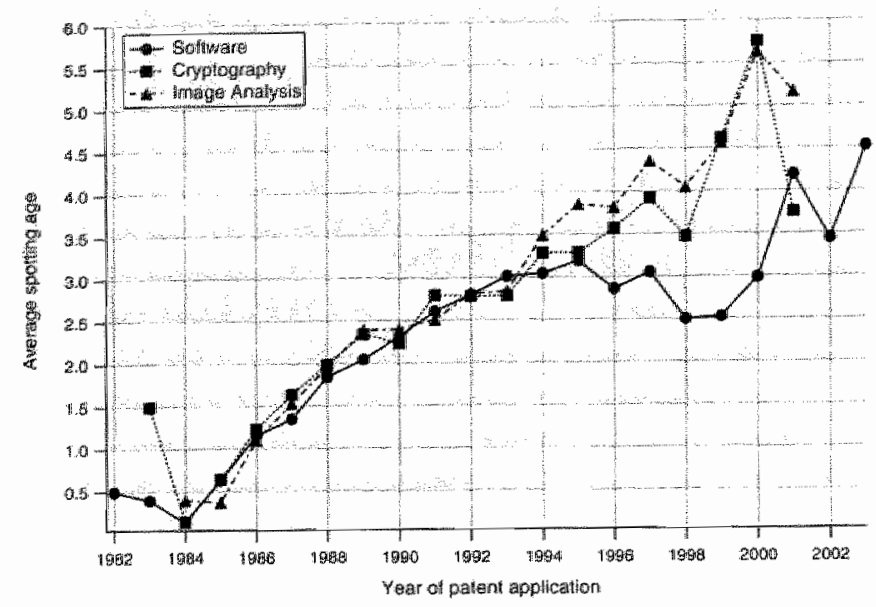

Figure 7.7. The spotting age of patents.

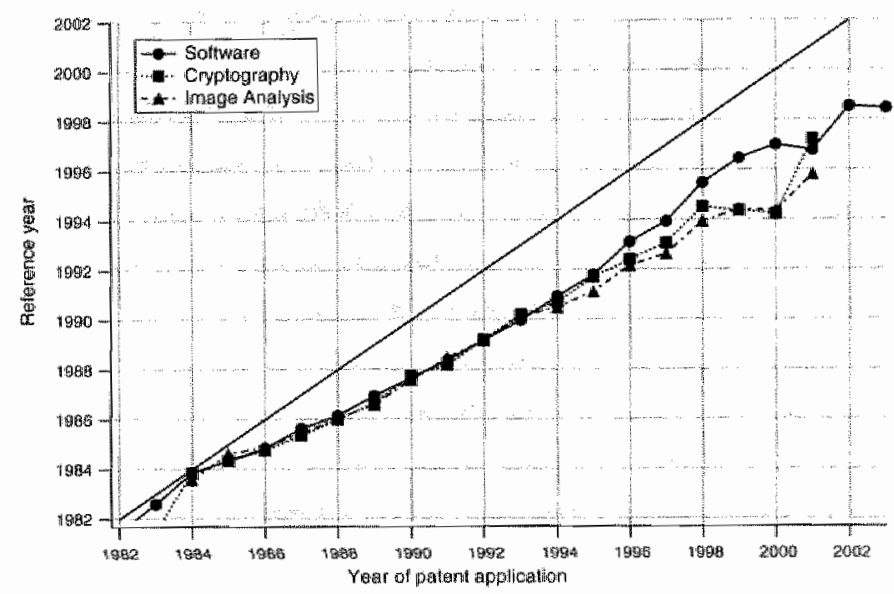

Figure 7.8 . The reference year of patents.

technologies (Table 7.4). However, cross-citations are largely influenced by the number of patents in the citing and cited classes. Therefore, we use a corrected ratio of cross-citations to patents, $C C_{p}$, which is defined as follows:

$$
C C_{i}=\frac{C C_{i}}{N_{i} \cdot N_{0}}, \quad \forall i \in I
$$

Where $C C_{i}$ is the number of cross citations by non-class i pattents, $N_{i}$ is the number of patents in class $i$ and $N_{c}$ is the number of patents that could potentially be cited. I denotes the group of classes that are included in the survey.

We define classes in which the average number of cross-citations is larger than 1. as generic classes and other classes are defined as specific-use technologies. Fol- 


\begin{tabular}{|l|l|l|l|l|l|l|l|l|l|l|l|}
\hline $\begin{array}{l}\text { Citing, } \\
\text { Ciled }\end{array}$ & 703 & 704 & 705 & 706 & 707 & 709 & 710 & 715 & 717 & 718 & Totad \\
\hline \hline 703 & - & 113 & 432 & 300 & 1215 & 1592 & 1842 & 396 & 1178 & 432 & 7500 \\
\hline 704 & 89 & - & 654 & 458 & 1832 & 1162 & 476 & 1193 & 311 & 99 & 6274 \\
\hline 705 & 294 & 663 & - & 542 & 3924 & 5178 & 1082 & 1174 & 791 & 579 & 14227 \\
\hline 706 & 429 & 550 & 716 & - & 1625 & 1088 & 389 & 535 & 513 & 27 & 6122 \\
\hline 707 & 400 & 876 & 2032 & 688 & - & 7180 & 2152 & 2195 & 2187 & 1153 & 18863 \\
\hline 709 & 409 & 550 & 2027 & 415 & 5097 & - & 5490 & 1463 & 1953 & 1293 & 18697 \\
\hline 710 & 417 & 275 & 809 & 136 & 2816 & 6984 & - & 586 & 1398 & 1694 & 15115 \\
\hline 715 & 172 & 991 & 1334 & 489 & 3461 & 3020 & 828 & - & 723 & 326 & 11344 \\
\hline 717 & 297 & 156 & 536 & 235 & 2250 & 2290 & 1113 & 553 & - & 621 & 8051 \\
\hline 718 & 169 & 87 & 353 & 109 & 1595 & 2280 & 1633 & 310 & 917 & - & 7453 \\
\hline
\end{tabular}

Table 7.4. Cross-citations by citing and cited classes.

\begin{tabular}{|l||l|l|l|l|l|l|l|l|l|l||c|}
\hline $\begin{array}{l}\text { Citsng/ } \\
\text { Cited }\end{array}$ & 703 & 704 & 705 & 706 & 707 & 705 & 710 & 715 & 717 & 718 & $C C_{p}$ \\
\hline 703 & - & 0.02 & 0.08 & 0.06 & 0.23 & 0.30 & 0.35 & 0.08 & 0.22 & 0.08 & $\mathbf{1 . 4 2}$ \\
\hline 704 & 0.01 & - & 0.04 & 0.03 & 0.13 & 0.08 & 0.03 & 0.08 & 0.02 & 0.01 & 0.43 \\
\hline 705 & 0.02 & 0.05 & - & 0.04 & 0.29 & 0.38 & 0.08 & 0.09 & 0.06 & 0.04 & 1.06 \\
\hline 706 & 0.07 & 0.09 & 0.11 & - & 0.25 & 0.17 & 0.06 & 0.08 & 0.08 & 0.04 & 0.95 \\
\hline 707 & 0.02 & 0.04 & 0.09 & 0.03 & - & 0.31 & 0.09 & 0.09 & 0.09 & 0.05 & 0.81 \\
\hline 709 & 0.02 & 0.02 & 0.08 & 0.02 & 0.19 & - & 0.21 & 0.05 & 0.07 & 0.05 & 0.70 \\
\hline 710 & 0.02 & 0.01 & 0.03 & 0.01 & 0.11 & 0.26 & - & 0.02 & 0.05 & 0.06 & 0.57 \\
\hline $\mathbf{7 1 5}$ & 0.02 & 0.14 & 0.19 & 0.07 & 0.50 & 0.44 & 0.12 & - & 0.10 & 0.05 & $\mathbf{1 . 6 3}$ \\
\hline $\mathbf{7 1 7}$ & 0.04 & 0.02 & 0.08 & 0.03 & 0.32 & 0.32 & 0.16 & 0.08 & - & 0.09 & $\mathbf{1 . 1 3}$ \\
\hline $\mathbf{7 1 8}$ & 0.05 & 0.03 & 0.10 & 0.03 & 0.46 & 0.66 & 0.47 & 0.09 & 0.27 & - & $\mathbf{2 . 1 6}$ \\
\hline
\end{tabular}

Table 7.5. The ratio of cross-citations to patents by citing and cited classes (generic classes emphasized).

lowing this definition, classes $703,705,715,717$ and 718 are generic, wheneas otiner classes are targeted toward specific uses of the technology (the generic classes are presented in bold typeface in Table 7.5).

Fig. 7.9 presents the growth in the number of patents by class. Most of the classes that are included in Fig. 7.9 show steep and continuous patterns of growth in patenting activity. Some of the technological classes (703 - modeling and simulation; 717 - software development, installation, and management) present. more moderate growth in the number of patents, in comparison to the majority of patent classes.

Until 1.995, the patterns of growth in software patents anong different classes were similar. From 1996 onwards, the growth patterns of software patents signifcantly vary among different classes. The results brought in Table 7.5 and Fig. 7.9 


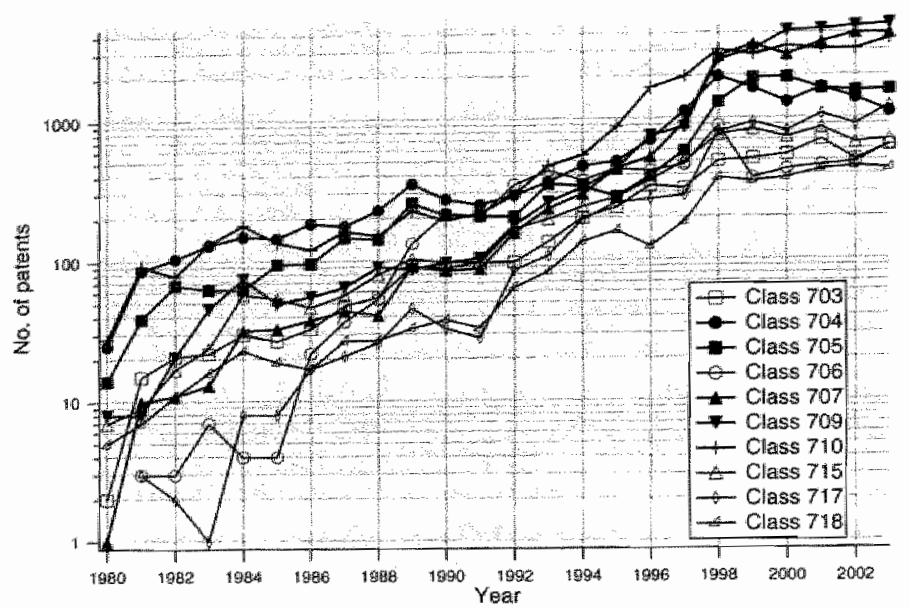

Figure 7.9. Technological classes with significant increase in the number of patents, $1980-2003$.

reveal that the prominent growth in the volume of patents has occurred mainly in specific-use classes, and in the generic class 705. The increase in patenting activity has been moderate in generic classes and the annual number of patents is lower than in specific-use classes. ${ }^{1.3}$

Those findings indicate that acquiring patent rights over specific inventions and applications is more important than obtaining exclusive rights over a broad spectrum of technologies and uses. Since 1996, most software firms patent their inventions to protect them from exploitation in specific markets. Firms are less motivated to expand their stronghold position to other markets or to block others from entering them by extensive development and patent protection of larger anounts of generic technologies.

\subsubsection{The Evolution of Open Source and Software Patenting}

In this section our analysis aims at identifying the dynamics of innovation and the links between proprietary and Open Source software, and whether the rise of Open Source has preceded or followed technological developments in proprietary technologies. Hiad massive development of Open Source projects preceded the rise in patent activity, it would imply that the Open Sonrce mode of programming is more successful in generating innovation than firms' R\&D. However, had the opposite phenomenon been identified, Open Source projects would typically follow and be influenced by development of proprietary software within firms. In this case,

\footnotetext{
Is Recently, patenting activity has even decreased in class 704 and in class 705 .
} 
Open Source projects would succed in attracting developers after introduction of new technologies in proprietary forms.

The pattern of innovation in proprietary software is measured by the number of patent grants by their application year and class. The evolution of Open Source projects is measured wia the number of new modules, added files and hines of code (LOC) per annum. The data on the development of various Open Source projects were obtained from the Libre Software Engineering website. ${ }^{19}$ Four different Open Source projects were selected for analysis on the basis of data avalability and popularity in use: 20

- EMACS (Editor MACroS) - A text editor.

- OpenBSD - An operating system derived from the BSD version of the UNIX system, originally developed at the University of California, Berkeley.

- KDE - A graphical desktop environment for Linux and Unix workstations.

- GNOME - A desktop environment and a development platiform for building applications that integrate into the user's desktop.

(Detailed descriptions of the projects and links to online communities of their developers and users can be found in www.sourceforge.net).

A group of six anonymous software scientists and engineers classified the projects according to the USPTO classes (the same process is carried out by the Patent Office examiners when new patents are filed). The choice of classes to which each project was compared was based on the majority's opinion. We use the taxonomy of Open Source projects by class to compare the evolution of the projects with the emergence of patenting activity in the corresponding classes.

Fig. 7.10 presents the development of the projects in terms of LOC, modules and files. The results show that a substantial growth in the volume of Open. Source projects typically follows the emergence of innovative outpui in proprietary software (taken by the application date) by a period of over two years.

Inmovation and the development of proprietary software seem to precede the technological trajectory of equivalent Open Source applications. Ghosh et. al. (2002) report that half of the programmers in Open Sources projects are enployed in developing proprietary software. Active participants in Open Source projects seem to follow a "double part-time concept", spending half of their working time programming Open Source applications and the other half developing proprietary software. Therefore, proprietary know-how, developed within frms, may largely affect the development of Open Source applications by generating

\footnotetext{
19The time series were read from the graphs in the Libre Sotware Engineering who site by using graphic tools (with an estimated precision level of $99.5 \%$, after the Libre Software Engineering refused our requests to receive the data.

${ }^{20}$ See Ghosh et. al.'s (2002) survey of software applications used by Open Source developers.
} 


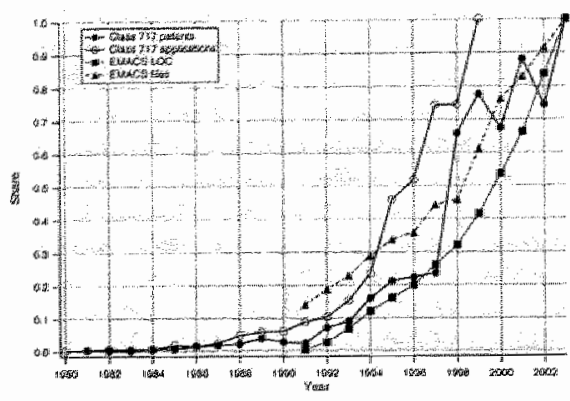

(a)

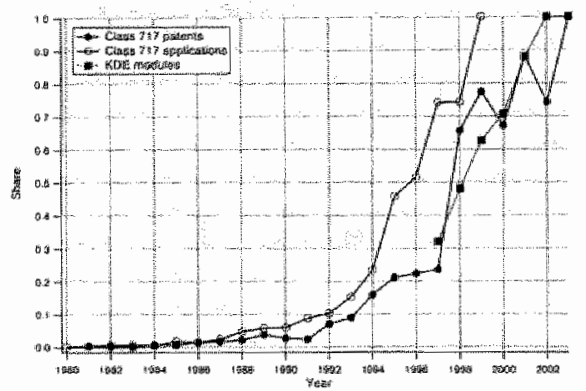

(C)

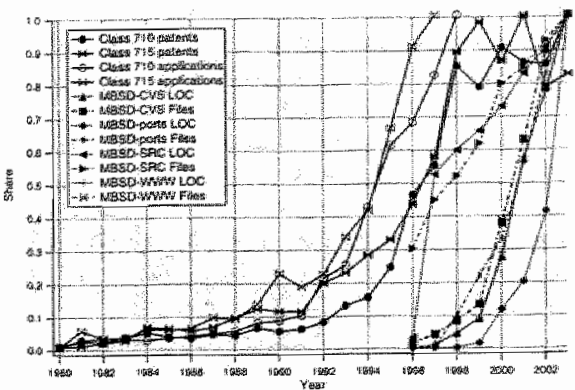

(b)

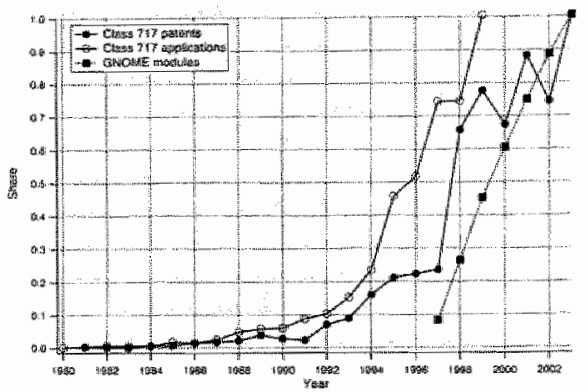

(d)

Figure 7.10. The evolution of Open Source projects and patenting in corresponding cliasses: (a) EMACS, (b) OpenBSD, (c) KDE, (d) GNOME.

knowledge spillovers from programmers that are employed in software firms to Open Source communities in which they participate.

\subsection{Conclusions}

The chapter identifes a shif in the patenting behaviour of firms and consecuent changes in the stmoture of ownership of software patents. Those changes largely result from the establishment of a new legislative framework of sofware IPRs by the USPTO in $1996^{21}$ Before 1996, jurisdiction had frequently been modified and typically built upon particular rulings that were interpreted and extended by Court to resolve new conflicts, often in unexpected ways (see Chapter 4). Consequently, inventors faced a high degree of uncertainty from a relatively unstable legal environment, while entering new markets with competing products or investing in software R\&D. For example, the likelhood of engaging in legal disputes with rivals over software inventions and the expected form of resolution could hardly be predicted on the basis of the existing jurisdiction.

21 The changes have mainly affected patents that were granted after 1998 , considering that $85 \%$ of the patents that were granted since 1996 were submitted after 1996 and their examination period was ower two years (USPTO, 2003 ). 
The publication of the "Examination Guidelines for Computer-Related Invenhons" (USPTO, 1996) formed a set of clear definitions and policy outines to provide a coherent framework for the legal protection of software and algorithms by patents and copyrights and a doctrimal basis to resolve conflicts over ownership rights of software technologies and applications. Although the Gudelines are of ten criticized as over-protective, ${ }^{22}$ the new legal framework has reduced the degree of uncertainty in the software industry and the risk of engaging in expensive legal disputes over development and use of soltwaxe inventions. Since the implementation of the Guidelines, and in spite of their shortcomings, patents were granted to more assignees than before. Hence, the new legislative framework has strengthened the potential of new entrants to compete with their inventions aganst incumbent firms, to use them as "bargaining chips" in cross-licensing agreenents to obtain access rights to protected technologies or to generate revenues by licensing them.

The volume of software patents has exponentially increased since 1980 . However, until 1995, increasing numbers of patents were granted to a relatively small group of assignees. Since 1996, the total number of assignees and the share of holders of small patent-portfolios are continuously increasing. The propensity of those patent-holders (mostly SMEs and individuals) to protect their software inventions by patents is higher than it was during the early-and mid-1990s. Hence, the structure of ownership of software patents has become less concentrated since the establishment of the USPTO's Guidelines. Yet, despite those fundamental changes and increasing concentration of ownership of cryptography and image analysis patents, software patents are less evenly dispensed than in those technologies.

The quality and the imnovative value of software patents appears to have deterorated until 1996. Multiple indices, based on forward citations, show continuous improvement in their quality and innovative walue since 1996. Soltware patents that were granted after 1996 are cited more often than before. Patent applications rarely refer to older patents as prior art.

Until 1995 the number of software patents in different technological classes had grown evenly. Later, the growth of software patents has significantly varied by the type of the tecinology: the volume of patents increased in specific-use irventions, whereas the increase in the number of patents in generic classes was relatively moderate. Patents were more frequently used in protecting specific applications than in appropriating a broad range of technologies. Those changes in the patenting behaviour of firms may be associated with the establishment of a new legislative framework in 1996 and with the re-organization of the patent. examination process by the USPTO.

22 See, for example, Bessen and Maskin (2000). 
Finally, our analysis illustrates how imnovation and technical know-how in software techologies are largely driven by development of proprietary technologies whthin firms. Open Source projects begin later, when large shares of the technology have alleady been patented, and they typically follow the evolutionary patterns of commercial software. 


\section{8}

\section{IPRs in a Knowledge-Based Economy: A New Frame-of-Analysis}

\subsection{The Challenge: Forming a Legal Framework of Software IPRs}

The debate on software IPRs has not only highlighted fundamental issues regarding the scheme of protection that software enjoys, it has also pointed out major gaps in the representation of computer programs as economic goods. In this respect, various interpretations of software propose a limited ontlook by referring only to particular aspects of computer programs.

The following issues stand in the center of the public debate:

- What is the exact nature of software and computational processes and how should they be properly represented as economic commodities?

- What are the similarities and differences between software applications and miachines?

- Should computer programs exjoy IPR protection like their physical equivalents?

- Which legal regime would induce the maximal degree of societal benefits and would satisfy private and public interests?

Court's attempts to resolve those issues by creating legal dofinitions have advarreed beyond economists' views. Yet, Court's rulings have often resulted in incoherent definitions, which address only in part the various abpects of computer programs and the magnitude of possible cases.

Pointing out the attributes that are common in software technologies and machinery, as well as those that distinguish both of them as economic goods, would assist in recognizing the sources of the controwersy of software patenting, particularly when physical inventions are patented without doubt. A histonical review of the evolution of information and software technologies is usefull in illuminating es- 
sential dimengions of software technologies and their development ower time. This oultook assists in particular in distinguishing the multifaceted entities that are cmbedded in computer programs, namely the "instructions", the "texts" and the "machines". Those aspects are further elaborated in this chapter with reference to the idea/expression doctrine and to the difficulties in drawing parallels between software and physical equivalents to establish a coherent juridical basis and legal policy of software IPRs.

The following section highlights the dissimilarities in the economic nature and market behaviour of ideas and expressions. The ways in which ideas and expressions are embedded, stimulate innovation and contribute to the technological landscape in computer programs vs. tangible goods assist in elucidating the sources of conflict between public and private interests and intellectual property ownership over information technologies.

\subsection{Markets for Goods and Ideas and How They Differ}

IPR doctrines distinguish between ideas and expressions, both in their legal definitions and in the ways they are treated as intellectual property. In the case of software, algorithms and techniques embedded in and carried out by computer programs are classified as "ideas" and protected by patents. The source code, interfaces and internal structure, sequence and organization of procedures and subroutines and the compilations," are protected as "expressions" by copyrights."

Copyrights have become increasingly important particularly in protecting graphic user interfaces, program designs and the internal organization of computer programs and the sequence of computational operations that they carry out. Although it seems that sofware patents outweigh copyrights both in importance as means of appropriation and in inflaming the recent debate, copyrights are pivotal in safeguarding various elements of computer programs. Further, copyright legis-

\footnotetext{
'Compilation is the executable form of a computer program, transformed from a highlevel language (such as Pascal or $\mathrm{C}++$ into machine language). It is the final, distributed product.

${ }^{2}$ Chapter 4 provides a detailed analysis of the evolution of software IPRs and a historical timeline.
} 
lation is not necessarily simple. Rulngs in recent copyright disputes demonstrate increasing degrees of complexity and juridical challenges.

Court's ruling in Whelan $v$. Jaslow (1986) significantly extended the scope of copyright protection for computer programs in the U.S. and later steered the enactment of the legal doctrine of the USPTO on patentability of computer programs and algorithms. The legal dispute began with copyright infringement of dental laboratory management software, Dentlab, originally programmed and distributed by Jasiow Dental Laboratory. Its procedures and functionalities were later re-written (in another computer language) and sold as a competitive application by Whelan Associates. In this precedent, Court held the opinion that "copyright protection of computer programs may extend beyond the programs' literal code to their structure, sequence, and organization" (Whelan v. Jaslow, 797 F.2d 1222, 1986; emphases added) and does not; include only the final program or its code-lines. This doctrine, commonly known as the SSO principle, expanded the scope of copyright protection of software far beyond the measures that regwlators had accepted (before Whelan, copyrights were granted only to published code-lines).

Traditionally, Patent Law protects ideas, technical and engineering sollutions including significant components of computer programs, such as algorithms. Yet, the extension of the scope of copyrights by Court provides additional protection to the internal organization and processes of computer programs, albeit those components are technical in essence and remain undisclosed.

The overlap between patents and copyrights in protecting intellectual property is peculiar to software. Similar doctrinal guidelines were not established for other technologies. Concerns over the joint protection by both copyrights and patents were raised during the hearings on the draft proposal of the USPTO Gaidelines. When the final version of the Guddelnes was finally accepted in 1996, it had become also a main object of legal critique. In addition to other issues raised in the debate on software IPRs, the role of the extended doctrine of copyrights in encouraging further innovative activity by applying stronger legal guidelines should also be thoroughly analyzed.

Reichman (1994) and Mackaay (1994) criticize Court's interpretation, which led to an extended scope of protection by both copyrights and patentis. They also advise against entrenching the rationale of Court's opinion while forming regulative guidelines of sofware IPRs and against granting copyright protection to other elements of computer programs, such as their interfaces and design, in addition to the source code.

\footnotetext{
"Finally, the USPTO decided to adopt Court's opinion and integrated Whelan ruling's rationale in its Gudelines.
} 
The joint protection of software by patents and copyrights restricts the possibilities of firms to learri from their rivals by using reverse engineering techniques." Legally, the possibilities of using reverse engineering in software is more restricted than in any other technology. In producing and testing new applications, computer developers are obliged to follow the orders of both Patent Law and Copyright Act, as well as mumerous interpretations by Court. ${ }^{5}$ Generally, reverse-engineering is legally allowed both by Copyright Law and by the Digital Millennium Copyright Act (DMCA) to test interoperability between the original product and other applications. However, special restrictions on reverse engineering of content encryption methods are made by the DMCA. " Therefore, application or reverse engineering of rival programs during interoperability tests may be risky for software developers, as it can infringe either copyrights of other developers (simply by fixation of the programs in the computer's memory). The result may have a hampering effect on innovation in information technologies, as interoperability between different software platforms, applications and product versions is essential to guarantee the successful operation of new programs before releasing then to the market.

Soltware patents present different challenges for software development. Innovation in software and information technologies is an incremental process that is largely based on re-programming and integration of existing components into new programs (Cohen and Lemley, 2001). However, Patent Law differs from the Copyright Act and does not include any privilleges for re-use of reverse-engineered components. In most cases, their use is recognized as unlawful, since their functionality and methods operation are protected by patents. Moreover, the ability of firms to learn from existent innovations is more limited as the degree of knowledge disclosure in software patents is lower than in other technological fields: software inventions and algorithms can be patented without revealing their source code. Yet, it is possible to include in software patent applications "abstract" claims over wide technological areas. Consequently, the opportunities of software developers to offer advanced and improved software products are increasingly restrained by water-tight legislation.

Other aspects of critique refer to the application of the doctrine of equivalents ${ }^{7}$ with a relatively broad scope in cases of software patent disputes and to the long

\footnotetext{
"See discussion on the learning channels of firms in Chapter 3.

5For example, in the recent case of Bowers o. Baystate Technologies (2003; 64 USPQ2d 1065, CA FC 2002) Supreme Court confirmed the right to prohibit rewerse engineering of software products via licensing agreements.

6Samuelson (1999) indicates that the DMCA's orders regarding reverse engineering of encryption software create potential hazards for the proper development of those technologies.

TThe doctrine of equivallents allows to prove infringement even when the claims are not literally infringed, when one makes minor departure from the patent claims to achireve the same function in substantially the same way.
} 
duration of patents in comparison to short life cycle of most software products. Those properties of the patent regime may hamper the efforts of second-comers to enter the market by inventing around living patents.

Opponents of the extended doctrine of patent and copyright protection anticipated that the new legal framework would be used by incumbent firms as strategic means to pre-empt new firms from entering the market. The recent case of Sony Computer Entertaimment v. Connectix Corp. (203 F.3d 596. 9th Circuit, 2000) demonstrates how some of those concerns were confirmed.

Sony sued Connectix for violating its copyrights by reverse-engineering interfaces and developing emulation of the Playstation console for personal computers. The company withdrew its suit after most of its claims were rejected by Court. In response, Sony filed another lawsuit arguing that Connectix infringed its patent rights over the same technology. ${ }^{8}$

The complexity of IPR regimes, their advantages and shortcomings to nourish sustainable development of technologies have been broadly discussed from various perspectives. However, the main body of literature on IPRs often treats different technologies in similar ways despite dissimilarities in their market behaviour and technological attributes. Although legal and economic scholars, software developers, consumer organizations and interest groups have devoted substantial efforts to define a coherent legal framework for software IPRs, the debate on the best scheme of protection is still ongoing. Policy makers continue to look for clear insights to follow while establishing legislation for future generations of information techonologies.

\subsection{Software Applications as Economic Goods}

\subsubsection{Manifold Dimensions of Software Products and Technologies}

Software products vary in economic and technological properties according to their stage of development and to forms of their distribution. Expanding the taxonomy of entities that are embedcled in computer programs, we can distinguish between elements of computer programs as follows:

1) The "behaviour" of a program - a set of technical and operational features, processes, functionalities and tasks that a program carries out. For example,

\footnotetext{
s Sony withdrew its succeeding lawsuat and suspended any legal procedures agans: Connectix after setting this case out-of-court. In the past Sony used a similar strategy against another producer of PlayStation emulators, Bleem, sung it at first for copyright violation (214 F.3d 1002, $9 \mathrm{th}$ Cincuit, 2000 plaintiff's claims for violation of its copyrights were rejected by Court) and later for patent infringement. Those legal procoedigs were probably arnong the main reasons for Bleem's demise.

See Sanuelson et. al. (1994).
} 
Enterprise Resource Planning (ERP) software manages a complete set of organizational processes: after receiving orders from customers, the system calculates the necessary inventory levels and automatically issues purchase orders for raw materials. The program calculates the necessary production capacities and personnel and. informs the logistics department of shortages and possible solutions (e.g. outsourcing the production of orders or delaying their due date).

2) Whe general aim and the output of the program - for example, report design program (e.g. Crystal Reports) receives as an input listed database fields, a set of criteria and the requested design of a report, and produces a document in a printable format.

3) Subcompilations - software objects within a prograrn that perform particular operations. Their functionality can be examined and re-programmed by others to produce functions, features, processes and algorithms that are similar to the original software objectis.

4) Algorithms - sequences of ordered steps and instructions that carry out particular functions in a computer program.

5) Technical and operational features that are carried out by a set of subroutines and procedures.

6) Source code - program statements that are usually written in a high-level programming language.

7) The final product - a software package, i.e. a compilation of the source code transformed into machine language.

Second comers can imitate any software component, behavioural or operational feature with relatively small efforts. Imitation takes place to reduce the R\&D costs of rivals or simply to introduce competing products at lower prices. ${ }^{20}$

The impact of imitation on the developer's market can vary according to the reproduced software elements and the markets targeted by second-comers. In the competitive scenario, intitation would threaten the inventor's revenues in varions ways, from duplicating final products (i.e. software piracy) to more complex modes of reproduction of functionality and advanced program elements. ${ }^{11}$ Inventors face the risk of being unable to recoup their $R \& D$ investments. Imitation of less valuable elements of software would generate insignificant effects on inventors when second comers enter remote market niches. Economic losses caused by imi-

\footnotetext{
10 This perspective is similar to the rationale of Rewand Theory and to Nordhaus: (1969) analysis of the patent system, in which imitation produces perfect substitutes without technological improvements that compete with the inventor's product.

II Assessment of equivalence between program features is difficult to carry out due to the abstract nature of software. In comparison, software piracy can be modelled with relative ease (see for example: Conner and Rumelt, 1991; Giwon et. al., 1995; Stolpe, 2000). Chapter 6 demonstrates how those difficulties can be resolved by employing a simulation model that is based on quality ladders to represent the technical capabilities of competing applications.
} 


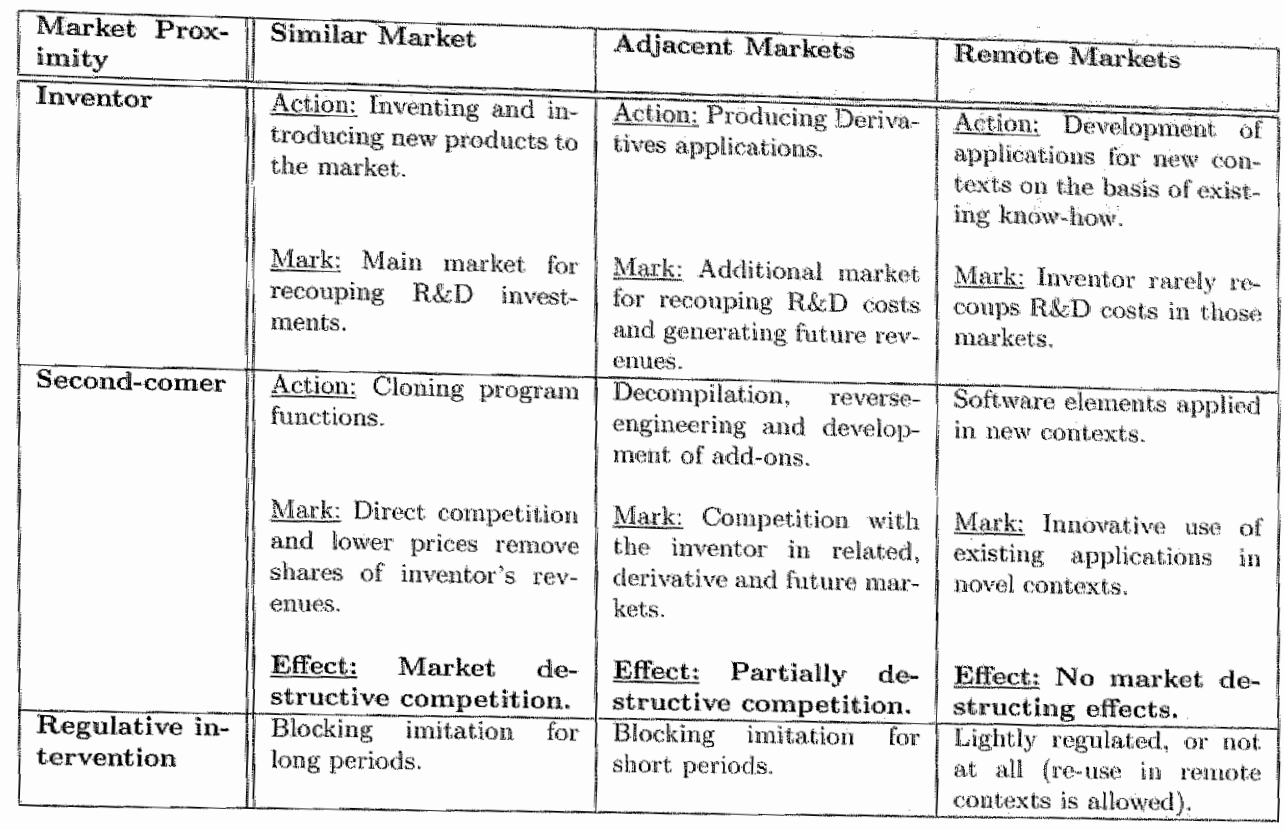

Table 8.1. Potential hazards and factors of failure in various sof ware markets (Based on: Sarnuelson et. al., 1994).

tation should be assessed in a wider perspective that includes equivalence between products and loss of present and future markets (see Table 8.1).

Software is usually vulnerable to imitation as applications reveal significant amounts of embedded knowledge and technicalities to programmers only by in specting their external interfaces and operation. The internai structure and mechanics of software and the know-how embedded within it can be revealed even when the source code remains undisclosed. Later, programmers implement the acquired know-how and relatively easily "clone" software applications and or neproduce similar functionality and features. Virtually ewery software component. can be re-programmed, improved and integrated into other applications. Moreover, in the majority of cases imitation is less costly than R\&D (Mansfield et. al., 1981). Users often prefer applying "clones". i.e. software products that largely" imitate other packages, ower the use of the original programs due to lower prices, superior quality, improved technical support or favourable licensing terms of the clones. 
Following the potential threats to inventors that imitation presents, legal protection should vary between long periods of exclusivity in markets that were origindly targeted by the inventor (yet, a shorter term than provided by patents or copyrights) to minor legal intervention when second comers' applications are distant from the original uses. However, one of the main challenges in applying the proposed market-oriented policy is the feasibility of establishing a new legislative framework that will bring a degree of uncertainty into the market. Consequently, irventors facing the risk of engaging in legal disputes with incumbent firms over use of similar product features will hesitate to enter the market even when their applications are significantly distinct from existing programs. Therefore, if the new policy fails to provide clear standards to evaluate ex-ante whether new product versions are sufficiently "remote" from the original programs and leaves the assessment to Court, it will probably have negative effects on the market in the long run.

\subsubsection{The Textual Nature of Computer Programs}

As the obvious metaphor of software source code is text, copyrights were originally used to protect the textual aspect of programs. Hence, the legal status of the source code of programs does not differ from any printed material, such as books or magazines, and thus automatically receives copyright protection. Copyrights protect three ellements of computer programs:

- The source code of a program.

- The structure, sequence and organization of a program.

- The final product (software package or compilation of the source code).

When likening the source code to published matter, the functional and technological essence of computer programs is partially dismissed. Had copyrights been granting protection only to code-lines, they would have covered only the textual aspect of applications. Although source code is generated and represented as text, in practice it defines a sequence of instructions that are transformed into an executable machine code, which is carried out by computers. In this respect the source code serves as an intermediate means for producing a good with required functionality. Although functionality of a program is reached throngh textual means, software functions and source code are legally and technically distinguished entities. Imitation can take place by programming new versions of the source code that capture the very same "behaviour" of the original program without duplicating or even without inspecting its source code. Therefore, software can be re-produced without copying any segment of the original source code. Put in a different way, programmers can follow a given application to produce a differ- 
ent version of source code that imitates the functionality of the original program (e.g. by writing it in another computer language) without infringing the inventor"s rights. In this respect, software can be described as a technological product whose means of production happens to be textual.

The second entity of software which is protected by copyrights is the compilation or the final product. Like other copy-protected commodities (e.g. phonograms and photographs) software does not have to be created in a textual form to protect its final product. The scope of copyright protection prohibits unauthorized reproduction and distribution of the final product in digital media. Hence, unauthorized duplication of computer programs is recognized wrongfol by Copyright Act (but it does not necessarily infringe the patent rights of the developers).

The third entity, the internal organization of a program, is perhaps the most challenging element in terms of constituting a legal policy with a well-stated economic rationale. It should prevent market destructive behaviour of competitors and yet it should not benefit any priwate parties at the expense of public welfare. For instance, had the scope of protection covered only textual aspects of software, competitors could have imitated and cloned functionality and "behaviour" of programs with a relative ease and compete with similar applications.

The ruling in the case of Whelan $v$. Jaslaw emphasizes the problems of forming a legal framework that protects the non-textual elements of computer programs by relying on the existing regime. The contexts of this case, which are elaborated in details in Chapter 4, exemplify how extended scope of a particular regime, in this case the scope of copyrights, may be in conflict with other legal schemes that aim at protecting different software elements. The extended doctrine may go way beyond the aims of the regime, resulting in further complexities and ambiguities. While copyrights had been established to protect artistic and literary works, the ruling expanded the regime to cover operational and semi-functional elementis of software To a large extent, the ruling threatens to remove substantial proportion of sernitechnical and operational elements of computer prograns from the public domain for very long periods. For example, the ways subroutines within applications interact with other procedures and inputs according to a given set of rules become the property of developers for their lifetine plus ninety years.

Critique of the Whelan ruling relies on the analogy between computer programs and machines. The similarities between software and machinery suggest that the extension of the scope of copyrights beyond the source code and the final product can be likened to protecting the arrangement and design of machinery components by copyrights. Organization of a set of functional parts of a machine is directed to achieve required "behaviour", desirable functionality and performance, either by physical or intangible means. Similarly, software objects are orchestrated in a 
program to accomplish the same goals.

The case of $S C O$ Group v. Autozone Inc. demonstrates the potential threats to innovation and to diffusion of advanced technologies that the expansion in the scope of copyrights exhibits. In March $2004 \mathrm{SCO}$, the owner of the copyrights and licensing rights of the UNIX $\mathrm{V}$ operating system, ${ }^{12}$ fled a complaint against Daimler-Chrysler and against Autozone, a retatler of automobile accessories for non-permissible use of the Linux operating system. According to the plaintiff, LinuX was "an operating system variant or clone of UNIX System V technology... "Linux is not just a "clone", but is intended to displace UNTX System V" (SCO Group $v$. Autozone Inc., 2004; $\S 13$ ). Therefore, its application infringed the rights of the UNIX $V$ owners as Linux arguably imitates the structure, sequence and organization of UNIX V. SCO's case against Daimler-Chrysler was dismissed by Court and its case against Autozone still proceeds.

SCO has chosen to target Linux users in its lawsuit, rather than commercial distributors of the operating system. It argued that the use of software "clones" (and not the unauthorized reproduction of its UNIX V system, as in other copyright disputes) is legally wrongful. The strategy of SCO to sue users of competing: operating systems has been perceived as an attempt to expand the scope of copy rights beyond the SSO doctrine. Previously, software producers would be sued over copyright infringements on the basis of the SSO doctrine and users would be sued only for non-permissible use of the plaintiff's products. SCO's strategy has opened the way to other firms to sue not only rivals but also users of competing products for applying programs that resemble to some degree their products. This legal practice can have engraving effects on the dynamics of software maxkets. Dominant firms would be able to strengthen their position by threatening potential entrants from competing with them and by suing customers of competing products. SMEs, in particular, would be infuenced to prefer a particular application only to avoid legal disputes over use of other products, even when those products incur significant improvements and cost savings (as in the case of the Open Source Linux).

\subsubsection{Software Applications as Computational Machines}

The history of computer science suggests that our views on software patents and their role in the development of information technologies should go beyond the contemporary debate on software patenting. A broader perspective that is based on the evolution of software technologies provides us with a more comprehensive vision of the techmo-economic attributes of computer programs and their market dynamics.

\footnotetext{
${ }^{12}$ Originally, the system was produced and distributed by AT\&T Bell Labs.
} 
Useful notions on the characteristics of computer programs as economic goods can be provided by likening software applications to computational machimes. Computational machines were developed first as physicall machinery employed to calculate a single task, particular mathematical function or a limited sequence of steps. Later, they evolved to Universal Machines that can perform multiple computational tasks and finally developed to the digital computer. Computational machines that were built to perform specific computational tasks increased productivity and innovative output in many situations and were granted patents without opposition.

Computational machines hold great potential to utilize non-skilled labour and to deploy human resources and skills in advanced tasks, rather than to allocatie personnel to conduct trivial arithmetic calculations. The scarcity of professional and creative labour is similar to scarcity of other sorts of capital. This notion was highlighted by Nicholson (1892): "There are certain kinds of brain-capacity [i.e. skills], the outcome of a conjunction of natural ability, education, exrerience and... opportunity, which are comparatively rare, and like other rare things, command a. scarcity value." (pp. 487-488). The scarcity of talented labour and its importance are emphasized as "intellects of this sort also directly or indirectly save much labour, or increase the efficiency of labour, or more generally add to the wealth of society, and therefore... deserve this scarcity value." (Ibid.; PP. 488)

Efficient deployment of labour releases workers from carrying out trivial tasks and routines. Instead, they can devote larger proportion of their time to generating new means and methods. The case of human computers exemplifies the use of machinery to perform the tasks of mathematicians. ${ }^{13}$ Automatization of simple arithmetic calculations and mathematical tasks was identified by Charles Babbage (1835), naming it the division of mental labour. Babbage argued that the primary improvement associated with use of automated calculations is to "avoid the loss arising from the employment of an accomplished mathematician in performing the lowest processes of arithmetic." (Ibid.; pg. 201). Further, in his description of the organization of the French government's project of calculating logarithmic tabbles, Babbage draws a hierarchy of three departments of skilled labour for accomplishing computational tasks successfully:

(1) Experienced mathematicians who carry out analytical investigations provide recipes and formulae to solve computational problems,

(2) workers with intermediate skills who interpret the formulae, substitute the variables with numerical expressions and organize the inputs from the manual computers in a format of calculated tables, and

13 The term "computers" is used here in its historical meaning: clerical workers that carried out arithmetical calculations manually, mainly for administrative purposes. 
(3) labour wh basic akils that carries out simple calculations.

Skilled mathematicians are the most knowledgeable and innovative sector of this organization and a significant parcel of the process, forming new methods for solving problems and simplifying cornputations. Any additional workers that were added to the first two departments could strengthen the problem solving capabilities in this project. Therefore, Babbage suggested substituting the third department's clerks with mechanical apparatus that was able to perform sirnple aritimetic calculations (at the level of addition, subtraction and multiplication of two numbers). Utilization of skilled labour could contribute to the efforts to develop new computational methods and to economize on tasks by implementing automated technologies.

Babbage's attempts to refine the quality of mathematical calculations led to the invention of the Difference Engine, a mechanical device that automatically calculates astronomical tables. The Engine simplified the work of astronomers and improved the accuracy of their calculations by eliminating human errors. Babbage later developed the Analytical Engine, a multi-purpose computing device, whose construction was never completed. ${ }^{14}$

A second major event in the history of modern computing was the publication of Turing"s seminal work in the mid 1930s (Turing, 1936). Thuing solved one of the main problems of modern mathematics, Filbert's tenth problem, in a way that laid the foundations for computer science. ${ }^{15}$ His theory served as a basis for computer operating and programming; which has remained virtually unchanged since then. The the Universal Machine, described by Turing, consists of four fundanental operations: storage of digital data, modification of the stored data (instructed by "behaviour tables" and code-lines), removal of data from the storage array and generation of output. Those basic functions of the Universal Machine were implemented in the design of digital computers. The result was a multi-purpose platform for computational tastls, capable of storing and manipulating massive amounts of data in very short durations.

The controversy around the patentability of mathematical algorithms and business methods points out major disadvantages of protecting basic computational techniques as intellectual property. Had the concept of the Universal Machine been invented earlier and patented, the patent-owners would virtually have dom-

\footnotetext{
${ }^{14}$ Babbage's attempts to produce the Difference Engine inspired two Swedish innovators, George and Edward Scheutz, who succeded in developing and manufacturing a different version of the machine, for which a French patent was granted (patent no. 13480, May 1850) (Buxton, 1988; Lindgren, 1990).

${ }^{15}$ Hilbert's tenth problem inquires whether a definite method for solving all mathe matical problems exists. Turing's proof, which introduced the new concept of computabie numbers, was a milestone in the evolution of computer science and was used as a theoretical basis for the development of digital computers after WWII.
} 
inated computer technologies for the following decades and would inave been able to preempt others from entering into the evolving field. ${ }^{16}$ However, substantid economic benefits result from disclosure and dissemination of technical and organizational know-how that re-assigns professional labour to advanced undertakings and removes repetitious and elementary tasks from its workload. Indeed, the use of software products requires hardware - a personal computer or a server. Yet, computations are more efficiently accomplished on a digital hardware than on any other application that uses physical machinery. Bresnahan et. al. (1999) indicate that "especially if we look at recordkeeping, remembering, simple calculating and comparing, and similar tasks, the result of IT use and the associated reorganization of work has been the systematic substitution of computer decisionmaking for human decisionmaking in clerical (and similar routine) work... a re-optimized organization will have new opportunities to substitute ont of using humans where computers have comparative advantage." Similarly, increasing the IT stock of firms and replacing physical machinery by software applications would yield significantly higher scales of computations and productivity gains (Brynjolfsson and Hitt, 1998). However, if hardware incorporates greater value for users than software and the source code has no additional value for the users (as in the case of unskilled users), consumers would favour the physical machinery over the digital equivalent.

Following the functional and "behavioural" prospects of software, one can appreciate the advantages of the analogy between computer programs and their physical equivalents, machines that perform the very same functions by mechanical means. This analogy builds upon several similarities between these different types of commodities. First, the merits of accomplishing productive and useful tasks by technical means is typical for software as it is typical for machines. Second, computer programs can be transformed with some degree of design efforts into physical machines, e.g. by representing their internal logos and organization with electronic circuits. Third, programming is based on construction and assembly of operational elements (such as procedures, data structures and algorithms) and corresponds to construction of machines from physical modules and components. Fourth, programs, like machines, are large and complex products and often require interoperability with other products to function properly.

Some scholars follow the rationale of the Alappat decision (1994) and argue that software and machinery are similar in essence and differ only in their way of

\footnotetext{
${ }^{16}$ Patent applications for a general purpose computen were rejected over the years for different reasons. In 1936, Zuse, a German engineer, submitted a patent application for a general purpose computer to the German Patent Office. Flowever, the Patent Office found the degree of novelty insufficient and rejected it. Later, the USPTO rejected Lekert and Mauchly's patent application for a general purpose computer, since the same machitae was introduced earlier by Atanasoff and von Neumann (int was not patented by them).
} 
construction: Machines are built from tangible materials and computer programs from textual mediators, which are later compled (see, for instance, Kretschmer, 2003). Following this argument, equivalence in software patents can be determined by comparing the efficiency of various algorithms (Chin, 1998), as in the case of comparing the scales of productivity of similar designs of machinery. However, computer programs vary from machines in operating via a formed set of instructions (which is not "textual", but mostly operational) that are applied as building blocks of products and technologies. Indeed, those components can be compared to advanced mechanisms, but the main difference is in the difficulty of imitation and reproduction of both genres. Imitation and reproduction of complex technologies (e.g. automobiles, drugs and chemicals) is a long process of reverse engineering, whereas in software decompilation and re-programming of elements and functionality are relatively rapid and require relatively standard techniques (such as "black-box testing"). ${ }^{17}$ In this respect, legislation often confuses between medium of creation (the program"s source code) and the artifact created by using it (the program's behaviowr'). Therefore, likening software applications to machines, copyright protection for the sonrce code does not make more sense than protecting the raw materials of machines (such as plastics and metals).

Samuelson et. al. (1994) propose different legal measures to judge novelty and equivalence of software inventions in case of patent dispute. Their test is based on the "behavioural" aspects of programs, which, they argue, are the main source of value in software applications. The authors define behaviour as a particular set of functions, technical features and information processing (inputs, internal sequence and algorithms and outputs). It is the way a program executes defined tasks and instructions in a form of code-lines or machine language. ${ }^{18}$

The ratiomale behind the proposed framework is as follows: Software applications compete and attract users on the basis of their functionalities, technical and operational features. When two computer programs have the same functionality and "behaviour", to the end user both programs seem indistinguishable and perfect: stibstitutes, even though their sounce code is completely different. Therefore, protecting the beheviour of programs within a limited scope of specific patent claims would maintain the source of walte of inventors and would enable the use of the patented behaviour in new contexts and applications by others.

Against that, some may argue that the proposal reflects only the value of

17 A testing technique whereby the internal structure and organization of a program. are not known to the tester and its source code is not accessible. The way of operation is revenled by following the way inputs are processed and produce the resulting outputs.

18 "This definition can be intenpreted as either "functionality", "technical features", "operational features", "instructions", "performance" of a program, a procedure within it or all those elements altogether, and requires further elaboration and clarity before applying it in new legal guidelines and in analyses of the present regime. 
programs for the end asers (through their behaviour), while the source code of programs creates a different type of value. The source code is a major source of value for skilled users, particularly while maintaining software applications or developing subsequent versions of programs. A source code that is more organiwed, well-structured and documented enables programmers to adapt it more easily to the needs of the organization and the end users. It can significantly reduce the expenditure of firms on information systems, despite similarities to other programs in the resultant "behaviour". Consequently, the structure of the code, the methodologies and tools that are employed in the development process can be as waluable as the final product.

However, the competitive value of commencial programs lies primarily in their functionality and not in their source code. Each version of the source code offers one way to obtain the required functionality and can be programmed differently. Usually the code-lines of new programs are crafted from scratch, their structure largely varies from similar applications and variables and declarations are given unique names. Code-lines provide an important source of learning, and programmers often follow examples from technical recipe-books and code librajies while producing their own programs. But copying large fragments of source code from one program to another is too complex or unfeasible.

The innovative element in software, which is also the most vulnerable to imitation, lies neither in the general purpose of programs nor in their source code. Both elements can be easily reproduced and distributed. Rather, it is the peculiar way in which software features and algorithms are incorporated into the source code and jointly operate to carry out computational tasks, which produces the major source of value of computer programs.

\subsubsection{Programming as Construction of Industrial Designs}

The previous sections of this chapter point out many similarities between computer programs and machines. Following this line of argument, software programming resembles to a large extent the industrial design of physical machines. Like machinery manufacturers that assemble mechanical parts and craft materials to construct their products, programmers produce software with required functionallity and features by combining source code elements, interfaces and data structures, readymade components and home-grown techniques. Similarly, the difierent production phases - the design phase, the manufacturing and the distribution of products exist in both technologies.

Understanding the distinction between the design and the manufacturing phases in information technologies is particularly important for policy-and law-makers, forming an ongoing adaptation of the legal doctrine. The modified legislation ex- 
panded the possibilities of software firms to own more elements of their technologies and products, and to protect them as intellectual property earlier. Therefore, the impact of the changing legislation on the market is not limited to the final products, but also affects their development process. Therefore, a comprehensive study of the legal framework on innovation sbould also include its effects on the development process.

The existing IPR doctrine (largely based on the distinction between idea and expression' differentiates between providing legal protection to the final good, which is produced in the manufacturing phase and later distributed, and to its technical basis, which is formed during the design phase. The division of product R\&D and production between "design" and "manufacturing" car determine which of the categories of the process would be classified within the design phase and hence would enjoy patent protection, whereas the "manufactured" products are protected as expressions (in the case of software by copyrights).

Sarnuelson et. al. (1994) designate the process of designing and progranming software applications a joint phase of "design". Following their classification, once development of a program is completed, production of additional copies (i.e. "software packages") is considered as the "manufacturing" phase.

We propose a somewhat different categorization in which the "design" phase includes software analysis and design and the "manufacturing" includes the programming (either for specific users or for mass distribution). Such a taxonomy would represent the nature of software development more adequately, as the equivalent to design of physical products, in which blueprints and production methods of the product are formed, is the analysis and design process of software. In this stage software analysts identify the needs of users, the aims and operational features of programs and their internal architecture. The design of a required "behaviour" aims at achieving a determined set of functional results in an efficient course of operation. It inwolves disintegration of a complex structure of a program into mumerous programming tasks, instructions, algorithms, interfaces and suburoutines. In this stage, programmers are involved in the "pre-production" of software, choosing development tools, approving the architecture of the program and assessing the technical feasibility of developing different features. Then, prom gramming follows the analysts' specifications and the chosen configuration of the program. Moneover, planning the development project of a new software and the dectiston upon the functionality and the features are assisted by tools and methodologies which include flowcharts, software specifications and CASE ${ }^{19}$ tools. Those are equivalent to tools that are used in the production planning and design of new physicall goods.

\footnotetext{
${ }^{19}$ Computer-Aided Software Engineering or Computer-Aided Systems Engineering.
} 
The novelty of software inventions lies either in new results of programs or in the originality of processes that generate them. Part of them can be accuired by imitating, reverse-engineering and decompiling other applications and by using available source code. In this respect, patents and copyrights provides a partial solution for protecting computer programs, as some software elements are nof fully protected by these regimes or by other legal schemes. ${ }^{20}$ Although the process of software design resembles the planming new machinery, elements of computer programs cannot be protected as industrial designs as they lack the "ornamental or aesthetic aspect of a useful article. Such particular aspect may depend on the shape, pattem or color of the article... reproducible by industrial means" (WTPO, 2001).

\subsection{The Rise and Fall of Metaphors in the Technological and Juridical Courses}

Programs are often created to provide new contexts that simplify or improve the ways existing processes are carried out. The design and functionality of computer programs create conceptual metaphors through which soltware operates and tasks are accomplished with relative ease. Moreover, real-world metaphors (such as machimery that is substituted for software) serve as comvenient references to provide users with functions of products that they used before and as a basis for adding advanced features to simplify the use to increase efficiency. To exemplify, a typewriter can be taken as a useful conceptual metaphor of word processors. As the basic functions of typewriters were transformed into and included in word processors, users are able "to migrate" from typewriters to their digital equivalents with litule training. Integrated spell checkers and thesauri are additional features that: were added to the basic versions of word processors and increased the value of the product for its users.

The coherence of operation of computer programs and their interoperability with other applications is an important source of value in software development. Coherent operation is often based on metaphors and on the ways the functions of the original product interact with the physical world. Similarly, a successful computer program integrates technical features of its physical equivalents and other processes that involve them. Moreover, the program enhances the performance of users by adding new technical and operational features that were difficult to implement in the physical product. Therefore, sofiware development does not re-

\footnotetext{
${ }^{20}$ During the 19805 , advances in the diesign of semiconductor masks wallenged the existing framework of IPRs by the lack of appropriate instruments to protect them. Finally, the enactment of the Semiconduotor Ohip Protection Act in 1984 provided the nocessary protection to complete designs and arbedded elements (Samuetson and Scotchmer, 2002).
} 
produce copies of plysical products in a digital form, but also applies them in new enviromments and contexts.

The course of employing metaphors to constitute IPR policies created two types of inefficiencies. The first source of inefficiencies resulted from a lack of suitable legal guidelines that accommodate the needs of the evolving industry for long periods. The second source of inefficiencies is more complex than the first. It refers to the application of a llegal framework which satisfies the needs and peculiarities of the industry due to a certain technological paradigm long after it: was replaced by a new and different technological environment. Completion of policy changes happens more than a decade after the emergence of new technological paradigms in information technologies. Therefore, in many cases legislative changes fail to resolve conflicts between the legal regime and the evolving market (historical taxonomy of software IPRs is brought in Chapter 4 ).

Software should not be legally protected as intellectual property if it simply replicates existing goods or applies similar contexts. Digitization encapsulates significant innowative value only when it contributes new technological or operational features.

The debate on the social and economic value of IPRs within the context of information techmologies highlights another controversy - the patentability of business methods. Business methods can be patented in the U.S. since the ruling in the case of State Street Bank Trust y. Signature Financial Group (1998; United States Court of Appeals for the Federall Circuit, 96-1327). Signature produces software for managing financial services. One of its applications is used for pooling fund assets, which monitors allocation of assets, income and expenses on the basis of daily changes in the market. Since 1993 the firm holds a patent for "data processing system for hub [i.e. portfolio] and spoke [i.e. partner funds] financial services configuration" (U.S. Patent no. 5,193,056). State Street Bank was sued by Sigmature for infringing its patent rights and in turn State Street Bank sought resolution in Court claming that the patent was invalid on several grounds: First, the patent was granted for a business method which was exempted from the scope of patents according to section 101 of the Patent Law ${ }^{21}$ Second, the patent (issued before the publication of the USPTO guidelines) protects mathematical algorithms and formulae that were at the time non-patentable. At the end of the juridical process, the U.S. Court of Appeals for the Federal Circuit concluded that business methods should not be excluded from the patentable subject matter anymore, stating that it "take[s] this apportunity to lay this ill-conceived exception

\footnotetext{
21 Section 101 states that "Whoever invents or discovers any new and useful process, machine, manufacture, or composition of matter, or any new and useful improvement thereof, may obtain a patent therefore, subject to the conditions and requirements of this titite."
} 
lo rest?

The decision, a recent statutory keystone in patenting software and other business services, has widened the scope of patents to business methods and financial software. Yet, the ruling preserves requirements of novelty and utility, but removes the necessary conditions of technical merits and tangible contribution to technology. The ruling states that "patentability does not turn on whether the claimed method does "business" instead of something else, but on whether the method, viewed as a whole, meets the requirements of patentability", and there fore business-related inventions can be protected by patents. However, the ruling stimulated other controversies and expanded the debate on software patenting. In particular, the degree of novelty necessary to obtain business patents seem lower than in other patent classes (Hall, 2003). For example, manual accounting processes that are converted into software can be protected by patents. Consequently, long-living business processes applied in firms' information systems or regular procedures that are carried out manually can be patented and excluded from the public domain, even though their contribution to technology is marginal.

\subsection{Re-Drawing a Fine Line Between Ideas and Expressions}

A large body of the economic literature has identified empirically and theoretically the significance of technical knowledge in stimulating innovation. In the new technological reality, production and R\&D are not only based on knowledge imputs for their production, but knowhedge is also produced as funal good in many industrial sectors. Further, issues of intellectual property rights predominantly rise from the shift in the technological paradigm from physical-goods economy towards "new" economy, which is based on intangible capital of information and know loow:

Different from physical goods, knowedge is infinitely expansible, as agents who acquire it do mot restrict others from abtaining and holding it simultaneously. Since knowledge based goods are based on technical know-how rather than on machinery and industrial processing, firms are able to imitate and rewerse-engineer products that are present in the market with relatively small efforts.

The first foundations of software IPR legislation were established in the U.S. case of Diamond $v$. Diehr (1981). In this case, Cout recognized computer prom grams patentable if they were embedded in physical machinery. Later, a series of ad-hoc rulings expanded the scope of protection and determined that software and algorithms patentable of and by themselves.

While both patents and copyrights are generally criticized as over-protective, providing monopoly over techmologies and cultural goods for long periods, soft- 
ware adds unique and complex dimensions to the debate, being protected by both patents and copyrights. Hence, when examining the economic effects of patents and copyrights separately, rather than evaluating their cumulative impact, those analyses refect only fragments of the dynamics of the market and the legal regime.

A different issute is the contribution of copyrights to the formation of innovative and creative output in software technologies. Computer programs typically contein source code, designed to carry out specific procedures, arithmetic and logical calculations for processing and manipulating data, which is compiled into binary format of machine language. Software sources can be transformed from one configuration to another, rewritten in a wariety of programming tools, applied in various technical environments ${ }^{22}$ and reverse-engineered. "Those characteristics are advantageous for employing computers as basal platforms for implementing a wide range of software applications. However, the same prospects present major challenges in determining the legal status of novel computer programs as intellectual assets. Apart from setting laws to protect the final products of computer programs (i.e. the compilations), legislators should assess the benefits and drawbacks of protecting other elements, either as inseparable features of the technology or as distinctive legal entities.

In a historical perspective, copyrights were granted to creative ontputs in their final forms and excluded the methods through which they were achieved from their scope of protection. For example, the process of calculating logarithmic tables, which involved substantial efforts of organization, calculations and validation techniques, could not be protected, but its final ovitput - a mathematical handbook could be granted copyrights.

Lacking a coherent policy that regulates and defines IPRs for the multiple entities of software, the legal discontinuity was fulfilled until the 1990 s by Court's ad-how rulings, which later shaped the legislation in the U.S. and worldwide. It was not before 1996 that the USPTO has published official policy guidelines for patenting and copy-protecting aspects of computer programs and algorithms. Since their publication, the Fxamination Guidelines for Computer-Related Inventions (Foral Verston, have infuenced software IPR policies worldwide.

To illustrate some of the implications of blurring the borders between expressions and ideas in recent doctrinall changes, allowances for reverse-engineering exemplify important prospects of Law and technical learning in fims. Reverseengineering encompasses positive effects on both innovation and interoperability of complimentary technologies. ${ }^{23}$ Firms can analyze features of competing prod-

\footnotetext{
${ }^{22}$ Such as operating systems, data management systems, or hardware such as desktops, "wise" mobile devices and handheld computers.

${ }^{2}$ Interoperability suggests that demand and supply of each component in the system. are strongly infuenced by technical advances in other elements.
} 
ucts and test the interfaces between their own technologies and market loading products. By joining new technologies and existing products they can expand the technological realm and add new ways of use. Therefore, reverse-engineering represents another method in which firms gain knowledge from the experience of rivals, not for the purpose of copying their products, but to improve the technology upon them. However, application of reverse-engineering methods is restricted by legal orders. While the Copyright Act does not impose any constiaints on reverse-engineering, Patent Law recognizes the application of teclanical knowledge by means of reverse-engineering infringing if the technology is protected by valid patents. The patent doctrine introduces a major conflict in technological fields where innovation is sequential and learning from rival technologies is essential for future developments. Allowing acquisition of technical know-how by reverseengineering contradicts the purpose of providing incentives to innovate through monopoly rights over inventions. Yet, this sort of know-how is essential in the production of software technologies.

Interrelatedness plays a significant role in software and information technologies: Technical progress of one component of the technology influences the development of other features and therefore affects the advance of the technology as a whole (Antonelli, 1993). However, strong levels of interrelatedness exist only when firms can learn from rival technologies and to improve them by merging them with their owm developments. Yet, this strategy cannot be implemented if major shares of the technology are protected by patents.

A different problem that rises from the implementation of computer programs usually goes beyond the limited definition of information processing. Software applications are embedded in a wide wariety of physical apparatus which involve man-machine and machine-machine interfaces, hardware and content and expand to new technologies (e.g. new forms of mobile telephony). The new technological contexts require new definitions of intellectual property and doctrinal guidelines.

Ideas and expressions are both significant for utilizing know-how in! new products and technologies. However, drawing a fine distinction between those types of innovative yields is difficult and existent taxomomies are often debated. Research frameworks that analyze the role of knowledge in the economy and their implications (e.g. evaluation of innowation policies) wonld reflect a limited outlook if analyses of the different functions of ideas and their expressions are excluded from the discussion.

\subsection{Conclusions}

The approach towards knowledge-based goods was largely shaped by Court's decision in the case of Whelan $v$. Jaslow. The case has re-shaped the definitions 
of property and induded intangibles whin the scope of IP protection. Moreover, it revolutonized long-living perspectives on the border-lines between expressions and ideas, which had becone solid establishments in "traditional" technologies. This case is a keystone in the chain of jurisdiction and IPR policies, which largely built upon it and hence secured its position in forming future legislation. The case led to formation of new classification of ideas and expressions, where new borderlines that separate them are drawn on a case-by-case basis, rather than through a broader and more versatile regulative effort. Consequently, the legal doctrine that was later established significantly extended the scope of copyrights for computer programs. The modified IP doctrine inchudes components of operability and design that are intrinsic to the techrology in the scope of copyrights, while otller rulings have meanwhile strengthened software IPRs by recognizing algorithms patentable. 


\section{Conclusions}

Policies of appropriation and intellectual property are far from being static and they constantly develop with changes in markets, institutions and technologies. While policy makers prefer to form generic legislative guidelines for patent filing and enforcement, since a general legal framework and extension in the scope of traditional IPR regimes typically reduce regulation costs and, therefore, both steps are desirable from a social standpoint. However, knowledge-based industries present diverse needs, which are loosely met by a general and simplified legal Gramework. High degrees of technological diversity and complex market mechanisms favour the constitution of "tailor-made" regimes, uniquely formed to fit the peculiar nature of each technology, its patterns of innovation and technological diffusion.

The case of software is peculiar in that it contains a conflict in which a single product is protected by two major legal mecharisms, i.e. patents and copyrights. Software IPRs illustrate how the borderline between ideas and expressions has blurred. Previously, a product was recognized as either encompassing ideas or being an expression of creativity, while in the case of software the product appears to be both. Although the case of software is currently a unique one, the juridical and technological trajectories have already paved the way for frequent application of loosely-related and remote doctrines to resolve issues of IPRs in information products and technologies and to draw new precedents."

Constitution of a proper legal doctrine of equivalence and robust vilings by drawing analogies between physical machines to their digital counterfeits largely depends on acknowledging both the utility in following this course of action and

\footnotetext{
${ }^{2}$ One example is the protection of databases in the EU by a suti-generis law, which grants a status of property to non-copyrightable facts and data. Another example is the US case of eBay, in which data stoned in the company"s servers and presented over the Internet were protected from extensive browsing by applying the trespass-to-chatters doctrine.
} 
the possible restrictions doing so. Although source code, sequence, structure and organization and compilations of programs fundamentally differ from each other in their technical and economic merits and from artistic and literary works, that are granted a similar protection by copyrights. The uniform legal scheme that protects those elements for Long periods would produce an over-protective legal framework that would result in negative effects on innovation and in anti-competitive behaviour. Yet, other valuable elements of software do not enjoy copyright protection. and can be easily imitated without infinging the inventor's rights.

The agenda for analysis of intellectual property rights presented in this thesis serwes as a reference to assess over-protective legislation in recent issues, such as business methods patenting. Further, as computer applications are slightly modified and applied on different platforms and hardware, software ("ideas") and online contents ("expressions") converge, the existing regimes may lead to economic inefficiencies and hinder innovation. Analysis of potential risks caused by over-protective legislation is a recommended practice in evaluating policies of innovation and technical change.

Following the evolution of computer technologies, software patents do not contradict the general purposes of the patent regime to nourish innovation by providing monopoly over technology. Software patents typically follow the conceptual guidelines by which patents were granted to physical machines that performed (albeit less efficiently) computational tasks and information processing. ${ }^{2}$ However, copyright protection granted to the internal organization of computer programs and to operational components seems to go far beyond its aim to protect artistic and literary works. Consequently, exclusive rights of reproduction are provided to quasi-technical features, such as interfaces and graphical design of computer applications, rather than limiting the scope of copyrights to final outputs (i.e. compiled versions of computer programs). The protection of software products and technologies as intellectual property blurred the traditional dichotomy between ideas and expressions and re-shaped the borders between patents and copyrights. The resulting overlap between both regines may result in economic inefficiencies, rising from indefinite guidelines for protection of ideas and expressions as intellectual assets. Further, the extended doctrine, by which software technology can be patented and copy-protected at the same time, can be regarded as an over-protective policy.

Essentially, the legal protection of software and algorithms as intellectual property is very much doubted. The emergence of the Open Source model has amplified the existent concems. In the Open Source model self-organizing groups operate as online communities of developers and offer a different system of incentives to

\footnotetext{
${ }^{2}$ Whether the present design of patents is optimal in terms of length and breadth or should be modified is discussed in Chapter 6 .
} 
their innovative members. However, the Open Source model does not necessarily address the majority of concerns that can be resolved within the present institntional and economic environment of IPRs by introducing new sub-gereris law to protect information technologies. Rather, advocates of Open Source and Free Software promote an alternative model that targets segments of the software market (i.e. voluntary participation in development, provision of complementary services for free software implementations as a source of revenues, home-grown applications and academic software) and do not address the needs of the majority of firms in the industry for means of appropriation. Should innovation policies be completely based on the Open Source model and abolish LPR regimes, the result is expected to be an under-protective regime in which knowledge disclosure and R\&D investments (primarily those made by large firms) will decrease.

Enquiries on the optimal level of protection of computer programs often rise in this context. Campaigns of the Open Source community promote complete or partial removal of intellectual property claims from the source code and its compilations to foster technical advance and freely accessible standards (Lerner and Tirole, 2000; won Krogh et. al, 2002). On the other extreme, others suggest that the present regime provides incentives to inventors and innovative SMEs (Heckel, 1992). In between those poles lie variants of traditional IP doctrines that involve elements from copyrights and patents and are mostly proposed as sui generis laws. From a historical standpoint, the significance of the Universal Machine approach, as pioneered by Babbage and later furthered by Turing and the development of the digital computer emphasize the benefits of producing multi-task platiforms. that support massive volumes of computations. One set of instructions can be easily modified or replaced by another, rather than constructing new machinery for every arithmetical task. Nevertheless, although the construction of new physical devices to perform computational tasks is far more costly and less efficient than carrying them out by computer programming, physical machines could be easily patented since the introduction of the Patent Law, whereas patent applications in which novel functions were implemented by more efficient means, i.e. by computer programs and algorithms, were rejected by the USPTO before the 1980s. However, while software patents are in the core of a continuous debate, the physical equivalents of computer programs (i.e. equiproent that was built to carry out computational tasks in the pre-era of digital computers) were granted patents with little public opposition. ${ }^{3}$ From an economic standpoint, computar tional machines fulfilled the measures of technical utility and novelty and, hence. obtained monopoly rights for fostering inmovation and social welfare. On the other

\footnotetext{
3 Patents in general were the subject of various public debates. However, no particular remonstration was particularly aliming at patents that were granted to "computationall machines".
} 
hand, patentability of ther digital equivalents, mathematical algorithms applied in computer programs, is often criticized as impeding progress in information technologies. Therefore, drawing parallels between both cases implies that patents issued for physical machinery that carry out informational and computational fasks could have also been regarded over-protective at the time, if similar juridical judgement were applied.

The outcomes of misapplying an inappropriate regime may vary from hindrance in the pace of innovation to slower diffusion of evolving technologies and emergence of monopolistic structure of ownership over information technologies. The negative effects are significant particularly in initial stages of development, adoption and use of new technologies.

A coherent legal framework is necessary to address the factors of potential market failures and at prevent lack of $R \& D$ investments, which results from reproduction of different software elements by competitors. Doing so, legislation has to consider the type and the consequences of imitation, the copied elements (i.e. the software entities) and whether introduction of a (partially) equivalent products by second comers threatens to remove substantial shares of revenues, thus lowering the propensity to invest in R\&D. However, even when competitors imitate functionality of a program but distribute it in adjacent markets, far from the inventor's marketplace, or apply it in new and different ways beyond the use that was envisioned by the inventor, the inverition has a value of novelty and does not harm the inventor's commercial activity.

While legislators and Court aim at resolving conflicts between the legal regime and the characteristics of software products and technologies, the solutions (provided by statutory rulings and regulatory guidelines) may contradict the needs and the attributes of computer programs and may create further conflicts. Therefore, the regime should also consider that a legal scheme devised to protect a specific sofiware element may be in confict with the best interests of other software entitices.

Establishment of legislation on the basis of Copyright Act, Patent Law and a numerous number of juridical precedents and the consequent hybrid regime can yield negative and undesirable outcomes, as described above. Comparing the level of protection provided to the various entities of software by legal means, the present regime exemplifies some of the problems that are associated with imbalance between public and private interests, resulting in over-and under-protective

\footnotetext{
${ }^{4}$ Lessig (1999) distinguishes between the aims of coordinating and regulating new technologies: while coordination limits liberty to enable certain activities (e.g. through the formation of common standards), regulation limits liberty within the activities themselves in order to achieve desirable outcomes. As in the case of other recent laws in information techmologies, the benefits of enacting regulative guidelines over establishing coordinative standards are also being questioned.
} 
legal schemes. The regime provides extensive protection to some elements of software for long periods, in comparison to the average lifetime of computer programs. At the same time, other elements are left amost unprotected and can be freely initated by competitors without violating the Law (e.g. functions and way particular sub-routines operate). An alternative solution that encompasses the various characteristics of computer programs with a minimal degree of overlap between means of protection can be accomplished through enactment of a sui-generis law. A new regime, especially designed to meet the anique needs and merits of software technologies and the dynamics of innowation in the software industry would incorporate elements of existing legislative regimes to guarantee an appropriate degree of certainty to new entrants and ability to predich and to avoid possible legal disputes. Implementation of a particular IPR regime to protect software goods and inventions, as described above, will recover the balance between public and private interests and ensure terms for competition and entry of innovative firms to the market. 



\section{References}

Abi-Saad P., David C., Gandon M., Weisenburger E. (2001), Rechenche B Developpement en France: Resultats 1999, Estimations 2000, Objectifs SocioEconomiques du BCRD 2001, Paris, Ministere de l'Education Nationale.

Aboody D., Lev B. (1998), "The Value Relevance of Intangibles: The Case of Software Capitalization", Journal of Accounting Rescarch, Vol. 36, pp. $161-191$.

Aghion P., Howitt P. (1992), "A Model of Growth through Creative Destruction", Econometrica, Vol. 60, No. 2, pp. 323-351.

Akerlof G.A. et. al. (2002), Amici Curiae in Eric Eldred et al. w. John D. Ashcroft, No. 01-618, Subraited to the U.S. Supreme Court, May 2002.

Allison J., Lemley M. (2000), "Whos Patenting What? An Empirical Exploration. of Patent Prosecution", Vanderbilt Law Review, Vol. 53, No. 6, pp. $2099-2148$.

Ancori B., Bureth A., Cohendet P. (2000), "The Economics of Knowledge: The Debate about Codification and Tacit Knowledge" , Industrial and Corporate Change, Vol. 9, No. 2, pp. 255-287.

Anderson P., Tushman M.L. (1990), "Technological Discontinuties and Dominant Designs: A Cyclical Model of Technological Change" Administrative Scim ence Quarterly, Voll. 35, pp. 604-633.

Antonelli C. (1993), "The Dynamics of Technological Interrelatedness: The Case of Information and Communication Technologies", In: Foray D., Freeman C. (eds.), Technology and the Wealth of Nations: The Dynamics of Constructed Advantage, London, Pinter Publishers and OECD.

Arditti F.D., Sandor R.L. (1973), "A Note on Variable Patent Life" , Journal of Industrial Economics, Voll. 21, No. 2, pp. 177-183.

Arora A., Cecagnoli M., Cohen W.M. (2003), "R\&D and the Patent Premium", NBER Working Paper, No. 9431, Cambridge, NBER.

Arrow K.J. (1962), "Economic Welfare and the Allocation of Resources for Invention", in: Nelson R.R. (1962) (ed.), The Rate and Direction of Imuentive Activity. Princeton University Press. 
Arthur W.B. (1987), "Competing Techologies, Increasing Returns and Lock-in by Historical Events", Economic Joumal, Vol. 99, No. 394, pp. 116-131. Arthur W.B. (1996), "Increasing Returns and the New World of Business" , Harvard Business Review, Vol. 74, No. 4, pp. 100-109.

Arundel A. (2000), "Patent - the Viagra of Innovation Policy?" Internal Report to the Expert Group in the Project "Innowation Policy in a KnowledgeBased Economy", Maastricht, MERIT.

Arundel A. (2001), "The Relative Effectiveness of Patents and Secrecy for Appropriation" "Rescarch Policy, Vol. 30, No. 4, pp. 611-624.

Babbage C. (1835), On the Economy of Machinery and Manufactures, 4th. Edition, London, Charles $\mathbb{K}$ night.

Barzel Y. (1997), Economic Analysis of Property Rights, 2nd Edition, Cambridge, Cambridge University Press.

Beck R.L. (1983), "The Prospect Theory of the Patent Systen and Unproductive Competition", Research in Law and Economics, Vol. 5, pp. 193-209.

Besen S.M., Raskind L.J. (1991), "An Introduction to the Law and Economics of Intellectual Property" "Journal of Economic Perspectives, Vol. 5, No. 1, pp. $3-27$.

Bessen J., Maskin E. (2000), "Sequential Innovation, Patents and Imitation", Working Paper No. 00-01, Massachusetts Institute of Technology.

Bessen J., Hunt R.M. (2004), "An Empirical Look at Software Patents", Working Paper No. 03-17R, Federal Reserve Bank of Plailadelphia.

Bessy C., Brousseau E. (1998), "Technology Licensing Contracts: Features and Diversity" , International Review of Law and Economics, Vol. 18, pp. 45. $\mathrm{L}-489$.

Bonaccorsi A., Rossi C. (2003), "Why Open Source Software Can Succeed", Research Policy, Vol. 32, No. 7, pp. 12431258.

Bowman A.W., Azzalini A. (1997), Applied Smoothing Techniques for Data Analysis, Oxford, Oxford University Press.

Branscomb A.W. (1990), "Computer Software-Protecting the Crown Jewels of the Information Economy", In: Rushing F.W., Brown C.G. (eds.) (1990).

Bresnahan T.F., Brymjolfsson E., Hitt L.M. (1999), "Information Technology, Workplace Organization and the Demand for Skilled Labor. Firm-Level Evidence", NBER Working Paper, No. 7136, Washington D.C., NBER.

Brueckman W. (1990), "Intellectual Property Protection in the European Conmunity", In: Rushing F.W., Brown C.G. (eds) (1990.

Brynjolfson E., Hit L.M. (1998), "Beyond the Productivity Paradox: Computers we the Catalyst for Bigger Changes", Communications of the ACM, Vol. 41, No. 8, pp. 49-55. 
Buxton H.W. (1988), Memorir of the Life and Labowrs of the Late Chames Babbbage Esq., F.R.S. Cambridge, MIT Press, Charles Babbage Institute Reprint Series, vol. 13.

Chin A. (1998), "Computational Complexity and the Scope of Software Patents", Jurimetrics, Vol. 39.

Chou C.F., Shy O. (1993), "The Crowding-Out Effects of Long Duration of Patents", RAND Journal of Economics, Vol. 24, No. 2, pp. 304-312.

Chisum D. (1986), "The Patentability of Algorithms" , University of Pittsburgh Low Review, Vol. 47, pp. 959-1022.

Clapes, A. (1993), Softwars: The Legal Battles for Control of the Global Softwane Industry, Westport, Quorom.

Cohen J.E., Lemley M.A. (2001), "Patent Scope and Innovation in the Software Industry" , California Law Review, Vol. 89, No. 1, pp. 1-57.

Cohen, S.A. (1999), "To Innovate or not to Immovate, That is the Question: The Functions, Failures, and Foibles of the Reward Function Theory of Patent Law in Relation to Computer Software Platforms", Michigan Telecommunications, Technology and Law Review, Vol. 5, No. 1.

Cohen W.M., Levinthal D. (1990), "Absorptive Capacity: A New Perspective on Learning and Innovation" , Administrative Science Quarlerly, Vol. 35, No. 1, pp. 128-152.

Cohen W.M., Nellson R.R., Walsh J.P. (2000), "Protecting Their Intellectual Assets: Appropriability Conditions and Why U.S. Manufacturing Firms Patent (or Not)", NBER Working Paper, No. 7552, Washington D.C., NBER.

Cohendet P., Meyer-Krahmer F. (2001), "The Theoretical and Policy Implications of Knowledge Codification" , Research Policy, Vol. 30, pp. 1563-1591.

Conner K.R., Rumelt K.P. (1991), "Software Piracy: An Analysis in Protection Strategies", Managenent Science, Vol. 37, No. 2, pp. 125-139.

Cornes $\mathbf{F}$., Sandler T. (1986), The Theory of Externatities, Public Goods and Club Goods, Cambridge, Cambridge University Press.

Cowan R. (1990), "Nuclear Power Reactors: A Study of Technological Lock-In", Journal of Economic History, Vol. 50, No. 3, pp. \$41-566.

Cowan R. (1991), "Tortoises and Hares: Choice Among Technologies of Unknown Merit", Economic Journal, Vol. 101, No. 407, pp. 801-814.

Cowan R., Gunby P. (1996), "Sprayed to Death: Path Dependence, Lock-In and Pest Control Strategies", Economic Journal, Vol. 106, No. 436, pp. 521-542.

Cowan R., Foray D. (1997), "The Economics of Codification and the Diffusion of Knowledge", Industrial and Corporate Change, Vol. 6, No. 3, pp. 
595-622.

Cowan R. David P.A., Foray D. (2000), "The Explicit Economics of Knowledge Codification and Tacitness" , Industrial and Corporate Change, Vol. 9, No. 2. pp. 211-253.

Cowan R., Harison E. (2001), "Intellectual Property Rights in a Knowledge-Based Economy", MERIT Study for the Duteh Advisory Council for Science and Techology Policy (AWT), AWT Background Study No. 21, May 2001, Mabstricht.

Cowan R., Jonard N. (2003), "The Dynamics of Collective Invention" , Joumal of Economic Behanior and Organization, Vo. 52, No. 4, pp. 513-532.

Dasgupta P. (1988), "Patents, Priority and Imitation or, the Economics of Races and Waiting Games", Economic Journal, Vol 98, No. 389, pp. 66-80.

Dasgupta P., David P.A. (1994), "Towards a New Economics of Science", Research Policy, Vol. 23, pp. 487-521.

David P.A. (1985), "Clio and the Economics of QWERTY", American Economic Reverw, Vol. 75, No. 2, pD. 332-337.

David P.A. (1990), "The Dymamo and the Computer: An Historical Perspective on the Modern Productivity Paradox" "American Economic Review Papers and Procedings, Vol. 80, No. 2, pp. 355-361.

David, P.A., Greenstein S. (1990), "The Economics of Compatibility Standards: An Introduction to Recent Research", Economics of Innovation and New Technologies, Vol. 1, pp. 3-41.

David P.A. (1993), "Intellectual Property Institutions and the Panda's Thumb: Patents, Copyrights and Trade Secrets in Economic Theory and History", In: Wallerstein M.B., Mogee M.E., Schoen R.A. (eds.), Global Dimensions of Intellectud Property Rights in Science and Technology, Washingtion D.C. National Academy Press.

Dovid P.A. (1994), "Why Are Institutions the "Carriers of History'?: Path Deperdence and the Evolution of Conventions, Organizations and Institutions", Structural Change and Economic Dynamics, Vol. 5, No. 2, pp. 205-220.

David, P.A. (2000), "A Tragedy of the Public Knowledge "Commons"? Global Science, Intellectual Property and the Digital Technology Boomerang", SIEPR Discussion Paper, No, 00-02, Stanford Institute for Economic Policy Research, September 2000.

David, P.A., Foray D. (2002), "An Introduction to the Econony of the Knowledge Society", International Social Science Journal, Vol. 54, No. 171, pp. 9 23.

Davis, R., Samuelson, P., Kapor, M.D., Reichman, J.H. (1996), "A New View of Intellectual Property and Soltware", Communications of the ACM, Vol. 
39, No. 3, pp. 21-30.

Davis L. (2004), "Should We Consider Altemative Incentives for Basic Researdh? Patents vs. Prizes", Economics of Innovation and New Technologies, Vol. 13, No. 5 .

Davis S.J., MacCrisken J., Murphy K.M. (2001), "Economic Perspectives on Soft. ware Design: PC Operating Systems and Platforms", NBER Working Paper, No. 8411, Washington D.C. NBER.

Denicoló, V. "Zanchettin P. (2002), "How should Forward Patent Protection be Provided?", International Joumal of Industrial Organization, Vol. 20, No. 6, pp. 801-827.

DiBona, C., Ockman, S., Stone, M. (eds.) (1999), Open Sources: Voices from the Open Sources Revolution, Sebastopol, O'Reilly and Associates.

Diotalevi, R.N. (1998), "Copyrighting Cyberspace: Unweaving a Tangled Web", Computer Law Review and Technology Journal, Spring 1998.

Dosi G. (1988), "Sources, Procedures and Microeconomic Effects of Imnovation" , Jowrnal of Economic Literature, Vol. 26, pp. 1120-1171.

Eisenberg R.S. (2000), "Amalyze This: A Law and Economics Agenda for the Patent System" , Vanderbilt Law Rewew, Vol. 53, No. 6, pp. 2081.2098. European Commission (1991), Council Directive on the legal protection of com puter programs $(92 / 250 / E E C)$, Council of the European Communities, Brussels, May 1991.

European Commission (1995), Green Paper: Copyright and Related Rights in the Information Society.

European Commussion (2000), Report from the Commission to the Council, the European Parliament and the Economic and the Social Committee on the Implementation and Effects of Directive 91/250/EEC on the Legal Protection of Computer Programs, COM (2000)199, Brussels, April 2000.

European Commission (2002), Proposal for a Dinective of the Eunopean Parliament and of the Council on the Patentabihty of Computer-Implemented Inventions, COM(2002) 92 Final, February 2002, Brussels.

European Patent Office (2001), Anmual Repont 2001, Munich, EPO.

Evans D.S., Nichols A.L., Reddy B. (2002), "The Rise and Fall of Leaders in Personal Computer Software" , In: Evans D.S. (ed.), Microsoft, Antitrust and the New Economy: Selected Essays, Ansterdam, Kluwer Academic Publishers.

Farrell, J., Saloner, G. (1985), "Standardization, Compatibility ard Innovation", Rand Journal of Economics, Vol. 16.

Farrell, J., Saloner, G. (1992), "Converters, Compatibility and the Control of Interfaces", Joumal of Industrial Economics, Vol. 40, No. 1. 
Freman C, Soete L. (1997), The Economics of Industrial Innovation, 3rd. Edition Cambridge, MTT Press.

Friedman D.D., Landes W.M., Posner" R.A. (1991), "Some Economics of Trade Secret Law", Journal of Economic Perspectives, Vol. 5, No. 1, pp. 6172.

Gallini N.T. (1992), "Patent Policy and Costly Imitation", RAND Joumal of Economics, Vol. 23, No. 1, pp. 52-63.

Gallini N.T., Trebiloock M.J. (1998), "Intellectual Property Rights and Competition Policy: A Framework for the Analysis of Economic and Legal lssues"; In: Anderson R.D., Gallini N.T. (eds.), Competition Policy and Intellectwal Property Rights in the Knowledge-based Economy, Industry Canada Research Series, Vol. 9. Calgary: University of Calgary Press.

Gallini N.T. (2002), "The Economics of Patents: Lessons from Recent U.S. Patent Reform", Journal of Economic Perspectives, Vol. 16, No. 2, pp. 131-154. Gandal N., Kende M., Rob R. (2000), "The Dynamics of Technological Adoption in Hardware/Software Systems: The Case of Compact. Disc Players", RAND Joumal of Economics, Vol. 31, No. 1, pp. 43-61.

Ghosh R.A., Glott R., Krieger B., Robles G. (2002), "Free/Libre and Open Source Software: Survey and Study FLOSS; Part IV: Surwey of Developers", Final Report, available in: http://www.infonomics.n]/FLOSS/report/Final4.htm.

Gilbert R.J., Newbery D.M.G. (1982), "Preemptive Patenting and the Persistence of Monopoly", American Economic Revrem, Vol. 72, No. 3, pp. 514-526.

Gilbert R., Shapiro C. (1990), "Optimal Patent Length and Breadth", RAND Journal of Economics, Vol. 21, No. 1, pp. 106-112.

Ginarte J.C., Park W.G. (1997), "Determinants of Patent Rights: A Cross-National Study" "Research Policy, Vol. 26, No. 3, pp. 283-301.

Givon M., Mahajan V., Muller E. (1995), "Software Piracy: Estimation of Lost Sales and the Impact on Soltware Diffusion", Journal of Marketing, Vol. 59, No. 1, pp. 29-37.

Graham S.J.H., Hall B.H., Harhoff D., Mowery D.C. (2002), "Post-lissue Patent "Quality Control": A Comparative Study of US Patent Re-examinations and European Patent. Oppositions", NBER Working Paper, No. 8807, Washington D.C., NBER.

Graham S.J.H., Mowery D.C. (2002), "Intellectual Property Protection in the U.S. Sofware Industry", in: Cohen W.M., Merrill S.A. (eds.), Patents in the Knowledge-Bosed Economy, National Academy Press, Washington D.C.

Granstrand O. (1999), The Economics and Management of Intellectual Property: Tounds Intellectual Capital, Cheltenham, Edward Elgar. 
Granstrand O. (2000), "The Shift Towards Intellectual Capitalism - The Role of Infocom Technologies", Research Policy, Vol. 29, No. 9, pp. 1061-1080.

Green J., Scotchmer S. (1995), "On the Division of Profit in Sequential Innovation", Rand Journal of Economics, Vol. 26, No. 1, pp. 20-33.

Grossman S.J. (1990), "Experimental Use or Fair Use as a Defense to Patent Infringement" "IDEA: Joumal of Law and Technology, Vol. 30, pp. 243264.

Grossman G.M., Helpman E. (1991), Innovation and Growth in the Global Economy, Cambridge, MIT Press.

Hagedoorn J. (2002), "Inter-firm R\&D partnerships: an overview of major trends and patterns since 1960", Resecrch Policy, Vol. 31, Na. 4, pp. 477492.

Hall B.H., Jaffe A.B., Trajtenberg M. (2001), "The NBER Patent Citations Data. File: Lessons, Insights and Methodological Tools", NBER Working Paper, No. 8498, October 2001.

Hall B.H., Ziedonis R.H. (2001), "The Determinants of Patenting in the U.S. Semiconductor Industry, 1980-94", Rard Journal of Economics, Vol. 32, No. 1, pp. $101-128$.

Hall B.H. (2003), "Business Method Patents, Innovation and Policy", EPIP conference on New Challenges to the Patent System, Munich, April 2003.

Hanel P. (2002), "IP Protection Practices by Manufacturing Firms" "Statistics Canada: Innovation Analysis Bulletin, Vol 4, No. 1, pp. 7-10.

Hannan, M.T., Freeman J. (1989), Organizational Ecology, Cambridge, Harvard University Press.

Heckel P. (1992), "Debunking the Software Patent Myths", Communications of the ACM, Vol. 35, No. 6, pp. 121-140.

Heller, M.A., Eisenberg, R.S. (1998), "Can Patents Deter Innovation? The Anticommons in Biomedical Research", Science, Vol. 280.

Hertel G., Niedner S., Hermann, S. (2003), "Motiwation of Software Developers in Open Source Projects: An Internet-based Survey of Contributors to the Linux Kernel", Forthcoming in Research Polsy. Special Issue on Open Source Software Development.

Holdemess, M. (1998), "Moral Rights and Authors' Rights: The Keys to the Information Age", Journal of Informalion, Law and Technology, Vol. 1. Horowitz A.W., Lai E.L.C. (1996), "Patent Length and Rate of Innovation" International Economic Review, Vol. 37, No. 4, pp. $785-801$.

Horstmann I., MacDonald G.M., Slivinski M. (1985), "Patents as Information Transfer Mechanisms: To Patent or (Maybe) not to Patent" "Jourzal of Political Economy, Vol. 93, No. 5, pp. 837-858. 
Jaffe, A.B., Trajtenterg M., Henderson R. (1993), "Geographic Localization of Knowledge Spillovers as Evidenced by Patent Citations", Quarterly Journal of Economics, Vol. 108, No. 3, pp. 577-598.

Jaffe A.B. (2000), "The U.S. Patent System in Transition: Policy Innovation and the Innovation Process", Research Palicy, Vol. 29, No. 4-5, pp. 531-5.57. Jaffe, A.B., Trajtenberg M. (2002), Patents, Citations, and Irmovations: $A$ Window on the Knowledge Economy. Massachusetts, MIT Press.

Jeppesen L.B., Mollin M.J. (2003), "Consumers as Co-developers: Learning and Innowation Outside the Firm", Techrology Analysis 6 Strategic Management, Vol. 15, No. 3, pp. 363-384.

Kamien M.L., Schwartz N.L. (1974), "Patent Life and R and D Rivalry". American Economic Review, Vol. 64, No. 1, pp. 183-187.

Karjala D.S. (1990), "Intellectual Property Rights in Japan and the Protection of Computer Software" "In: Rushing F.W., Brown C.G. (eds.) (1990.

Khan B.Z. (1995), "Property Rights and Patent Litigation in Early NineteenthCentury America", Joumal of Economic History, Vol. 55, No. 1, pp. $58-97$.

Kim L. (1998), "Crisis Construction and Organizational Learning: Capability Building in Catching-up at Hyundai Motor", Organization Science, Vol. 9, No. 4, pp. 506-52ע.

Kitch E.W. (1977), "The Nature and Function of the Patent System", Journal of Law and Economics, Vol. 20, pp. 265-290.

Klemperer P. (1990), "How Broad Should the Scope of Patent Be?", RAND Journal of Economics, Vol. 21, No. 1, pp. 113-130.

Klette T.J., Griliches Z. (1998), "Empirical Patterns of Firm Growth and R\&D Investment: A Quality Ladder Model Interpretation", NBER Working Paper, No. 6753, Cambridge, NBER.

Kretschmer M. (2003), "Software as Text and Mechine: The Legal Capture of Digital Innowation", Journal of Information, Law and Technology, Vol. 3, No. 1.

Kuester J.R., Thompson L.E. (2001), "Risks Associated with Restricting Business Method and E-Commerce Putents", Georgia State University Law Review, Vol. 17, No. 3, pp. 657-689.

Laffont J.J., Rey P., Tirole, J. (1998), "Network Competition: Overview and Nondiscriminatory Pricing", RAND Joumal of Economics, Vol. 29 , No. 1. pp. $1-37$.

Lakhani, K., von Hippel, E., (2000), "How Open Source Software Works: 'Free' User to User Assistance", MT Sloas School of Management Working Poper, No. 4117, May 2000. 
Landes W.M., Posner R.A. (1989), "An Economic Analysis of Copynight Law" ; Journal of Legal Studies, Vol. 18, pp. 325-363.

Lerner J. (1994), "The Importance of Patent Scope: An Empirical Analysis" , RAND Journal of Economics, Vol. 25, No. 2, pp. 319.333.

Lerner J. (2000), "Patent Policy Imnovation: A Clinical Examination", Vanderbalt Law Review, Vol. 53, No. 6, pp. 1841, 1856.

Lerner J., Tirole J. (2002), "Some Simple Economics of Open Source", Joumal of Industrial Economics, Vol. 50.

Lessig L. (1999), "The Limits in Open Code: Regulatory Standards and the Future of the Net", Berkeley Technology Law Journal, Vol. 14, No. 2.

Lessig L. (2002), "Open Source Baselines: Compared to What?" "In: Hahn R.W. (ed.) (2002), Government Policy toward Open Sounce Softuare, Washington D.C. AEI-Brookings Joint Center for Regulatory Studies.

Levin R.C., Klevorick A.K., Nelson R.R., Winter S.G. (1987), "Appropriating the Returms from Industrial Research and Development" , Brooking Papers on Economic Actiwity, Vol. 3, pp. 783-831.

Lichtman D. (2000), "Property Rights in Emerging Platform Teclinologies", Journal of Legal Studies, Vol. 29, No. 2, pp. 615-648.

Lindgren M. (1990), Glory and Faiture: The Difference Engines of Johann Muller, Charles Babbage and Georg and Edvard Scheutz, Massachusetts, MTT Press.

Machlup F., Penrose E. (1950), "The Patent Controwersy in the Nineteenth Century", Journal of Economic History, Voll. 10, No. 1, pp. 1-29.

Machlop F. (1958), An Economic Review of the Patent System, Study No. 15, Subcommittee on Patents, Trademarks and Copyrights of the U.S. Senate Judiciary Committee, Washington D.C., US Government Printing Office. Mackaay E. (1994), "Legal Hybrids: Beyond Property and Monopoly?" ,Calumbia Law Review, Vol. 94, No. 8, pp. 2030-2043.

Mairesse J., Tumer L. (2002), "Measurement and Explanation of the Intensity of Co Co-publication in Scientific Research: An Analysis at the Laboratory Level", 10th International Conference on Panel Data, Berlin, July 2002. Maloney M.T., McCormick R.E. (1995), "Realignment in Telecommunications" Managerial and Decision Economics, Vol. 16, No. 4, pp. 401-425.

Mansell R., Stemueller W.E. (2000), Mobilizing the Information Society: Strategies for Growth and Opportunity, Oxford, Oxford University Press.

Mansfield F., Schwartz M., Wagner S. (1981), "Imitation Costs and Patents: An Empirical Study", Economic Joumal, Vol. 91, No. 364, pp. 907-918.

Mansfield E. (1986), "Patents and Innovation: An Empirical Study", Management Science, Vol. 32, No, 2, pp. 173-181. 
Maurseth P.B., Verspagen B. (2002), "Knowledge Spillowers in Europe: A Patent

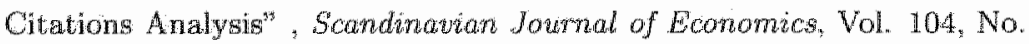
4. pp. $531-545$.

McFetridge D.G. (1995), "Science and Technology: Perspectives for P'ublic Policy" - Occessianal Paper, No. 9, July 1995, Ontario, Industry Canada.

Mckelvey M. (2001), "The Economic Dynamics of Software: Three Competing Business Models Exemplifed Through Microsolt, Netscape and Linux", Economics of Innowation and New Technologies, Vol. 10, No. 3, pp. $199-236$.

Menell P. (1989); "An Analysis of the Scope of Copyright Protection for Computer Programs", Stanford Law Review, Vol. 41, 1045-1104.

Merges R.P., Nelson R.R. (1990), "On the Complex Economics of Patent Scope" , Columbia Law Revieu, Vol. 90, No. 4, pp. 839-916.

Merges R.P., Nelson R.R. (1994), "On Limiting or Encouraging Riwalry in Technical Progress: 'The Effect of Patent Scope Decisions", Journal of Economic Behavior and Organzation, Vol. 25, No. 1, pp. 1.-24.

Merges R.P. (1999), "As Many as Six Impossible Patents Before Breakfast: Property Rights for Business Concepts and Patent System Reform", Berkeley Technology Law Journal, Vol. 14, No. 2.

Morrison, A. (1999), "Hijack on the Road to Xanadu: The Infringenent of Copyright in HTML Documents via Networked Computers and the Legitimacy of Browsing Hypermedia Documents", Journal of Information, Law and Technology, Vol. 1.

National Research Council (1997), Intellectual Property Rights and Research Tools in Molecular Biology, Washington D.C., National Academy Press.

Nelson R.R., Winter. S.G. (1982), Evolutionary Theory of Economic Change, Cambridge, Harvard University Press.

Nelson, R.R. (1994), "Intellectual Property Protection for Cumulative Systems Technology", Columbia Law Rewiew, Vol. 94, No. 8.

Nichols, K. (1998), Inventing Software: The Rise of "Computer-Related" Patents, Westport, Quorum Books.

Nicholson J.S. (1892), "Capital and Labour: Their Relative Strength", Economic Jownal, Vol. 2, No. 7, pp. 478-490.

Nordhatus W.D. (1969), Invention, Growth and Welfare: A Theoretical Theatment of Technological Change, Massachusetts, MlT Press.

Nondheus W.D. (1972), "The Optimum Life of a Patent: Reply", American Economic Review, Vol. 62, No. 3, pp. 428-431.

O'Donoghue T., Scotchmer S., Thisse J.F. (1998), "Patent Breadth, Patent Life and the Pace of Technological Progress" Jounnal of Economics and Man- 
agement Strategy, Vol. 7, No. 1, pp. 1-32.

OECD (1998), 21st Century Technologies: Promises and Perils of a Dynomic Future, Paris, OECD Publication Service:

OECD (1998), Measuring Intangible Investment: The Treatment of the Components of Intangible Investment in the UN model Survey of Computer Semvices, Paris, OECD Publication Service.

OECD (1998), Measuring Electronic Commence: International Trade in Saftware, Committee for Information, Computer and Communications Policy, Directorate for Science, Technology and Industry, Paris, OECD Publication Service.

OECD (2000), Information Technology Outiook 2000, Paris, OECD Publication Service.

OECD (2002), Information Technology Outhook 2002, Paris, OECD Publication Service.

OECD (2004), The Economic Impact of ICT: Measurement, Evidence and Implications, Paris, OECD Publication Service.

Ordover J.A. (1991), "A Patent. System for Both Diffusion and Exclusion" , dournal of Econornic Perspectives, Vol. 5, No. 1, pp. 43-60.

Ostergard R.L. (2000), "The Measurement of Intellectual Property Rights Protection", Journal of International Business Studies, Vol. 31, No. 2, pp. 349-360.

PC Magazine (2001), "Performance Tests: File Server Throughput and Response Times", November 2001, Available in:

ht.tp://www.pcmag.com/article2/0,4149,16227,00. .spp (viewed October 2003).

PC Magazine (2002), "Samba Rums Rings Around Win2000", April 2002, Available in:

http://www. vnunet.com/News/11311.14 (viewed October 2003).

Penrose E. (1951). The Economics of the International Palent Systen, Baltimore, John Hopkins University Press.

Perens B. (1999), "The Open Source Definition" , in: DiBona C., Ockman C., Stone M. (eds.), Open Sources: Voices from the Open Sources Revalution, Sebastopol, O'Reilly \& Associanes.

Polanyi M. (1967), The Tacit Dimension, New York, Doubleday.

Quah D. (1997), "Increasingly Weightless Economies" Bank of England Quarterly Bulletin, Vol. 37, No. 1, pp. 49-56.

Raymond, E.S. (1999), The Cathedral and the Bazaar, Sebastopol, O'Reilly and Associates.

Reese B., Stenberg D. (2001), "Working Without Copyleft", O'Reuly Network, Available in: 
http//ww orellynet.com/pub/a/policy/2001/12/12/transition.html (viewed Oetober 2003 ).

Reichman JH. (1994), "Legal Hybrids Between the Patent and Copyright Paradigms", Columbia Law Review, Vol. 94, No. 8, pp. 2432-2558.

Reinganum J. (1983), "Uncertain Innovation and the Persistence of Monopoly", American Economic Review, Vol. 73, No. 4, pp. 741-748.

Rice J. (2003), "Collaborative Production Strategies for Technological Innovation and Leadership in Network Industries: The Case of Bluetooth", Presented at the DRUID Winter Conference, Klarskovgaard.

Rothman J.B., Buckman J. (2001), "Which OS is Fastest for High-Performance Network Applications?" Sys Admin, Vol. 10, No. 7.

Rushing F.W., Brown C.C. (eds.) (1990), Intellectual Property Rights in Science, Technology and Economic Performance: International Comparisons, Boulder, Westiview Press.

Samulson P. (1990), "Should Program Algorithms be Patented?" Communications of the ACM, Vol. 33, No. 8, pp. 23-27.

Samuelson, P. (1993), "A Case Study on Computer Programs", in: Wallerstein M.B., Mogee M.E., Schoen R.A. (eds.) (1993), Global Dimensions of Intellectual Property Rights in Science and Technology, Washington D.C., National Academy Press.

Samuelson P., Davis R., Kapor M.D., Reichman J.H. (1994), "A Manifesto Concerning the Legal Protection of Computer Programs", Colwmbia Law Review, Vol. 94, No. 8.

Samuelson P. (1999), "Intellectual Property and the Digital Economy: Why the Anti-Circumvention Regulations Need to be Revised", Berkeley Technology Lowe Joumal, Vol. 14, No. 2.

Samuelson P., Scotchmer S. (2002), "The Law and Economics of Reverse Engineering", Yale Law Journal, Vol. 111, pp. 1575-1663.

Scherer F. (1972), "Nordhans' Theory of Optimal Patent Life: A Geometric Interpretation". American Economic Review, Vol 62, pp. 422-427.

Schonleld M., Restaino L. (2002), "Bioinformatics Patent Litigation Strategy: A Heightened Role For Experts", Mealey's Litigation Report: Patents, avail. able in: www.brownraysman.com/pubs/articles/pdf/PatComm909.pdf

Schmookler J. (1950), "The Interpretation of Patent Statistics" "Journal of the Patent Office Society, Vol. 32, No. 2, pp. 123-146.

Schumm, B. (1996), "Escaping the World of "I Know It When I See It": A New Test for Software Patentability", Michigan Telecommunication and Tech nology Law Review, Vol. 2. 
Schumpeter J.A. (1975), Capitalsm, Socialism and Democnacy, New York, Harper (orig. pub. 1942).

Scotchmer S. (1991), "Standing on the Shoulders of Giants: Cumulative Research and the Patent Law". Jowrnal of Economic Perspectives, Vol. 5, No, 1 , pp. $29-41$.

Scotchmer S. (1996), "Protecting Early Imnovators: Should Second-Generation Products be Patentable?" , RAND Joumal of Economics, Vol. 27, No. 2. pp. 322-331.

Scotchmer S. (2005), Innovation and Incentizes, Massachusetts, MTT Press.

Shy O., Thisse J.F. (1999), "A Strategic Approach to Software Protection", Jour" nal of Economics and Management Strategy, Vol. 8, No. 2, pp. 163-190. SIIA (1999), 1999 "Special 301" Review - Comments of the Computer Software Industry on Policies and Practices of Foreign Countries Regarding Intellectual Property Rights, Software and Information Industry Association. SIIA (2001), "1997-2001 Piracy Rates and Losses", Report, Software and Information Industry Association.

Silverberg G., Verspagen B. (1994), "Collective Learning, Innovation and Growth in a Boundedly Rational, Evolutionary World", Journal of Evolutionary Economics, Vol. 4, No. 3, pp. 207-226.

Smith B.L. (2002), "The Future of Software: Enabling the Marketplace to Decide", In: Hahn R.W. (ed.) (2002), Government Policy towand Open Source Software, Washington D.C., AEI-Brookings Joint Center for Regulatory Studies.

SPA (1997), 1997 Global Software Pracy Report, Business Software Allance and Software Publishers Association.

SPA (1998), 1998 Global Softuare Piracy Report, Software Publishers Association. SPA (2002), Seventh Annual BSA Ptracy Study, Soltware Publishers Association. Stallman, R. (1999), "The GNU Operating System and the Free Software Movement", in: DiBona et. al. (eds.) (1999).

Steinmueller W.E. (1996), "The U.S. Software Industry: An Analysis and Interpretive History", In: Mowery D. C. (ed.), The International Computer Software Indiustry: A Comparative Study of Industry Evolution and Structure, New York, Oxford University Press.

Stalpe, M. (2000), "Protection Against Software Piracy: A Study of Techrology Adoption for the Enforcement of Intellectual Property Rights" "Econ. nomics of Innovation and New Technology, Vol. 9, No. 1.

Syrowik, D.R. (1996), "Software Patents - Just Make a Good Thing Better", Michigan Telecommunication and Technology Law Review, Vol. 2. 
Tandon P. (1982), "Optimal Patents with Compulsory Licensing" , Jowrnal of Political Esonomy, Vol. 90, No. 3, pp. 470-486.

Tirole J. (1988), The Theory of Industrial Organization, Cambridge, MIT Press. Trajtenberg M. (1989), "The Welfare Analysis of Product Innovations, with an Application to Computed Tomography Scanners" Joumal of Political Econony, Vol. 97, Na. 2, pp. 444-479.

Trajtenberg M. (1990), "A Penry for Your Quotes: Patent Citations and the Value of Innovations", RAND Joumal of Economics, Vol. 21, No. 1, pp. 172-187.

Towse R. (1999), "Copyright and Economic Incentives: an Application to Performers' Rights in the Music Industry", Kyklos, Vol. 52, No. 3, pp. $369-390$.

Turing A.M. (1936), "On Computable Numbers, with an Application to the Entscheidungsproblem", Proceedings of the London Mathematical Society, Series 2. Vol. 2, November 1936.

USPTO (1996), Examination Gudelines for Computer-Related Inventions - Final Version, Washington D.C., US Patent and Trademark Office.

USPTO (2000), "Patent Counts by Class by Year, 1977-1999", Washingtor, Report, U.S. Patent and Trademark Office.

USPTO (2003), Performance and Accountability Report - Fiscal Year 2003, Washington, U.S. Patent and Trademark Office.

USPTO (2004), "Patenting In "Thechnology Classes, Breakout by Geographic Origin (State and Country): Count of 1999 - 2003 Utility Patent Grants, By Calendar Year of Grant With Patent Counts Based on Primary Patent Classification", Available in:

http:/www.uspto.gow/web/offices/ac/ido/oeip/taf/tecstc/classes.htm, Washington, U.S. Patent and "Trademark Office.

Van Dijk T. (1996), "Patent Height and Competition in Product Improvements", Joumal of Industrial Economics, Vol. 44, No. 2, pp. 151-167.

Verspagen B, De Loo I. (1999), "Technology Spillovers Between Sectors and Over Time." Technological Forecasting and Sockal Change, Vol. 60, pp. $215-$ 235.

Verspagen B., Caniêls M.C.J. (2001), "Barriers to Knowledge Spillovers and Regional Convergence in an Evolutionary Model", Joumal of Evolutionary Economics, Vol. 11, No. 3, pp. 307-329.

Vollesman W. (1998), Measuring Intangible Investment: Initial Cuidelines for the Collection and Comparison of Data on Intangible Investment, Paris, OECD Publication Service. 
Von Hippel E. (1982), "Approprability of Imnowation Beneft as a Predictor of the Source of Innovation", Reseanch Policy. Vol. 11, pp. 95-115.

Von Krogh G., Spaeth S., Lakhani K. (2002), "Commmity, Joining, and Specialization in Open Source Software Innovation: A Case Study" "Research Policy, Forthcoming.

Wade J. (1995), "Dynamics of Organizational Communities and Technological Bandwagons: An Empirical Investigation of Community Ewolution in the Microprocessor Market", Strategic Management Jourmal, Vol. 16, pp. $111-133$.

Waterson M. (1990), "The Economics of Product Patents", American Economic Review, Vol. 80, No. 4, pp. $860-869$.

West J. (2003), "How Open is Open Enough? Melding Proprietary and Open Source Platform Strategies", Research Palicy, Vol. 32, No, 7, pp. 12591.285 .

White KE. (2002), "FESTO: A Case Contravening the Convergence of Doctrine of Equivalents Jurisprudence in Germany, The United Kingdom, and the United States", Michigan Telecomminications and Technolagy Laus Review, Vol. 8, No. 1, pp. 1-37.

WIPO (1998), Introduction to Intellectual Property Theory and Practice, London, Kluwer Law International.

WIPO (2001), Collection of Papers on Intellectual Property, WIPO Publication. No. 773(E), Geneva, WIPO Worldwide Academy.

Witek K.E. (1996), "Developing a Comprehensive Software Claim Drafting Strategy for US Software Patents", Berkeley Technology Law Joumal, Vol. 11. No. 2.

World Trade Organization (1995), Agreement on Thade-Related Aspects of Intellectual Property Rights, WTO.

Wright B.D. (1983), "The Economics of Invention Incentives: Patents, Prizes and Research Contracts", American Economic Review, Vol. 73, No. 4, pp. 691-707.

Young, R. (1999), "Giving It Away: How Red Hat Sofware Stumbled Across a. New Economic Model and Helped Improve an Industry", in. DiBona et. al. (eds.) (1999). 



\section{A}

\section{Proof of Propositions 5 and 6}

\section{Proof of Proposition 5:}

From Equation 5.13, we receive:

$$
\frac{\partial \pi}{\partial \alpha}=\frac{-\Psi(\alpha) c_{1}}{\left(\alpha c_{1}+(1-\alpha) \bar{c}\right)^{2}}+\frac{(1-\alpha) \frac{\partial \psi}{\partial \alpha}}{\left(\alpha c_{1}+(1-\alpha) \bar{c}\right)}=0
$$

Solving for $\Psi(\alpha)$ :

$$
\Psi(\alpha)=\frac{(1-\alpha)\left(\alpha c_{1}+(1-\alpha) \bar{c}\right)}{c_{1}} \cdot \frac{\partial \Psi}{\partial \alpha}
$$

(a) If $\left.\frac{\partial \pi}{\partial \alpha}\right|_{\alpha=0} \leq 0$, then from Equation A.1:

$$
\frac{-\Psi(0) a}{\bar{c}^{2}}+\frac{1}{\bar{c}} \cdot \frac{\partial \Psi(0)}{\partial \alpha} \leq 0
$$

And

$$
\Psi(0) \geq \frac{\partial \Psi(0)}{\partial \alpha} \cdot \frac{\bar{c}}{c_{1}}
$$

As revenue is positive and decreasing wh $\alpha$, the firm would choose $\alpha^{*}=0$. Consider also the case $\left.\frac{\partial \pi}{\partial \alpha}\right|_{a=1} \geq 0$. Then, from Equation A.1:

$$
\frac{-\Psi(1) c_{1}}{c_{1}^{2}} \geq 0
$$

Hence, $\Psi(1) \leq 0$. Since $\bar{c}>c_{1}>0$ and no positive revenue is generated at $\alpha=1$, the firm would choose full opennes to minimize casts.

(b) If $\left.\frac{\partial \pi}{\partial \alpha}\right|_{\alpha=0} \geq 0$ and $\left.\frac{\partial \pi}{\partial \alpha}\right|_{\alpha=1} \leq 0$, then we look for an interim value of $\alpha$, $0<\alpha^{*}<1$, in which profits are maximized. 
Simplitimg Equation A.I:

$$
\frac{\Psi(\alpha) c_{1}}{\frac{\partial \psi}{\partial \alpha}}=\alpha\left(c_{1}-2 \bar{c}\right)-\alpha^{2}\left(\alpha_{1}-\bar{c}\right)+\bar{c}
$$

Solving Equation A.6 for ox, we receive:

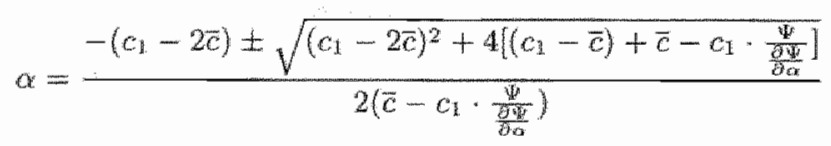




\section{B}

Distribution of Software,

Cryptography and Image Analysis

Patents 


\begin{tabular}{|c|c|c|c|c|c|c|c|c|c|c|c|c|}
\hline 8 & 18 & 2 & 6 & 8 & 8 & $\frac{0}{4}$ & $\frac{y}{8}$ & y & $\vec{\infty}$ & 8 & 10 & 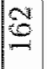 \\
\hline 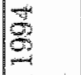 & $E$ & 6 & 8 & 8 & $\vec{b}$ & 8 & 8 & $\mathscr{Q}$ & 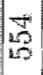 & $\Leftrightarrow$ & 19 & 2 \\
\hline$g$ & 8 & $I 0$ & 2 & 18 & $\mathrm{~F}$ & $\approx$ & 3 & $\left(\begin{array}{c}\infty \\
8\end{array}\right.$ & $\mathscr{E}$ & 2 & 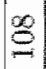 & $\infty$ \\
\hline 8 & $\mathscr{8}$ & 9 & $\sigma$ & 丞 & 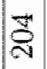 & 茾 & 10 & 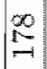 & $\vec{a}$ & 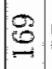 & 18 & 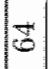 \\
\hline$\vec{g}$ & $\approx$ & 10 & 8 & $\frac{0}{3}$ & $\stackrel{5}{\circ}$ & 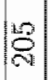 & $\infty$ & 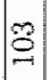 & $\frac{2}{\mathrm{D}}$ & 8 & $\infty$ & 18 \\
\hline 8 & $\stackrel{8}{\%}$ & 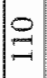 & $\infty$ & $\mathbb{N}$ & $\underset{\partial}{a}$ & $\frac{+7}{\infty}$ & 18 & 8 & $\stackrel{8}{2}$ & $\sigma$ & 2 & $\infty$ \\
\hline$\infty$ & $\underset{7}{g}$ & 官 & F. & in & 8 & 2 & $\sigma$ & $\infty$ & 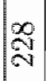 & 8 & 9 & $\infty$ \\
\hline$\infty$ & \pm & 12 & 18 & 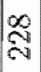 & $\stackrel{9}{\longrightarrow}$ & 28 & $F$ & 8 & $\stackrel{8}{9}$ & $\mathscr{\infty}$ & 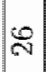 & $\infty$ \\
\hline$\infty_{n=1}^{\infty}$ & $\infty$ & $\mathbb{N}$ & $\mathscr{\infty}$ & 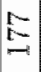 & 邑 & $\infty$ & स & 18 & $\underline{-1}$ & 12 & $\vec{\nabla}$ & 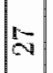 \\
\hline$\infty$ & 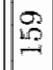 & 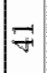 & 8 & $\stackrel{\mathscr{L}}{\sim}$ & 8 & 今 & $\infty$ & $1 \%$ & $\vec{\Phi}$ & ๖ & $\approx$ & 1 \\
\hline$\infty$ & $\infty$ & 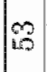 & $\stackrel{\mathbb{N}}{\infty}$ & $\stackrel{0}{\exists}$ & 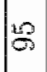 & H & $\infty$ & 6 & @ि & $\mathbb{D}$ & $\infty$ & $\Leftrightarrow$ \\
\hline$\infty$ & $\infty$ & 8 & 8 & 19 & 8 & $\#$ & 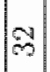 & in & $\infty$ & 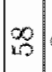 & $\infty$ & 8 \\
\hline $\mathbb{0}$ & 8 & $\vec{\infty}$ & 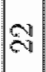 & 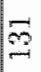 & 8 & $m$ & $\because$ & f & 9 & $\stackrel{N}{*}$ & -1 & $\because$ \\
\hline$\stackrel{\infty}{\sigma}$ & 9 & $\infty$ & $\overrightarrow{a i}$ & $\stackrel{8}{9}$ & 8 & $\infty$ & $\exists$ & $\vec{N}$ & $R$ & $\cong$ & $\curvearrowright$ & 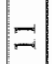 \\
\hline$\underset{0}{\infty}$ & in & $\mapsto$ & $=$ & $\infty$ & 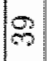 & $\infty$ & $\Theta$ & $\infty$ & 6 & $\infty$ & $\infty$ & 10 \\
\hline $\begin{array}{l}\infty \\
0 \\
=\end{array}$ & 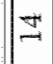 & - & $\infty$ & 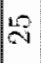 & \pm & & $\rightarrow$ & $\infty$ & $|\infty|$ & 1 & & $x$ \\
\hline 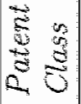 & $\infty$ & $\begin{array}{l}\infty \\
\infty \\
\infty\end{array}$ & 8 & $\stackrel{D}{2}$ & 10 & $\mathbb{R}$ & $\hat{E}$ & 8 & $\frac{9}{r}$ & 19 & $F$ & $\frac{\infty}{n}$ \\
\hline
\end{tabular}




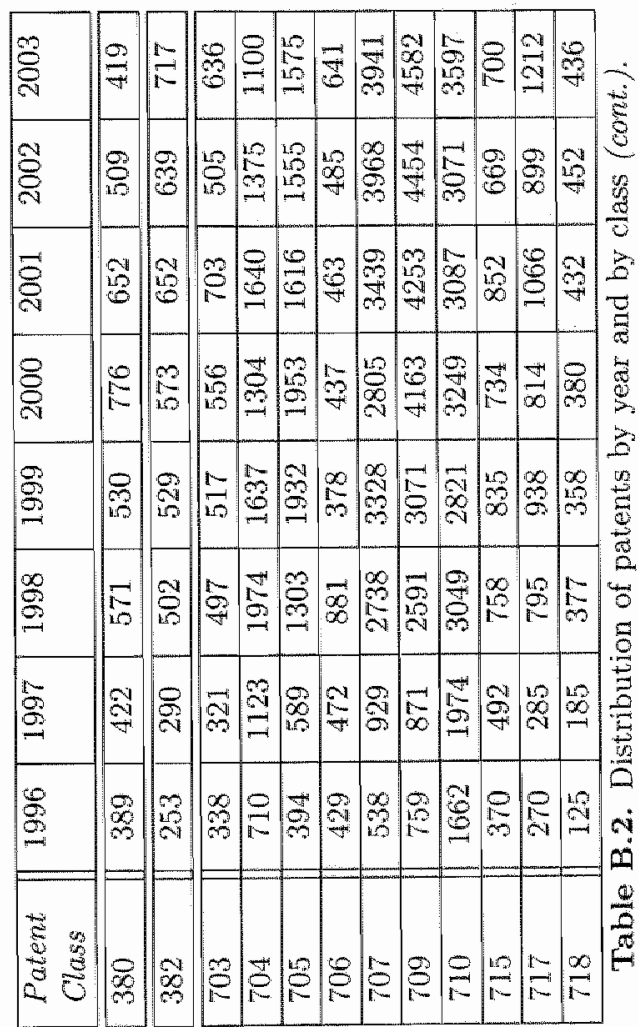




\section{Summary in Dutch (Samenvatting)}

Het beleid met betrekking tot de bescherming van intellectueel eigendom is allesbehalve statisch en ontwikkelt zich constant als gevolg wan veranderingen in markten, regels en technologieën. Beleidsmakers willen algemene wettelijke richthijnen formuleren voor het registreren van octrooien. Dit beogen zij ondlat een algemeen wettelijk kader en uitbreiding van de reikwijdte van traditionele regimes van intellectueel eigendomsrechten in de regel leidt tot verlaging van do kosten van regulering. Vanuit maatschappelijk oogpunt zijn beide stappen wenselijk. Kennisbedrijven hebben echter andere behoeften, waaraan in globale termen wordt voldaan door een algemeen en eenvoudiger wettelijk kader. Een hoge mate van technologische diversiteit en complexe marktmechanismen bevorderen de formulering van regimes 'op maat', die perfect aansluiten op de specifieke aard van elke technologie en elk patroon van innovatie en technologische diffusie.

Het geval van software is bijzonder: én enkel product wordt beschermd door. twee belkngrijke wettelijke mechanismen: octrooien en auteursrechten. IPRs voor software illustreren hoe de scheidingslijn tussen ideeën en uitdrukkingen is vervaagd. Vroeger was het zo dat een product ofwel werd gexien als een verzameling ideeën ofwel als een uitdrukking van creativiteit. Bij software lijkt het om beide te gaan en is er sprake wan een uniek geval: de juridische en technologische trajecten hebben al een weg gebaand voor veelvuldige toepassing van losjes met elkaar verbonden en gesoleerde doctrines om tot een oplossing te komen voor problemen met IPRs in informatieproducten en -technologieën en om nieuwe precedenten te scheppen.

De opzet van de analyse van IPRs in dit proefschrift kan worden gezien als een referentiekader voor de evaluatie van wetgeving die in recente gevallen overmatige bescherming biedt, zoals het octrooieren van zakenmethoden. Software ("ideeen" em online-informatie ("uitdrukkingen") vallen steeds vaker samen narmate computertoepassingen licht worden gewijzigd en worden toegepast op verschillende platforms en hardware, waarbij de bestaande regimes kunnen leiden tot economische inefficiëntie en een rem kunnen zetten op innovatic. Een analyse van potentiele risicos als gevolg wan overbeschermende wetgeving wordt aanbevolen bij lhet eval- 
weren van beleicl woot innovatie en technologische verandering.

Net als in de evolutic van computertechnologieën zijn softwareoctrooien niet strijdig met de algemene doelstelingen van het octrooiregime, d.w.z. om innowatie te bevorderen door middel van een monopolie over een bepaalde technologie. Softwareoctrooien wolgen normaal gesproken de conceptuele richtlijnen wataij octrooien werden toegekend aan fysicke machines, die (zij het minder effictént) computertaken ultwoerden en informatie verwerkten. Bescherming van auteursrechten toegekend aan de interne organisatie wan computerprogramma's en operationele onderdelen lijken echter veel verder te gaan dan de doelstelling om artisticke en literaire werken te beschermen. Dus werden exclusieve reproductierechten toegekend voon quasi-techmische onderdelen, zoals interfaces en het grafische ontwerp van computertoepassingen, in plaats van de reikwijdte wan auteursrechten te beperken tot eindproducten (d,w.z. samengestelde versies van computerprogramma's). Door de bescherming van softwareproducten en technologieèn als intellectued eigendom is de traditionele tweedeling tussen ideeèn en witdrukkingen vervagad en is de grens tussen octrooien en auteursrechten verlegd. De hierdoor ontstane overlap tussen beide regimes kan leiden tot economische inefficiëntie als gevolg van onduidelijke richtijnen voor de bescherming van ideeèn en uitdrukkingen als intellectueel eigendom. De uitgebreide doctrine watrbij softwaretechnologie wordt geoctrooieerd en tegelijkertijd beschermd tegen imitatie, kan worden betiteld als 'overbeschermend' beleid.

In feite wordt de wettelijke bescherming van software en algoritmen als intellectueel eigendom emstig in twijfel getrokken. De opkomst van het Open Sourcemodel heeft deze bestaande gevoelens van onrust alleen maen aangewakkerd. In het Open Source-model opereren zichzelf organiserende groepen als online gemeenschappen van ontwikhelaars die hun imnowatieve leden een ander systeem van stimwi bieden. Het; Open Sourcemodel is echter niet per se gericht op het wegnemen van de grootste twijfels binnen de huidige institutionele en economische omgeving van IPRs, via de invoering van een niewwe su generis-wet ter bescherming van informatietechnologieen. Integendeel, voorstanders van Open Source en vrije software pleiten voor een alternatief model dat zich richt op segmenten van de softwaremarkt. Deze segmenten zijn onder andere: de wrijwillige deelname in ontwikkeling; lhet voorzien in anvullende diensten van de implementatie van vrije software als bron van inkomsten; de priwaati ontwikkelde toepassingen; en academische software. Zij houden zich niet bezig met de behoeften van de meerderheid van bedrijven in de industrie als het gaat om middelen van bescherming. Een innovatiebeleid dat volledig gebaseerd is op het Open Source-model en een eind maakt aan IPRregimes, zal resulteren in een regime dat juist te wreinig bescheming biedt en waardoor de ontsluiting van kennis en investeringen in onderzoek en ontwikkeling 
(vooral bimen grote bedrijven) zullen afnemen.

In dit verband werpt zich de vraag op wat het optimale niveau van bescherming van computerprogramma's dan well is. De voorstanders van Open Source pleiten voor volledige of gedeeltelijke opheffing van intellectuele eigendonsrechten m.b.t. de broncode en de samenstel.ingen daarvan ter bevordering van technische verandering en vrij toegankelijke standaarden (Lerner \& Tirole, 2000 von Krogh a. a, 2002). Anderen voeren aan dat het hudige regime uitwinders en innovatieve bedrijven binnen het MKB juist stimuleert. (Heckel, 1992). Tussen deze twee extremen bevindt zich een aanta] varianten van traditionele IPR-doctrines die elementen van zowel auteursrechten als octrooien bevatten en doorgaans als sui generis-wetten worden gepresenteerd.

De gevolgen van verkeerde toepassing van een ongeschikt regime kumnen variëren van belemmering van het innovatieproces tot vertragde diffusie van voortschrijdende technologieën en de opkomst van monopolistische eigendonstructuren m.b.t. informatietechnologieën. De negatieve effecten zijn significant, vooral in de beginfase van ontwikkeling, adoptie en gebruk van nieuwe technologieën. Een samenhangend wettelijk kader is dan ook nodig on de factoren van potentieel marktfalen aan te pakken en te voorkomen dat bedrijven niet meer investeren in onderzoek en ontwikkeling als gevolg van het reproduceren van verschillende software-elementen door concurrenten. Daarbij moet men bij de wetgeving rekening houden met het type en de gevolgen van imitatie, de gemiteerde elementen (d.w.z. de softwareeenheden), en met de vraag of de invoering van een (gedeeltelijk) gelijkwaardig product door opvolgers een aanzienlijke bron van inkomsten dreigt weg te nemen, waardoor zij geneigd zijn minder in onderzoek en ontwikkeling te investeren.

Terwij] wetgevers en rechtbanken zich ten doel stellen een oplossing te zoeken woor conflicten bussen het wettelike regime en de kenmerken van sofwareproducten en technologieen, spreken de oplossingen (in de vorn van statutaire uitspraken en strakke richtijnen) de behoeften en kenmerken van cornputerprogrammas wellicht tegen met mogetink verdere conflicten als gevolg. Bij de ontwikkeling van een regime dient men ar dan ook rekening mee te houden dat een wethlyke regeling net als doel een specifuk sofware-element te beschemen, tegenstrijdig kan zijn met de belangen van anclere sotware-entiteiten.

Een nieuw te ontwikkelen regime dat ten doel heeft tegemoet te komen aun de unieke behoeften en verdienstex wan softwaretechnologieën en de dynamiek wan innovatie in de softwarebedrigven, omvat elementen wan bestarnde wetgevende regimes om de juiste mate van zekerheid te waxborgen voom nenwkomers en het vermogen om eventuele wetcelifke geschillen te woorspellen en vorkmen. Implementatie van een IPR-regime ter bescheming van sofwaregoederen en-utwindingen zoals herboven is beschreven, herstelt het evenwicht tussen publieke belangen en 
privébelangen en warborgt de woorwarden woor concurrentie en toetreding tot de mark van innowatieve bedrijven. 


\section{Curriculum Vitae}

Elad Harison was born in Haifa, Israel, on May 13th 1971. He attended secondary education at the Hatreali Ha'iwri School from 1983 to 1989. In 1993 he obtained his B.Sc. from the Faculty of Industrial Engineering and Management at the Technion - Israel Research Institute.

During the following six years he was working as a logistic engineer and as an information systems analyst at the Israeli Navy Computing Center, where he specialized in Enterprise Resource Planning systems. From 1997 to 1999 he completed his Master in Engineering at the Faculty of Industrial Engineering and Management at the Technion.

In 1999 he joined the Ph.D. programme at the Maastricht Economic Research Institute on Innovation and Technology (MERIT), University of Maastricht. In 2001 he was awarded a National Doctoral Research Fellowship (OiO) funded by the Netherlands Organization for Scientific Research (NWO). The final stages of his research were funded by a fellowship from the Dutch Ministry of Economic Affairs.

Elad completed two research projects on Intellectual Property Rights in a Knowledge-Based Economy for the Dutch Advisory Council for Science and Technology Policy (AWT) with Robin Cowan. He participated in the European Commission's Expert Group on Intellectual Property Rights Aspects of Internet Collaborations. Between December 2003 and May 2004 he visited the Copenhagen Business School as Marie Curie doctoral fellow. Currently, he participates in MERIT's study on the Effects of Patenting Computer-Implemented Inventions for the EC. He is also a member of the EC:s Network-of-Excellence on European Policy for Property (EPIP). During his Ph.D. research, he presented his work on numerous occassions to conferences and to policy makers.

Since January 2005 Elad is working as Assistant Professor in Business and Information and Communications Technologies at the Department of Economics, University of Groningen. 